UNIVERSIDADE ESTADUAL PAULISTA “JÚLIO DE MESQUITA FILHO” INSTITUTO DE BIOCIÊNCIAS, LETRAS E CIÊNCIAS EXATAS

VALÉRIA VENDRAME

\title{
OS VERBOS VER, OUVIR E SENTIR E A EXPRESSÃO DA EVIDENCIALIDADE EM LÍNGUA PORTUGUESA
}

SÃO JOSÉ DO RIO PRETO 


\section{VALÉRIA VENDRAME}

\section{OS VERBOS VER, OUVIR E SENTIR \\ E A EXPRESSÃO DA EVIDENCIALIDADE EM LÍNGUA PORTUGUESA}

Tese apresentada ao Instituto de Biociências, Letras e Ciências Exatas da Universidade Estadual Paulista, Campus de São José do Rio Preto, para obtenção do título de Doutor em Estudos Linguísticos

Área de concentração: Análise Linguística

Orientadora: Profa. Dra. Marize Mattos Dall'Aglio Hattnher

Data da aprovação: 13 de agosto de 2010 
Vendrame, Valéria.

Os verbos ver, ouvir e sentir e a expressão da evidencialidade em língua portuguesa / Valéria Vendrame. - São José do Rio Preto : [s.n.], 2010.

173 f. : il. ; $30 \mathrm{~cm}$.

Orientador: Marize Mattos Dall'Aglio Hattnher Tese (doutorado) - Universidade Estadual Paulista, Instituto de

Biociências, Letras e Ciências Exatas

1. Linguística. 2. Funcionalismo (Linguística). 3. Análise linguística (Linguística). 4. Gramática funcional. 5. Evidencialidade. 6. Verbos de percepção. I. Dall'Aglio-Hattnher, Marize Mattos. II. Universidade Estadual Paulista, Instituto de Biociências, Letras e Ciências Exatas. III. Título.

$$
\text { CDU }-81^{\prime} 1
$$




\section{COMISSÃO JULGADORA}

Profa. Dra. Marize Mattos Dall'Aglio Hattnher - Orientadora

Universidade Estadual Paulista “Júlio de Mesquita Filho" (UNESP)

\section{Prof. Dr. Kees Hengeveld}

Universidade de Amsterdã (UvA)

Profa. Dra. Rosane de Andrade Berlinck

Universidade Estadual Paulista "Júlio de Mesquita Filho" (UNESP)

Prof. Dr. Sebastião Carlos Leite Gonçalves

Universidade Estadual Paulista “Júlio de Mesquita Filho" (UNESP)

Profa. Dra. Sandra Denise Gasparini Bastos

Universidade Estadual Paulista "Júlio de Mesquita Filho" (UNESP) 


\section{AGRADECIMENTOS}

À Marize, pelo carinho, pela amizade, pela cumplicidade, pelo incentivo, pela segurança, pela confiança, por me encorajar a alçar vôos cada vez mais altos, por me ensinar os vários significados que motivação pode ter e por me ajudar a recuperar o fôlego para transferir as minhas ideias para o papel;

Ao Prof. Dr. Kees Hengeveld, pela acolhida durante meu estágio na Universidade de Amsterdã, pela disponibilidade e disposição em discutir os meus dados, pelas orientações valiosas, que, num primeiro momento, ajudaram a definir os rumos desta pesquisa e, num segundo momento, contribuíram para consolidar muitas das análises aqui presentes;

Ao Prof. Dr. Sebastião Carlos Leite Gonçalves e às Profas. Dras. Sandra Denise Gasparini Bastos, Rosane de Andrade Berlinck e Gisele Cássia de Sousa, pelas importantes contribuições que, em momentos diferentes, deram para o desenvolvimento deste trabalho;

Ao Alvaro, pelas revisões, pelo carinho, pela preocupação e pelos momentos de descontração;

Aos colegas do GPGF, pelas discussões sobre a GDF, que me proporcionaram um melhor entendimento da teoria;

Aos meus amigos e aos meus amores (Maria Clara, Nathan e Fabiano), minha fonte inesgotável de energia, por me cercarem de carinho e alegria, por me animarem e por compreenderem minha ausência;

À minha família, em especial minha mãe, meus irmãos, Ednilson e Reinaldo, e minhas cunhadas, Tânia e Vanessa, pelo incentivo e pelo apoio incondicional sempre, até mesmo quando minhas decisões me levavam para longe;

À Capes, Coordenação de Aperfeiçoamento de Pessoal do Ensino Superior, pelo auxílio financeiro que viabilizou meu estágio de doutorado na Universidade de Amsterdã;

meus sinceros agradecimentos. 


\section{SUMÁRIO}

INTRODUÇÃO.

Introdução 16

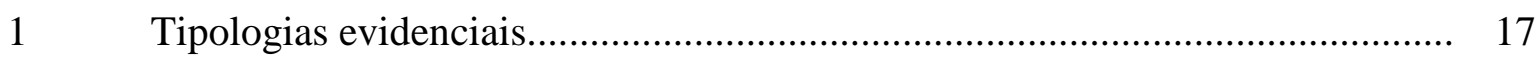

$2 \quad$ A evidencialidade em língua portuguesa................................................... 22

\section{CAPÍTULO II: OS VERBOS DE PERCEPÇÃO E A EXPRESSÃO DA} EVIDENCIALIDADE.

Introdução.

$1 \quad$ Tipologias dos verbos de percepção.......................................................... 34

$2 \quad$ Usos evidenciais dos verbos de percepção....................................................... 49

CAPÍTULO III: A EVIDENCIALIDADE NA GRAMÁTICA DISCURSIVOFUNCIONAL

Introdução.

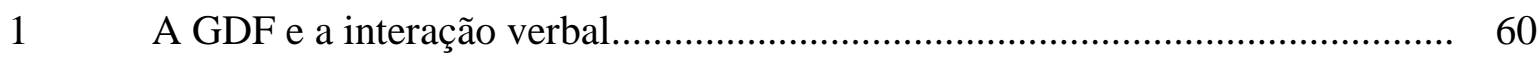

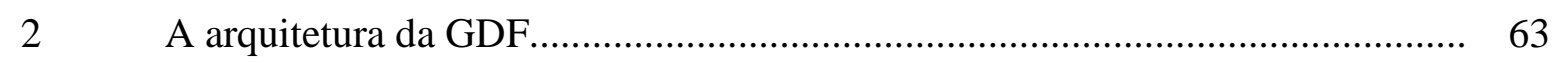

3 A tipologia dos evidenciais de acordo com a GDF..................................... 92

\section{CAPÍTULO IV: UNIVERSO DA PESQUISA E PROCEDIMENTOS} METODOLÓGICOS

Introdução.

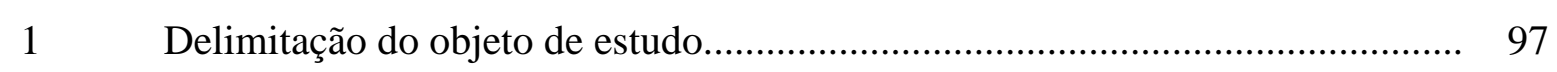

$2 \quad$ Procedimentos de busca dos dados........................................................... 103

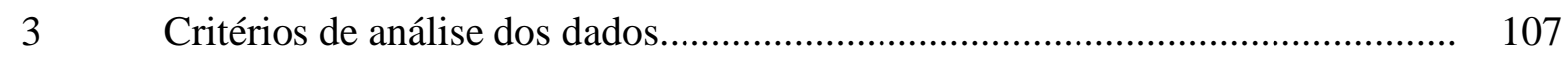


CAPÍTULO V: OS VERBOS VER, OUVIR E SENTIR E A EXPRESSÃO DA EVIDENCIALIDADE EM LÍNGUA PORTUGUESA

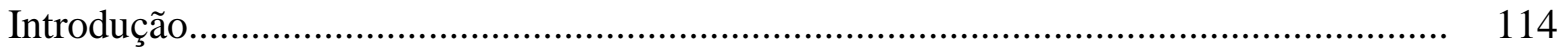

1 A descrição da evidencialidade no Nível Interpessoal......................................... 115

2 A descrição da evidencialidade no Nível Representacional................................... 118

2.1 A evidencialidade reportativa.................................................................. 119

2.2 A evidencialidade inferida..................................................................... 124

2.3 A evidencialidade deduzida............................................................... 129

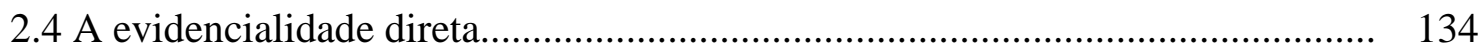

2.5 Outras características dos subtipos evidenciais codificados por ver, ouvir e

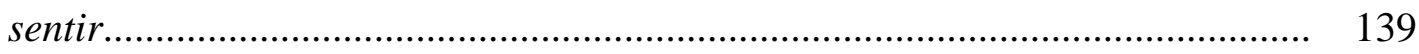

2.5.1 Modo de obtenção da informação e fonte da informação........................ 140

2.5.2 Tempo e aspecto na expressão da evidencialidade................................ 142

3 A descrição da evidencialidade no Nível Morfossintático..................................... 148

3.1 Duas Expressões Linguísticas................................................................... 149

3.2 Uma Expressão Linguística................................................................. 151

3.3 Outro tipo de estrutura evidencial......................................................... 160

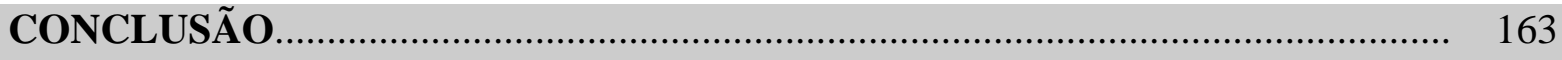

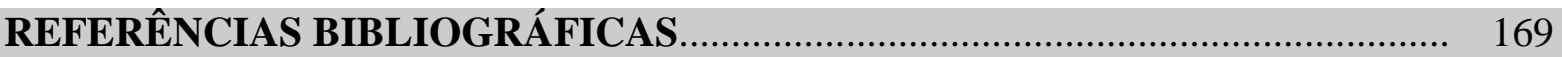




\section{LISTA DE FIGURAS E QUADROS}

\section{FIGURAS}

Figura 1. Tipologia dos evidenciais em língua portuguesa segundo Dall'AglioHattnher (2001).

Figura 2. Tipologia dos evidenciais em língua portuguesa segundo Vendrame (2005).

Figura 3. A GDF dentro da teoria de interação verbal (HENGEVELD; MACKENZIE, 2008, p.6)

Figura 4. Esquema geral da GDF (HENGEVELD; MACKENZIE, 2008, p.13)...

\section{QUADROS}

Quadro 1. O paradigma básico dos verbos de percepção em inglês (VIBERG, 1984, p.128) 36

Quadro 2. O paradigma básico dos verbos de percepção em português. 36

Quadro 3. A constituição da Expressão Linguística.

Quadro 4. Classificação das orações complemento (adaptado de HENGEVELD; MACKENZIE, 2008, p.363).

Quadro 5. Verbos de percepção e categoria semântica do complemento (BRAGA et al., em preparação).

Quadro 6. Verbos de percepção e categoria semântica do complemento 
Quadro 7. Estruturas subjacentes interpessoais da evidencialidade.

Quadro 8. Verbos de percepção por tipo de evidencialidade, camada e nível da GDF.

Quadro 9. Estruturas subjacentes representacionais da evidencialidade reportativa.

Quadro 10. Estruturas subjacentes representacionais da evidencialidade inferida....

Quadro 11. Estruturas subjacentes representacionais da evidencialidade deduzida..

Quadro 12. Verbos de percepção por tipo de evidencialidade, camada e nível da GDF II

Quadro 13. Estrutura subjacente representacional da evidencialidade direta.

Quadro 14. Estruturas subjacentes representacionais da evidencialidade.

Quadro 15. Estruturas sintáticas e tipos de evidencialidade

Quadro 16. Estrutura subjacente morfossintática da evidencialidade codificada por duas Expressões Linguísticas.

Quadro 17. Forma da Oração subordinada completiva por tipo de evidencialidade.

Quadro 18. Estrutura subjacente morfossintática da evidencialidade codificada por Oração adverbial

Quadro 19. Estruturas subjacentes morfossintáticas da evidencialidade codificada por Oração subordinada completiva.

Quadro 20. Estrutura subjacente morfossintática da evidencialidade direta. 
+/-id: +/-identificável

+/- s: $\quad+$ - específico

$\Phi: \quad$ função

$\mathrm{A}_{1}: \quad$ ato

A: actor (ator)

A: adressee (ouvinte)

A: adjetivo

AC: amostra censo

Abl: ablativo

ABS: absolutivo

Adp: $\quad$ sintagma adposicional

Adv: advérbio

AFF: afetado

ANIM: animado

$\mathrm{C}_{1}$ : $\quad$ conteúdo comunicado

$\mathrm{Cl}_{1}: \quad$ clause (oração)

${ }^{\operatorname{dep}} \mathrm{Cl}_{1}$ : oração dependente

CORR: correlativo

DECL: declarativa

DEM: demonstrativo

dist: distante

DS: $\quad$ sujeito diferente

$\mathrm{e}_{1}$ : $\quad$ estado-de-coisas

ep 1 : episódio

EV: evidencialidade

EX: existencial

$\mathrm{f}_{1}: \quad$ propriedade

$\mathrm{F}_{1}$ : força ilocucionária

Foc: foco

FUT: futuro

GDF: Gramática Discursivo-Funcional

GF: $\quad$ Gramática Funcional

Gw: $\quad$ grammatical word (palavra gramatical)

IMP: imperativo

INF: infinitivo

IND: modo indicativo

INTER: interrogativa

$1_{1}: \quad$ lugar

L: locativo

Le: $\quad$ expressão linguística

$\mathrm{m}_{1}: \quad$ modo

$\mathrm{M}_{1}$ : movimento

Motiv: motivação

$\mathrm{N}: \quad$ noun (substantivo)

NEG: negação

NON.A/S: não-nominativo

$\mathrm{Np}$ sintagma nominal 


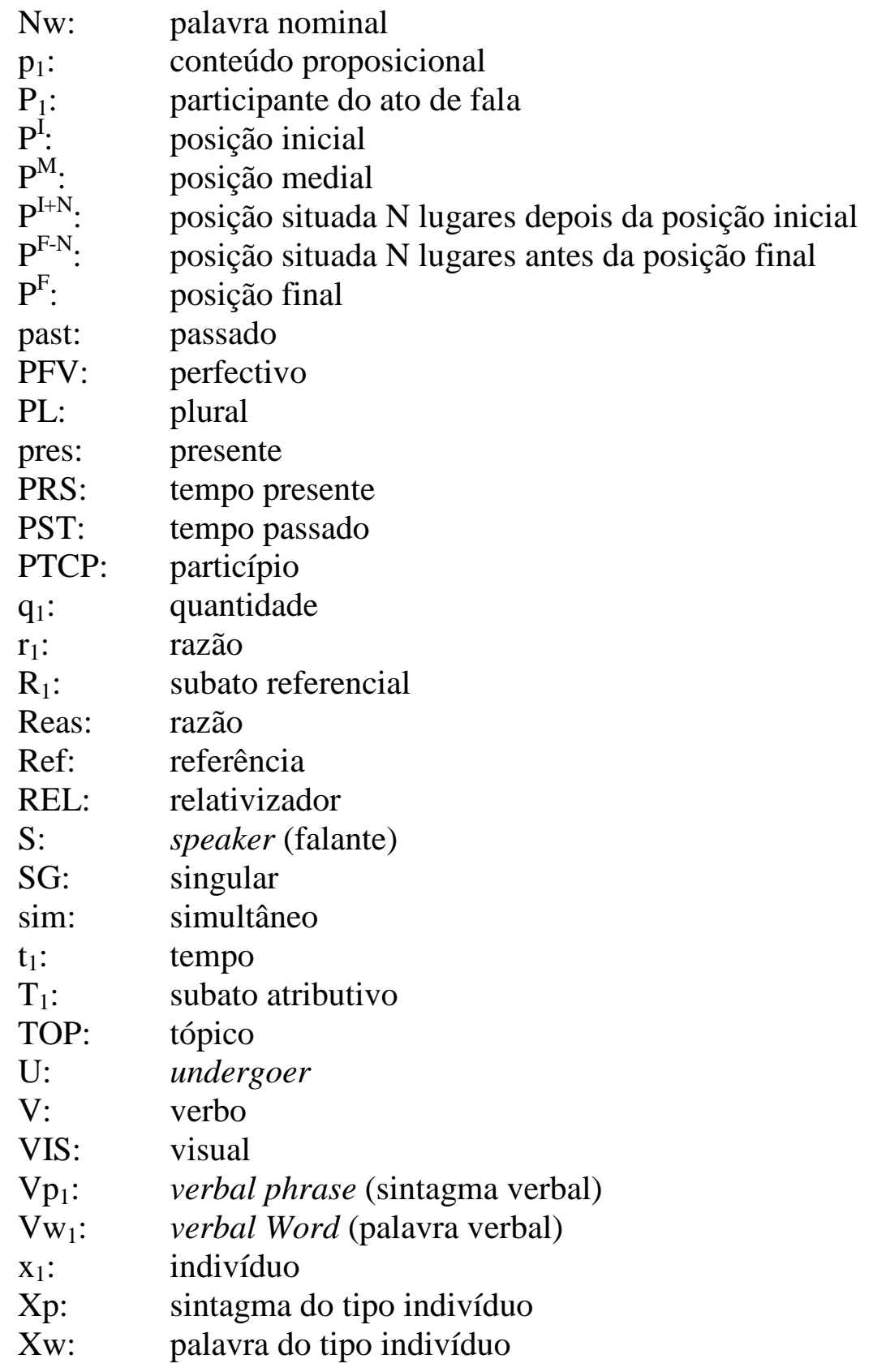




\section{RESUMO}

A evidencialidade corresponde à explicitação da fonte da informação contida em um enunciado. Em muitas línguas, ela é codificada por meios gramaticais que indicam se a informação transmitida foi obtida de maneira direta, por meio de percepção sensorial, ou de maneira indireta, por meio de um relato ou uma inferência. Apesar de existir um grande número de trabalhos que tratam da evidencialidade gramatical, poucos são os estudos que consideram a evidencialidade expressa lexicalmente. A presente pesquisa surge como uma proposta de descrição da evidencialidade lexical expressa por meio de verbos de percepção em língua portuguesa. Mais especificamente, busca-se investigar quais são os tipos de contextos sintático-semânticos em que os verbos de percepção ver, ouvir e sentir têm valor evidencial e quais sentidos evidenciais estão relacionados com cada contexto. A teoria que embasa este estudo é a da Gramática Discursivo-Funcional (GDF), um modelo de gramática que "procura entender como unidades linguísticas são estruturadas em termos da realidade que elas descrevem e das intenções comunicativas com as quais elas são produzidas, e molda isso em uma implementação dinâmica da gramática" (HENGEVELD; MACKENZIE, 2008, p.2). Dentro da GDF, a evidencialidade é descrita em termos de níveis ou camadas de acordo com as características semântico-pragmáticas e morfossintáticas que a estrutura evidencial apresenta. O material de análise desta pesquisa é composto por amostras do português brasileiro falado e escrito. A partir da análise dos dados, foi possível identificar quatro tipos evidenciais codificados pelos verbos analisados: evidencialidade reportativa, expressa pelos verbos ver e ouvir, evidencialidade inferida, deduzida e direta, esses três tipos codificados pelos verbos ver, ouvir e sentir. Uma vez que um mesmo verbo pode codificar diferentes tipos de evidencialidade, na caracterização de cada tipo levou-se em conta uma série de fatores sintático-semânticos e pragmáticos. O modelo de descrição linguística da GDF se mostrou bastante útil no tratamento do fenômeno aqui investigado. A descrição sintática das ocorrências revelou especificidades que caracterizam alguns tipos evidenciais. A descrição semântica mostrou que as diferenças entre os tipos de evidencialidade se refletem em diferentes camadas e que existem restrições na localização temporal dos verbos que ocorrem nas estruturas evidenciais dependendo do tipo evidencial. A descrição pragmática demonstrou as diferentes organizações estratégicas de que o falante pode se servir na expressão da fonte da informação e do modo como ela foi obtida. A partir da compreensão de todos esses aspectos envolvidos nas ocorrências analisadas, conclui-se que os verbos ver, ouvir e sentir são formas de expressão da evidencialidade bastante produtivas em língua portuguesa.

Palavras-chave: evidencialidade; verbos de percepção; Gramática Discursivo-Funcional. 


\begin{abstract}
Evidentiality is understood as the marking of the source of evidence a speaker has for his/her statement. In many languages, it is expressed by grammatical means that indicate whether the information was obtained in a direct way, via sensorial perception, or in an indirect way, via report or inference. Although there are many studies on grammatical evidentiality, only a few take lexical evidentiality into account. This research aims at describing lexical evidentiality expressed by perception verbs in Portuguese by investigating the verbs ver (to see), ouvir (to hear) and sentir (to feel) in order to find out the evidential meanings related to them and the syntactic and semantic contexts in which they occur. The theoretical background of accounting perception verbs here rests on Functional Discourse-Grammar (FDG), a model of grammar which "aims to understand how linguistic units are structured in terms of the world they describe and the communicative intentions with which they are produced, and models this in a dynamic implementation" (HENGEVELD; MACKENZIE, 2008, p.2). Within FDG, evidentiality is described in terms of levels and layers according to the semantic, pragmatic and morphosyntactic features the evidential structure presents. The data analyzed here comprise samples of spoken and written Brazilian Portuguese. The results show that the three verbs are used to express four types of evidentiality: reportative evidentiality, expressed by ver and ouvir, inferential, deductive and direct evidentiality, all these three kinds expressed by ver, ouvir and sentir. Taking into account that the same verb may be used with different types of evidentiality, a number of syntactic, semantic and pragmatic aspects were considered in the description of each type. FDG model was very useful in the approach to the phenomenon under study. The syntactic description of the data showed specificities that characterize some evidential types. The semantic description indicated that the differences among the various types of evidentiality reflect in the different layers and that there are restrictions in the temporal localization of the verbs of the evidential structures depending on the evidential type. The pragmatic description demonstrated the different strategic orderings speakers may use in order to indicate the source of information and the way it was obtained. Considering all these aspects involved in the data analyzed, the conclusion is that the verbs ver, ouvir and sentir are very productive means of expressing evidentiality in Portuguese.
\end{abstract}

Keywords: evidentiality; perception verbs; Functional Discourse Grammar. 


\section{INTRODUÇÃO}

A evidencialidade é o fenômeno linguístico que expressa a fonte da informação contida em um enunciado. Em muitas línguas, tal fenômeno é codificado por meio de itens gramaticais, como afixos, clíticos e morfemas. Em língua portuguesa, ele é expresso primordialmente por meio de itens lexicais, como verbos, advérbios e locuções prepositivas. Diferentemente de línguas que codificam a evidencialidade gramaticalmente, nas quais há itens gramaticais específicos para cada subtipo de evidencialidade, em língua portuguesa, um mesmo item lexical pode codificar mais de um tipo de evidencialidade. Em muitos casos, apenas a análise do contexto mais amplo em que o item ocorre pode trazer pistas para a identificação do tipo de evidencialidade codificado por ele.

Dentre os itens lexicais disponíveis aos falantes do português para expressar as fontes das informações que veiculam, os verbos são, sem dúvida, a forma mais comum de expressão de evidencialidade. Em diferentes línguas, segundo Aikhenvald (2004, p.271), os verbos de percepção, aqueles que denotam visão, audição, tato, olfato e paladar, são a fonte para o desenvolvimento de marcadores evidenciais. No estágio atual da língua portuguesa, não se observa o desenvolvimento de marcadores evidenciais a partir da gramaticalização de verbos de percepção. Ainda assim, concordando com o que se propõe em vários trabalhos sobre línguas como o inglês e o alemão (cf. CHAFE, 1986; ANDERSON, 1986; WOODBURY, 2006; WHITT, 2009), acredita-se que tais verbos possam ser considerados formas de expressão da evidencialidade. Nesse sentido, a hipótese geral deste trabalho é a de que os verbos de percepção em língua portuguesa podem ser considerados evidenciais. Em que tipos 
de construções esses verbos assumem sentido evidencial e quais tipos de evidencialidade estão relacionados com cada construção é o que se pretende investigar.

Tal investigação tem como base teórica a Gramática Discursivo-Funcional (doravante GDF). No modelo de gramática proposto pela GDF, a evidencialidade, assim como qualquer outro fenômeno linguístico, é descrita em termos de níveis ou camadas de acordo com as características semântico-pragmáticas e morfossintáticas que o item ou a construção evidencial apresenta na língua em estudo. Assim, dentro da GDF, os diferentes tipos de evidencialidade são alojados em diferentes níveis ou camadas. A partir da classificação da evidencialidade proposta pela GDF e dos princípios analíticos desse modelo, busca-se descrever os usos evidenciais dos verbos ver, ouvir e sentir.

Esses três verbos foram selecionados por serem os representantes mais prototípicos de cada sentido (ver para visão, ouvir para audição e sentir para tato, olfato e paladar) e por estarem relacionados com uma ampla variedade de sentidos evidenciais. Apesar de a presente investigação levar em conta apenas três verbos, acredita-se que a classificação aqui empreendida também seja válida para os outros verbos de percepção.

Tendo em vista a perspectiva funcionalista adotada nesta pesquisa, os dados analisados dizem respeito a usos reais da língua portuguesa. O material de análise é proveniente de amostras de língua oral, do Banco de Dados Iboruna (GONÇALVES, 2007), e de textos publicados na Internet, em blogs e fóruns de discussão.

Sustentando a hipótese, já mencionada, de que os verbos de percepção constituem formas de expressão lexical da evidencialidade, os dados levantados foram analisados com o objetivo maior de descrever os aspectos sintáticos, semânticos e pragmáticos das estruturas em que os verbos ver, ouvir e sentir são usados e permitem uma leitura evidencial. Com essa proposta de trabalho, busca-se responder às seguintes perguntas: 
i) Em que tipos de construções esses verbos assumem sentido evidencial?

ii) Quais são os tipos de evidencialidade relacionados com cada construção?

iii) Quais são os tipos de evidencialidade relacionados com cada verbo?

iv) Tendo em vista a polissemia característica dos três verbos, qual é a importância do contexto semântico e pragmático para a determinação do tipo de evidencialidade codificado por eles?

v) Qual é a configuração semântica de cada uma das estruturas em que os verbos atuam como evidenciais?

vi) Qual é a configuração morfossintática de cada uma das estruturas em que esses verbos atuam como evidenciais?

Com essa proposta de análise dos verbos de percepção ver, ouvir e sentir, pretende-se mostrar que a expressão lexical da evidencialidade, apesar de não ser sistemática, também pode ser enquadrada nos mesmos subtipos semântico-pragmáticos da evidencialidade gramatical.

Uma segunda expectativa deste trabalho, de natureza teórica, é demonstrar a adequação da abordagem em níveis e camadas proposta pela GDF ao estudo de um fenômeno linguístico que requer a consideração de unidades maiores que a frase para a sua análise, como é o caso da evidencialidade.

Este trabalho está organizado da seguinte forma: no Capítulo I, é feita a caracterização geral da evidencialidade baseada em diversos trabalhos que tratam do tema em diferentes línguas e também em português; no Capítulo II, são apresentadas algumas tipologias sobre os verbos de percepção e as particularidades dos usos evidenciais desses verbos; no Capítulo III, explora-se o modelo da GDF, em que é baseada a descrição do fenômeno em estudo; no Capítulo IV, é apresentado um detalhamento sobre como foi feita a seleção dos três verbos considerados neste estudo, são apresentados os procedimentos de busca dos dados e são 
expostos os critérios considerados durante a análise dos dados; no Capítulo V, é apresentada a análise dos dados; finalmente, na Conclusão, são apresentados os resultados obtidos. 


\section{CAPÍTULO I}

\section{A EVIDENCIALIDADE}

\section{INTRODUÇÃO}

A evidencialidade corresponde, em termos genéricos, à explicitação da fonte da informação contida em um enunciado. O termo "evidencialidade", tal como conhecido atualmente nos estudos linguísticos, foi introduzido por Jakobson (1957 apud FLOYD, 1999, p.4) como uma tentativa de nomear "uma categoria linguística distinta de modo e que se referia à marcação da fonte da informação em geral". ${ }^{1,2}$ No entanto, apenas com a publicação de Evidentiality: the Linguistic Coding of Epistemology (CHAFE; NICHOLS, 1986) é que o uso do termo passa a ser mais recorrente na Linguística. Tal obra consiste na compilação dos trabalhos apresentados na conferência de Berkeley (EUA), em 1981, a primeira conferência dedicada integralmente ao assunto. Desde a década de 1980, portanto, a evidencialidade vem sendo tratada a partir de várias perspectivas em línguas do mundo todo.

Atualmente, podem ser encontrados muitos estudos sobre a codificação da evidencialidade em diferentes línguas, demonstrando a complexidade e a variedade dos sistemas evidenciais (cf. JOHANSON; UTAS, 2000; AIKHENVALD; DIXON, 2003; AIKHENVALD, 2004; os números especiais das revistas Journal of Pragmatics, vol.33, n.3, 2001, e Functions of Language, vol.16, n.1, 2009, dentre outros trabalhos).

\footnotetext{
${ }^{1}$ a grammatical category distinguished from mood that concerned the marking of information source in general (FLOYD, 1999, p.4).

${ }^{2}$ Todas as traduções presentes neste trabalho são de minha autoria.
} 
Na seção 1, a seguir, são apresentadas algumas tipologias evidenciais propostas por pesquisadores que estudaram as diferentes formas de codificação da evidencialidade em diversas línguas do mundo. Na seção 2, são descritos os estudos sobre a evidencialidade em língua portuguesa.

\section{TIPOLOGIAS EVIDENCIAIS}

Um dos estudos tipológicos pioneiros sobre a evidencialidade no qual muitos outros estudos se basearam é o de Willet (1988), que estudou as marcas evidenciais gramaticais em 38 línguas ameríndias. Nessa pesquisa, o autor distingue dois tipos de evidência - a direta e a indireta - levando em conta a natureza primária ou secundária da fonte da informação utilizada pelo falante.

Os mecanismos de evidência direta, segundo Willet, são utilizados quando o falante é testemunha direta da informação contida em seu enunciado, ou seja, o falante declara-se fonte da informação e ainda informa que viu, ouviu, ou teve algum contato sensorial com o fato qualificado evidencialmente.

A evidência indireta, por outro lado, é utilizada quando o falante afirma saber da situação descrita por meios verbais (evidencialidade relatada) ou somente por meio de inferência (evidencialidade inferida). O autor ainda subdivide a evidência indireta relatada em: i) de segunda mão, quando o falante afirma ter ouvido a situação descrita de alguém que foi testemunha direta; ii) de terceira mão, quando o falante afirma ter ouvido sobre a situação descrita, mas não de uma testemunha direta (boato); e iii) mito, quando o falante afirma que a situação descrita é parte de uma história oral consagrada. A evidência indireta inferida é também subdivida em: i) inferência de resultado, quando o falante infere a situação descrita de evidências observáveis, e ii) inferência de raciocínio, quando o falante infere a situação descrita com base na intuição, na lógica, em experiências prévias, ou algum construto mental. 
A título de ilustração, apresentam-se as diferentes formas gramaticais de expressão evidencial usadas na língua indígena kashaya, falada na Califórnia e descrita no trabalho de Willet (1988, p.67): - $y(a)$ marca evidência visual direta, como em (01), -do marca evidência relatada, como em (02), e -q(a) marca evidência inferida, como em (03):

(01) momaay

entrou:EV

(Acabei de ver que) ele entrou.

(02) qacuhse hqamac'ke $\underline{\text { domta }}$

grama:jogo jogar:FUTURO:ASSERÇÃO:EV:RESPOSTA

Me disseram que eles vão jogar o jogo da grama.

(03) cuhnii $\mathrm{mu}^{\mathrm{a}} \mathrm{aq}^{3}$

O pão está assado (eu posso sentir)

Botne (1997), ao estudar o sistema evidencial do lega, uma língua banto falada no leste do Zaire, propõe uma classificação para os evidenciais diferente da classificação proposta por Willet (1988). Botne aponta dois problemas na classificação de Willet: o primeiro diz respeito à colocação, num mesmo patamar, das evidências relatadas e inferidas, e o segundo refere-se ao uso confuso da terminologia, tendo em vista que Willet usa tipos "de evidência" e "fontes de evidência" para se referir à subdivisão dos evidenciais em evidência atestada, relatada e inferida.

Para Botne, existem duas instâncias diferentes que parecem estar superpostas no trabalho de Willet: i) o modo como se obteve a informação (mode of knowing, termo emprestado de CHAFE, 1986), o que corresponderia ao "tipo de evidência", de Willet, e ii) a fonte da informação. Com essa separação, ao classificar uma evidência como atestada, relatada ou inferida, o que se está mostrando é o modo como a informação foi obtida. A fonte

\footnotetext{
${ }^{3} \mathrm{O}$ autor não apresenta glosa para este exemplo.
} 
da informação pode ser o próprio falante ou outra pessoa, self e other, nos termos de Frawley (1992 apud BOTNE, 1997).

Segundo Botne (1997), essas duas diferentes abordagens em relação à organização da informação, a de Willet (1988) e a de Frawley (1992), têm relação direta com as características específicas da evidencialidade na(s) língua(s) em estudo. Assim sendo, ainda segundo Botne, existem línguas em que o sistema evidencial está baseado no modo de obtenção da informação, que pode ser de forma direta (atestada) ou indireta (relatada e inferida), como proposto no trabalho de Willet (1988). Em outras línguas, o princípio primário de organização dos evidenciais está baseado na divisão de fonte do conhecimento: o próprio falante ou uma outra fonte, como é apresentado em Frawley (1992 apud BOTNE, 1997).

Aikhenvald (2004), em seu estudo sobre a evidencialidade gramatical em mais de 500 línguas de várias partes do mundo, assim como Willet, não faz distinção entre "fonte da informação" e "modo de obtenção da informação". Para a autora, marcar a fonte da informação que alguém transmite indica como essa pessoa adquiriu tal informação. Dessa forma, levando em conta a fonte da informação como sendo o significado primário da evidencialidade enquanto categoria gramatical, Aikhenvald organiza sua descrição do fenômeno em termos da complexidade e dos significados codificados pelos "sistemas evidenciais". 4

No estudo de Aikhenvald, portanto, as línguas são agrupadas conforme o sistema gramatical evidencial que apresentam. Tais sistemas, segundo a autora, variam em termos da quantidade de fontes da informação codificadas e em termos da maneira como elas são marcadas. Existem sistemas mais simples, de duas possibilidades, que marcam, por exemplo, evidência direta (ou de primeira mão) e evidência indireta (não de primeira mão). Há sistemas de três escolhas, que envolvem, pelo menos, uma especificação sensorial, como, por exemplo,

\footnotetext{
4 A autora define "sistema evidencial", utilizando as palavras de Johanson (2003), como "um conjunto paradigmático de formas” (AIKHENVALD, 2004, p.67).
} 
evidência direta (ou visual), e especificações de evidencialidade inferida e relatada. Os sistemas de quatro possibilidades envolvem uma ou duas especificações sensoriais, como, por exemplo, evidência visual e evidência sensorial não-visual, e especificações de evidencialidade inferida e relatada. Os sistemas evidenciais mais complexos são aqueles que permitem cinco ou mais possibilidades de codificação de evidencialidade. Um exemplo desse tipo de sistema seria aquele que marcasse evidência visual, sensorial não-visual, inferida, assumida e reportativa.

Com relação à codificação da evidencialidade, de um modo geral, diferentes formas gramaticais podem ser usadas: afixos, clíticos, partículas ou formas verbais especiais (verbos auxiliares). No entanto, Aikhenvald (2004) lembra que a evidencialidade pode não formar uma categoria uniforme, expressa por uma mesma categoria gramatical em determinada língua. Pelo contrário, os sentidos evidenciais de uma língua podem ser codificados por formas pertencentes a diferentes categorias gramaticais e até mesmo estar fundidos com outras categorias, como tempo verbal.

Aikhenvald é bastante categórica ao dizer que a evidencialidade é uma categoria gramatical codificada apenas por formas que fazem parte da gramática de uma língua. Segundo a autora, não se pode dizer que o inglês, por exemplo, possui evidencialidade, uma vez que, nessa língua, expressões que indicam fonte de informação não são obrigatórias e não constituem uma categoria gramatical. Assim, línguas como o inglês, em que há primordialmente meios lexicais que expressam sentidos relacionados com a fonte da informação, possuem "estratégias evidenciais", 5 e não uma categoria (ou sistema) evidencial.

Os estudos de Willet (1988), Frawley (1992) e Botne (1997), sumariamente expostos acima, também consideram apenas a evidencialidade gramatical. $\mathrm{Na}$ verdade, a grande

\footnotetext{
${ }^{5}$ De um modo mais específico, estratégias evidenciais são, segundo Aikhenvald (2004, p.105), "categorias e formas que adquirem sentidos secundários de alguma forma relacionados com a fonte da informação [...] elas são diferentes dos evidenciais propriamente ditos, cujo primeiro - e não raramente o único - sentido é a fonte da informação."
} 
maioria dos estudos que tratam do tema diz respeito a línguas em que a evidencialidade é marcada por meios gramaticais. Segundo Aikhenvald (2004), aproximadamente um quarto das línguas existentes no mundo apresenta evidenciais gramaticais. Nessas línguas, todos os enunciados contêm a especificação do tipo de fonte na qual o falante se baseou para fazer suas afirmações, o que significa que os falantes dessas línguas devem deixar explícito, por meio de marcas gramaticais, se viram, ouviram, inferiram ou obtiveram a informação a partir da percepção por meio de um outro sentido.

A respeito de línguas que expressam a fonte da informação por meios lexicais, Floyd (1999, p.29) afirma que “o uso de um sintagma evidencial pode conter nuanças semânticas que estão ausentes em línguas com sistemas mais gramaticalizados." ${ }^{\circ}$ Sobre essa diferença de nuança, Dahl (1990, p.685 apud FLOYD, 1999, p.29) observa que

esta nuança [...] deve-se claramente a uma implicatura conversacional de Grice: o ouvinte assume que o falante não usaria o qualificador evidencial se não houvesse nenhuma boa razão para fazer isso. Mas note que, se o uso de um marcador evidencial é obrigatório, esta implicatura é propensa a se enfraquecer ou desaparecer - o falante não precisa de nenhuma boa razão para o uso exceto se a gramática o requer. ${ }^{7}$

O fato de haver, na expressão lexical da evidencialidade, outros significados envolvidos não elimina do enunciado seu estatuto evidencial. Pode-se dizer então que, de um modo geral, toda língua de alguma forma tem meios de marcar a fonte da informação, mas nem toda língua tem evidencialidade gramatical. "Ter meios lexicais para opcionalmente especificar a fonte do conhecimento é provavelmente universal"8 (AIKHENVALD, 2004, p.10).

\footnotetext{
${ }^{6}$ the overt use of an evidential phrase may carry semantic nuances that are absent in languages with more grammaticalized systems (FLOYD, 1999, p.29).

${ }^{7}$ This nuance ... [in the English sentences] is clearly due to a Gricean conversational implicature: the listener assumes that the speaker would not supply the evidential qualifier if there were not a good reason for doing so. But notice that if the use of an evidential marker is obligatory, this implicature is bound to weaken or disappear - the speaker needs no good reason for the use except that the grammar requires it (DAHL, 1990, p.685 apud FLOYD, 1999, p.29).

${ }^{8}$ Having lexical means for optional specification of the source of knowledge is probably universal (AIKHENVALD, 2004, p.10).
} 
A consideração da marcação lexical da evidencialidade como válida traria, de acordo com Floyd (1999), sérias consequências para uma comparação tipológica justamente pela questão das diferentes nuanças dos dois tipos de marcação da evidencialidade. Isso não significa que não se possa abordar a evidencialidade lexical em línguas individuais, como mostram os trabalhos de Vendrame (2005), Gonçalves (2003), Dall'Aglio-Hattnher (2001, 2007) e Casseb-Galvão (2001), dentre outros, sobre o português e Chafe (1986) sobre o inglês.

Neste trabalho, a evidencialidade é considerada um fenômeno existente em todas as línguas, que pode ser codificado de diferentes maneiras de acordo com os recursos gramaticais ou lexicais que a língua oferece. A partir desse ponto de vista, pode-se considerar que a evidencialidade, de acordo com as suas diferentes formas de manifestação, pode formar sistemas gramaticais fechados, sistemas gramaticais em desenvolvimento, sistemas mistos (que contêm formas gramaticais e lexicais) e sistemas de marcação lexical.

\section{A EVIDENCIALIDADE EM LÍNGUA PORTUGUESA}

Nos estudos sobre evidencialidade, especialmente naqueles que tratam de sua expressão lexical, é recorrente o tema dos limites entre evidencialidade e modalidade epistêmica, uma vez que, além de indicar a fonte de um conteúdo proposicional e de assegurar a confiabilidade do enunciado, os evidenciais também podem marcar o grau de comprometimento do falante com a verdade da proposição.

Segundo Dendale e Tasmowski (2001), em línguas que possuem um sistema evidencial gramaticalizado, a evidencialidade é uma categoria gramatical em que a indicação da fonte é seu sentido primário. Em línguas cuja expressão da evidencialidade acontece por meios lexicais, como é o caso do português, é comum que o mesmo item lexical que indica a 
fonte da informação também exprima (in)certeza e (des)comprometimento por parte do falante, não sendo fácil estabelecer qual desses valores é o primário.

Assim, alguns trabalhos sobre a evidencialidade em língua portuguesa tratam também da modalidade epistêmica, buscando relacionar as diferentes formas de expressão dessas duas qualificações e seus graus variados de (in)certeza e (des)comprometimento em determinados tipos de texto. Um trabalho de referência nesse sentido é o de Dall'Aglio-Hattnher (2001), em que a autora aponta a falta de consenso sobre o estabelecimento das relações de escopo entre as duas qualificações.

Segundo a autora, existem duas tendências nos estudos sobre a modalidade e a evidencialidade: "a que considera a evidencialidade como uma categoria gramatical englobada pela modalidade epistêmica e a que considera a evidencialidade como uma instância semântica não só superior, mas também, e principalmente, necessária para a qualificação modal epistêmica” (DALL'AGLIO-HATTNHER, 2001, p.1). A autora insere seu estudo dentro da segunda tendência e apresenta justificava para isso citando Nuyts (1993, p.496 apud DALL'AGLIO-HATTNHER, 2001, p.10), segundo o qual "sem evidência, nenhuma avaliação de probabilidade de um estado de coisas é possível; pode-se então apenas dizer que não se sabe." Concordando com De Haan (1997), a autora considera que “evidencialidade e modalidade epistêmica são claramente diferentes: enquanto os julgamentos epistêmicos são baseados no grau de certeza que o falante tem sobre o conteúdo enunciado, os evidenciais indicam as fontes a partir das quais o falante obteve a informação enunciada" (DALL'AGLIO-HATTNHER, 2001, p.60).

A partir da tipologia dos evidenciais de Willet (1988) e dos dados encontrados em discursos políticos e textos científicos, Dall'Aglio-Hattnher (2001) propõe a seguinte tipologia para os evidenciais em língua portuguesa: 
Evidencialidade direta $\{$ atestada

Evidencialidade indireta $\left\{\begin{array}{l}\text { relatada } \\ \text { inferida }\end{array}\left\{\begin{array}{l}\text { definida } \\ \text { indefinida } \\ \text { domínio comum }\end{array}\right.\right.$

Figura 1. Tipologia dos evidenciais em língua portuguesa segundo Dall'Aglio-Hattnher (2001)

Com relação à evidencialidade direta, a autora afirma que, "ao contrário do que acontece nas línguas em que a evidencialidade é expressa gramaticalmente, na língua portuguesa a expressão de um conhecimento originado na experiência do próprio falante parece dispensar a marca evidencial” (DALL'AGLIO-HATTNHER, 2001, p.33). Nesse sentido, um dos objetivos da presente pesquisa é verificar se os verbos de percepção se prestam à expressão da evidencialidade direta, completando essa lacuna na descrição do sistema evidencial lexical da língua portuguesa.

Ao trabalho pioneiro de Dall'Aglio-Hattnher (2001) seguiram-se outras pesquisas. As pesquisas de Santos (2008), Lucena (2008), Carioca (2005) e Vendrame (2005) são exemplos de investigações que também abordaram o tema da modalidade e da evidencialidade a partir do ponto de vista funcionalista.

Santos (2008) analisa a expressão lexical da evidencialidade, investigando os efeitos comunicativos dessa categoria em comparação com os da modalidade epistêmica na fala e na escrita. Ao analisar um corpus composto por dez artigos acadêmicos e dez entrevistas orais concedidas pelos autores desses textos, a autora mostra que modalizadores epistêmicos que incidem sobre a proposição e os evidenciais inferenciais ocorrem com mais frequência nos textos orais, favorecendo um grau de comprometimento maior por parte do falante. Nos textos escritos, por outro lado, os modais mais frequentes são os que incidem sobre a predicação e os evidenciais mais recorrentes são os reportativos. A autora justifica esse resultado 
argumentando que no artigo acadêmico devem transparecer objetividade e imparcialidade e que o autor desse tipo de texto normalmente deve se ancorar na autoridade de uma fonte que goza de prestígio.

Tratando exclusivamente da qualificação evidencial, Vendrame (2005) analisa a expressão da evidencialidade em construções complexas no discurso científico primário. Seguindo Botne (1997), Vendrame propõe uma revisão da tipologia de Dall'Aglio-Hattnher (2001), separando as duas instâncias envolvidas na expressão da evidencialidade — o modo de obtenção da informação e a fonte da informação — e realocando a evidencialidade de domínio comum. A tipologia proposta em Vendrame (2005, p.69) é a seguinte:

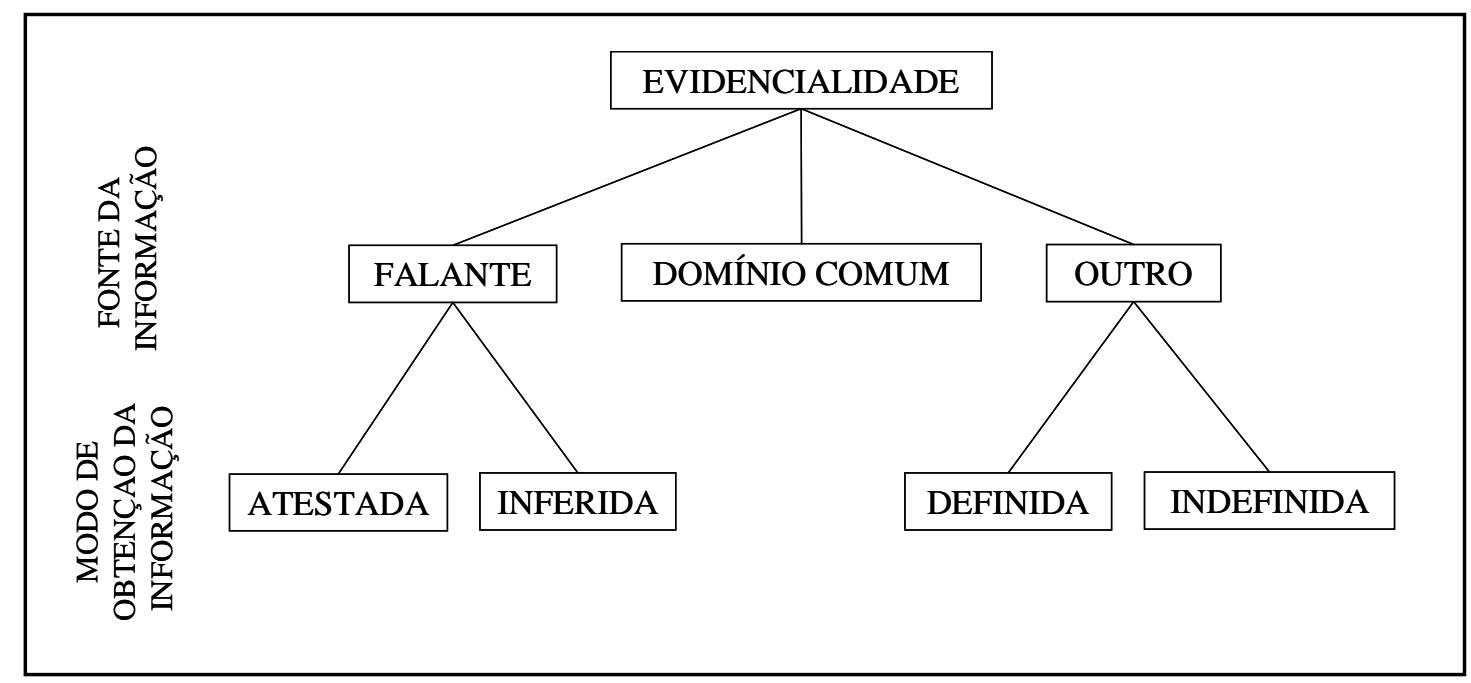

Figura 2. Tipologia dos evidenciais em língua portuguesa segundo Vendrame (2005)

De acordo com essa tipologia, há três tipos de fonte da informação: o falante, o domínio comum e o outro (ou diferente do falante). Quando a fonte da informação é o próprio falante, ele pode explicitar o modo como a informação chegou ao seu conhecimento: de forma atestada, por meio de percepção sensorial, ou inferida, por meio de inferência. A evidencialidade de domínio comum, por meio da qual o falante transmite uma informação amplamente conhecida, que faz parte do domínio comum, deixa de ser um subtipo da evidencialidade relatada, como acontece na tipologia de Dall'Aglio-Hattnher (2001), uma vez que é difícil precisar o modo de obtenção da informação nos casos de evidencialidade de domínio 
comum; o relato é apenas uma das formas pelas quais uma informação desse tipo pode chegar ao conhecimento do falante. Com relação ao terceiro tipo de evidencialidade, que marca a fonte da informação como sendo diferente do falante, a única forma de o falante expressar o modo de obtenção da informação é por meio de um relato, que pode ser apresentado com uma fonte definida ou com uma fonte indefinida.

Com base nessa tipologia, os evidenciais encontrados em artigos científicos primários das áreas de humanas, exatas e biológicas foram analisados em Vendrame (2005). A partir dos resultados, foi possível depreender que, nas introduções, o alto percentual de evidencialidade relatada contribui para a inserção do trabalho em um domínio específico do saber e para a construção da imagem de especialista; nas conclusões, o maior uso da evidencialidade inferida mostra que este é o lugar em que os cientistas assumem as ideias e os conhecimentos gerados como seus; e, na seção destinada à apresentação dos resultados/discussão, há um predomínio de evidencialidade relatada definida, o que mostra que os resultados obtidos pelos falantes estão, em grande medida, ancorados em informações de outros pesquisadores, mas há também alto percentual de evidencialidade inferida, que indica que os falantes expõem seus resultados muitas vezes de uma forma relativizada, protegendo-se de uma possível crítica quanto à validade de seus achados.

Carioca (2005) também analisa a evidencialidade em um tipo de texto científico, as dissertações acadêmicas. Ao analisar apenas as introduções e as conclusões de dez dissertações da área de Ciências Humanas, a autora demonstra que os tipos evidenciais mais frequentes são os inferenciais e os reportativos e que os efeitos de sentido associados ao uso evidencial, pelo menos no que diz respeito ao corpus em questão, estão relacionados com a promoção de um baixo comprometimento do escritor com relação às informações apresentadas. 
Também buscando relacionar a evidencialidade com graus de comprometimento, Lucena (2008) investiga a expressão evidencial em trinta discursos proferidos na Assembleia Legislativa do Ceará. Os resultados obtidos pela autora mostram que há um predomínio de evidenciais relatados de fonte definida, o que comprova que os políticos que proferiram os trinta discursos analisados, de um modo geral, preferem "não se comprometer com a informação reportada, assegurando ao interlocutor a possibilidade de avaliar por si só a validade da informação, de acordo com a qualidade da fonte expressa" (LUCENA, 2008, p.121).

O que todas essas pesquisas sobre a modalidade e a evidencialidade em língua portuguesa têm em comum, além da base teórica funcionalista, é a descrição da expressão lexical da evidencialidade. Há ainda outras duas pesquisas dedicadas ao tema que também adotam uma base teórica funcionalista e analisam a expressão lexical da evidencialidade, mas diferenciam-se das demais por descreverem o processo de mudança pelo qual passam alguns verbos que têm sentidos relacionados com a modalidade e com a evidencialidade. Trata-se dos trabalhos de Casseb-Gavão (2001) e Gonçalves (2003).

Casseb-Galvão (2001) investiga o processo de gramaticalização desenvolvido pela predicação matriz (ele) diz que, que tem como alvo os usos evidenciais expressos pelo operador proposicional [disk ${ }^{\mathrm{i}}$. A autora demonstra que a construção (ele) diz que, que introduz discurso indireto e tem traços evidenciais citativos, é a forma fonte do processo de gramaticalização. Tomando como ponto de partida essa forma fonte, Casseb-Galvão identifica os outros usos que integram o contínuo que descreve o desenvolvimento de diz que até chegar ao item alvo da trajetória de mudança, o operador [disk ${ }^{\mathrm{i}}$, e propõe a seguinte escala de gramaticalização: 
Citativo, Intuitivo $>$ Reportativo de mito $>$ Assumido $>$ Inferido $>$ De boato $>$ Especulativo 9

A autora comprova, com dados de língua oral do português contemporâneo, que, no desenvolvimento do diz que em direção a sua constituição como operador evidencial, ocorreu

dessemantização da forma fonte, a partir da transferência conceptual do mundo real, [+ concreto], para o mundo do discurso, [+ abstrato]. No plano morfossintático, deu-se a reanálise dos elementos constitutivos da expressão, a qual gerou uma reestruturação na configuração enunciativa. No plano fonológico, as mudanças nas fronteiras da estrutura entoacional atestam a reanálise e a nova função, [d $\mathrm{i} \mathrm{s} \mathrm{k}^{\mathrm{i}}$ ] (CASSEBGALVÃO, 2001, p.219).

Esse estudo de Casseb-Galvão (2001) é de grande relevância no âmbito dos estudos sobre a evidencialidade em língua portuguesa porque é o primeiro a apontar um marcador evidencial gramatical.

Também com o intuito de investigar o desenvolvimento de marcadores de evidencialidade em língua portuguesa por meio do processo de gramaticalização, Gonçalves (2003) toma como objeto de estudo as construções com o verbo parecer. O autor analisa, a partir de dados sincrônicos e diacrônicos do português brasileiro, os diferentes usos do verbo parecer, buscando estabelecer relações entre eles.

Gonçalves identificou cinco tipos de construções diferentes com o verbo parecer, que foram por ele organizadas na seguinte escala de gramaticalização:

\footnotetext{
${ }^{9}$ Ocorrências apresentadas por Casseb-Galvão (2001, p. 173 - 176) para ilustrar cada um desses usos são: Citativo: Tia Ursula diz que a água daqui faz bem ao cabelo. Intuitivo: Calma, inspetor. Algo me diz que o Genival tem novidades para nós. Reportativo de mito: Diz que era um rei, tinha uma filha por casar... Assumido: B: Diz que pedacim do chifre cura quebrante. M: Do chifre direito. Do chifre esquerdo, cura espinhela caída. Inferencial: Pois é, no Cassino da Urca, olha que chique. Parece até que ela é uma jovem muito simpática, culta, prendada... E rica, é claro. Diz que a família dela tem muito dinheiro. De boato: - E a mulher? Levaram lá pra dentro. - Diz que lá dentro escutam a gente sim. Especulativo: Inda conhece pobre? Que beleza... Diz que tem dois meninos procurando o pai ali na esquina.
} 
Parecer $_{1}$ (predicado verbal) $>$ Parecer $_{2}$ (suporte da predicação / operador modal) $>$ Parecer $_{3}$ (predicado de atitude proposicional) $>$ Parecer $_{4}$ (quase-satélite atitudinal) $>$ Parecer $_{5}$ (satélite atitudinal $)^{10}$

Segundo o autor, o uso mais concreto de parecer, o parecer, , que tem como significado "ter a mesma aparência de", possui uma "base 'evidencial' (lato sensu), pois parte de uma constatação e de um julgamento do falante acerca de estados de coisas observáveis no mundo" (GONÇALVES, 2003, p.101). No entanto, esse uso do verbo, devido a suas propriedades sintático-semânticas, não apresenta valor modal ou evidencial (stricto sensu).

Nos casos de parecer $_{2}$, o verbo perde o estatuto de predicado, funcionando como cópula-suporte, mas pode ainda ter seu sentido relacionado com "ter semelhança de" ou "ter a aparência de", assim como parecer $_{1}$; a diferença é que, em parecer $_{2}$, a comparação e a avaliação acontecem entre uma entidade referencial e um construto mental do falante, e não entre duas entidades referenciais como é o caso de parecer $_{1}$. Além disso, parecer $_{2}$ possibilita uma interpretação modal objetiva (não-certeza, probabilidade) ou ainda uma interpretação evidencial, uma vez que, em alguns desses usos, pode-se considerar que o falante se revela fonte da informação contida no conteúdo proposicional.

O verbo parecer, nas construções que Gonçalves denominou parecer $_{3}$, é analisado como um predicado que encaixa um conteúdo proposicional. Com relação a parecer ${ }_{2}$, parecer $_{3}$ sofre reanálise sintático-semântica e passa a subcategorizar não apenas predicações do tipo estado, mas também outros tipos de complementos (finitos ou não-finitos). Nos casos de parecer $_{3}$, não há dúvidas sobre os valores evidenciais e epistêmicos desse uso: ao mesmo

\footnotetext{
${ }^{10}$ Ocorrências apresentadas por Gonçalves (2003, p.96-97) para ilustrar cada um desses usos são: Parecer 1 : Fica uma delícia (est) Fica uma delícia ... que (inint) Não fica aquele - fica cajuzinho cre/ caramelo, [o amendoim] fica parecendo um caramelo. Parecer ${ }_{2}$ : [E e F vêm falando sobre a política nacional] E: o senhor me parece uma pessoa bem politizada mesmo, né?. Parecer 3 : D: você conhece por acaso as ( ) ... as ( ) do hipódromo? L: do hipódromo? Há um negócio que se chama aras... agora [o aras me parece que não é no hipódromo]... é o local onde o cavalo é é é é... é cuidado... é tratado... Parecer 4 : [o pedágio passou para parece que setenta cruzeiro a partir de dia prime- depois de amanhã]. Parecers: Naquele tempo não se tomava uísque tomava-se chope então tinha um barrilzinho de cho:pe uns... uns sanduíches... [naquele tempo devia ser presunto e queijo ... parece] ... eu não me lembro bem ((risos)) mas devia ser assim.
} 
tempo em que o falante se mostra como fonte da inferência expressa pelo verbo, ele se descompromete com o valor de verdade da proposição, que é apresentada como provável/possível.

Os usos de parecer que se encontram mais à direita da escala de gramaticalização proposta por Gonçalves são caracterizados como satélites atitudinais de caráter adverbial e são distinguidos apenas por propriedades formais: parecer $_{4}$ funciona como um quase-satélite e parecer $_{5}$, como um satélite. Com relação aos valores semânticos de parecer $_{4,5}$, Gonçalves afirma que são os mesmos de parecer $_{3}$, apenas os meios categoriais são diferentes. Segundo o autor, "os casos de parecer $_{4,5}$ equiparam-se, então, a satélites de atitudes proposicionais $\sigma_{3}$, que atuam diretamente na camada proposicional, a exemplo de parecer 3 " (GONÇALVES, 2003, p.122). Ao utilizar um satélite do tipo parecer $_{4,5}$, o falante avalia o conteúdo proposicional ou parte dele, dependendo da localização do item na oração. A diferença entre parecer $_{4}$ e parecer $_{5}$ reside na presença do complementizador "que", no primeiro caso, e em sua ausência no segundo caso. Em parecer $_{4}$, o complementizador "que" está ainda atrelado ao verbo, mas ele não introduz um complemento oracional, como acontece em parecer $_{3}$. De acordo com Gonçalves, a presença do complementizador em parecer 4 marca com clareza o constituinte que ele escopa, o que nem sempre acontece em parecer $_{5}$. O uso mais gramaticalizado de parecer, parecer $_{5}$, além de ser caracterizado pela ausência do complementizador "que", mostra-se completamente independente do ponto de vista sintático no enunciado modalizado, podendo ocorrer em diferentes posições (iniciais, mediais e finais), ao passo que parecer $_{4}$ só pode ser usado em posição medial.

Ao concluir seu trabalho, Gonçalves propõe que o verbo parecer, que em seu atual estágio de mudança marca tanto modalidade epistêmica quanto evidencialidade, pode vir a se desenvolver ainda mais e assumir, em determinados contextos, um valor puramente evidencial. Tal prognóstico apresentado por Gonçalves e os resultados a que chegou Casseb- 
Galvão (2001) apontam para o fato de um sistema evidencial gramatical estar em desenvolvimento na língua portuguesa. Segundo Gonçalves (2003, p.231), “a exemplo de outras línguas com sistema gramatical de EV, é possível que o PB venha a gramaticalizar somente evidência indireta e a assumir a evidência direta como forma não-marcada ou marcada por zero." O desenvolvimento de expressões gramaticais de evidencialidade indireta também desperta atualmente a atenção do Grupo de Estudos Discurso \& Gramática. Conforme afirmam Oliveira e Votre (2009, p.109-110),

constituem interesse mais recente os recursos situados no âmbito da evidencialidade, para dar suporte ao que se afirma, quer sustentando o dito em pessoas, quer no imaginário popular. Abre-se, assim, nova vertente de estudo sobre gramaticalização e discursivização de expressões centradas em pessoas, como segundo fulano, conforme sicrano, de acordo com beltrano, já dizia fulano, como dizia meu pai, minha vó etc. A outra vertente aponta para evidência centrada no imaginário social, com expressões do tipo: como já diziam os antigos, como diz o ditado, conforme todos sabemos, todos sabemos, sabemos, sabe-se etc.

Conforme foi apresentado nesta seção, as pesquisas funcionalistas sobre a evidencialidade em língua portuguesa se agrupam em dois blocos: i) aquelas que descrevem o comportamento da evidencialidade em um tipo específico de texto, buscando explicar os efeitos de sentido gerados pelos diferentes tipos evidenciais com base nas características do tipo de texto analisado, e ii) aquelas que, focalizando uma única forma de expressão da evidencialidade, buscam explicar, a partir do ponto de vista sincrônico e/ou diacrônico, a trajetória de gramaticalização pela qual passou essa forma e os sentidos evidenciais que ela adquiriu nesse processo.

No presente trabalho, um terceiro caminho para o estudo da evidencialidade é trilhado. A análise aqui empreendida não se enquadra no primeiro grupo de pesquisas, uma vez que não tem o objetivo de caracterizar a evidencialidade em nenhum tipo específico de texto, nem no segundo, porque não estuda o processo de gramaticalização de formas evidenciais. Considerando a evidencialidade como um fenômeno universal, diferente da modalidade, que 
pode ser expresso por meios gramaticais e/ou lexicais em qualquer língua, este trabalho busca descrever os usos evidenciais dos verbos de percepção ver, ouvir e sentir. A opção por verbos deve-se ao fato de essa ser a forma de expressão da evidencialidade mais produtiva em língua portuguesa, conforme comprovam os diferentes estudos apresentados anteriormente (DALL'AGLIO-HATTNHER，2001; VENDRAME，2005; CARIOCA，2005; SANTOS, 2008; LUCENA, 2008). Dentro do paradigma verbal, os verbos de percepção são o tipo de verbo que permite a expressão de uma variabilidade maior de tipos de evidencialidade. Em muitas línguas eles são, inclusive, a forma fonte da qual derivam evidenciais gramaticais (cf. AIKHENVALD, 2004, p.273-274). Com este estudo, pretende-se preencher uma lacuna na descrição da evidencialidade em língua portuguesa, analisando de forma mais específica a evidencialidade expressa por meio dos verbos de percepção. 


\section{CAPÍTULO II}

\section{OS VERBOS DE PERCEPÇÃO E A EXPRESSÃO DA EVIDENCIALIDADE}

\section{INTRODUÇÃO}

Os verbos de percepção têm sido objeto de pesquisas linguísticas pertencentes a diferentes vertentes teóricas sob vários aspectos. Eles já foram estudados, por exemplo, a partir do ponto de vista tipológico (VIBERG, 1984), da mudança semântica (SWEETSER, 1990), da gramaticalização (HEINE et al., 1991), da complementação (DIK; HENGEVELD, 1991; CARVALHO, 2004), da polissemia (IBARRETXE-ANTUAÑO, 1999), dentre outros.

A presente pesquisa se beneficia dos resultados de alguns desses trabalhos para fundamentar a análise sobre os verbos de percepção evidenciais. Apesar de existirem trabalhos sobre os verbos de percepção em língua portuguesa (BARROS, 1977; CARVALHO, 2004; RODRIGUES, 2009, dentre outros), que tratam de vários aspectos dessa classe verbal, ainda faltava uma pesquisa que relacionasse esses verbos, em sua complexidade semântico-pragmática e estrutural, com a evidencialidade.

Neste Capítulo, algumas tipologias sobre os verbos de percepção são apresentadas na seção 1. A partir da análise de estudos sobre os verbos de percepção em diferentes línguas, algumas características que esses verbos precisam apresentar para serem considerados evidenciais são discutidas na seção 2 . 


\section{TIPOLOGIAS DOS VERBOS DE PERCEPÇÃO}

O campo semântico da percepção é organizado de acordo com os cinco sentidos: visão, audição, tato, olfato e paladar. Em diferentes estudos sobre os verbos de percepção em inglês (cf. POUTSMA, 1926; VIBERG, 1984; LEECH, 1971; PALMER, 1966), esses verbos são classificados de acordo com o sentido envolvido e com o papel semântico de seus sujeitos. Assim, são distinguidos três grupos: verbos de percepção ativa, verbos de percepção passiva e verbos de estímulo perceptivo.

Do primeiro grupo fazem parte verbos que indicam uma percepção ativa por parte do referente-sujeito, ou seja, a percepção é conscientemente controlada pelo referente-sujeito. A seguir, são apresentados exemplos de verbos de percepção ativa em português: ${ }^{11}$

(04) Pedro olhou para os pássaros.

(05) Pedro escutou a música. ${ }^{12}$

(06) Pedro tocou a toalha (para ver quão macia ela era).

(07) Pedro cheirou o cigarro (para ver se o fumo era forte).

(08) Pedro degustou a comida (para ver se não estava salgada).

Do segundo grupo fazem parte verbos que indicam uma percepção passiva, ou seja, a percepção acontece independentemente da vontade do referente-sujeito da oração. Em português, exemplos de verbos de percepção passiva são:

(09) Pedro viu os pássaros.

(10) Pedro ouviu os pássaros.

(11) Pedro sentiu uma pedra debaixo de seu pé.

\footnotetext{
${ }^{11}$ Os exemplos apresentados de (4) a (8) são adaptados de Viberg (1984, p.125).

12 Apesar de o verbo escutar ter sido incluído dentre os verbos de percepção ativa, como apresentando o significado "estar consciente do que se está ouvindo", esse verbo também pode permitir uma leitura passiva. Uma oração do tipo "escutei os pássaros", em que não há controle do sujeito sobre a ação de escutar, é perfeitamente possível em língua portuguesa.
} 
(12) Pedro sentiu cheiro de cigarro na sala.

(13) Pedro sentiu gosto de alho na comida.

Diferentemente dos verbos do primeiro grupo, não há registros, em português, de verbos de percepção passiva específicos para os sentidos tátil, olfativo e gustativo. O verbo usado na expressão desses três tipos de percepção é o sentir, que precisa ser complementado por nomes de percepção olfativa e gustativa, como "cheiro" ("sentir cheiro") e "gosto" ("sentir gosto"), por exemplo, para expressar, respectivamente, percepção olfativa e gustativa, conforme se observa em (12) e (13).

O terceiro grupo contém verbos de percepção cujos sujeitos são o estímulo da percepção. Em português, os verbos de percepção parecem não servir a esse uso, exceto no que diz respeito à percepção olfativa. A seguir são apresentados exemplos em inglês de verbos de estímulo perceptivo (cf. VIBERG, 1984, p.125) e seus correspondentes em português:

(14) a. Peter looked happy.

b. Peter parecia feliz.

(15) a. Peter sounded happy.

b. Peter parecia feliz.

(16) a. The cloth felt soft.

b. A toalha parecia / era macia.

(17) a. Peter smelled good / of cigars.

b. Peter cheirava bem / a cigarros.

(18) a. The food tasted good / of garlic.

b. A comida tinha gosto bom / de alho. 
Como se pode observar pelas traduções dos cinco exemplos do inglês, não é possível usar, em português, verbos de percepção na maioria dos casos. Apenas o verbo de percepção cheirar, como se vê em (17b), pode ser usado como verbo de estímulo perceptivo.

Levando em conta esses três tipos de construções em que os verbos de percepção ocorrem e os cinco sentidos que eles codificam, Viberg (1984) propõe o paradigma básico dos verbos de percepção com base no qual realiza seu estudo tipológico em 53 línguas. O Quadro a seguir, adaptado de Viberg (1984, p.128), mostra o paradigma básico dos verbos de percepção aplicado ao inglês:

\begin{tabular}{|l|ccc|}
\cline { 2 - 4 } \multicolumn{1}{c|}{} & Percepção ativa & Percepção passiva & Estímulo perceptivo \\
\hline Visão & look at & see & look \\
\hline Audição & listen to & hear & sound \\
\hline Tato & \multicolumn{3}{c|}{ feel } \\
\hline Paladar & \multicolumn{3}{c|}{ taste } \\
\hline Olfato & \multicolumn{3}{c|}{ smell } \\
Quadro 1. O paradigma básico dos verbos de percepção em inglês (VIBERG, 1984, p. 128)
\end{tabular}

Como se pode observar, em inglês há itens lexicais diferentes para expressar percepção ativa, percepção passiva e estímulo perceptivo para duas modalidades de sentido: visão e audição, ao passo que há apenas um item lexical para codificar tato, paladar e olfato.

Em português, o paradigma básico dos verbos de percepção é organizado da seguinte forma:

\begin{tabular}{|l|ccc|}
\cline { 2 - 4 } \multicolumn{1}{c|}{} & Percepção ativa & Percepção passiva & Estímulo perceptivo \\
\hline Visão & olhar & ver & - \\
\hline Audição & escutar & ouvir & - \\
\hline Tato & tocar & sentir & - \\
\hline Paladar & experimentar & sentir gosto & - \\
\hline Olfato & cheirar & sentir cheiro & cheirar (a) \\
\hline
\end{tabular}

Quadro 2. O paradigma básico dos verbos de percepção em português ${ }^{13}$

\footnotetext{
${ }^{13}$ Os verbos apresentados neste Quadro não são os únicos que podem ser incluídos no campo semântico da percepção em língua portuguesa. Eles foram selecionados por serem os mais comuns, neutros e prototípicos, mas muitos outros verbos de percepção poderiam ser distribuídos entre os três grupos.
} 
Como se pode observar na segunda coluna do Quadro 2, o português tem verbos diferentes para cada modalidade de sentido para indicar percepção ativa.

Com relação à percepção passiva, os itens lexicais usados para cada modalidade são diferentes dos usados no primeiro grupo, de percepção ativa, mas, dentro do segundo grupo, o verbo sentir é usado para cobrir mais de um sentido. Nos casos de percepção passiva gustativa e olfativa, o verbo sentir deve ainda ser complementado por um nome que indica o sentido envolvido, como se pode ver nos exemplos (12) e (13), acima. Segundo Viberg (1984), algumas línguas, como o persa e o curdo, usam compostos verbais que consistem de um verbo de significado mais geral combinado com um nome que sinaliza o sentido para expressar diferentes tipos de percepção.

Com relação aos verbos de estímulo perceptivo, apenas a modalidade olfativa é codificada por um verbo de percepção, conforme exemplificado em (17b). As outras quatro modalidades de sentido, no que se refere aos usos do terceiro grupo (estímulo perceptivo), não são codificadas, em língua portuguesa, por verbos de percepção, conforme exemplificado em (14b), (15b), (16b) e (18b). Em muitas línguas, as construções do terceiro grupo são codificadas por verbos que se originaram de verbos de percepção visual, como é o caso do latim, suaíli, coreano, turco, japonês, alemão, dentre outros (cf. VIBERG, 1984; BARRON, 1997). Em português, o verbo parecer, que é usado para codificar pelo menos três tipos diferentes de modalidades de sentido nas construções do terceiro grupo, origina-se de um verbo apresentativo. Como mostra Gonçalves (2003, p.147), “o verbo parecer tem suas origens na forma *parescere (do lat. vulgar), incoativo de parere, 'aparecer' [...] e pode, primeiramente, ser considerado um verbo de apresentação (de surgimento em cena), com sentido de 'aparecer, mostrar-se"”. Apesar de não derivar de um verbo de percepção, a origem do verbo parecer está, de certa forma, relacionada ao sentido da visão, uma vez que "aparecer" é o mesmo que "tornar-se visível, perceptível". 
Ao tratar da polissemia observada em grande parte dos verbos de percepção de sua amostra, Viberg (1984, p.136) propõe a seguinte hierarquia, que se aplica "quando um verbo tem um significado prototípico conectado a uma modalidade de sentido e esse significado é estendido para cobrir uma outra modalidade": ${ }^{14}$

$$
\text { visão }>\text { audição }>\text { tato }>\left\{\begin{array}{l}
\text { olfato } \\
\text { paladar }
\end{array}\right.
$$

Segundo o autor, essa hierarquia implica que um verbo que tenha um significado básico pertencente a um sentido mais à esquerda na hierarquia pode ter seu significado expandido de modo a cobrir algum sentido (ou todos) localizado mais à direita na hierarquia. $\mathrm{O}$ autor observa, no entanto, que tal polissemia é mais comumente encontrada nos verbos de percepção passiva, sendo poucos os casos de verbos polissêmicos pertencentes aos grupos dos verbos de percepção ativa e de estímulo perceptivo, pelo menos no que se refere aos verbos de percepção da amostra de 53 línguas estudadas por ele.

Com relação aos sentidos mais à direita na hierarquia, o autor afirma que, com os dados de que dispõe, não é possível estabelecer uma ordem entre olfato e paladar, mas garante que os valores prototipicamente relacionados a esses dois sentidos não se estendem para cobrir tato, audição ou visão, o que confirma a unidirecionalidade da extensão de significados de sua hierarquia.

Viberg utiliza exemplos do verbo see, do inglês, para ilustrar a aplicação da hierarquia. Da mesma forma, o verbo ver, em português, tem seu significado prototípico relacionado com a visão, mas também é usado para cobrir significados relacionados aos outros sentidos, como se pode ver nos exemplos a seguir, adaptados de Viberg (1984, p.139):

\footnotetext{
${ }^{14}[\ldots]$ when a verb has a prototypical meaning connected to one sense modality and that meaning is extended to cover another modality (VIBERG, 1984, p.136).
} 
(19) Pedro escutou o CD para ver se ficou bem gravado.

(20) Pedro pegou a toalha para ver quão macia ela era.

(21) Pedro experimentou a comida para ver se ela estava salgada.

(22) Pedro cheirou a sopa para ver se ela continha alho.

Com relação aos outros verbos de percepção passiva apresentados no Quadro 2, ouvir não é usado para expressar outros sentidos senão o da audição. O verbo sentir, por outro lado, é polissêmico, sendo usado na expressão de significados relacionados aos sentidos tátil, olfativo e gustativo. Não é possível, no entanto, precisar qual é o sentido prototípico de sentir, a partir do qual os outros sentidos seriam derivados. Nos registros mais antigos de sentire, do latim, de onde sentir se origina, o sentido do verbo é simplesmente "perceber", podendo ser usado para expressar qualquer modalidade de sentido (cf. VIBERG, 1984; CARVALHO, 2004). Viberg afirma que os verbos originários de sentire, do latim, no estágio atual de línguas românicas como o espanhol, o português, o francês e o romeno, tiveram seus sentidos restritos aos sentidos tátil, olfativo e gustativo e sugere que, se há um sentido mais proeminente, este deve ser o relacionado ao sentido tátil. Apesar de a observação acerca do sentido mais proeminente dos verbos derivados de sentire ter sido feita por Viberg em caráter especulativo, o que se observa na língua portuguesa condiz com o que foi sugerido pelo autor. Como se vê nos exemplos apresentados em (11), (12) e (13) e no Quadro 2, o verbo sentir não precisa ser especificado quando é usado com o sentido de percepção tátil, mas precisa ser acompanhado por um nome especificador da modalidade de sentido quando se refere à percepção olfativa e gustativa. Essa diferença semântica talvez possa ser considerada um indício de que o sentido mais primitivo de sentir, no português, é o de percepção tátil, mas, para se fazer qualquer afirmação mais categórica, um estudo mais aprofundado sobre os usos desse verbo é necessário, o que foge aos objetivos desta pesquisa. 
Viberg não trata dos significados não-físicos dos verbos de percepção, mas admite que eles existem e são muitos. Como lembra Ibarretxe-Antuaño (1999), muitos trabalhos já trataram dos significados abstratos que os verbos de percepção expressam. A autora cita as pesquisas de Betchel (1879), Kurath (1921) e Buck (1949) sobre o assunto, mas lembra que nenhum desses autores oferece uma teoria que explique por que os vários sentidos dos verbos de percepção estão relacionados.

Sweetser (1990), por outro lado, investiga, a partir do ponto de vista da linguística cognitiva, as relações sistemáticas entre os diferentes significados e os caminhos de mudança semântica dos verbos de percepção do inglês. Para tanto, a autora pesquisa as relações entre os agrupamentos semânticos sincrônicos dos verbos de percepção do inglês e ainda tenta estabelecer paralelos entre esses vários significados e suas mudanças históricas.

De acordo com Sweetser (1990), os significados não-físicos dos verbos de percepção são originários dos significados físicos por meio de um processo de metaforização. Tal trajetória de mudança de sentidos mais concretos para sentidos mais abstratos não acontece apenas no campo semântico dos verbos de percepção. Nas línguas indo-europeias, como observa Kurath (1921 apud SWEETSER, 1990, p.28), palavras que denotam emoções são geralmente derivadas de palavras que se referem a ações ou sensações físicas. Esse é o caso, por exemplo, da função física do coração de bombear sangue para o corpo, que está relacionada com emoções fortes como amor, paixão, ansiedade, medo. Esse empréstimo de conceitos e palavras do meio físico para se referir a estados psicológicos ou atividades mentais é chamado, por Sweetser (1990), de metáfora MIND-AS-BODY (metáfora de base corporal), que é motivada pelas correspondências entre nossas experiências externas e nossos estados internos (emocionais e cognitivos). A autora sugere que a metáfora $M I N D-A S-B O D Y$ corresponde ao que Lakoff e Johnson (1980) chamaram "metáfora conceitual". 
Os verbos de percepção visual, segundo Sweetser (1990, p.33), normalmente desenvolvem sentidos abstratos relacionados com a atividade mental. Assim, a autora apresenta duas transferências metafóricas para os verbos de percepção visual do inglês:

i) visão física $\rightarrow$ conhecimento, entendimento. A base para essa metáfora está no estatuto primário da visão como uma fonte de dados. Estudos sobre evidencialidade em diferentes línguas mostram que dados provenientes de percepção visual direta são o tipo de conhecimento considerado mais confiável;

ii) visão física $\rightarrow$ "visão" mental. A base para essa metáfora está na relação forte entre visão e conhecimento e nas propriedades estruturais que os domínios visual e intelectual compartilham, ou seja, somos capazes de focar nossas atenções visuais e mentais, de monitorar estímulos visualmente e mentalmente.

Com relação aos verbos de percepção auditiva, Sweetser (1990, p.35) apresenta como sentidos deles derivados prestar atenção e obedecer, mas lembra que a trajetória de mudança semântica também pode ocorrer na direção contrária, ou seja, palavras com significados mais abstratos relacionados com atenção e entendimento passam a denotar audição física, como é o caso de entendre, que, no francês moderno, significa ouvir (percepção física). ${ }^{15}$

No que se refere ao sentido tátil, a autora afirma que, nas línguas indo-europeias, o verbo cujo significado denota percepção tátil (feel, em inglês, e sentir, em português, por exemplo) também é usado para indicar qualquer tipo de percepção sensorial (SWEETSER, 1990, p.35). Além desse sentido mais geral, os verbos de percepção tátil também expressam sentimento emocional.

A percepção olfativa, em inglês, pode indicar a detecção de características ruins de alguém ou de alguma situação (“I smell something fishy about this deal” (SWEETSER, 1990,

\footnotetext{
${ }^{15}$ A mesma inversão na trajetória de mudança semântica acontece com o verbo de percepção visual do inglês recognize, que deriva da raiz latina gno- ("saber"), e denota, no inglês atual, percepção física (cf. SWEETSER, 1990, p.35).
} 
p.37)). Esse mesmo uso do verbo de percepção olfativa é observado em português em orações do tipo: Isso não está me cheirando bem, quando se referem a atitudes ou situações ruins.

A percepção gustativa, segundo Sweetser, está relacionada com preferências pessoais no mundo mental (taste, em inglês, por exemplo, pode significar preferência por comida, roupas, obras de arte etc.). Ibarretxe-Antuaño (1999, p.112) supõe que isso aconteça devido ao fato de o sentido do paladar estar fortemente associado com a discriminação refinada. Em híndi, por exemplo, há seis variações principais de gostos e sessenta e três misturas possíveis (BUCK, 1949, p.1031 apud IBARRETXE-ANTUAÑO, 1990, p.113). O sentido do paladar é, então, segundo Ibarretxe-Antuaño (1999, p.113), "bastante acurado a partir de um ponto de vista descritivo, uma vez que ele permite que nos expressemos muito precisamente quando queremos descrever um gosto." 16

Sweetser tenta mostrar que as correspondências entre o vocabulário de percepção física e as palavras dele derivadas que denotam sensações e ações internas são altamente motivadas. A autora explica tais motivações por meio de paralelos e analogias que podem ser feitos entre os domínios da sensação física e da sensação interna.

Assim, o sentido da visão está relacionado com o intelecto por vários motivos: i) a visão e o pensamento possibilitam a seleção, ou focalização, de um estímulo entre muitos outros; ii) a visão é a fonte primária de apreensão de dados objetivos sobre o mundo; esse sentido nos fornece mais informações do que os outros; iii) a visão nos fornece informações a distância ${ }^{17}$ (e o domínio intelectual e objetivo é considerado uma área de "distância pessoal", em comparação com a intimidade ou proximidade do domínio emocional e subjetivo); iv) a visão é idêntica para pessoas diferentes, ou seja, diferentes pessoas olhando para a mesma

\footnotetext{
${ }^{16}[. .$.$] very accurate from a descriptive point of view, as it allows us to express ourselves very precisely when we$ want to describe a taste (IBARRETXE-ANTUAÑO, 1999, p.113).

17 Tanto o sentido da visão quanto o da audição são conhecidos na literatura sobre o assunto como os "sentidos distantes", uma vez que não é necessário contato direto entre o indivíduo que percebe e o objeto percebido para que a percepção aconteça por meio desses dois sentidos (cf. IBARRETEXE-ANTUAÑO, 1999).
} 
cena provavelmente verão a mesma situação (esse aspecto corrobora a característica de objetividade do sentido da visão).

A função principal do sentido da audição é, segundo Sweetser, a comunicação linguística. ${ }^{18}$ Esse sentido é, então, nosso principal meio de influência intelectual e emocional sobre as pessoas e está relacionado com a recepção interna de ideias (no sentido de "entender" o que se ouve), com avisos, advertências, e, consequentemente, com a obediência. Assim como o sentido da visão, a audição também acontece a distância e se relaciona com a objetividade e com o processo intelectual. No entanto, o sentido da audição está relacionado com o intelecto apenas no que diz respeito aos aspectos comunicativos.

Sweetser não apresenta motivações para os poucos usos metafóricos das palavras relacionadas ao sentido olfativo, mas relaciona os significados mais abstratos das palavras relativas aos sentidos gustativo e tátil com o fato de esses sentidos exigirem contato físico direto entre quem percebe e o objeto da percepção. A subjetividade, a intimidade e a emoção que os sentidos metafóricos derivados do vocabulário relacionado com as sensações físicas gustativas e táteis expressam são motivadas, de acordo com Sweetser, pela proximidade exigida por esses dois tipos de percepção. A autora enfatiza essa ideia de proximidade lembrando que a percepção gustativa não se dá apenas pela proximidade com o objeto a ser percebido, mas pela ingestão dele, e que as respostas de prazer e dor proporcionadas pela percepção tátil são extremamente subjetivas, altamente dependentes de quem toca os objetos alvos da percepção.

Muitos estudos mostram que as diferenças entre os significados, tanto físicos quanto metafóricos, dos verbos de percepção se refletem em diferentes tipos sintáticos dos complementos que esses verbos encaixam (cf. CAPLAN, 1973; BOLINGER, 1974;

\footnotetext{
18 Buck (1949 apud SWEETSER, 1990, p.35) observa que, nas línguas indo-europeias nomes derivados de verbos de percepção auditiva geralmente não denotam som, mas, sim, o conteúdo do discurso ouvido.
} 
KIRSNER; THOMPSON, 1976; DECLERK, 1981; DIK; HENGEVELD, 1991; HORIE, 1993, entre outros).

O estudo tipológico de Dik e Hengelveld (1991) sobre os complementos dos verbos de percepção é especialmente relevante para esta pesquisa porque, além de ambos serem desenvolvidos a partir da mesma base teórica, é o primeiro a mostrar que "as diferenças entre os complementos dos verbos de percepção podem ser entendidas em termos da estrutura oracional hierárquica usada na Gramática Funcional para representar as orações” (DIK; HENGEVELD, 1991, p.231). ${ }^{19}$ Segundo os autores, existem quatro leituras possíveis para as construções com verbos de percepção: i) percepção imediata ${ }^{20}$ de indivíduo; ii) percepção imediata de estado-de-coisas; iii) percepção mental de conteúdo proposicional e iv) recepção do conteúdo proposicional de um ato de fala. A seguir, cada uma dessas leituras é apresentada de acordo com Dik e Hengeveld (1991).

\section{i) Percepção imediata de indivíduo}

Esse tipo de construção diz respeito à percepção imediata de um indivíduo por outro. O exemplo que os autores dão desse tipo de percepção, traduzido para o português, é:

(23) Eu vi seu irmão ontem.

(Adaptado de DIK; HENGEVELD, 1991, p.237)

Em (23), o verbo ver especifica uma relação entre dois indivíduos: eu e seu irmão. Nesse tipo de construção, o verbo de percepção toma como segundo argumento termos que designam entidades de primeira ordem, ou seja, entidades que podem ser tocadas e localizadas no tempo e no espaço. Tais entidades, obviamente, devem ser algo que possa ser objeto de percepção por meio de algum sentido.

\footnotetext{
${ }^{19}$ [...] the differences between perception-verb complements can be understood in terms of the hierarchical clause structure used in FG to represent utterances (DIK; HENGEVELD, 1991, p.231).

${ }^{20}$ Ao utilizarem o termo "percepção imediata" os autores querem dizer que a percepção ocorre de maneira direta (cf. DIK; HENGEVELD, 1991, p.239).
} 
As entidades de primeira ordem que os verbos de percepção tomam como complemento nesse tipo de leitura podem ser modificadas por modificadores de diversos tipos, como se pode observar na reprodução dos exemplos que os autores apresentam para entidades de primeira ordem modificadas:

(24) I saw the naked wrestler.

'Eu vi o lutador nu.'

(25) I saw the running wrestler.

'Eu vi o lutador correndo.'

(Adaptados de DIK; HENGEVELD, 1991, p.251)

A tradução para o português dessas duas orações mostra que essa língua, pelo menos nos contextos apresentados em (24) e (25), não permite a ordenação "modificador + termo", como acontece no inglês. A ordenação dos constituintes do português "termo + modificador", principalmente quando o modificador está no gerúndio, possibilita uma dupla interpretação: considerar [lutador] como um argumento de primeira ordem de ver e [correndo] como "adjunto predicativo" desse argumento, ou considerar [lutador correndo] como sendo um argumento de segunda ordem de ver. De acordo com a primeira interpretação, a oração (25) representaria uma percepção imediata de indivíduo ao passo que, de acordo com a segunda leitura, ela seria uma percepção imediata de estado-de-coisas.

Dik e Hengelveld (1991, p.253) salientam que a diferença entre essas duas leituras pode ser muito sutil na prática, uma vez que construções como (25) estão na zona limítrofe em que a reinterpretação de uma percepção imediata de indivíduo em termos de percepção imediata de estado-de-coisas pode facilmente ocorrer. Assim, segundo os autores, muitas orações são ambíguas, permitindo as duas leituras, como é o caso da seguinte oração, traduzida de Dik e Hengeveld (1991, p.253): 
(26) a. Eu vi [um homem] [caindo da escada].

b. Eu vi [um homem caindo da escada].

Em (26a), está representada a leitura de percepção imediata de indivíduo e, em (26b), a percepção imediata de estado-de-coisas. Existem razões, no entanto, segundo Dik e Hengeveld (1991, p.254), para que, em alguns casos, seja preferida uma leitura em detrimento da outra. Os exemplos dados pelos autores, traduzidos para o português, são:

(27) Eu senti Hank espalhando o esterco.

(28) Eu ouvi o fazendeiro matando o porco.

Em (27), o que foi sentido não foi o cheiro de Hank, mas do esterco, e, em (28), o que foi ouvido não foi o fazendeiro (na circunstância em que matava o porco). Ambos os casos devem, segundo os autores, ser interpretados como percepção imediata de estado-de-coisas, e não como percepção imediata de indivíduo.

ii) Percepção imediata de estado-de-coisas

Essa segunda leitura corresponde à percepção de um estado-de-coisas por um indivíduo, conforme o exemplo a seguir ilustra (adaptado DIK; HENGEVELD, 1991, p.238):

(29) Eu vi seu irmão atravessar a rua.

Em (29), o verbo ver especifica uma relação entre um indivíduo, eu, entidade de primeira ordem, e um estado-de-coisas, seu irmão atravessar a rua, entidade de segunda ordem. Algumas características desse tipo de construção são: o estado-de-coisas da oração matriz e o estado-de-coisas da oração complemento devem ser simultâneos; o estado-de-coisas da oração complemento deve ser perceptível por meio de algum sentido; o estado-de-coisas da oração complemento não pode ser negado independentemente em relação à oração matriz (essa 
característica tem forte relação com a anterior, uma vez que não se pode perceber algo que não ocorreu).

\section{iii) Percepção mental de conteúdo proposicional}

Os autores definem esse tipo de construção como sendo a aquisição de conhecimento por meio de um dos sentidos por um indivíduo. O exemplo que os autores dão para ilustrar esse tipo de construção, traduzido para o português, é:

(30) Eu vi que Maria tinha chorado.

(Adaptado de DIK; HENGEVELD, 1991, p.238)

Nesse caso, o verbo ver especifica uma relação entre a entidade de primeira ordem $e u$, um indivíduo, e a entidade de terceira ordem Maria tinha chorado, um conteúdo proposicional. De acordo com Dik e Hengeveld (1991), há dois tipos de percepção mental: a primária e a secundária. A percepção mental primária diz respeito ao relato de uma aquisição direta de conhecimento por meio da percepção, enquanto a percepção mental secundária relata a aquisição de um conhecimento que é resultado de um cálculo mental feito com base no que é percebido por meio de algum sentido. No exemplo a seguir, traduzido de Dik e Hengeveld (1991, p. 239-240), a oração em (31a) descreve a percepção mental primária e a em (31b) descreve a percepção mental secundária:

(31) a) Eu vi que a biblioteca estava vazia, b) então eu vi que a Helen não estava lá.

Em (31a), a informação contida no complemento do verbo ver é apresentada como tendo sido adquirida pelo falante de maneira direta, por meio da visão, enquanto a informação contida no complemento de (31b) é a conclusão a que o falante chegou a partir da observação de que a biblioteca estava vazia. 
A percepção mental difere da percepção imediata de estado-de-coisas em vários aspectos: a) não há necessidade de simultaneidade entre os estados-de-coisas da oração matriz e da oração encaixada na percepção mental, b) os complementos de construções que denotam percepção mental não precisam necessariamente conter um estado-de-coisas perceptível (uma oração como Eu vi que a discussão foi inútil é perfeitamente possível a partir de uma leitura de percepção mental); c) os complementos de construções do tipo percepção mental podem ser negados independentemente: Eu vi que ele não veio.

iv) Recepção do conteúdo proposicional de um ato de fala

A quarta leitura apresentada pelos autores acontece com verbos de percepção visual e auditiva e se refere à recepção do conteúdo de um ato de fala por um indivíduo. O exemplo dado pelos autores, traduzido para o português, é apresentado a seguir (cf. DIK; HENGEVELD, 1991, p. 238):

(32) Eu ouvi que você provavelmente vai cantar no Royal Albert Hall na próxima semana.

Nesse caso, o verbo ouvir especifica uma relação entre a entidade de primeira ordem eu e a entidade de terceira ordem você provavelmente vai cantar no Royal Albert Hall na próxima semana, um conteúdo proposicional que foi dito por uma terceira pessoa.

Uma característica importante dos complementos de orações que expressam a recepção de um conteúdo proposicional é que a entidade percebida é de natureza linguística, ou seja, ela corresponde a informações que foram ditas ou escritas por outras pessoas e ouvidas ou lidas pela pessoa representada pela entidade de primeira ordem. Assim, o que diferencia os complementos de construções do tipo iii) dos complementos de orações do tipo iv), em ambos os casos conteúdos proposicionais, é o fato de que, no primeiro caso, o conteúdo proposicional se origina no próprio falante ao passo que, no segundo caso, ele se 
origina em outra pessoa (cf. DIK; HENGEVELD, 1991, p.247). Em construções que expressam recepção de conteúdo proposicional sempre é possível explicitar a origem do conteúdo comunicado, como acontece em (33) e (34), a seguir:

(33) Eu ouvi do John que o Peter brigou.

(34) Eu vi no jornal que o Peter brigou.

\section{USOS EVIDENCIAIS DOS VERBOS DE PERCEPÇÃO}

Como exposto no Capítulo I, a evidencialidade corresponde à expressão da fonte da informação veiculada pelo falante. Em outras palavras, os evidenciais descrevem as maneiras pelas quais as informações são percebidas pelo falante. Especialmente em línguas que não possuem evidenciais gramaticais, ou que possuem poucos, como é o caso do português, os verbos de percepção são fortes candidatos a assumirem valor evidencial, como já dito, uma vez que é por meio da percepção que apreendemos muitas informações sobre o mundo. No entanto, não é todo e qualquer uso dos verbos de percepção que expressa evidencialidade. Existem algumas características que os verbos de percepção precisam apresentar para serem considerados evidenciais. Tais características passam a ser exploradas.

Uma das principais características de um verbo evidencial é a dêixis, considerada por muitos autores como algo inerente à evidencialidade (cf. JAKOBSON, 1957; MASLOVA, 2003; JOSEPH, 2003; DE HAAN, 2001; 2003; 2005, dentre outros). Alguns desses autores chegam, inclusive, a considerar a evidencialidade uma categoria dêitica (MASLOVA, 2003; DE HAAN, 2005). De acordo com De Haan (2005), o significado básico da evidencialidade é marcar a relação entre o falante e as ações e eventos descritos por ele; assim, a função preenchida pela evidencialidade pode ser comparada às funções exercidas, por exemplo, pelos demonstrativos, que marcam a relação entre falantes e objetos. A partir dessa perspectiva, o 
autor explica que a evidencialidade direta é usada quando o falante deseja mostrar que o estado de coisas ocorre dentro de sua esfera dêitica, ao passo que a evidencialidade indireta (inferida e reportativa) é usada para mostrar que o estado de coisas ocorre fora da esfera dêitica do falante.

Assim, levando em conta a noção de dêixis imbricada na noção de evidencialidade, pode-se dizer que, quando um falante utiliza um evidencial, ele adota um ponto de vista particular com relação à fonte da informação que veicula. Como o próprio falante sempre está envolvido, de alguma forma, com a percepção ou recepção das informações, ele é o centro dêitico de grande parte das orações que expressam evidencialidade. ${ }^{21}$ Consequentemente, o falante e seu correlato gramatical de pessoa ocupam posição especial nos paradigmas evidenciais.

Nesse contexto, os verbos de percepção evidenciais, além de seus significados básicos relacionados à percepção, devem conter um significado dêitico por meio do qual a evidência para a proposição é indicada. Tal significado dêitico, devido à natureza desses verbos, sempre recai sobre o falante, o que exige, do ponto de vista morfossintático, o uso da primeira pessoa do singular. Nas duas orações apresentadas a seguir, o verbo ver é usado, mas só em (35) ele tem valor evidencial:

(35) Eu vi as crianças correndo.

(36) Pedro viu as crianças correndo.

No primeiro caso, o falante indica que a informação de que as crianças estavam correndo foi obtida com base em percepção visual direta, um caso de evidencialidade direta, portanto. No segundo caso, há apenas a indicação do que Pedro viu, sem nenhuma referência ao modo como o falante obteve a informação sobre a corrida das crianças ou sobre o fato de Pedro ter

\footnotetext{
${ }^{21}$ Os casos de evidencialidade reportativa expressos por meio de verbos de dizer constituem exemplos de codificação da evidencialidade em que o centro dêitico não recai sobre o falante.
} 
visto as crianças correndo. Em (36), portanto, o verbo ver não tem valor evidencial, embora seja um verbo de percepção.

De Haan (2005) diferencia os três tipos de evidencialidade - direta, inferida e reportativa - a partir da noção de dêixis. Segundo o autor, a evidencialidade direta visual, como mostra o exemplo em (35), refere-se à situação dêitica em que o falante está a uma distância visual da ação descrita. No caso da evidencialidade direta auditiva, o falante deve estar em condições em que possa ouvir sons referentes ao estado de coisas, como acontece em (37), a seguir:

(37) Eu ouvi os pássaros cantando.

No que se refere à evidencialidade inferida, De Haan afirma que esse tipo de evidencialidade é usado quando o falante não presencia o estado de coisas pessoalmente, mas vê evidências de que ele aconteceu, como ilustrado em (38):

(38) Vi que alguém jantou aqui. (Dito por alguém que vê os pratos sujos sobre a mesa)

A evidencialidade reportativa, segundo De Haan, compartilha com a evidencialidade direta auditiva o fato de o falante receber input sonoro; a diferença é que, no caso dos evidenciais reportativos, esse input é verbal, ou seja, o falante descreve um estado de coisas que foi relatado por uma terceira pessoa.

Em seu artigo, De Haan (2005) não trata da evidencialidade baseada nos sentidos do tato, olfato e paladar, como faz com os sentidos da visão e da audição. O autor apenas se refere a esses outros sentidos quando apresenta dois exemplos: um da língua kashaya pomo, em que o morfema - qa pode indicar tanto evidencialidade inferida quanto evidencialidade direta olfativa, gustativa ou tátil, e outro da língua hualapia, em que o morfema evidencial $-o$, 
quando usado para expressar evidencialidade inferida, pode denotar uma ampla variedade de evidências, dentre elas as evidências olfativas.

Apesar de De Haan não tratar desses subtipos da evidencialidade, também é possível pensar tanto na evidencialidade direta tátil, olfativa e gustativa quanto na evidencialidade inferida baseada em evidências obtidas por meio do tato, do olfato e do paladar em termos dêiticos. A diferença entre esses subtipos evidenciais e os baseados na visão e na audição está na relação mais próxima entre o falante e os estados-de-coisas descritos por ele nos casos de evidencialidade que envolvem os sentidos tátil, olfativo e gustativo. Nesses casos, o contexto extralinguístico a que os evidenciais se referem corresponde à realidade interna do falante, já que o resultado da percepção, pelo menos no que diz respeito às percepções tátil e gustativa, está disponível apenas para o falante, conforme foi discutido na seção anterior com base no trabalho de Sweetser (1990).

Outro aspecto que caracteriza orações com verbos de percepção que permitem uma leitura evidencial está relacionado à estrutura dessas orações. Somente orações em que podem ser identificadas duas proposições ${ }^{22}$ possibilitam uma leitura evidencial. A comparação dos exemplos apresentados a seguir deixa clara essa diferença:

(39) Eu vi o cachorro.

(40) Eu vi o cachorro comendo ração.

Em (39), há apenas uma proposição, que representa o fato de o falante ter visto um cachorro. Em (40), há duas proposições: "o falante viu a ação do cachorro" e "o cachorro estava comendo ração". A primeira proposição é o que permite ao falante afirmar a segunda proposição, ou seja, a percepção visual serve como evidência para o falante afirmar o que o cachorro estava fazendo. Só o exemplo apresentado em (40), portanto, tem valor evidencial.

\footnotetext{
${ }^{22}$ O termo "proposição" é usado aqui em seu sentido lógico.
} 
Existem algumas construções, no entanto, que, mesmo sendo constituídas de uma única proposição, permitem uma leitura evidencial. É o que acontece, por exemplo, com os verbos de estímulo perceptivo do inglês (41) e com o verbo parecer do português (42):

\section{(41) You look tired. \\ (42) Você parece cansado.}

Nos dois casos, apesar de haver apenas uma proposição, há duas instâncias de significação: o ato de percepção e a inferência baseada nessa percepção (o falante observa algum traço físico em seu interlocutor que relaciona com um estado emocional). Os exemplos apresentados em (41) e (42) são casos, portanto, de evidencialidade inferida com base em percepção visual. Como visto na seção 1 deste Capítulo, os verbos de percepção em português não são usados em construções como (41). Tais usos são preenchidos pelo verbo parecer, exemplificado novamente em (42).

Levando em conta a classificação dos verbos de percepção proposta por Viberg (1984), dos três tipos de verbos de percepção (verbos de percepção ativa, de percepção passiva e de estímulo perceptivo), apenas os verbos de percepção passiva se prestam à expressão da evidencialidade em língua portuguesa. Com exceção do verbo cheirar, não há verbos de estímulo perceptivo em português, e nenhum dos contextos em que esse verbo ocorre permite uma leitura evidencial. Os verbos de percepção ativa não se prestam à expressão da evidencialidade porque, segundo Whitt (2009, p.1086), em orações como “eu olhei para o cachorro comendo a ração", por exemplo, o ato de percepção intencional não serve como a fonte da informação de que "o cachorro está comendo a ração". Numa oração como essa, o fato de o cachorro estar comendo a ração já é tomado como conhecido pelo falante, que simplesmente indica sua intenção em observar o ato. Se, por outro lado, um verbo 
de percepção passiva é usado, como em "vi o cachorro comendo a ração", é a visão que permite ao falante afirmar que o cachorro estava comendo.

Com relação aos tipos oracionais em que os verbos de percepção assumem valor evidencial, em português apenas orações declarativas afirmativas abrigam verbos de percepção evidenciais. Orações declarativas negativas, em que o verbo de percepção está sob o escopo da negação, bloqueiam a leitura evidencial, como se observa na oração a seguir:

Não vi o cachorro comendo ração.

Nesse caso, o falante nega que tenha tido contato visual com o evento de o cachorro comer a ração. Tendo em vista que a evidencialidade corresponde à explicitação do modo como o falante obteve a informação que veicula, a negação do verbo em (43) representa a negação da percepção.

De Haan (1999) chega a afirmar que uma das propriedades definidoras dos evidenciais é o fato de eles não ocorrerem sob o escopo da negação e assegura que essa restrição é válida translinguisticamente. Aikhenvald (2004), no entanto, em seu estudo tipológico sobre a evidencialidade em aproximadamente 500 línguas, comprova que, apesar de a fonte da informação realmente não poder ser negada em muitas línguas, existem outras em que os evidenciais podem perfeitamente ocorrer sob o escopo da negação. A autora dá exemplos em que a experiência visual, e não o verbo em si, é negada, como acontece a seguir, numa oração da língua akha (AIKHENVALD, 2004, p.256):

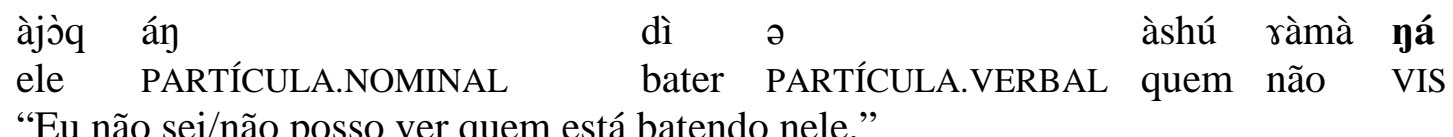
"Eu não sei/não posso ver quem está batendo nele."

É possível perceber claramente que a incidência da negação, em (44), recai sobre a partícula evidencial, que denota evidencialidade direta visual. 
As considerações sobre a relação entre evidencialidade e negação feitas por De Haan (1999) e Aikhenvald (2004) mostram que é preciso ser cauteloso ao fazer generalizações sobre critérios que possam ser aplicados translinguisticamente, uma vez que determinadas características dos evidenciais em algumas línguas podem não ocorrer em outras.

Segundo Aikhenvald (2004), a ausência de evidenciais em orações interrogativas e imperativas é uma característica da grande maioria das línguas estudadas por ela, mas existem casos bastante específicos em que ocorrem evidenciais nesses tipos de orações (cf. AIKHENVALD, 2004, p.242-256). Em português, orações interrogativas e imperativas com verbos de percepção também não permitem uma leitura evidencial, uma vez que os evidenciais servem para especificar a fonte das afirmações feitas pelo próprio falante e o modo como ele chegou às informações que veicula.

Com relação ao tempo e ao modo verbal, os sentidos evidenciais dos verbos de percepção só se manifestam no presente e no passado do modo indicativo. Estudos tipológicos sobre a evidencialidade mostram que é muito raro haver expressão da evidencialidade no futuro (AIKHENVALD, 2004) por razões de ordem lógica: não se pode ter presenciado um evento que ainda não aconteceu.

Woodbury (1986), ao tratar das interações entre o tempo e a evidencialidade em construções complexas do sherpa e do inglês, estabelece relações entre os tempos verbais dos predicados da oração matriz e da oração encaixada e os tipos de evidencialidade. Todas essas relações seguem, segundo o autor, o seguinte princípio: “quando a referência temporal de uma categoria evidencial é diferente daquela da proposição com a qual ela ocorre, o valor evidencial resultante será não-experiencial"23 (WOODBURY, 1986, p.195).

As mesmas considerações feitas por Woodbury sobre a relação da evidencialidade com o tempo verbal em orações complexas do inglês também são válidas para o português.

\footnotetext{
${ }^{23}$ When time reference of an evidential category is different from that of the proposition with which it occurs, the resulting evidential value will be nonexperiential (WOODBURY, 1986, p.195).
} 
Segundo o autor, quando o verbo da oração matriz está no presente e o verbo da oração complemento não, o resultado é um evidencial não-experiencial, ou seja, essas orações não expressam evidencialidade direta, como se pode observar nos exemplos a seguir (adaptados de WOODBURY, 1986, p.198):

(45) Vejo que o Pedro estava bebendo cerveja.

(46) Vejo que o Pedro vai beber cerveja.

O tipo de evidencialidade expresso nessas duas orações é a inferida. A oração (45) indica que o falante pode ter inferido que Pedro estava bebendo ao ver, por exemplo, uma garrafa de cerveja vazia, e a inferência apresentada em (46) pode ter sido resultado da observação de uma garrafa de cerveja cheia, por exemplo.

Quando ambos os verbos, da oração matriz e da oração complemento, estão no presente, o valor evidencial da construção é, segundo Woodbury, ambíguo, como se observa em (47):

(47) Vejo que o Pedro está bebendo cerveja.

(Adaptado de WOODBURY, 1986, p.198)

Essa oração pode ser interpretada como uma percepção direta do ato de beber em que Pedro está envolvido, o que corresponde à evidencialidade direta visual, ou como uma inferência feita a partir, por exemplo, da observação, por parte do falante, de uma garrafa e um copo com cerveja. De acordo com essa interpretação, (47) codifica evidencialidade inferida.

Por outro lado, segundo Woodbury (1986, p.199), não há dúvidas sobre a interpretação evidencial de uma oração cujo complemento está na forma não-finita e sua referência temporal é, portanto, idêntica à da oração matriz. Isso é o que acontece em (48):

(48) Eu vejo o Pedro bebendo cerveja. 
Nesse caso, a única leitura evidencial possível é a de que o falante obteve a informação da oração complemento por meio de observação visual direta, o que configura um caso de evidencialidade direta visual.

Em orações em que o verbo de percepção está no presente e o complemento encontrase na forma não-finita gerundiva, existe uma outra possibilidade de interpretação além da leitura direta: a leitura imaginativa. De acordo com Rodrigues (2007), vários autores (OLSSON, 1976; LEMHAGEN, 1979; BOIVIN, 1998; WILLEMS e DEFRANCQ, 2000) afirmam que a interpretação imaginativa ocorre em contextos em que a percepção está situada na imaginação do experienciador. O exemplo a seguir, adaptado de Rodrigues (2007), pode ser interpretado de duas formas, a partir de uma leitura concreta ou de uma leitura imaginativa:

(49) Eu vejo meu filho ganhando a medalha de ouro.

Se o evento em que o filho do falante ganha a medalha é real e ocorre diante de seus olhos, a leitura da oração é a de percepção concreta, direta, e tal uso do verbo ver representa um tipo de evidencialidade direta. Se, por outro lado, essa oração representa a situação que está na mente do falante, o verbo ver está sendo usado no sentido imaginativo e pode ser parafraseado pelo verbo imaginar. Não se trata, nesse caso, de um exemplo de evidencialidade.

Quando o verbo da oração matriz está no passado, segundo Woodbury, podem ser feitas as mesmas considerações sobre os tipos de complemento e os tipos evidenciais. A seguir, são apresentadas versões no passado para as orações apresentadas em (45), (47) e (48):

(50) Eu vi que o Pedro tinha bebido cerveja. (cf. (45) Vejo que o Pedro estava bebendo cerveja.)

(51) Eu vi que o Pedro bebeu cerveja. (cf. (47) Vejo que o Pedro está bebendo cerveja.)

(52) Eu vi o Pedro bebendo cerveja. (cf. (48) Eu vejo o Pedro bebendo cerveja.) 
Os valores evidenciais das orações apresentadas de (50) a (52) são os mesmos das orações correspondentes no presente apresentadas em (45), (47) e (48). Em (50), como a referência temporal da oração matriz é diferente da referência temporal da oração complemento, de acordo com o princípio proposto por Woodbury, a leitura evidencial é a nãoexperiencial. Ou seja, a oração apresentada em (50) só pode ser interpretada como sendo evidencialidade inferida, mesma interpretação dada a (45). Em (51), a referência temporal das orações matriz e complemento é a mesma, o que possibilita uma dupla interpretação: percepção direta (evidencialidade direta visual) ou percepção indireta (evidencialidade inferida). Tal ambiguidade também é observada no tempo presente (cf. 47). Por fim, em (52), não há marcação de tempo na oração complemento, uma vez que ela se apresenta na forma não-finita e, assim, identifica-se simultaneidade entre o evento da oração complemento e o da oração matriz, ou seja, a ação de Pedro beber cerveja aconteceu no mesmo momento da percepção dessa ação pelo falante. A única interpretação evidencial possível, portanto, é a de percepção direta, como acontece em (48).

A comparação entre as orações (45), (47) e (48), de um lado, e (50), (51) e (52), do outro, revela que não importa se o verbo da oração matriz está no presente ou no passado, o que determina o valor evidencial "é a combinação do tipo de complemento com a sequência temporal"24 (WOODBURY, 1986, p.199).

Do que foi exposto nesta seção, conclui-se que os verbos de percepção em língua portuguesa só assumem valor evidencial quando são verbos de percepção passiva (de acordo com a classificação de Viberg (1984)) usados em contextos em que podem ser identificadas duas proposições, uma expressando a evidência e a outra a informação propriamente dita. A oração que contém o verbo de percepção evidencial deve, necessariamente, ter como sujeito oracional a primeira pessoa do singular, dada a natureza dêitica da evidencialidade, e ser uma oração declarativa afirmativa no presente ou no passado do modo indicativo.

\footnotetext{
${ }^{24}[\ldots]$ it is a combination of complement type and tense sequence [...] (WOODBURY, 1986, p.199).
} 


\section{CAPÍTULO III}

\section{A EVIDENCIALIDADE NA GRAMÁTICA DISCURSIVO-FUNCIONAL}

\section{INTRODUÇÃO}

A GDF (HENGEVELD; MACKENZIE, 2008) é a sucessora da Gramática Funcional (GF - DIK, 1997a, 1997b). Apesar de a GDF compartilhar muitos dos pressupostos teóricos da GF, ela se consolida como uma teoria autônoma. Como se pode depreender pelo nome da teoria, na GDF é dado destaque à influência dos aspectos discursivos sobre a forma linguística. Os autores esclarecem, no entanto, que a GDF não é uma gramática do discurso, não é uma teoria que descreve a organização do discurso, mas sim um modelo de gramática que codifica intenções e conceitualizações. "A GDF procura entender como unidades linguísticas são estruturadas em termos da realidade que elas descrevem e das intenções comunicativas com as quais elas são produzidas e molda isso em uma implementação dinâmica da gramática"25 (HENGEVELD; MACKENZIE, 2008, p.2).

Para subsidiar a análise da expressão da evidencialidade por meio dos verbos ver, ouvir e sentir, um resumo geral da teoria da GDF é apresentado a seguir. Na seção 1, a GDF é localizada dentro do contexto mais amplo de uma teoria de interação verbal. O Componente Gramatical é descrito de uma forma mais detalhada na seção 2, que discute unicamente os níveis e unidades importantes para a descrição da evidencialidade, não contemplando outros aspectos da teoria. Por fim, a seção 3 apresenta como a evidencialidade é tratada na GDF.

\footnotetext{
${ }^{25}$ FDG aims to understand how linguistic units are structured in terms of the world they describe and the communicative intentions with which they are produced, and models this in a dynamic implementation of the grammar (HENGEVELD; MACKENZIE, 2008, p.2).
} 


\section{A GDF E A INTERAÇÃO VERBAL}

A GDF é concebida como o componente gramatical de uma teoria mais ampla de interação verbal. ${ }^{26}$ A Figura 3 mostra como os três componentes não-gramaticais do modelo de interação verbal se relacionam com o componente gramatical:

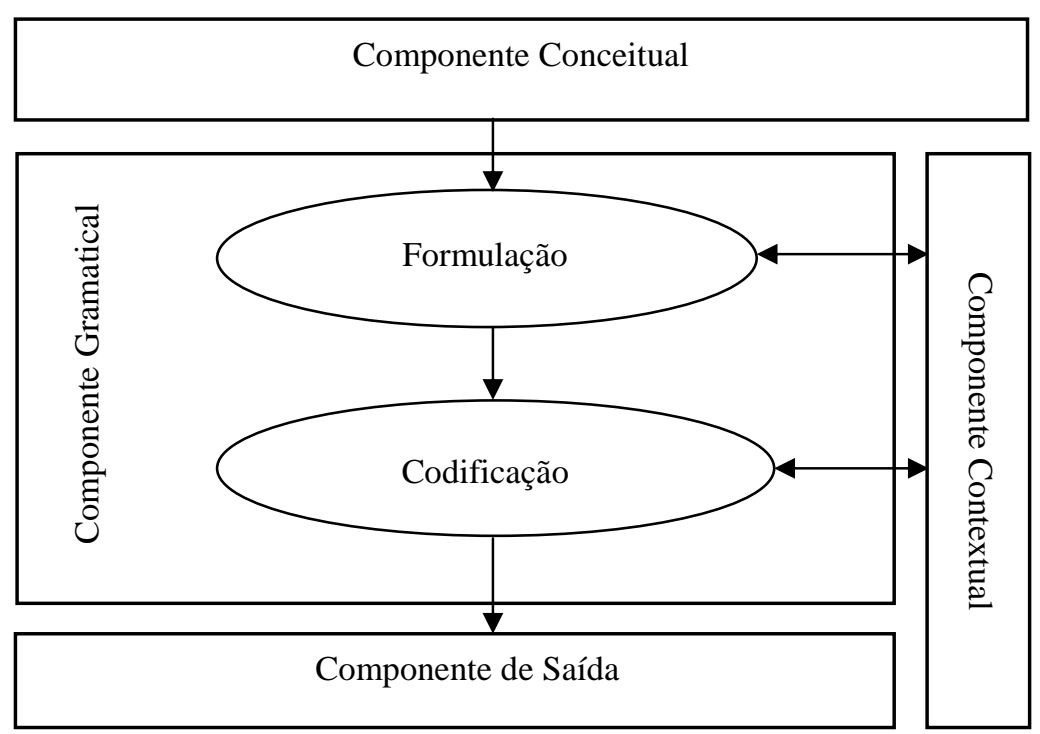

Figura 3. A GDF dentro da teoria de interação verbal (HENGEVELD; MACKENZIE, 2008, p.6)

Como se pode observar na Figura 3, é por meio das operações de Formulação (Formulation) ${ }^{27}$ e de Codificação (Encoding) que ocorre a interação entre o componente gramatical e os outros três componentes. A primeira operação “diz respeito às regras que determinam o que constitui representações semânticas e pragmáticas subjacentes válidas em uma língua” e a segunda "diz respeito a regras que convertem essas representações semânticas e pragmáticas em representações fonológicas e morfossintáticas"28 (HENGEVELD; MACKENZIE, 2008, p.2).

\section{O Componente Conceitual (Conceptual Component) é responsável pelo} desenvolvimento tanto da intenção comunicativa que está pressuposta em cada ato de

${ }^{26}$ O modelo geral de interação verbal do qual a GDF faz parte é inspirado, segundo Hengeveld e Mackenzie (2008), em estudos do psicolinguista Levelt (1989).

${ }^{27}$ No sistema notacional da GDF, os nomes dos componentes, dos níveis de análise e das operações, assim como as variáveis usadas do Nível Interpessoal, são escritos com iniciais maiúsculas.

${ }^{28}$ Formulation concerns the rules that determine what constitute valid underlying pragmatic and semantic representations in a language. Encoding concerns the rules that convert these pragmatic and semantic representations into morphosyntactic and phonological ones (HENGEVELD; MACKENZIE, 2008, p.2). 
linguagem quanto das conceitualizações com relação a eventos extralinguísticos relevantes. Segundo Hengeveld e Mackenzie (2008, p.7), “o Componente Conceitual não inclui cada aspecto da cognição que é potencialmente relevante para a análise linguística, mas apenas aqueles que afetam a intenção comunicativa imediata." 29 O Componente Conceitual é considerado a força motriz por trás do Componente Gramatical, uma vez que a intenção comunicativa determina os fatos linguísticos do Componente Gramatical.

A ligação entre o Componente Conceitual e o Componente Gramatical é feita por meio da operação de Formulação, que traduz configurações conceituais em distinções semânticas e pragmáticas disponíveis em uma língua. Tal operação é, portanto, diferente de uma língua para outra.

O Componente Contextual (Contextual Component) abriga informações de curto prazo relevantes para o Componente Gramatical na forma de enunciados que podem servir de base para enunciados subsequentes e informações de longo prazo sobre a interação que são importantes para as distinções requeridas pela língua que está sendo usada. Em outras palavras, o Componente Contextual armazena informações linguísticas necessárias para o desenvolvimento dos enunciados e informações não-linguísticas sobre a situação que afetam as escolhas de determinados fatos linguísticos.

Como se vê na Figura 3, o Componente Contextual também recebe input do Componente Gramatical por meio das operações de Formulação e de Codificação, armazenando informações sobre as intenções comunicativas e sobre aspectos semânticopragmáticos e morfossintáticos da expressão linguística. Em outras palavras, uma vez introduzida no discurso uma entidade, de qualquer nível da gramática, essa entidade passa a fazer parte do Componente Contextual. A anáfora é um fenômeno que ilustra claramente a relação entre o Componente Gramatical e o Contextual: por meio da referência anafórica,

${ }^{29}$ The Conceptual Component does not include every aspect of cognition that is potentially relevant for linguistic analysis, but only those that affect the immediate communicative intention (HENGEVELD; MACKENZIE, 2008, p.7). 
antecedentes que fazem parte do Componente Contextual são retomados no Componente Gramatical. Hengeveld e Mackenzie (2008, p.14) ressaltam que a representação dessas relações entre os dois componentes na Figura 3 é uma simplificação muito grande se considerada a partir da perspectiva do usuário da língua; no entanto, como o foco da teoria é o Componente Gramatical, os autores decidiram, por enquanto, não trabalhar com toda a complexidade dessas relações.

O Componente de Saída (Output) converte as estruturas do Componente Gramatical em expressões linguísticas, que podem ser de diferentes naturezas: i) acústicas, no caso da fala; ii) gestuais, no caso de línguas de sinais; e iii) ortográficas, no caso da escrita. Um exemplo de atuação do Componente de Saída na fala é a representação por meio de pausas das fronteiras entre unidades linguísticas ou entre enunciados.

Os autores frisam que não tratam, em seu livro, da constituição interna dos componentes não-gramaticais. Pesquisas vêm sendo desenvolvidas nesse sentido por alguns pesquisadores: Anstey (2002), sobre o Componente Conceitual, e Connolly (2004, 2007), sobre o Componente Contextual, entre outros.

Na Figura 3, as flechas em sentido descendente mostram a orientação da GDF. Tal orientação "é motivada pela hipótese de que um modelo de gramática será mais efetivo quanto mais sua organização se assemelhar ao processamento linguístico no indivíduo",30 (HENGEVELD; MACKENZIE, 2008, p.1). Dessa forma, no modelo da GDF, o ponto de partida é a intenção comunicativa e o ponto de chegada são as expressões linguísticas. Os autores ressaltam, no entanto, que a GDF não é um modelo do falante ou do processamento linguístico; ela é um modelo de gramática que tenta refletir a característica descendente do processo de produção linguística, característica já comprovada por psicolinguistas (cf. LEVELT, 1989).

\footnotetext{
${ }^{30}[. .$.$] is motivated by the assumption that a model of grammar will be more effective the more its organization$ resembles language processing in the individual (HENGEVELD; MACKENZIE, 2008, p.1).
} 


\section{A ARQUITETURA DA GDF}

A Figura 4, a seguir, apresenta uma descrição detalhada da estrutura do Componente Gramatical e mostra de uma forma mais específica como ele interage com os outros três componentes não-gramaticais:

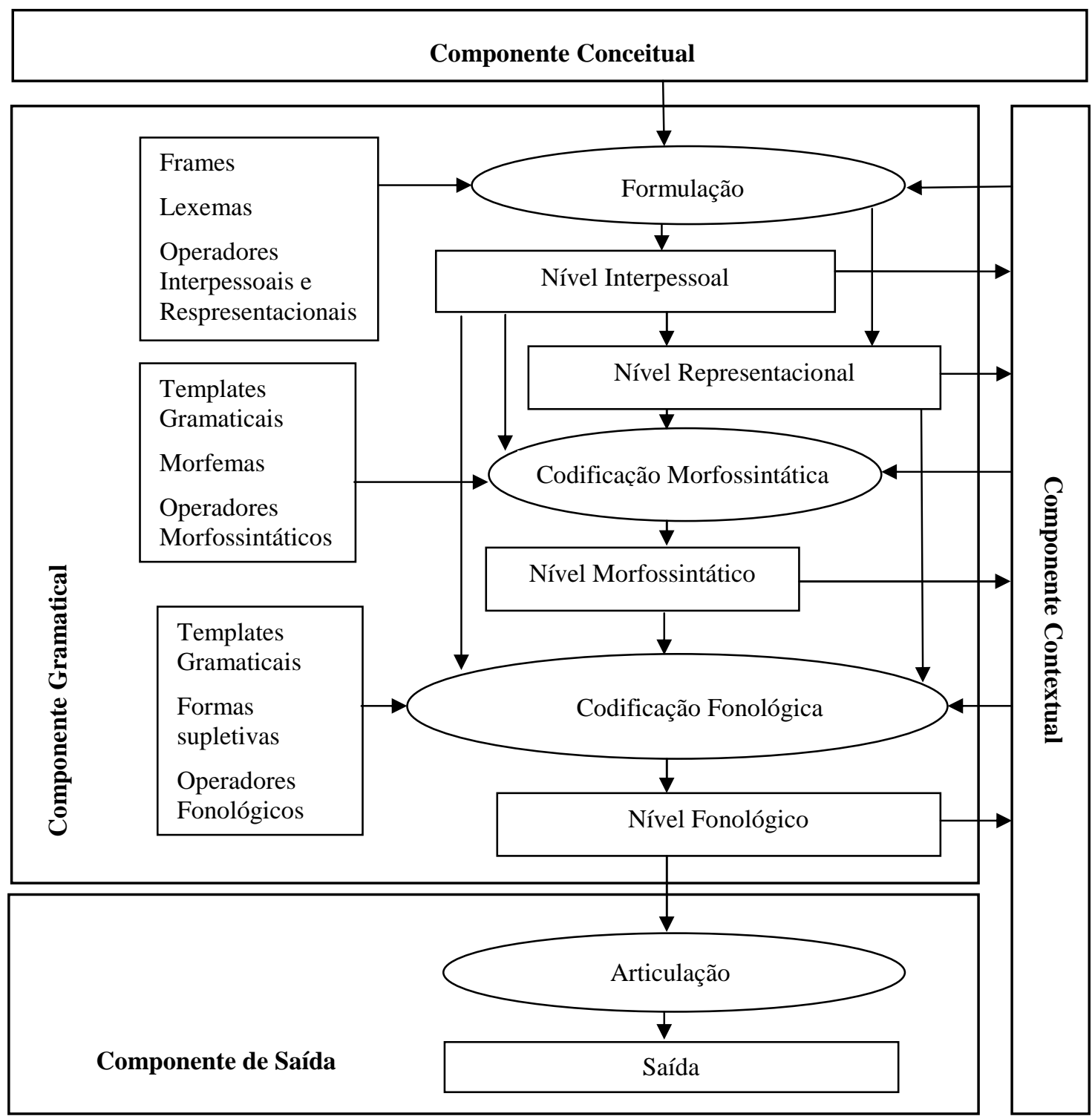

Figura 4. Esquema geral da GDF (HENGEVELD; MACKENZIE, 2008, p.13)

Dentro dos componentes, as elipses contêm operações, os quadrados contêm os primitivos usados nas operações e os retângulos contêm os níveis de representação produzidos pelas operações. Seguindo a orientação descendente do modelo, a explicação da Figura 4 será feita 
de cima para baixo, com base no seguinte exemplo, produzido em um contexto em que o Ouvinte quer entrar em uma pastagem onde há um touro:

Há um touro no pasto!

(Adaptado de HENGEVELD; MACKENZIE, 2008, p.43)

No Componente Conceitual, é desenvolvida a intenção comunicativa (fazer um alerta) e as representações mentais correspondentes (sobre o evento que gera perigo). Essas representações conceituais são traduzidas em representações pragmáticas e semânticas nos Níveis Interpessoal e Representacional, respectivamente, por meio da operação de Formulação. As regras de Formulação fazem uso de um conjunto de primitivos que contém esquemas, lexemas e operadores. Tais regras são diferentes de língua para língua; consequentemente, representações conceituais parecidas podem ter diferentes representações pragmáticas e semânticas em diferentes línguas. Em língua portuguesa, como exemplificado em (53), para alertas de perigo é selecionada a Ilocução Declarativa, em outras línguas essa mesma intenção comunicativa é codificada com outros tipos de Ilocução.

A seleção da Ilocução Declarativa, em (53), combinada com um operador Enfático, é feita no Nível Interpessoal. No Nível Representacional, a entidade que causa perigo é designada como parte de um esquema de predicação locativo.

As configurações dos Níveis Interpessoal e Representacional são traduzidas em estruturas morfossintáticas, no Nível Morfossintático, por meio da Operação de Codificação Morfossintática. As regras da Codificação Morfossintática contam com um conjunto de primitivos que contém Templates Morfossintáticos, Morfemas Gramaticais e Operadores Morfossintáticos. No exemplo apresentado em (53), a ordem dos constituintes característica de construções existenciais é um exemplo do resultado da operação de Codificação Morfossintática. 
As estruturas dos Níveis Interpessoal, Representacional e Morfossintático, da mesma forma, são traduzidas em estruturas fonológicas por meio da operação de Codificação Fonológica. As regras de Codificação Fonológica contam com um conjunto de primitivos que contém Templates Fonológicos, Formas Supletivas e Operadores Fonológicos.

O Nível Fonológico é o input para a operação de Articulação, que, no caso da língua falada, possui as regras fonéticas para a produção de enunciados adequados. A Articulação ocorre fora da gramática, no Componente de Saída.

Como se pode perceber na Figura 4, e pelo que foi exposto acima sobre ela, no Componente Gramatical há quatro níveis de análise: o Interpessoal, o Representacional, o Morfossintático e o Fonológico. Em cada nível, a expressão linguística é analisada em termos das distinções relevantes para o nível em questão. Só são representadas distinções que realmente ocorrem na gramática da língua envolvida. Dependendo do fenômeno que se deseja analisar e de sua forma de manifestação na língua em estudo, não há necessidade de ele ser analisado nos quatro níveis. Assim sendo, nesta subseção, só serão caracterizados os níveis relevantes para a análise do fenômeno em estudo.

O Nível Interpessoal representa uma unidade linguística em termos de sua função comunicativa. Ele capta todas as distinções da Formulação que dizem respeito à interação entre Falante e Ouvinte, como noções retóricas da estruturação do discurso e distinções pragmáticas que revelam como os Falantes constroem suas mensagens tendo em vista as expectativas do Ouvinte. Somente as distinções interpessoais refletidas na forma linguística são descritas no Nível Interpessoal. Não só no Nível Interpessoal, mas em qualquer nível de análise da GDF, só são consideradas distinções gramaticalmente relevantes.

No Nível Interpessoal, a estrutura hierárquica a seguir se aplica: 


$$
\left(\mathrm{M}_{1}:\left(\mathrm{A}_{1}:\left[\left(\mathrm{F}_{\mathrm{I}}\right)\left(\mathrm{P}_{1}\right)_{\mathrm{S}}\left(\mathrm{P}_{2}\right)_{\mathrm{A}}\left(\mathrm{C}_{1}:\left[\ldots\left(\mathrm{T}_{1}\right)\left(\mathrm{R}_{1}\right) \ldots\right]\left(\mathrm{C}_{1}\right)\right)\right]\left(\mathrm{A}_{1}\right)\right)\left(\mathrm{M}_{1}\right)\right)^{31}
$$

A unidade de análise hierarquicamente mais alta neste nível é o Movimento (Move M), definido como "a unidade livre mínima de discurso capaz de entrar em uma estrutura de troca” $^{32}$ (KROON, 1997, p.20). Nas palavras de Hengeveld e Mackenzie (2009, p.9), o Movimento é uma contribuição autônoma para a interação em desenvolvimento: ele pode requerer uma reação ou ser a própria reação a outro Movimento. O Movimento consiste de um ou mais Atos Discursivos (A), "a menor unidade identificável de comportamento comunicativo"33 (KROON, 1997, p.20). Os Atos podem estar em uma relação de equipolência, quando o Falante dá estatuto comunicativo igual aos dois Atos, ou de dependência, quando o falante dá estatuto comunicativo desigual a dois Atos. No exemplo a seguir, há dois Movimentos, um Movimento de Iniciação provocado por A e um Movimento de Reação provocado por B:

\section{A: O que aconteceu ontem no jogo?}

B: O Palmeiras ganhou. E o Corinthians perdeu.

(Adaptado de HENGEVELD; MACKENZIE, 2008, p.53)

No Movimento de Reação (B), há dois Atos que estão em uma relação de equipolência. A estrutura subjacente a seguir representa o estatuto comunicativo igual dos dois Atos:

$$
\left(\mathrm{M}_{\mathrm{I}} \text { : }\left[\left(\mathrm{A}_{\mathrm{I}} \text { : -Palmeiras ganhou- }\left(\mathrm{A}_{\mathrm{I}}\right)\right)\left(\mathrm{A}_{\mathrm{J}} \text { : - Corinthians perdeu- }\left(\mathrm{A}_{\mathrm{J}}\right)\right)\right]\left(\mathrm{M}_{\mathrm{I}}\right)\right)^{34}
$$

\footnotetext{
${ }^{31}$ Apesar de o texto desta tese usar traduções para os termos da GDF, como, por exemplo, "Movimento", "Ato", "Falante", "Ouvinte", nas estruturas subjacentes a notação será feita tal qual apresentada em Hengeveld e Mackenzie (2008).

${ }^{32}[\ldots]$ the minimal free unit of discourse that is able to enter into an exchange structure (KROON, 1997, p.20).

${ }^{33}[\ldots]$ the smallest identifiable unit of communicative behaviour (KROON, 1997, p.20).

${ }^{34}$ No sistema notacional da GDF, os travessões são usados quando não há necessidade de se explicitarem todos os detalhes para a análise do fenômeno em questão. Nesses casos, um travessão é usado no início e no fim do fragmento, indicando que o trecho vai ser analisado como um todo.
} 
O exemplo a seguir ilustra uma relação de dependência entre dois Atos. Tal relação é indicada como uma função retórica no Ato Discursivo dependente:

Tome cuidado, pois vai haver pegadinhas na prova.

(Adaptado de HENGEVELD; MACKENZIE, 2008, p.53-54)

Em (57), há um Movimento constituído de dois Atos Discursivos: o primeiro Ato ( $\mathrm{A}_{\mathrm{I}}$ : -tome cuidado- $\left(\mathrm{A}_{\mathrm{I}}\right)$ ) com Ilocução Imperativa e o segundo Ato (Subsidiário - $\left(\mathrm{A}_{\mathrm{J}}\right.$ : -vai haver pegadinhas na prova- $\left.\left(\mathrm{A}_{\mathrm{J}}\right)\right)$ ) com Ilocução Declarativa e função retórica de Motivação, uma vez que serve para indicar a motivação que levou o Falante a enunciar o primeiro Ato. Tal análise pode ser representada da seguinte forma:

$$
\left(\mathrm{M}_{\mathrm{I}}:\left[\left(\mathrm{A}_{\mathrm{I}}:\left[\left(\mathrm{F}_{\mathrm{I}}: \operatorname{IMP}\left(\mathrm{F}_{\mathrm{I}}\right)\right)\right]\left(\mathrm{A}_{\mathrm{I}}\right)\right)\left(\mathrm{A}_{\mathrm{J}}:\left[\left(\mathrm{F}_{\mathrm{J}}: \operatorname{DECL}\left(\mathrm{F}_{\mathrm{J}}\right)\right)\right]\left(\mathrm{A}_{\mathrm{J}}\right)\right)_{\mathrm{Motiv}}\right]\left(\mathrm{M}_{\mathrm{I}}\right)\right)
$$

A Ilocução é uma característica fundamental que diferencia entre si os Atos Discursivos, indicando o uso conversacional convencionalizado de cada Ato. Ela é uma das formas existentes nas línguas para representar a intenção comunicativa do Falante. A Ilocução Declarativa (DECL), por exemplo, é usada quando o Falante informa o Ouvinte sobre o Conteúdo Proposicional evocado pelo Conteúdo Comunicado, a Ilocução Interrogativa (INTER) representa o pedido do Falante para que o Ouvinte responda ao Conteúdo Proposicional evocado pelo Conteúdo Comunicado e a Ilocução Imperativa (IMP) é usada pelo Falante para orientar o Ouvinte a praticar a ação evocada pelo Conteúdo Comunicado. Em síntese, a Ilocução especifica a relação entre os Participantes e o Conteúdo Comunicado.

Os Participantes da interação $\left(\left(\mathrm{P}_{1}\right)\right.$ e $\left.\left(\mathrm{P}_{2}\right)\right)$ se alternam como Falante e Ouvinte; tais papéis são indicados como funções, semelhantes às funções semânticas de Agente e Recipiente, respectivamente. O Conteúdo Comunicado contém a totalidade do que o Falante deseja evocar na sua comunicação com o Ouvinte. Cada Conteúdo Comunicado consiste de 
um ou mais Subatos, que podem ser de dois tipos: Subatos Atributivos (Ascriptive Subacts (T)), por meio dos quais o Falante evoca propriedades, e Subatos Referenciais (Referential Subacts - (R)), por meio dos quais o Falante evoca um referente. A análise do exemplo (59), a seguir, mostra como todas essas unidades são representadas:

(59) Pedro ama Maria.

$\left(\mathrm{A}_{\mathrm{I}}:\left[\left(\mathrm{F}_{\mathrm{I}}: \operatorname{DECL}\left(\mathrm{F}_{\mathrm{I}}\right)\right)\left(\mathrm{P}_{\mathrm{I}}\right)_{\mathrm{S}}\left(\mathrm{P}_{\mathrm{J}}\right)_{\mathrm{A}}\left(\mathrm{C}_{\mathrm{I}}:\left[\left(\mathrm{T}_{\mathrm{I}}\right)\left(+\mathrm{id} \mathrm{R}_{\mathrm{I}}:\right.\right.\right.\right.\right.$ Pedro $\left.\left(\mathrm{R}_{\mathrm{I}}\right)\right)\left(+\mathrm{id} \mathrm{R}_{\mathrm{J}}\right.$ : Maria $\left.\left.\left(\mathrm{R}_{\mathrm{J}}\right)\right)\right]$ $\left.\left.\left.\left(\mathrm{C}_{\mathrm{I}}\right)\right)\right]\left(\mathrm{A}_{\mathrm{I}}\right)\right)$

(Adaptado de HENGEVELD; MACKENZIE, 2008, p.110)

Em (59), há um Ato com uma Força Ilocucionária Declarativa. Os Participantes $\mathrm{P}_{\mathrm{I}}$ e $\mathrm{P}_{\mathrm{J}}$ não são especificados. O Conteúdo Comunicado contém três Subatos: um Subato Atributivo $\left(\mathrm{T}_{\mathrm{I}}\right)$ e dois Subatos Referenciais $\left(\left(\mathrm{R}_{\mathrm{I}}\right)\right.$ e $\left.\left(\mathrm{R}_{\mathrm{J}}\right)\right)$. O único Subato Atributivo de (59), expresso pelo verbo ama, aparece no Nível Interpessoal apenas como $\left(\mathrm{T}_{\mathrm{I}}\right)$, uma vez que a atribuição é executada por meio da seleção de um item lexical no Nível Representacional. Os dois Subatos Referenciais, por outro lado, são preenchidos no Nível Interpessoal, (+id $\mathrm{R}_{\mathrm{I}}$ : Pedro $\left.\left(\mathrm{R}_{\mathrm{I}}\right)\right)$ e (+id $\mathrm{R}_{\mathrm{J}}$ : Maria $\left(\mathrm{R}_{\mathrm{J}}\right)$ ). Isso acontece porque, nos dois casos, os Subatos contêm nomes próprios, que não têm conteúdo semântico e, consequentemente, vão ser sempre representados no Nível Interpessoal, e não no Representacional. Nos dois casos, os referentes são marcados pelo operador "+id" como identificáveis pelo Ouvinte; em outras palavras, em (59), ao se referir a Pedro e a Maria, o Falante assume que o Ouvinte pode identificar tais referentes. No exemplo a seguir, pronomes são usados no lugar dos nomes próprios:

(60) Eu a amo.

Em (60), a representação de cada Subato de Referência é um pouco diferente. O primeiro Subato se refere a um Participante do ato de fala, primeira pessoa do singular, e é representado da seguinte forma: (+id $\mathrm{R}_{\mathrm{I}}:[+\mathrm{S},-\mathrm{A}]\left(\mathrm{R}_{\mathrm{I}}\right)$ ). Em outras palavras, esse Subato contém um referente identificável pelo Ouvinte $(+\mathrm{id})$, que envolve o Falante $(+\mathrm{S})$ e não 
envolve o Ouvinte (-A). O segundo Subato, que se refere à terceira pessoa do singular, é representado como $\left(+\mathrm{id} \mathrm{R}_{\mathrm{J}}:[-\mathrm{S},-\mathrm{A}]\left(\mathrm{R}_{\mathrm{J}}\right)\right)$. Nesse caso, o referente também é identificável pelo Ouvinte (+id), mas não envolve o Falante (-S) nem o Ouvinte (-A).

Com relação à identificabilidade do referente, diferentemente do que acontece em (59) e (60), o Falante pode assumir que o Ouvinte não é capaz de identificar o referente. Nesse caso, o operador "-id" deve ser usado na representação do Subato Referencial. Outro aspecto concernente à identificabilidade do referente diz respeito à indicação de que o próprio Falante pode ou não identificar o referente. Esse aspecto se reflete no uso dos operadores “+s" e "-s", que significam, respectivamente, específico, quando o referente é identificável pelo Falante, e não-específico, quando o referente não pode ser identificado pelo Falante. Diferentes combinações dos operadores “+/-id" e "+/-s" são possíveis; duas delas são apresentadas a seguir:

(61) Alguém me ajudou com o quebra-cabeças.

(62) Quem roubou a minha bicicleta?

(Adaptados de HENGEVELD; MACKENZIE, 2008, p.122)

Em (61), a combinação $\{-\mathrm{id},+$ s $\}$ se aplica, uma vez que o Subato de Referência em destaque é identificável apenas pelo Falante. Em (62), ao contrário, o referente é assumido como identificável apenas pelo Ouvinte, o que resulta na combinação dos operadores $\{+\mathrm{id},-\mathrm{s}\}$.

No Nível Representacional, são considerados os aspectos semânticos das unidades linguísticas. O termo "semântico" é usado na GDF de uma forma bastante específica, com dois sentidos diferentes: i) "as maneiras pelas quais a língua se relaciona com o mundo extralinguístico que ela descreve" e ii) "os significados de unidades lexicais (semântica lexical) e de unidades complexas (semântica composicional) sem levar em conta as maneiras 
em que essas são usadas na comunicação" ${ }^{35}$ (HENGEVELD; MACKENZIE, 2008, p.128129). Utilizando o exemplo a seguir, os autores explicam como a noção de referência deve ser entendida no Nível Interpessoal e no Nível Representacional:

(63) Eu vi um leão.

(Adaptado de HENGEVELD; MACKENZIE, 2008, p.129)

A expressão um leão deve ser entendida, no Nível Interpessoal, como uma expressão que o Falante usa para se referir a um animal da classe dos leões e, no Nível Representacional, como uma expressão que se refere a um animal da classe dos leões. Para diferenciar esses dois usos da noção de referência, os autores utilizam o termo "referência" apenas para o uso interpessoal, acional; para o uso representacional, semântico, o termo usado é "designação".

As unidades de análise do Nível Representacional, de um modo geral, são descritas em termos do tipo de entidade que elas designam. Há vários tipos de entidades, ou categorias semânticas, relevantes para a análise de uma língua. Aos três tipos de entidades distinguidos por Lyons (1977) Hengeveld e Mackenzie (2008) acrescentam uma categoria de ordem mais baixa, a Propriedade, e propõem quatro categorias semânticas básicas: Conteúdo Proposicional (p), Estado-de-Coisas (e), Propriedade (f) e Indivíduo (x). Além dessas categorias semânticas básicas, segundo Hengeveld e Mackenzie, dependendo dos recursos disponíveis na língua, podem ser identificados outros tipos de categorias no Nível Representacional: Episódio (ep), Lugar (1), Tempo (t), Modo (m), Quantidade (q) e Razão (r). Todas essas entidades passam a ser descritas a seguir.

O Conteúdo Proposicional (p) é a unidade mais alta do Nível Representacional. Ele diz respeito a construtos mentais, crenças e expectativas e podem ser factuais, quando são conhecimentos ou crenças sobre o mundo real, ou não-factuais, quando são desejos ou

\footnotetext{
${ }^{35}[\ldots]$ the ways in which language relates to the extra-linguistic world it describes [...] the meanings of lexical units (lexical semantics) and complex units (compositional semantics) in isolation from the ways these are used in communication (HENGEVELD; MACKENZIE, 2008, p.128-129).
} 
expectativas com relação a um mundo imaginário. No exemplo a seguir, o complemento do verbo ver corresponde a um Conteúdo Proposicional:

(64) Pedro viu que Maria está contente.

$\left(\mathrm{p}_{\mathrm{i}}:\left(\operatorname{ep}_{\mathrm{i}}:\left(\mathrm{e}_{\mathrm{i}}:\left[\left(\mathrm{f}_{\mathrm{i}}:\left[\left(\mathrm{f}_{\mathrm{j}}: \operatorname{ver}\left(\mathrm{f}_{\mathrm{j}}\right)\right)\left(\mathrm{x}_{\mathrm{i}}\right)\left(\mathrm{p}_{\mathrm{j}}:\left(\mathrm{ep}_{\mathrm{j}}:\left(\mathrm{e}_{\mathrm{j}}:\left[\left(\mathrm{f}_{\mathrm{k}}:\left[\left(\mathrm{f}_{1}:\right.\right.\right.\right.\right.\right.\right.\right.\right.\right.\right.\right.\right.$ contente $\left.\left.\left.\left.\left.\left(\mathrm{f}_{\mathrm{l}}\right)\right)\left(\mathrm{x}_{\mathrm{j}}\right)\right]\left(\mathrm{f}_{\mathrm{k}}\right)\right)\left(\mathrm{e}_{\mathrm{j}}\right)\right]\right)$ $\left.\left.\left.\left.\left.\left.\left.\left.\left(e \mathrm{p}_{\mathrm{i}}\right)\right)\left(\mathrm{p}_{\mathrm{j}}\right)\right)\right]\left(\mathrm{f}_{\mathrm{i}}\right)\right)\left(\mathrm{e}_{\mathrm{i}}\right)\right]\right)\left(\mathrm{ep}_{\mathrm{i}}\right)\right)\left(\mathrm{p}_{\mathrm{i}}\right)\right)$

O Episódio (ep) consiste de um ou mais Estados-de-Coisas tematicamente coerentes, que possuem unidade ou continuidade de Tempo (t), Lugar (l) e Indivíduos (x). Em diversas línguas, essa categoria semântica é muito comum, como acontece, por exemplo, em línguas que apresentam ligações do tipo tail-head. O exemplo a seguir, segundo Hengeveld e Mackenzie (2008, p.163-164), ilustra um caso de Episódio em inglês:

(65) Coming out, stopping to check the mailbox, taking a look at the driveway and pausing to adjust his hat, he walked to his car.

$\left(\mathrm{ep}_{\mathrm{i}}\right.$ : $\left[\left(\mathrm{e}_{\mathrm{i}}\right.\right.$ : -coming out- $\left.\left(\mathrm{e}_{\mathrm{i}}\right)\right)\left(\mathrm{e}_{\mathrm{j}}\right.$ : -stopping to check the mailbox- $\left.\left(\mathrm{e}_{\mathrm{j}}\right)\right)\left(\mathrm{e}_{\mathrm{k}}\right.$ :-taking a look at the driveway- $\left.\left(\mathrm{e}_{\mathrm{k}}\right)\right)\left(\mathrm{e}_{\mathrm{l}}\right.$ :-pausing to adjust his hat- $\left.\left(\mathrm{e}_{1}\right)\right)\left(\mathrm{e}_{\mathrm{m}}\right.$ : -he walked to his car- $\left.\left.\left.\left(\mathrm{e}_{\mathrm{m}}\right)\right)\right]\left(\mathrm{ep}_{\mathrm{i}}\right)\right)$

'Só depois de sair, de parar para checar a caixa de correio, de olhar para a estrada e de parar para arrumar seu chapéu, ele caminhou em direção a seu carro.'

Nesse exemplo, as orações com verbos na forma não-finita, juntamente com a última oração com verbo na forma finita, constituem um Episódio dentro de uma narrativa maior. A localização temporal do Episódio como um todo é marcada pelo operador de tempo absoluto codificado apenas no último verbo da série, o único na forma finita. A terminação verbal dos verbos não-finitos indica simultaneidade, que, nesse caso, segundo Hengeveld e Mackenzie (2008, p.164), “deve ser interpretada como ocorrência na mesma zona de tempo absoluto, e não como ocorrência no mesmo momento no tempo."36 Para os autores, somente os Episódios podem ser localizados em tempo absoluto, ao passo que os Estados-de-Coisas são localizados

\footnotetext{
${ }^{36}[. .$.$] should be interpreted as occurring in the same absolute time zone, and not as 'occurring at the same$ moment in time,"” (HENGEVELD; MACKENZIE, 2008, p.164).
} 
em tempo relativo. Essa diferença pode ser observada na seguinte representação do exemplo (65), apresentada por Hengeveld e Mackenzie (2008, p.163):

(66) (past ep $\left.p_{i}:\left[\left(\operatorname{sim} e_{i}\right),\left(\operatorname{sim} e_{j}\right),\left(\operatorname{sim} e_{k}\right),\left(\operatorname{sim} e_{1}\right),\left(\operatorname{sim} e_{m}\right)\right]\left(e p_{i}\right)\right)$

Os Estados-de-Coisas (e) dizem respeito a eventos e estados que podem ser localizados em tempo relativo e podem ser avaliados em termos de sua realidade. Nos dois exemplos a seguir, o verbo ver descreve a percepção direta de um evento (cf. HENGEVELD; MACKENZIE, 2008, p. 168-169):

(67) O homem viu o jogo.

(68) O homem viu seu time jogar.

O complemento do verbo ver, nos dois casos acima, é um evento; a diferença está na forma como o segundo argumento é expresso: lexicalmente no primeiro caso e configuracionalmente no segundo. Esses exemplos ilustram uma característica dos Estadosde-Coisas: eles são caracterizados por Propriedades, tanto Lexicais como Configuracionais. As representações de ambos os exemplos mostram como a aplicação de Propriedades ocorre na organização semântica dos Estados-de-Coisas:

(69) $\quad\left(\mathrm{e}_{\mathrm{i}}:\left(\mathrm{f}_{\mathrm{i}}:\right.\right.$ jogo $\left.\left.\left(\mathrm{f}_{\mathrm{i}}\right)\right)\left(\mathrm{e}_{\mathrm{i}}\right)\right)$

(70) $\quad\left(\mathrm{e}_{\mathrm{i}}:\left(\mathrm{f}_{\mathrm{i}}:\left[\left(\mathrm{f}_{\mathrm{j}}: \operatorname{jogar}\left(\mathrm{f}_{\mathrm{j}}\right)\right)\left(\mathrm{x}_{\mathrm{i}}:-\mathrm{time}-\left(\mathrm{x}_{\mathrm{i}}\right)\right)\right]\left(\mathrm{f}_{\mathrm{i}}\right)\right)\left(\mathrm{e}_{\mathrm{i}}\right)\right)$

Em (69), a variável que representa o Estado-de-Coisas ( $\mathrm{e}_{\mathrm{i}}$ ) é restringida por uma Propriedade Lexical $\left(\mathrm{f}_{\mathrm{i}}\right)$, realizada por meio do lexema jogo. Em (70), $\left(\mathrm{f}_{\mathrm{i}}\right)$ é uma Propriedade Configuracional, realizada por meio de um esquema de predicação que consiste de uma unidade que denota a Propriedade Lexical $\left(f_{j}\right.$ : jogar $\left.\left(f_{j}\right)\right)$ e outra unidade que denota o Indivíduo $\left(\mathrm{x}_{\mathrm{i}}\right.$ : -time- $\left.\left(\mathrm{x}_{\mathrm{i}}\right)\right)$. 
Como dito anteriormente, os Estados-de-Coisas são caracterizados pela localização em tempo relativo, que pode ser codificado por meio de modificadores e operadores. No exemplo a seguir, adaptado de Hengeveld e Mackenzie (2008, p.171), há um exemplo de um Estadode-Coisas localizado em tempo relativo codificado por um modificador:

(71) Maria saiu antes do jantar.

$\left(\mathrm{e}_{\mathrm{i}}:\left(\mathrm{f}_{\mathrm{i}}:[-\right.\right.$ Maria saiu- $\left.]\left(\mathrm{f}_{\mathrm{i}}\right)\right)\left(\mathrm{e}_{\mathrm{i}}\right)_{\phi}:\left[\left(\mathrm{t}_{\mathrm{i}}:-\right.\right.$ antes do jantar- $\left.\left.\left.\left(\mathrm{t}_{\mathrm{i}}\right)\right)\left(\mathrm{e}_{\mathrm{i}}\right)_{\phi}\right]\right)$

Uma evidência de que antes do jantar é um modificador que atua na camada do Estado-deCoisas é o fato de ele poder ocorrer dentro do escopo de expressões que marcam tempo absoluto, como ontem, por exemplo:

(72) Ontem Maria saiu antes do jantar.

O Indivíduo (x) é a categoria semântica que designa entidades concretas, que ocupam um lugar no espaço, de forma tal que dois Indivíduos não podem ocupar o mesmo lugar. Na estrutura subjacente do exemplo a seguir, adaptado de Hengeveld e Mackenzie (2008, p.237238), observa-se como a unidade semântica Indivíduo é representada:

O presidente chegou.

(past ep $\mathrm{p}_{\mathrm{i}}:\left(\operatorname{sim} \mathrm{e}_{\mathrm{i}}:\left[\left(\mathrm{f}_{\mathrm{i}}:\left[\left(\mathrm{f}_{\mathrm{j}}: \operatorname{chegar}\left(\mathrm{f}_{\mathrm{j}}\right)\right)\left(\mathrm{x}_{\mathrm{i}}:\left[\left(\mathrm{f}_{\mathrm{k}}\right.\right.\right.\right.\right.\right.\right.$ : presidente $\left.\left.\left.\left.\left.\left.\left.\left(\mathrm{f}_{\mathrm{k}}\right)\right)\left(\mathrm{x}_{\mathrm{i}}\right)\right]\right)\left(\mathrm{f}_{\mathrm{i}}\right)\right)\left(\mathrm{e}_{\mathrm{i}}\right)\right]\right)\left(\mathrm{ep}_{\mathrm{i}}\right)\right)$

A variável $\left(\mathrm{x}_{\mathrm{i}}\right)$ designa um Indivíduo nessa camada representacional. Esse Indivíduo possui a Propriedade $\left(\mathrm{f}_{\mathrm{k}}\right.$ ) lexicalmente expressa que mostra tal designação. Em outras palavras, o Indivíduo $\left(\mathrm{x}_{\mathrm{i}}\right)$ de $(73)$ possui a propriedade $\left(\mathrm{f}_{\mathrm{k}}\right)$ de ser presidente.

Como foi visto na explicação do exemplo (59) acima, nomes próprios são representados como unidades do Nível Interpessoal (Subatos de Referência (R) ou de Atribuição (T)). Se, em (73), em vez do nome "presidente" ocorresse um nome próprio, a unidade semântica correspondente ao Subato "João" não teria informação lexical. A seguir, a 
sentença (74) é reescrita com um nome próprio e representada nos Níveis Interpessoal e Representacional:

(74) João chegou.

NI: $\left(\mathrm{A}_{\mathrm{I}}:\left[\left(\mathrm{F}_{\mathrm{I}}: \operatorname{DECL}\left(\mathrm{F}_{\mathrm{I}}\right)\right)\left(\mathrm{P}_{\mathrm{I}}\right)_{\mathrm{S}}\left(\mathrm{P}_{\mathrm{J}}\right)_{\mathrm{A}}\left(\mathrm{C}_{\mathrm{I}}:\left[\left(\mathrm{T}_{\mathrm{I}}\right)_{\mathrm{Foc}}\left(\mathrm{R}_{\mathrm{I}}\right.\right.\right.\right.\right.$ : João $\left.\left.\left.\left.\left.\left(\mathrm{R}_{\mathrm{I}}\right)\right)\right]\left(\mathrm{C}_{\mathrm{I}}\right)\right)\right]\left(\mathrm{A}_{\mathrm{I}}\right)\right)$

NR: $\left(\operatorname{ep}_{\mathrm{i}}:\left(\mathrm{e}_{\mathrm{i}}:\left[\left(\mathrm{f}_{\mathrm{i}}:\left[\left(\mathrm{f}_{\mathrm{j}}: \operatorname{chegar}\left(\mathrm{f}_{\mathrm{j}}\right)\right)\left(\mathrm{x}_{\mathrm{i}}\right)\right]\left(\mathrm{f}_{\mathrm{i}}\right)\right)\left(\mathrm{e}_{\mathrm{i}}\right)\right]\right)\left(\mathrm{ep}_{\mathrm{i}}\right)\right)$

A unidade $\left(\mathrm{x}_{\mathrm{i}}\right)$ do Nível Representacional corresponde ao Subato $\left(\mathrm{R}_{\mathrm{I}}\right.$ : João $\left.\left(\mathrm{R}_{\mathrm{I}}\right)\right)$ do Nível Interpessoal. Apesar de essa unidade não ser preenchida no Nível Representacional, ela não pode ser omitida nesse nível, uma vez que tem papel importante na valência do ambiente semântico. $^{37}$

As Propriedades (f) são uma categoria semântica que não tem existência independente. Elas podem apenas ser avaliadas em termos de sua aplicabilidade. As Propriedades possuem um papel fundamental na construção de representações semânticas. Uma vez que a GDF tem como princípio a organização hierárquica das unidades linguísticas, as Propriedades, por serem as unidades hierarquicamente menores do Nível Representacional, vão estar presentes nas representações semânticas de todas as unidades nesse nível.

Como já foi mencionado anteriormente na descrição dos Estados-de-Coisas, existem dois tipos de Propriedades: as Lexicais e as Configuracionais. Exemplos de Propriedades Lexicais dados por Hengeveld e Mackenzie (2008, p.215) são:
(75) $\quad\left(\mathrm{f}_{\mathrm{i}}:\right.$ homem $\left.\left(\mathrm{f}_{\mathrm{i}}\right)\right)$
(76) $\quad\left(f_{j}\right.$ : inteligente $\left.\left(f_{j}\right)\right)$
(77) $\left(\mathrm{f}_{\mathrm{k}}\right.$ : alto $\left.\left(\mathrm{f}_{\mathrm{k}}\right)\right)$

\footnotetext{
37 Os pronomes são muito similares aos nomes próprios, também correspondendo a Subatos no Nível Interpessoal, mas não são preenchidos nesse nível como os nomes próprios. Aparecem nas representações do Nível Representacional apenas como $\left(\mathrm{x}_{\mathrm{i}}\right)$, tendo a variável preenchida apenas no Nível Morfossintático.
} 
As duas últimas Propriedades podem ser usadas na formação de uma outra Propriedade:

$\left(f_{j}\right.$ : inteligente $\left(f_{j}\right):\left[\left(f_{k}:\right.\right.$ alto $\left.\left.\left.\left(f_{k}\right)\right)\left(f_{j}\right)\right]\right)$

'altamente inteligente'

Nesse caso, $\left(\mathrm{f}_{\mathrm{k}}\right)$ é uma Propriedade de uma Propriedade. Tal combinação de Propriedades pode ainda ser usada na caracterização de um Indivíduo, como se pode observar na representação a seguir:

(79) $\quad\left(\mathrm{x}_{\mathrm{i}}:\left[\left(\mathrm{f}_{\mathrm{i}}: \operatorname{man}\left(\mathrm{f}_{\mathrm{i}}\right)\right)\left(\mathrm{x}_{\mathrm{i}}\right)\right]:\left[\left(\mathrm{f}_{\mathrm{j}}:\right.\right.\right.$ inteligente $\left(\mathrm{f}_{\mathrm{j}}\right):\left[\left(\mathrm{f}_{\mathrm{k}}:\right.\right.$ alto $\left.\left.\left.\left.\left.\left(\mathrm{f}_{\mathrm{k}}\right)\right)\left(\mathrm{f}_{\mathrm{j}}\right)\right]\right)\left(\mathrm{x}_{\mathrm{i}}\right)\right]\right)$ 'homem altamente inteligente'

Os exemplos (78) e (79) mostram como as Propriedades Lexicais são importantes para a construção de representações semânticas de outras categorias.

As Propriedades Configuracionais, que correspondem ao inventário de esquemas de predicação relevantes de uma língua, são igualmente relevantes na construção de representações semânticas. A aplicação de uma Propriedade Configuracional pode ser observada na representação semântica do exemplo a seguir, adaptado de Hengeveld e Mackenzie (2008, p.181):

(80) A tempestade causou estragos.

$\left(e_{i}:\left(f_{i}:\left[\left(f_{j}:\right.\right.\right.\right.$ causar $\left.\left(f_{j}\right)\right)\left(e_{j}:\left(f_{k}:\right.\right.$ tempestade $\left.\left.\left(f_{k}\right)\right)\left(e_{j}\right)\right)\left(e_{k}:\left(f_{1}:\right.\right.$ estrago $\left.\left.\left.\left.\left.\left(f_{1}\right)\right)\left(e_{k}\right)\right)\right]\left(f_{i}\right)\right)\left(e_{i}\right)\right)$

O Estado-de-Coisas $\left(\mathrm{e}_{\mathrm{i}}\right)$ apresentado em (80) consiste de uma Propriedade Configuracional $\left(\mathrm{f}_{\mathrm{i}}\right)$ que estabelece uma relação entre dois Estados-de-Coisas $\left(\left(e_{j}\right)\right.$ e $\left.\left(e_{k}\right)\right)$. Em outras palavras, como se pode ver na representação, a variável Estado-de-Coisas (e) é restrita por um esquema de predicação. 
Dentre os operadores que atuam na camada da Propriedade Configuracional existem aqueles que codificam distinções aspectuais, especificando a constituição temporal interna dos Estados-de-Coisas. Tais operadores podem codificar a fase do desenvolvimento de um Estado-de-Coisas (distinções Aspectuais Fasais) e a (in)completude do desenvolvimento de um Estado-de-Coisas (oposição Perfectivo e Imperfectivo). Exemplos do primeiro grupo de operadores são os seguintes, do galês (adaptados de HENGEVELD; MACKENZIE, p.210):

(81) Mae 'r dyn yn gweld y ci

está o homem em vendo o cão

'O homem está vendo o cão.

(82) Mae 'r dyn wedi gweld y ci

está o homem depois vendo o cão

'O homem viu o cão.

Em (81), o Estado-de-Coisas é caracterizado como estando em desenvolvimento no ponto de referência (Aspecto Progressivo) e, em (82), o Estado-de-Coisas é caracterizado como já tendo acontecido no ponto de referência (Aspecto Resultativo).

O exemplo a seguir, do italiano, é apresentado por Hengeveld e Mackenzie (2008, p.211) para ilustrar a oposição Perfectivo-Imperfectivo:
Gianni leggeva
quando entrai
Gianni ler.PST.IMP
quando entrar.PST.PFV
'Gianni estava lendo quando eu entrei.

O operador que marca Aspecto Perfectivo caracteriza o Estado-de-Coisas da entrada do Falante como tendo terminado dentro do período de tempo do Estado-de-Coisas da leitura de Gianni, marcado com Aspecto Imperfectivo.

Os Lugares (1), assim como os Indivíduos (x), são entidades concretas, tangíveis. A diferença entre essas duas categorias semânticas está no fato de cada uma ser concebida de maneira diferente no Componente Conceitual. Hengeveld e Mackenzie (2008, p.248) ilustram 
essa diferença dando o exemplo de um mesmo fenômeno na realidade externa que pode ser mentalmente construído de duas formas. Segundo os autores, "uma casa" pode ser concebida por um futuro comprador como um Lugar, um local para morar, ao passo que a mesma casa pode ser concebida pelo vendedor como um Indivíduo, uma mercadoria para ser vendida. Essa distinção é refletida linguisticamente no uso das palavras home e house, do inglês. A primeira é especializada para ocorrer em designações de Lugares e a segunda, em designações de Indivíduos. As duas representações a seguir, transcritas de Hengeveld e Mackenzie (2008, p.248), mostram a diferença entre as duas entidades:

(84) $\quad\left(l_{i}:\left[\left(f_{i}:\right.\right.\right.$ home $\left.\left.\left._{N}\left(f_{i}\right)\right)\left(l_{i}\right)_{\phi}\right]\right)$ 'a home' (um lar)

(85) $\quad\left(\mathrm{x}_{\mathrm{i}}:\left[\left(\mathrm{f}_{\mathrm{i}}:\right.\right.\right.$ house $\left.\left.\left._{\mathrm{N}}\left(\mathrm{f}_{\mathrm{i}}\right)\right)\left(\mathrm{x}_{\mathrm{i}}\right)_{\phi}\right]\right)$ 'a house' (uma casa)

Lexemas que indicam lugares em português são, por exemplo, aeroporto e lugar, representados a seguir:

(86) $\quad\left(\mathrm{l}_{\mathrm{i}}:\left[\left(\mathrm{f}_{\mathrm{i}}:\right.\right.\right.$ aeroporto $\left.\left.\left._{\mathrm{N}}\left(\mathrm{f}_{\mathrm{i}}\right)\right)\left(\mathrm{l}_{\mathrm{i}}\right)_{\phi}\right]\right)$

(87) $\quad\left(\mathrm{l}_{\mathrm{i}}:\left[\left(\mathrm{f}_{\mathrm{i}}: \operatorname{lugar}_{\mathrm{N}}\left(\mathrm{f}_{\mathrm{i}}\right)\right)\left(\mathrm{l}_{\mathrm{i}}\right)_{\phi}\right]\right)$

Essa mesma análise deve ser feita para advérbios que indicam lugar, como dentro e fora, por exemplo. A diferença entre os substantivos e os advérbios indicadores de lugar reside no fato de o significado dos advérbios ser mais dependente do contexto do que o significado dos substantivos.

(88) $\quad\left(\mathrm{l}_{\mathrm{i}}:\left[\left(\mathrm{f}_{\mathrm{i}}:\right.\right.\right.$ dentro $\left.\left.\left.\mathrm{Adv}_{\mathrm{d}}\left(\mathrm{f}_{\mathrm{i}}\right)\right)\left(\mathrm{l}_{\mathrm{i}}\right)_{\phi}\right]\right)$

(89) $\quad\left(l_{\mathrm{i}}:\left[\left(\mathrm{f}_{\mathrm{i}}:\right.\right.\right.$ fora $\left.\left.\left._{A d v}\left(\mathrm{f}_{\mathrm{i}}\right)\right)\left(\mathrm{l}_{\mathrm{i}}\right)_{\phi}\right]\right)$

As expressões de lugar também podem ser configuracionais e ter a forma de uma oração. Nesses casos, a categoria Lugar é definida em termos de um Estado-de-Coisas 
localizado no local em questão. O exemplo dado pelos autores desse tipo de construção, traduzido para o português, é apresentado a seguir (cf. HENGELD; MACKENZIE, 2008, p.254).

(90) Eu gosto de onde você pendurou aquele quadro.

$\left(\mathrm{l}_{\mathrm{i}}:\left(\right.\right.$ past ep $_{\mathrm{i}}:\left(\mathrm{e}_{\mathrm{i}}:\left[\left(\mathrm{f}_{\mathrm{i}}:\left[\left(\mathrm{f}_{\mathrm{j}}: \operatorname{pendurar}_{\mathrm{V}}\left(\mathrm{f}_{\mathrm{j}}\right)\right)\left(\mathrm{x}_{\mathrm{i}}\right)_{\mathrm{A}}\left(\operatorname{dist} \mathrm{x}_{\mathrm{j}}:\left[\left(\mathrm{f}_{\mathrm{k}}:\right.\right.\right.\right.\right.\right.\right.$ quadro $\left.\left.\left.\left._{\mathrm{N}}\left(\mathrm{f}_{\mathrm{k}}\right)\right)\left(\mathrm{x}_{\mathrm{j}}\right)_{\phi}\right]\right)\left(\mathrm{l}_{\mathrm{i}}\right)_{\mathrm{L}}\right]$ $\left.\left.\left.\left.\left.\left(\mathrm{f}_{\mathrm{i}}\right)\right)\left(\mathrm{e}_{\mathrm{i}}\right)_{\phi}\right]\right)\left(\mathrm{ep}_{\mathrm{i}}\right)\right)\right)$

Os autores chamam o tipo de estrutura em destaque em (90) de "oração relativa sem núcleo" e a caracterizam da seguinte forma: “à variável $\left(l_{i}\right)$ é atribuído o Estado-de-Coisas $\left(\mathrm{e}_{\mathrm{i}}\right)$ que por sua vez contém outra ocorrência da variável $\left(l_{\mathrm{i}}\right)^{\text {"38 }}$ (HENGEVELD; MACKENZIE, 2008, p.254).

A categoria semântica Tempo (t) se refere aos diversos tipos de expressões de tempo: àquelas ligadas ao momento da fala (como ontem, no próximo mês), às que estabelecem pontos relativos na linha do tempo (como antes de domingo), àquelas que se relacionam a um calendário socialmente estabelecido (como terça, domingo de Páscoa), àquelas que identificam um ponto na linha do tempo (como momento, às 14 horas) e àquelas que indicam um período na linha do tempo (como período, março) (cf. HENGEVELD; MACKENZIE, 2008, p257). A variável utilizada para representar essa categoria é $t$, como se pode ver nas representações a seguir:

(91) $\quad\left(\mathrm{t}_{\mathrm{i}}:\left[\left(\mathrm{f}_{\mathrm{i}}:\right.\right.\right.$ momento $\left.\left.\left._{\mathrm{N}}\left(\mathrm{f}_{\mathrm{i}}\right)\right)\left(\mathrm{t}_{\mathrm{i}}\right)_{\phi}\right]\right)$

(92) $\quad\left(\mathrm{t}_{\mathrm{i}}:\left[\left(\mathrm{f}_{\mathrm{i}}:\left[\left(\mathrm{f}_{\mathrm{j}}: \operatorname{antes} \mathrm{adp}_{\text {Adp }}\left(\mathrm{f}_{\mathrm{j}}\right)\right)\left(\mathrm{t}_{\mathrm{j}}:\left[\left(\mathrm{f}_{\mathrm{k}}: \operatorname{domingo} \mathrm{O}_{\mathrm{N}}\left(\mathrm{f}_{\mathrm{k}}\right)\right)_{\text {Ref }}\right]\left(\mathrm{t}_{\mathrm{j}}\right)_{\phi}\right)\right]\left(\mathrm{f}_{\mathrm{i}}\right)\right)\left(\mathrm{t}_{\mathrm{i}}\right)_{\phi}\right]\right)$

(Adaptado de HENGEVELD; MACKENZIE, 2008, p.257)

\footnotetext{
${ }^{38}[\ldots]$ to the variable $\left(l_{i}\right)$ is assigned the State-of-Affairs $\left(e_{i}\right)$ which itself contains another occurrence of the variable $\left(l_{i}\right)$ (HENGEVELD; MACKENZIE, 2008, p.254).
} 
As expressões de tempo, assim como as de lugar, podem ter a forma de uma oração, sendo, portando, configuracionais, como acontece no exemplo a seguir, traduzido de Hengeveld e Mackenzie (2008, p.260), em que a oração em destaque é do tipo relativa sem núcleo.

(93) Eu gosto quando as folhas caem das árvores.

$\left(\mathrm{t}_{\mathrm{i}}:\left(\mathrm{e}_{\mathrm{i}}:\left[\left(\mathrm{f}_{\mathrm{i}}:\left[\left(\mathrm{f}_{\mathrm{j}}: \operatorname{cair}_{\mathrm{V}}\left(\mathrm{f}_{\mathrm{j}}\right)\right)\left(\mathrm{x}_{\mathrm{i}}:\left[\left(\mathrm{f}_{\mathrm{k}}: \text { folhas }_{\mathrm{N}}\left(\mathrm{f}_{\mathrm{k}}\right)\right)\left(\mathrm{x}_{\mathrm{i}}\right)_{\phi}\right]\right)_{\mathrm{U}}\left(\mathrm{x}_{\mathrm{j}}:\left[\left(\mathrm{f}_{\mathrm{l}}: \text { árvore }_{\mathrm{N}}\left(\mathrm{f}_{\mathrm{l}}\right)\right)\left(\mathrm{x}_{\mathrm{i}}\right)_{\phi}\right]\right)_{\mathrm{Abl}}\right]\right.\right.\right.\right.$ $\left.\left.\left.\left.\left(\mathrm{f}_{\mathrm{i}}\right)\right)\left(\mathrm{e}_{\mathrm{i}}\right)_{\phi}\right)\right]:\left[\left(\mathrm{t}_{\mathrm{i}}\right)\left(\mathrm{e}_{\mathrm{i}}\right)_{\phi}\right]\right)$

Segundo Declerck (1996 apud HENGEVELD; MACKENZIE, 2008), expressões de tempo construídas na forma de orações podem levar à interpretação de um simples Estado-deCoisas, como pode ser observado no exemplo a seguir:

(94) Eu gostei quando você deu a ele um biscoito.

que indica que o Falante gostou do Estado-de-Coisas de alguém dar um biscoito, e não propriamente do momento do ato de dar (cf. HENGEVELD; MACKENZIE, 2008, p.260).

A categoria semântica Modo, representada pela variável $m$, diz respeito a expressões linguísticas que designam a maneira como um Estado-de-Coisas acontece. Exemplos dessa categoria semântica em português são:

(95) Maria dançou lindamente.

$\left(\mathrm{m}_{\mathrm{i}}:\left[\left(\mathrm{f}_{\mathrm{i}}: \operatorname{linda}_{\mathrm{A}}\left(\mathrm{f}_{\mathrm{i}}\right)\right)\left(\mathrm{m}_{\mathrm{i}}\right)\right]_{\phi}\right)$

Em (95), seguindo Hengeveld e Mackenzie (2008), a expressão "lindamente" deve ser interpretada como "de uma maneira linda", assim, como se observa na representação de (95), a variável $\left(\mathrm{m}_{\mathrm{i}}\right)$ possui a Propriedade "linda", que é analisada como um adjetivo. O processo de sufixação de -mente está situado no Nível Morfossintático. 
Diferentemente de (95), em que o núcleo da expressão de modo é lexical, em (96) e (97), a seguir, as expressões de modo são configuracionais.

(96) Eu admiro o modo como ela dança.

$\left(\mathrm{m}_{\mathrm{i}}:\left[\left(\mathrm{f}_{\mathrm{i}}:\left[\left(\mathrm{f}_{\mathrm{j}}: \operatorname{modo}_{\mathrm{N}}\left(\mathrm{f}_{\mathrm{j}}\right)\right)\left(\operatorname{sim~e}_{\mathrm{i}}:\left[\left(\mathrm{f}_{\mathrm{k}}:\left[\left(\mathrm{f}_{\mathrm{l}}: \operatorname{dançar}_{\mathrm{V}}\left(\mathrm{f}_{\mathrm{j}}\right)\right)\left(\mathrm{x}_{\mathrm{i}}\right)_{\mathrm{A}}\right]\left(\mathrm{f}_{\mathrm{k}}\right)\right)\left(\mathrm{e}_{\mathrm{i}}\right)_{\phi}\right]\right)_{\operatorname{Ref}}\right]\left(\mathrm{f}_{\mathrm{i}}\right)\right)\left(\mathrm{m}_{\mathrm{i}}\right)_{\phi}\right]\right)$

(97) Eu admiro como ela dança.

$\left.\left(\mathrm{m}_{\mathrm{i}}:\left(\operatorname{sim} \mathrm{e}_{\mathrm{i}}:\left[\left(\mathrm{f}_{\mathrm{i}}:\left[\left(\mathrm{f}_{\mathrm{j}}: \operatorname{dançar}_{\mathrm{V}}\left(\mathrm{f}_{\mathrm{j}}\right)\right):\left(\mathrm{m}_{\mathrm{i}}\right)\left(\mathrm{f}_{\mathrm{j}}\right)\right)\left(\mathrm{x}_{\mathrm{i}}\right)_{\phi}\right]\left(\mathrm{f}_{\mathrm{i}}\right)\right)\left(\mathrm{e}_{\mathrm{i}}\right)_{\phi}\right]\right)\right)$

A diferença entre (96) e (97) está no fato de a oração relativa de (96), como ela dança, ter um núcleo, modo, ao passo que em (97) o núcleo não está presente; tem-se, nesse caso, uma oração relativa sem núcleo.

A categoria semântica Quantidade designa quantias de fenômenos incontáveis e números de fenômenos contáveis. A variável $q$ é usada para representar essa categoria, como ilustra a representação a seguir da expressão uma grande quantidade de queijo (HENGEVELD; MACKENZIE, 2008, p. 268).

(98) $\quad\left(\mathrm{q}_{\mathrm{i}}:\left[\left(\mathrm{f}_{\mathrm{i}}:\left[\left(\mathrm{f}_{\mathrm{j}}:\right.\right.\right.\right.\right.$ quantidade $\left.\left.\left.\left._{\mathrm{N}}\left(\mathrm{f}_{\mathrm{j}}\right)\right)\left(\mathrm{x}_{\mathrm{i}}:\left[\left(\mathrm{f}_{\mathrm{k}} \text { : queijo } \mathrm{N}_{\mathrm{N}}\left(\mathrm{f}_{\mathrm{k}}\right)_{\phi}\right)\right]\left(\mathrm{x}_{\mathrm{i}}\right)\right)_{\text {Ref }}\right]\left(\mathrm{f}_{\mathrm{i}}\right)\right)\left(\mathrm{q}_{\mathrm{i}}\right)_{\phi}\right]:\left[\left(\mathrm{f}_{\mathrm{i}}:\right.\right.$ grande $_{\mathrm{A}}$ $\left.\left.\left.\left(\mathrm{f}_{\mathrm{l}}\right)\right)\left(\mathrm{q}_{\mathrm{i}}\right)_{\phi}\right]\right)$

Assim como acontece com as categorias de Tempo, Lugar e Modo, expressões de Quantidade também podem ter núcleos configuracionais, como é o caso do exemplo apresentado a seguir, traduzido de Hengelveld e Mackenzie (2008, p.271).

(99) É impressionante quanto ele come.

$\left(\mathrm{q}_{\mathrm{i}}:\left(\operatorname{sim} \mathrm{e}_{\mathrm{i}}:\left(\mathrm{f}_{\mathrm{i}}:\left[\left(\mathrm{f}_{\mathrm{j}}: \operatorname{comer}_{\mathrm{V}}\left(\mathrm{f}_{\mathrm{j}}\right)\right)\left(\mathrm{x}_{\mathrm{i}}\right)_{\mathrm{A}}\left(\mathrm{q}_{\mathrm{i}}\right)_{\phi}\right]\left(\mathrm{f}_{\mathrm{i}}\right)\right)\left(\mathrm{e}_{\mathrm{i}}\right)\right)\right)$

Esse caso também se configura como uma oração relativa sem núcleo, assim como os exemplos apresentados em (90), (93) e (97). 
Por fim, tem-se a categoria semântica Razão (r), que, segundo Hengeveld e Mackenzie (2008, p.272), “pode ser considerada um tipo especial de Conteúdo Proposicional, uma vez que ela representa os pensamentos que conduzem um agente humano a agir de determinado modo." ${ }^{39}$ Dois exemplos da categoria Razão são apresentados a seguir:

(100) Não está clara a razão pela qual ele partiu.

$$
\left(\mathrm{r}_{\mathrm{i}}:\left[\left(\mathrm{f}_{\mathrm{i}}:\left[\left(\mathrm{f}_{\mathrm{j}}: \operatorname{razão}_{\mathrm{N}}\left(\mathrm{f}_{\mathrm{j}}\right)\right):\left(\mathrm{e}_{\mathrm{i}}:\left[\left(\mathrm{f}_{\mathrm{k}}:\left[\left(\mathrm{f}_{\mathrm{l}}: \operatorname{partir}_{\mathrm{V}}\left(\mathrm{f}_{\mathrm{l}}\right)\right)\left(\mathrm{x}_{\mathrm{i}}\right)_{\mathrm{A}}\right]\left(\mathrm{f}_{\mathrm{k}}\right)\right)\left(\mathrm{e}_{\mathrm{i}}\right)_{\phi}\right]\right):\left[\left(\mathrm{r}_{\mathrm{i}}\right)_{\text {Reas }}\left(\mathrm{e}_{\mathrm{i}}\right)_{\phi}\right]\right)\right]\right)\right.
$$

(101) Não está claro por que ele partiu.

$$
\left(\mathrm{r}_{\mathrm{i}}:\left(\mathrm{e}_{\mathrm{i}}:\left[\left(\mathrm{f}_{\mathrm{i}}:\left[\left(\mathrm{f}_{\mathrm{j}}: \operatorname{partir}_{\mathrm{V}}\left(\mathrm{f}_{\mathrm{j}}\right)\right)\left(\mathrm{x}_{\mathrm{i}}\right)_{\mathrm{A}}\right]\left(\mathrm{f}_{\mathrm{i}}\right)\right)\left(\mathrm{e}_{\mathrm{i}}\right)_{\phi}\right]:\left[\left(\mathrm{f}_{\mathrm{k}}:\left(\mathrm{r}_{\mathrm{i}}\right)_{\text {Reas }}\left(\mathrm{f}_{\mathrm{k}}\right)\right)\left(\mathrm{e}_{\mathrm{i}}\right)_{\phi}\right]\right)\right)
$$

Em ambos os casos, os trechos em destaque dizem respeito a orações relativas, com núcleo no primeiro caso (a palavra razão) e sem núcleo no segundo.

Os Níveis Interpessoal e Representacional, discutidos até aqui, estão relacionados com a operação de Formulação, uma vez que traduzem as intenções comunicativas em estruturas específicas subjacentes às formas linguísticas. Os Níveis Morfossintático e Fonológico estão relacionados com a operação de Codificação, uma vez que tais níveis são responsáveis por codificar as distinções representacionais e interpessoais. Como dito no início deste Capítulo, apenas os aspectos relevantes da GDF para a descrição do fenômeno em estudo são apresentados. Assim, são tratados, a seguir, alguns pontos do Nível Morfossintático, mas não são apresentadas as especificidades do Nível Fonológico, uma vez que as distinções feitas nesse nível não são relevantes para o fenômeno aqui investigado.

O Nível Morfossintático é o responsável por receber informações semânticas e pragmáticas e organizá-las em uma única representação estrutural, que será convertida em um construto fonológico no Nível Fonológico. Assim como os Níveis Interpessoal e Representacional, o Nível Morfossintático é organizado hierarquicamente. Hengeveld e

\footnotetext{
${ }^{39}$ [...] could be considered a special type of Propositional Content, as they represent the thoughts that drive a human agent to act in a certain way (HENGEVELD; MACKENZIE, 2008, p.272).
} 
Mackenzie (2008, p.291) apresentam o seguinte esquema geral e abstrato de uma Expressão Linguística, a maior unidade de análise do Nível Morfossintático:

$$
\begin{aligned}
& \left(\mathrm{Le}_{1}:\left[\left(\mathrm{Cl}_{1}:\left[(\mathrm{Xw})\left(\mathrm{Xp}_{1}:\left[(\mathrm{Xw})\left(\mathrm{Xp}_{2}\right)\left(\mathrm{Cl}_{2}\right)\right]\left(\mathrm{Xp}_{1}\right)\right)\left(\mathrm{Cl}_{3}\right)\right]\left(\mathrm{Cl}_{1}\right)\right)\right]\left(\mathrm{Le}_{1}\right)\right) \\
& \mathrm{Le}=\text { Expressão Linguística } \\
& \mathrm{Cl}=\text { Oração } \\
& \mathrm{Xp}=\text { Sintagma (do tipo } \mathrm{x}) \\
& \mathrm{Xw}=\text { Palavra (do tipo } \mathrm{x})
\end{aligned}
$$

Esse esquema mostra que a Expressão Linguística contém Orações. Cada Oração pode conter uma ou mais Palavras, um ou mais Sintagmas e uma ou mais Orações. Cada sintagma pode, da mesma forma, conter uma ou mais Palavras, um ou mais Sintagmas e uma ou mais Orações. Por fim, a Palavra também tem uma estrutura interna, que é constituída de uma série de Morfemas.

Segundo Hengeveld e Mackenzie (2008, p.308), “uma Expressão Linguística é qualquer conjunto de pelo menos uma unidade que pode ser usada independentemente." ${ }^{40}$ Nos casos em que a Expressão Linguística abriga mais de uma unidade, tais unidades constituem morfossintaticamente um conjunto, sem que uma seja parte da outra. Orações e Sintagmas podem se combinar de diferentes maneiras dentro da Expressão Linguística, conforme resume o Quadro a seguir, adaptado de Hengeveld e Mackenzie (2008, p.309):

\begin{tabular}{|l|c|c|c|}
\cline { 2 - 4 } \multicolumn{1}{c|}{} & Dependência mútua & Dependência de uma unidade & Não-dependência \\
\hline Oração & Equiordenação & Cossubordinação & Coordenação \\
\hline Sintagma & Equiordenação & Extraoracionalidade & Enumeração \\
\hline
\end{tabular}

Quadro 3. A constituição da Expressão Linguística

\footnotetext{
${ }^{40}$ A Linguistic Expression is any set of at least one unit that can be used independently (HENGEVELD; MACKENZIE, 2008, p.308)
} 
Nos casos de equiordenação, as Orações ou os Sintagmas de uma Expressão Linguística são mutuamente dependentes, como ilustram os exemplos (103) e (104), da língua Kashmiri, transcritos de Hengeveld e Mackenzie (2008, p.308):

(103) So cha t’u:t já:n geva:n yu:t mohni o:s. ela é CORR muito.boa cantar.PRS.PTCP REL Mohan era 'Ela canta assim como Mohan costumava cantar.

$\left(\mathrm{Le}_{1}:\left[\left({ }^{\mathrm{dep}} \mathrm{Cl}_{1}\right)\left({ }^{\mathrm{dep}} \mathrm{Cl}_{2}\right)\right]\left(\mathrm{Le}_{1}\right)\right)$

(104) Yuth vosta:d t'uth tsa:th.

REL professor CORR discípulo

'O discípulo é como o professor.'

$\left(\mathrm{Le}_{1}:\left[\left(\mathrm{Xp}_{1}\right)\left(\mathrm{Xp}_{2}\right)\right]\left(\mathrm{Le}_{1}\right)\right)$

Quando, em uma Expressão Linguística, uma unidade pode ser usada independentemente e a outra não, tem-se cossubordinação, entre Orações (105), e extraoracionalidade, entre Sintagma e Oração (106):

(105) Peima fitau-fe-e-te wate tepau-a-?a.

cuidadosamente jogar-PF-1/2.SG-DS NEG quebrar-3.SG-IND

'Eu o joguei cuidadosamente e ele não quebrou.'

"Mim tendo o jogado cuidadosamente, ele não quebrou."

$\left(\mathrm{Le}_{1}:\left[\left({ }^{\mathrm{dep}} \mathrm{Cl}_{1}\right)\left({ }^{\mathrm{dep}} \mathrm{Cl}_{\mathrm{n}-1}\right)\left(\mathrm{Cl}_{\mathrm{n}}\right)\right]\left(\mathrm{Le}_{1}\right)\right)$

(106) Os estudantes, eles ouviram as notícias ontem.

$\left(\mathrm{Le}_{1}:\left[\left(\mathrm{Xp}_{1}\right)\left(\mathrm{Cl}_{1}\right)\right]\left(\mathrm{Le}_{1}\right)\right)$

(Adaptados de HENGEVELD; MACKENZIE, 2008, p.308)

Finalmente, quando não há dependência entre as unidades de uma Expressão Linguística, mas a combinação dessas unidades forma uma única unidade formal, tem-se coordenação, entre Orações (107), e Enumeração, entre Sintagmas (108):

(107) O Palmeiras ganhou e o Corinthians perdeu.

$\left(\mathrm{Le}_{1}:\left[\left(\mathrm{Cl}_{1}\right)\left(\mathrm{Cl}_{\mathrm{n}-1}\right)\left(\mathrm{Gw}_{1}\right)\left(\mathrm{Cl}_{\mathrm{n}}\right)\right]\left(\mathrm{Le}_{1}\right)\right)$ 
(108) (Qual é o seu pedido?) Um Big Mac, batatas fritas e uma Coca. $\left(\mathrm{Le}_{1}:\left[\left(\mathrm{Xp}_{1}\right)\left(\mathrm{Xp}_{\mathrm{n}-1}\right)\left(\mathrm{Gw}_{1}\right)\left(\mathrm{Xp}_{\mathrm{n}}\right)\right]\left(\mathrm{Le}_{1}\right)\right)$

(Adaptados de HENGEVELD; MACKENZIE, 2008, p.309)

No que diz respeito à Oração, Hengeveld e Mackenzie (2008, p.310) apresentam a seguinte fórmula para línguas configuracionais como o inglês:

(109) $\left(\mathrm{Cl}_{1}:\left[(\mathrm{Xw})(\mathrm{Xp})_{\{\phi\}}(\mathrm{Cl})_{\{\phi\}}\right]\left(\mathrm{Cl}_{1}\right)\right)$

Nesse tipo de língua, uma Oração $(\mathrm{Cl})$ consiste de uma configuração sequenciada de Palavras $(\mathrm{Xw})$, Sintagmas $(\mathrm{Xp})$ e outras Orações (subordinadas - Cl). As Palavras da camada da Oração só podem ser gramaticais, como Conjunções e Partículas, por exemplo, uma vez que os elementos lexicais são sempre núcleos de Sintagmas no Nível Morfossintático.

A ordenação dos elementos no Nível Morfossintático é feita a partir de posições apropriadas dependendo da língua. São identificadas três posições absolutas dentro da Oração: a posição inicial $\left(\mathrm{P}^{\mathrm{I}}\right)$, a posição medial $\left(\mathrm{P}^{\mathrm{M}}\right)$ e a posição final $\left(\mathrm{P}^{\mathrm{F}}\right)$. Outras posições podem ser definidas em relação às três posições absolutas, como as posições pós-inicial $\left(\mathrm{P}^{\mathrm{I}+1}\right)$, pósmedial $\left(\mathrm{P}^{\mathrm{M}+1}\right)$ e penúltima $\left(\mathrm{P}^{\mathrm{F}-\mathrm{I}}\right)$. Todas essas posições são esquematizadas da seguinte forma:

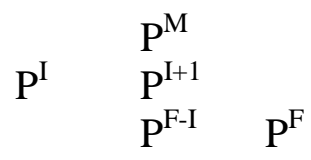

Tais posições dentro da Oração podem refletir a organização das unidades do Nível Interpessoal e do Nível Representacional ou não. Assim, segundo Hengeveld e Mackenzie (2008), há três tipos de alinhamento: i) alinhamento interpessoal, em que a organização morfossintática reflete a organização do Nível Interpessoal, em termos das funções pragmáticas (Tópico, Foco etc.) de Subatos e/ou em termos de sua referência (definitude, especificidade etc.); ii) alinhamento representacional, em que a organização morfossintática 
reflete a organização do Nível Representacional, no que diz respeito a funções semânticas (Ator, Beneficiário etc.) de categorias semânticas ou a designação delas (animacidade, pessoa etc.); iii) alinhamento morfossintático, em que a organização morfossintática tem sua própria estruturação em termos das funções sintáticas (Sujeito, Objeto) de constituintes morfossintáticos e/ou em termos de complexidade ou peso, não sendo um reflexo direto da organização dos outros níveis.

Especialmente relevante para este estudo é o alinhamento morfossintático determinado pela complexidade de um constituinte. Em português, a posição final é preferida por Orações subordinadas, uma vez que são mais complexas, como mostram os exemplos a seguir (adaptados de HENGEVELD; MACKENZIE, 2008, p.331):

(111) É uma pena que ele tenha ido embora.

(112) O homem foi embora porque ele não suporta cigarro.

Tendo em vista que as funções das Orações subordinadas apresentadas em (111) e (112) são diferentes, o que determina a posição preferida é a constituição morfossintática delas.

Em se tratando de aspectos mais internos da Oração, a marcação de pessoa no verbo, também importante para o fenômeno em estudo, pode ser feita de duas formas: por meio de referência cruzada e de concordância (de argumento). Hengeveld e Mackenzie (2008, p.350) explicam que a referência cruzada diz respeito aos casos em que "a marcação de pessoa no verbo é suficiente por si só e pode opcionalmente ser expandida por um argumento realizado lexicalmente." ${ }^{41} \mathrm{O}$ exemplo apresentado a seguir, da língua kabardian, é dado pelos autores para ilustrar esse tipo de fenômeno:

\footnotetext{
${ }^{41}[. .$.$] person marking on the verb is sufficient by itself and may optionally be expanded by a lexically realized$ argument (HENGEVELD; MACKENZIE, 2008, p.350)
} 

(113) (wa)
(as) (a-r)
Ø-q'ว-s-ž-w-Pa-ar-ś.
você
$\operatorname{mim} 3-\mathrm{ABS}$
3.ABS-AFF-1-novamente-2-dizer-PST-DECL
'Você disse isso para mim.'

(Adaptado de HENGEVELD; MACKENZIE, 2008, p.350)

Em kabardian, os prefixos ligados ao verbo são suficientes para se referir aos Participantes, mas pode haver a expressão desses participantes por meio de formas livres, como se observa em (113). Tanto as formas presas quanto as formas livres expressam Subatos Referenciais. Assim, em (113), tem-se dois Subatos Referenciais para se referir a cada Participante, o que configura casos de aposição de elementos referenciais.

Diferentemente dos casos de referência cruzada, nos casos de concordância a marcação de pessoa no verbo não é considerada um elemento referencial. Em casos de concordância, o sujeito é obrigatoriamente realizado por uma forma livre, pronominal ou lexical, e existe "um mecanismo que copia as características relevantes do Sintagma Nominal de Sujeito no verbo"42 (HENGEVELD; MACKENZIE, 2008, p350). O francês é uma das poucas línguas em que se observam casos de concordância sintática não referencial. O exemplo dessa língua dado por Hengeveld e Mackenzie (2008, p.350-351) para ilustrar um caso de concordância é apresentado a seguir:

(114) Nous chant-ons.

'Nós cantamos.'

$\left(\mathrm{Cl}_{\mathrm{i}}:\left[\left(\mathrm{Np}_{\mathrm{i}}:\left(\mathrm{Nw}_{\mathrm{i}}: / \mathrm{nu} /\left(\mathrm{Nw}_{\mathrm{i}}\right)\right)\left(\mathrm{Np}_{\mathrm{i}}\right)\right)_{\text {Subj }}\left(\mathrm{Vp}_{\mathrm{i}}:\left(\mathrm{Vw}_{\mathrm{i}}: / \int \widetilde{\mathrm{t}} /\right.\right.\right.\right.$-pres< $\left.\left.\left.<1 . \mathrm{Pl}>\left(\mathrm{Vw}_{\mathrm{i}}\right)\right)\left(\mathrm{Vp}_{\mathrm{i}}\right)\right]\left(\mathrm{Cl}_{\mathrm{i}}\right)\right)$

Na representação do exemplo (114), observa-se que a característica "primeira pessoa do plural”, copiada do sujeito, aparece ligada à expressão de tempo, com a qual se funde.

O português, à primeira vista, parece ser uma língua em que a expressão de sujeito ocorre por meio da referência cruzada, uma vez que a marcação do sujeito no verbo é por si só

\footnotetext{
${ }^{42}[. .$.$] a mechanism which copies the relevant features of the Subject Noun Phrase to the verb (HENGEVELD;$ MACKENZIE, 2008, p350).
} 
suficiente, sendo opcional a realização do sujeito por meio de formas livres, como se pode observar nos exemplos a seguir:

(115) (Eu) canto

(116) (Nós) cantamos.

Existem casos, no entanto, em que a marcação de pessoa no verbo não é suficiente para a identificação do sujeito, e a sua expressão por meio de formas livres passa a ser obrigatória, como acontece nos exemplos a seguir:

(117) Você canta

(118) Ele canta

(119) A gente canta

Vários estudos vêm mostrando que há uma tendência no português brasileiro em se manifestar o sujeito por meio de formas livres (cf. LIRA, 1982; PAREDES SILVA, 1988; DUARTE, 1993, 1995, 2003). A razão para essa tendência parece ser as mudanças no paradigma flexional do português: os pronomes de segunda pessoa do singular (tu) e do plural (vós) não são mais usados, sendo substituídos pelos pronomes "você" e "vocês", e a primeira pessoa do plural (nós) está gradualmente perdendo espaço para a expressão "a gente”.

Uma vez que tanto "você" quanto "a gente" requerem um verbo na terceira pessoa, o paradigma verbal do português brasileiro vem se tornando restrito a três formas distintas: forma marcada para a primeira pessoa do singular (eu), forma não-marcada singular (você, ele/a, a gente) e forma não-marcada plural (vocês, eles/as).

Considerando esse novo paradigma, não é possível distinguir apenas pela flexão verbal, por um lado, a segunda e a terceira pessoa do singular da primeira pessoa do plural, e, por outro lado, a segunda e terceira pessoa do plural. Tendo em vista essa reestruturação do 
paradigma flexional verbal no português brasileiro, que pede a realização de sujeito por meio de formas livres quando os verbos são conjugados nessas pessoas, não se pode dizer que no português brasileiro há apenas referência cruzada no que diz respeito à concordância de argumento. Um estudo sobre isso, levando em conta a perspectiva discursivo-funcional, ainda precisa ser feito.

Como dito anteriormente, as Orações podem ter como constituintes outras Orações. As Orações subordinadas são descritas, no Nível Morfossintático, em termos da unidade representacional ou interpessoal que representam. Em (120), por exemplo, a Oração subordinada é uma Proposição, que ocupa a posição de argumento. Em (121), tem-se um Estado-de-Coisas que ocupa a posição de modificador:

(120) O homem acredita que a esposa voltará.

$\left(\mathrm{p}_{\mathrm{i}}:\left(\mathrm{e}_{\mathrm{i}}:\left[\left(\mathrm{f}_{\mathrm{i}}:\left[\left(\mathrm{f}_{\mathrm{j}}: \operatorname{acreditar}\left(\mathrm{f}_{\mathrm{j}}\right)\right)\left(\mathrm{x}_{\mathrm{i}}:\left[\left(\mathrm{f}_{\mathrm{k}}: \operatorname{homem}\left(\mathrm{f}_{\mathrm{k}}\right)\right)\left(\mathrm{x}_{\mathrm{i}}\right)\right]\right)\left(\mathrm{p}_{\mathrm{j}}:\left(\mathrm{e}_{\mathrm{j}}:\left[\left(\mathrm{f}_{\mathrm{k}}:\left[\left(\mathrm{f}_{\mathrm{l}}: \operatorname{voltar}\left(\mathrm{f}_{\mathrm{l}}\right)\right)\right.\right.\right.\right.\right.\right.\right.\right.\right.\right.$ $\left(\mathrm{x}_{\mathrm{j}}:\left[\left(\mathrm{f}_{\mathrm{m}}\right.\right.\right.$ : esposa $\left.\left.\left.\left.\left.\left.\left.\left.\left.\left.\left.\left.\left(\mathrm{f}_{\mathrm{m}}\right)\right)\left(\mathrm{x}_{\mathrm{j}}\right)\right]\right)\left(\mathrm{f}_{\mathrm{k}}\right)\right)\right]\left(\mathrm{e}_{\mathrm{j}}\right)\right]\right)\left(\mathrm{p}_{\mathrm{j}}\right)\right)\left(\mathrm{f}_{\mathrm{i}}\right)\right)\left(\mathrm{e}_{\mathrm{i}}\right)\right]\right)\left(\mathrm{p}_{\mathrm{i}}\right)\right)$

(121) O homem saiu quando a mulher retornou.

$\left(e_{i}:\left[\left(f_{i}:\left[\left(f_{j}: \operatorname{sair}\left(f_{j}\right)\right)\left(x_{i}:\left[\left(f_{k}:\right.\right.\right.\right.\right.\right.\right.$ homem $\left.\left.\left.\left.\left.\left.\left(f_{k}\right)\right)\left(x_{i}\right)_{U}\right]\right)\right]\left(f_{i}\right)\right)\left(e_{i}\right)\right]:\left(t_{i}:\left[\left(e_{j}:\left[\left(f_{1}:\left[\left(f_{m}:\right.\right.\right.\right.\right.\right.\right.$ retornar $\left.\left(f_{m}\right)\right)\left(x_{j}:\left[\left(f_{n}:\right.\right.\right.$ mulher $\left.\left.\left.\left.\left.\left.\left.\left.\left.\left(f_{n}\right)\right)\left(x_{j}\right)\right]\right)\right]\left(f_{1}\right)\right)\left(e_{j}\right)\right]:\left[\left(t_{i}\right)\left(e_{j}\right)\right]\right)\left(e_{i}\right)\right]\right)$

(Adaptados de HENGEVELD; MACKENZIE, 2008, p.362)

Camadas do Nível Interpessoal também podem entrar no Nível Representacional e ocupar a posição de argumentos e modificadores; isso acontece quando se faz referência a unidades comunicativas. No exemplo a seguir, a Oração subordinada corresponde a um Conteúdo Comunicado que ocupa a posição de argumento:

(122) Ouvi que ele foi promovido.

$\left(\mathrm{p}_{\mathrm{i}}:\left(\mathrm{ep}_{\mathrm{i}}:\left(\mathrm{e}_{\mathrm{i}}:\left[\left(\mathrm{f}_{\mathrm{i}}:\left[\left(\mathrm{f}_{\mathrm{j}}: \operatorname{ouvir}\left(\mathrm{f}_{\mathrm{j}}\right)\right)\left(\mathrm{x}_{\mathrm{i}}\right)\left(\mathrm{C}_{\mathrm{I}}:\left[\left(\mathrm{p}_{\mathrm{j}}:\left(\mathrm{ep}_{\mathrm{j}}:\left(\mathrm{e}_{\mathrm{j}}:\left[\left(\mathrm{f}_{\mathrm{k}}:\left[\left(\mathrm{f}_{\mathrm{l}}:\right.\right.\right.\right.\right.\right.\right.\right.\right.\right.\right.\right.\right.\right.\right.$ promovido $\left.\left.\left(\mathrm{f}_{\mathrm{l}}\right)\right)\left(\mathrm{x}_{\mathrm{j}}\right)\right]$ $\left.\left.\left.\left.\left.\left.\left.\left.\left.\left.\left.\left.\left.\left(\mathrm{f}_{\mathrm{k}}\right)\right)\left(\mathrm{e}_{\mathrm{j}}\right)\right]\right)\left(\mathrm{ep}_{\mathrm{j}}\right)\right)\left(\mathrm{p}_{\mathrm{j}}\right)\right)\right]\left(\mathrm{C}_{\mathrm{i}}\right)\right)\right]\left(\mathrm{f}_{\mathrm{i}}\right)\right)\left(\mathrm{e}_{\mathrm{i}}\right)\right]\right)\left(\mathrm{ep}_{\mathrm{i}}\right)\right)\left(\mathrm{p}_{\mathrm{i}}\right)\right)$ 
A complexidade interna das Orações subordinadas descritas em termos de unidades do Nível Representacional ou Interpessoal é refletida nas estruturas oracionais no Nível Morfossintático. Tendo em vista essa forte relação entre o Nível Morfossintático e os dois níveis mais altos, as construções subordinadas são classificadas, no Nível Morfossintático, em termos das camadas interpessoais ou representacionais que estão subjacentes a elas. $\mathrm{O}$ que determina o tipo de unidade, representacional ou interpessoal, da Oração subordinada, no caso das Orações completivas, é a semântica do predicado matriz e, no caso das Orações adverbiais, é a função semântica ou a conjunção lexical que restringe as camadas com as quais a Oração subordinada pode combinar.

Subjacentes às Orações subordinadas podem estar as seguintes camadas: Movimento, Ato e Conteúdo Comunicado, do Nível Interpessoal, e Proposição, Episódio, Evento e Propriedade, do Nível Representacional. O Quadro 4, a seguir, adaptado de Hengeveld e Mackenzie (2008, p.363), apresenta exemplos de predicados que encaixam essas diferentes unidades:

\begin{tabular}{|c|l|l|}
\hline $\begin{array}{c}\text { Tipo de } \\
\text { Oração } \\
\text { complemento }\end{array}$ & \multicolumn{1}{|c|}{ Função/Significado do predicado encaixador } & \multicolumn{1}{|c|}{$\begin{array}{c}\text { Exemplo de } \\
\text { predicado }\end{array}$} \\
\hline M & Situar um Movimento em um discurso mais amplo & Concluir \\
\hline A & Relacionar Atos discursivos entre si & Adicionar \\
\hline C & Transmissão ou recepção de Conteúdo Comunicado & Ouvir \\
\hline $\mathrm{p}$ & Atitude Proposicional, Inferência & Acreditar, Parecer \\
\hline ep & Situar Episódios uns em relação aos outros & Acontecer \\
\hline $\mathrm{e}$ & Percepção Direta, Volição & Ver, Querer \\
\hline $\mathrm{f}$ & Aspecto, modalidade orientada para o Participante & Começar, Ser capaz \\
\hline
\end{tabular}

Quadro 4. Classificação das Orações complemento (adaptado de HENGEVELD; MACKENZIE, 2008, p.363)

As Orações subordinadas podem ter diferentes formas. Em língua portuguesa, de um modo geral, elas podem ou não ser introduzidas por conjunção. Nos casos de Orações 
subordinadas introduzidas por conjunções, é a presença da conjunção que marca o estatuto de construção subordinada à Oração, uma vez que esta tem as propriedades de uma Oração principal, como verbo na forma finita acompanhado por seus argumentos. Além de ligar uma Oração à outra e sinalizar o estatuto de subordinada, as conjunções também participam na expressão de significado, como se pode ver nos exemplos a seguir (adaptados de HENGEVELD; MACKENZIE, 2008, p.353):

(123) Não vi [que Pedro chegou.]

(124) Não vi [se Pedro chegou.]

(125) Maria não vem [porque Pedro está doente.]

Nos dois primeiros casos, duas conjunções são usadas para introduzir Orações subordinadas completivas: em (123), a conjunção que marca a factualidade da Oração complemento e, em (124), a conjunção se marca a não-factualidade da Oração. ${ }^{43}$ Em (125), a conjunção porque expressa a função semântica da Oração subordinada adverbial em relação à Oração principal. Com relação à ordenação dos constituintes da Oração, de acordo com Hengeveld e Mackenzie (2008), em casos como os apresentados em (123), (124) e (125), deve-se considerar que a conjunção ocorre sempre na posição $\mathrm{P}^{\mathrm{I}}$ da Oração subordinada, o que acarreta o posicionamento dos outros constituintes da Oração subordinada em posições à direita da $\mathrm{P}^{\mathrm{I}}$.

Quando não há a presença da conjunção, as Orações subordinadas, em língua portuguesa, apresentam-se na forma não-finita, ${ }^{44}$ com verbos reduzidos de infinitivo, gerúndio ou particípio, ou com nominalizações. As características das Orações subordinadas nãofinitas, de um modo geral, são: i) ausência da conjunção; ii) menos distinções de tempo, modo

\footnotetext{
${ }^{43}$ De acordo com Hengeveld (1998), uma oração factual descreve um evento considerado real da perspectiva do ponto de referência temporal da oração principal e uma oração não-factual descreve um evento considerado irreal da perspectiva do ponto de referência temporal da oração principal.

${ }^{44}$ Hengeveld e Mackenzie (2008, p.356) preferem usar o termo deranking ("redução"), para se referirem às formas não-finitas dos verbos, e balancing ("balanceamento"), para se referirem às formas finitas, porque, segundo eles, esses termos são mais apropriados translinguisticamente. Uma vez que este trabalho não tem a pretensão de estabelecer comparações entre diferentes línguas, os termos finito e não-finito, que se aplicam perfeitamente ao português, são usados.
} 
e aspecto do que nas Orações finitas (pode haver algumas distinções aspectuais na Oração subordinada, mas sua referência temporal é dependente da referência temporal da Oração principal), iii) impossibilidade de ocorrência como Oração independente. ${ }^{45}$ A seguir são apresentados três exemplos de Orações subordinadas não-finitas, com verbo reduzido de infinitivo em (126), com verbo reduzido de gerúndio em (127) e com nominalização em (128):

(126) Vi [Pedro chegar.]

(127) Vi [Pedro chegando.]

(128) Vi [a chegada de Pedro.]

Nos três casos, o Estado-de-Coisas da Oração subordinada é apresentado como simultâneo ao da Oração principal. A Oração subordinada de (127) se diferencia das outras duas no que diz respeito ao aspecto, uma vez que o emprego do gerúndio enfatiza a duração do evento (Aspecto Progressivo).

De acordo com Hengeveld e Mackenzie (2008), a forma da Oração subordinada pode ser determinada pela natureza da camada interpessoal ou representacional que está subjacente a ela. Os autores afirmam que "a partir de uma perspectiva translinguística, uma forte generalização que pode ser feita é a de que é mais provável que a Oração subordinada seja do tipo reduzida quanto mais baixa for a camada em que ela se assenta"46 (HENGEVELD; MACKENZIE, 2008, p.366). Assim, espera-se que Orações subordinadas que correspondem a Moves, Atos ou Conteúdos Comunicados, por exemplo, sejam mais comumente expressas por meio de Orações finitas, ao passo que Orações que representam Estado-de-Coisas ou Propriedades tendam a ser expressas por Orações não-finitas.

\footnotetext{
${ }^{45}$ Para um detalhamento maior das diferenças entre Orações subordinadas finitas e não-finitas (com verbos infinitivos e nominalizações), ver Santana (2010).

${ }^{46}$ From a crosslinguistic perspective, a strong generalization that can be made is that a subordinate Clause is more likely to be of the deranked type the lower the layer on which it is based (HENGEVELD; MACKENZIE, 2008, p.366).
} 


\section{A TIPOLOGIA DOS EVIDENCIAIS DE ACORDO COM A GFD}

De acordo com os princípios da GDF, tanto as formas lexicais quanto as formas gramaticais de codificação da evidencialidade são acomodadas dentro do modelo. De um modo geral, marcadores lexicais, como advérbios, por exemplo, são chamados de modificadores, e marcadores gramaticais, como afixos, por exemplo, são chamados de operadores. Modificadores e operadores podem pertencer a diferentes níveis ou camadas, dependendo da função que exercem.

Na GDF, são consideradas três categorias evidenciais: a reportatividade, a evidencialidade inferida e a percepção de evento. Cada uma dessas categorias atua em camadas diferentes, e a primeira atua em um nível diferente das outras duas, conforme se apresenta a seguir.

No Nível Interpessoal, atuam os marcadores reportativos, que servem para indicar que o Falante está retransmitindo um Conteúdo Comunicado expresso por outro Falante dentro de seu próprio Ato Discursivo. O exemplo a seguir, adaptado de Hengeveld e Mackenzie (2008, p.103), ilustra a ocorrência de dois reportativos:

(129) (...) "Eu não vou embora agora,” disse Pedro. "Mas já está tarde,” disse Maria. (...)

Em um contexto em que o Falante narra um diálogo entre Pedro e Maria, "disse Pedro" e “disse Maria” são considerados reportativos, uma vez que indicam a fonte, ou o falante real, do Conteúdo Comunicado que está entre aspas. O trecho todo deve ser analisado, no Nível Interpessoal, como contendo dois Movimentos, cada um com um Ato Discursivo. Dentro de cada Ato Discursivo, há um Conteúdo Comunicado, que aparece entre aspas, e um modificador reportativo.

No Nível Representacional, a evidencialidade ocorre nas camadas da Proposição e do Estado-de-Coisas. No primeiro caso, ela especifica a maneira como o Falante teve acesso à 
informação contida no Conteúdo Proposicional: i) por meio de inferência com base em evidência sensorial; ii) com base em inferência derivada de conhecimento existente; e iii) com base em conhecimento geral acumulado na comunidade (HENGEVELD; MACKENZIE, 2008, p.155). A seguir, é apresentado um exemplo de evidencialidade na camada da Proposição, da língua pawnee (adaptado de HENGEVELD; MACKENZIE, 2008, p.155):

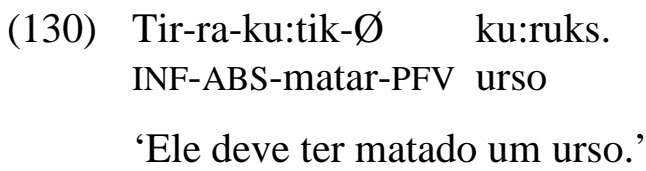

Nesse caso, o operador tir indica que o Falante inferiu que alguém matou um urso.

Há, ainda, na camada da Proposição, um outro tipo evidencial, chamado de genericidade por Hengeveld e Mackenzie (2008, 156). Segundo os autores, por meio desse tipo evidencial, um Conteúdo Proposicional é apresentado como sendo parte do conhecimento compartilhado em uma comunidade. Em outros estudos, esse tipo evidencial é chamado de domínio comum (cf. DALL'AGLIO-HATTNHER, 2001; VENDRAME, 2005).

Na camada do Estado-de-Coisas, a evidencialidade corresponde à Percepção de Evento, uma categoria que marca se o Estado-de-Coisas foi testemunhado diretamente pelo Falante por meio de algum sentido. No exemplo a seguir, da língua tariana, observa-se a percepção de um Evento codificada por um operador de percepção visual:

$\begin{array}{llll}\text { (131) Waha } & \text { ikasu-nuku } & \text { hĩ-nuku } & \text { alia-naka. } \\ \text { nós } & \text { agora-TOP.NON.A/S } & \text { DEM.ANIM-TOP.NON.A/S } & \text { EX-VIS.PRS } \\ & \text { 'Aqui estamos nós agora (conversando).' } & \end{array}$

(Adaptado de HENGEVELD; MACKENZIE, 2008, p.177)

Nesse caso, o morfema naka é usado para indicar que o Falante está vendo o Estado-deCoisas descrito. Observa-se que, como ocorre nos sistemas evidenciais de muitas línguas, o morfema indicador de evidencialidade indica simultaneamente tempo. 
Essa tipologia também contempla os sentidos evidenciais codificados por outras formas além de modificadores e operadores, como é o caso dos verbos de percepção. Ao se relacionarem as características dos verbos de percepção evidenciais, discutidas na seção 2 do Capítulo II, com a implementação da gramática e a tipologia dos evidenciais, propostas pela GDF e apresentadas neste Capítulo, é possível observar como as intenções comunicativas determinam as unidades linguísticas e de que forma estas são organizadas de acordo com a realidade que descrevem.

Em outras palavras, se o Falante deseja transmitir uma informação que foi apreendida por meio de um de seus sentidos, ele pode fazer isso de três formas, dependendo da natureza da informação obtida e do modo como ela foi percebida, que está relacionado com o sentido envolvido na percepção. O Falante pode, por meio de verbos de percepção, veicular uma informação linguística lida ou ouvida, uma informação que é resultado de um cálculo mental ou uma informação que é resultado de uma percepção física. Essas três intenções comunicativas se relacionam com diferentes tipos de evidencialidade e as diferenças entre elas se refletem na descrição das unidades linguísticas dentro dos níveis da GDF.

A tipologia dos evidenciais proposta em Vendrame (2005), brevemente exposta na seção 2 do Capítulo I, apesar de não ter sido organizada a partir de uma estrutura hierárquica, não é conflitante com a tipologia proposta por Hengeveld e Mackenzie (2008). Em Vendrame (2005), os tipos evidenciais são diferenciados em duas instâncias (a fonte da informação e o modo de obtenção da informação), que estão de certa forma pressupostas na organização hierárquica dos tipos evidenciais de Hengeveld e Mackenzie (2008). A separação dessas duas instâncias na pesquisa de Vendrame (2005) foi importante porque os usos evidenciais dos diferentes tipos de predicados considerados no estudo (verbos de dizer, de conteúdo proposicional, de percepção mental e de conhecimento) se caracterizam, em primeiro lugar, pelo tipo de fonte da informação, sendo o modo de obtenção da informação relevante para 
alguns tipos evidenciais (evidencialidade atestada e inferida), mas não para outros (evidencialidade relatada e de domínio comum).

No presente estudo, ao contrário, a instância que parece prevalecer é a do modo de obtenção da informação. Em outras palavras, a expressão da evidencialidade por meio de verbos de percepção focaliza o modo como o Falante obteve a informação: por meio de algum tipo de percepção, e não necessariamente a fonte da informação. Nos casos de evidencialidade reportativa expressos por meio de verbos de percepção, a fonte da informação pode não ser expressa e, nos casos de evidencialidade inferida e de percepção de evento, a fonte da informação é o próprio sujeito da percepção, ou seja, o Falante. Com relação à evidencialidade de domínio comum, os verbos de percepção não se prestam à sua expressão justamente pelo fato de o modo de obtenção desse tipo de evidencialidade dificilmente poder ser recuperado (cf. VENDRAME, 2005 para mais detalhes sobre esse tipo de evidencialidade).

Isso posto, e considerando a expectativa de natureza teórica deste trabalho, que é a de demonstrar a adequação da abordagem em níveis e camadas da GDF para o estudo da evidencialidade em língua portuguesa, adotou-se a tipologia dos evidenciais proposta por Hengeveld e Mackenzie (2008). Optou-se, no entanto, por utilizar o termo "evidencialidade direta" em vez de "percepção de evento", uma vez que o termo utilizado por Hengeveld e Mackenzie é amplo e pode abranger casos de percepção que não se configuram como casos de evidencialidade. Como visto na seção 2 do Capítulo II, a oração a seguir, por exemplo, pode ser considerada um caso de percepção de evento, mas não um caso de evidencialidade direta:

Pedro viu as crianças correndo.

Como discutido no Capítulo II, nesse caso, há apenas a indicação do que Pedro viu, da percepção do evento por ele. Como vem sendo discutido ao longo deste trabalho, a 
evidencialidade expressa por meio dos verbos de percepção deve necessariamente envolver a percepção do Falante. Dessa forma, no Capítulo V, dedicado à análise dos dados, são discutidas as características semântico-pragmáticas e morfossintáticas específicas dos verbos ver, ouvir e sentir quando expressam evidencialidade reportativa, inferida e direta. 


\section{CAPÍTULO IV}

\section{UNIVERSO DA PESQUISA E PROCEDIMENTOS METODOLÓGICOS}

\section{INTRODUÇÃO}

Este Capítulo apresenta os procedimentos metodológicos adotados nesta pesquisa. $\mathrm{Na}$ seção 1, apresenta-se um detalhamento de como os três verbos, ver, ouvir e sentir, foram selecionados. Além disso, nessa mesma seção, são apresentadas as restrições que foram consideradas na distinção entre os usos desses verbos como simples verbos de percepção e os usos deles como verbos de percepção evidenciais. Na seção 2, é caracterizado o universo linguístico de onde os dados foram retirados e são apresentados os procedimentos de busca utilizados. Na seção 3, são especificados os critérios considerados durante a análise dos dados.

\section{DELIMITAÇÃO DO OBJETO DE ESTUDO}

A escolha dos verbos ver, ouvir e sentir foi feita com a ajuda dos mapas semânticos, um modelo metodológico relativamente recente que tem sido utilizado com o intuito de representar geometricamente relações semânticas entre diferentes usos ou funções de itens gramaticais e lexicais (cf. CROFT, 2001; 2003; HASPELMATH, 2003). Essa metodologia, quando aplicada a uma língua em particular, facilita a visualização de similaridades e diferenças de sentido de itens gramaticais e lexicais. Neste estudo, esse método foi usado com a intenção de se identificarem verbos de percepção relacionados com a maior variedade possível de usos evidenciais.

Em um estudo sobre os verbos de percepção em língua portuguesa a partir de uma 
perspectiva funcional (BRAGA et al., em preparação), ${ }^{47}$ foram buscados, em diferentes dicionários, verbos cujos significados se relacionassem com cada um dos cinco sentidos: visão, audição, olfato, paladar e tato. Esses verbos foram organizados de acordo com o tipo de percepção que exprimem e a categoria semântica dos complementos que eles podem tomar como segundo argumento. Os resultados dessa organização estão reunidos no Quadro 5, em que o sinal "+" indica que é possível a ocorrência da categoria semântica como complemento do verbo e o sinal “-” indica que a ocorrência não é possível:

\begin{tabular}{|c|c|c|c|c|c|c|}
\hline \multirow{2}{*}{$\begin{array}{c}\text { Tipo de } \\
\text { percepção }\end{array}$} & \multirow{2}{*}{$\begin{array}{l}\text { Verbo de } \\
\text { percepção }\end{array}$} & \multicolumn{5}{|c|}{ Categoria semântica do complemento de acordo com a GDF } \\
\hline & & Propriedade & Indivíduo & $\begin{array}{c}\text { Estado- } \\
\text { de-Coisas }\end{array}$ & $\begin{array}{c}\text { Conteúdo } \\
\text { Proposicional }\end{array}$ & $\begin{array}{c}\text { Conteúdo } \\
\text { Comunicado }\end{array}$ \\
\hline \multirow{8}{*}{$\begin{array}{l}\text { Percepção } \\
\text { visual }\end{array}$} & Ver & + & + & + & + & + \\
\hline & Observar & + & + & + & + & - \\
\hline & Notar & + & + & + & + & - \\
\hline & Perceber & + & + & + & + & - \\
\hline & Avistar & + & + & + & + & - \\
\hline & Visualizar & + & + & + & + & - \\
\hline & Enxergar & + & + & + & + & - \\
\hline & Olhar & + & + & + & - & - \\
\hline \multirow{3}{*}{$\begin{array}{l}\text { Percepção } \\
\text { auditiva }\end{array}$} & Ouvir & + & + & + & + & + \\
\hline & \begin{tabular}{|l|} 
Escutar \\
\end{tabular} & + & + & + & + & + \\
\hline & Perceber & + & - & - & - & - \\
\hline \multirow{6}{*}{$\begin{array}{l}\text { Percepção } \\
\text { gustativa }\end{array}$} & Sentir & + & + & + & + & - \\
\hline & Perceber & + & + & + & + & - \\
\hline & Degustar & + & + & - & - & - \\
\hline & Saborear & + & + & - & - & - \\
\hline & Provar & + & + & - & - & - \\
\hline & Experimentar & + & + & - & - & - \\
\hline \multirow{6}{*}{$\begin{array}{l}\text { Percepção } \\
\text { tátil }\end{array}$} & Sentir & + & + & + & + & - \\
\hline & Perceber & + & + & + & + & - \\
\hline & Palpar & + & + & - & - & - \\
\hline & \begin{tabular}{|l|} 
Tatear \\
\end{tabular} & + & + & - & - & - \\
\hline & Apalpar & + & + & - & - & - \\
\hline & Tocar & + & + & - & - & - \\
\hline \multirow{3}{*}{$\begin{array}{l}\text { Percepção } \\
\text { olfativa }\end{array}$} & Sentir & + & + & + & + & - \\
\hline & Perceber & + & + & + & + & - \\
\hline & Cheirar & + & + & - & - & - \\
\hline
\end{tabular}

Quadro 5. Verbos de percepção e categoria semântica do complemento (BRAGA et al., em preparação)

\footnotetext{
${ }^{47}$ Trata-se de pesquisa realizada em conjunto com Maria Luiza Braga, Kees Hengeveld e Edson R. F. de Souza, na Universidade de Amsterdã, paralelamente ao desenvolvimento do projeto de doutorado sanduíche durante o período de setembro de 2007 a agosto de 2008. O artigo com os resultados dessa pesquisa encontra-se em fase final de redação.
} 
A título de ilustração, é apresentado, a seguir, um exemplo de cada tipo de complemento encaixado em alguns verbos de percepção. ${ }^{48}$ Em (132), o verbo experimentar exprime a percepção gustativa de uma Propriedade (o sabor de um sorvete):

(132) A série Häagen-Dazs Reserve está bem interessante. Já experimentamos o sabor romã com chocolate, que foi aprovadíssimo por todos.

Em (133), o complemento do verbo cheirar, que codifica a percepção olfativa, é do tipo Indivíduo:

(133) Cheirei aquele homem, tão lindo, tão especial.

O verbo sentir, em (134), usado para exprimir percepção tátil ${ }^{49}$, introduz um Estado-deCoisas como complemento:

(134) E hoje tenho mais uma novidade, senti ela mexer de verdade. Já sentia umas cosquinhas em baixo na barriga, mas hoje sentada aqui na frente do computador, senti uma passada rápida mais forte, como se fosse o bracinho, ai que felicidade.

Em (135), o verbo ver é usado em sentido abstrato, denotando percepção mental e encaixando um Conteúdo Proposicional como complemento:

(135) Vi que ficaram meio chateados comigo e saíram.

Finalmente, em (136), há um exemplo de complemento do tipo Conteúdo Comunicado encaixado no verbo de percepção auditiva ouvir:

(136) Durante a transmissão do jogo São Paulo x Boca Júniors ouvi que o Flá tá negociando com o Alex Dias para o ano quem vem.

\footnotetext{
${ }^{48}$ Os exemplos de (132) a (136) foram retirados de Braga et al. (em preparação).

${ }^{49}$ Por tato se entende o sentido por meio do qual se conhece ou se percebe, usando o corpo, forma, consistência, peso, temperatura, aspereza etc. de outro corpo ou de algo. Assim, a percepção tátil pode ocorrer pelo toque ou aproximação do objeto alvo de percepção em qualquer parte, externa ou interna, do corpo.
} 
Correlacionando os resultados apresentados no Quadro 5 com a tipologia dos evidenciais proposta pela GDF, é possível depreender que nem todos os verbos que constam desse Quadro podem ser usados na expressão da evidencialidade, uma vez que muitos deles só encaixam complementos do tipo Propriedade e Indivíduo, e a evidencialidade, como discutido no Capítulo III, atua nas camadas do Estado-de-Coisas, da Proposição e do Conteúdo Comunicado. Assim, do universo de verbos pesquisados em Braga et al., foram selecionados somente aqueles que aceitam como complemento essas categorias semânticas:

\begin{tabular}{|c|c|c|c|c|}
\hline \multirow{2}{*}{$\begin{array}{c}\text { Tipo de } \\
\text { percepção }\end{array}$} & \multirow{2}{*}{$\begin{array}{l}\text { Verbo de } \\
\text { percepção }\end{array}$} & \multicolumn{3}{|c|}{ Categoria semântica do complemento de acordo com a GDF } \\
\hline & & Estado-de-Coisas & $\begin{array}{c}\text { Conteúdo } \\
\text { Proposicional }\end{array}$ & $\begin{array}{l}\text { Conteúdo } \\
\text { Comunicado }\end{array}$ \\
\hline \multirow{7}{*}{$\begin{array}{l}\text { Percepção } \\
\text { visual }\end{array}$} & Ver & + & + & + \\
\hline & Observar & + & + & - \\
\hline & Notar & + & + & - \\
\hline & Perceber & + & + & - \\
\hline & Avistar & + & + & - \\
\hline & Visualizar & + & + & - \\
\hline & Enxergar & + & + & - \\
\hline \multirow{2}{*}{$\begin{array}{l}\text { Percepção } \\
\text { auditiva }\end{array}$} & Ouvir & + & + & + \\
\hline & Escutar & + & + & + \\
\hline \multirow{2}{*}{$\begin{array}{l}\text { Percepção } \\
\text { gustativa }\end{array}$} & Sentir & + & + & - \\
\hline & Perceber & + & + & - \\
\hline \multirow{2}{*}{$\begin{array}{l}\text { Percepção } \\
\text { tátil }\end{array}$} & Sentir & + & + & - \\
\hline & Perceber & + & + & - \\
\hline \multirow{2}{*}{$\begin{array}{l}\text { Percepção } \\
\text { olfativa }\end{array}$} & Sentir & + & + & - \\
\hline & Perceber & + & + & - \\
\hline
\end{tabular}

Quadro 6. Verbos de percepção evidenciais e categoria semântica do complemento

Buscando verbos que pudessem ser usados em uma maior variedade de contextos evidenciais, uma nova seleção foi feita a partir dos verbos presentes no Quadro 6. Como se pode observar, dentre os verbos de percepção visual, apenas o verbo ver pode ocorrer com os três tipos de complemento, sendo o único, portanto, desse subgrupo de verbos, que pode servir à expressão dos três tipos de evidencialidade e por isso foi escolhido para ser analisado no presente estudo. 
Com relação aos verbos que expressam percepção auditiva, apesar de tanto ouvir quanto escutar poderem encaixar os três tipos de complemento, apenas ouvir foi selecionado porque o traço [+ controle] exibido pelos sujeitos de escutar em alguns contextos não é compatível com a expressão da evidencialidade. Como dito na seção 2 do Capítulo II, o ato de percepção intencional não serve de fonte da informação, apenas indica a intenção do Falante em observar o Estado-de-Coisas que descreve. ${ }^{50}$

Com relação aos outros três tipos de percepção, gustativa, olfativa e tátil, como se pode observar no Quadro 6, os verbos sentir e perceber são usados, independentemente do sentido envolvido na percepção, com complementos do tipo Estado-de-Coisas e Conteúdo Proposicional. A opção pelo verbo sentir deve-se ao fato de ele exprimir percepções que são mais puramente físicas do que o verbo perceber, quando ambos encaixam Estado-de-Coisas. Em outras palavras, enquanto o sentido de sentir está relacionado com a descrição de uma sensação física, o de perceber se relaciona com a aquisição de conhecimento por meio da percepção. Pode-se dizer então que, apesar de ambos poderem ser usados em contextos mais abstratos (encaixando complemento do tipo proposicional), quando se trata de contextos mais concretos, de percepção física, o verbo sentir é prototípico.

Além da camada interpessoal ou representacional com a qual os verbos de percepção se relacionam em seus usos evidenciais, outros aspectos devem ser observados quando se analisa a natureza evidencial de uma estrutura. Conforme foi exposto no Capítulo II, quando os verbos de percepção apresentam pessoa do sujeito diferente da primeira pessoa do singular, tempo verbal diferente do presente ou passado e negação, eles não se prestam à expressão da evidencialidade. Assim, alguns usos desses verbos não foram considerados na busca dos dados, por não estarem relacionados com a evidencialidade. Exemplos desses usos não evidenciais dos verbos de percepção são apresentados a seguir:

\footnotetext{
${ }^{50}$ Um estudo mais aprofundado dos usos evidenciais dos verbos ouvir e escutar ainda precisa ser feito. Apesar da diferença entre esses verbos no que diz respeito à intencionalidade do sujeito, em alguns casos, eles parecem ser intercambiáveis e igualmente evidenciais, como é o caso do exemplo apresentado em (136).
} 
(137) Os pais da menina a viram sair precipitadamente da água antes de desmaiar na praia de Umagico, na península de Cap York. ${ }^{51}$

(http://verdadeabsoluta.net/triste/agua-viva-gigante-mata-crianca-na-australia)

Em (137), o verbo ver se encontra na terceira pessoa do plural. Tem-se, nesse caso, o relato de uma percepção por parte do referente-sujeito da oração matriz, e não por parte do falante. $\mathrm{O}$ uso evidencial de uma construção deve necessariamente remeter à maneira como o falante obteve a informação, o que explica a obrigatoriedade da primeira pessoa em construções evidenciais com verbos de percepção.

Com relação ao tempo verbal, muitos estudos mostram que são raros os casos de línguas que expressam evidencialidade no futuro. O tempo de um verbo evidencial normalmente marca quando a informação foi adquirida, por isso a evidencialidade está fortemente relacionada aos tempos do presente e do passado. Um verbo de percepção no futuro, como em (138), por exemplo, não possibilita uma leitura evidencial da construção, uma vez que não expressa o modo como o falante obteve a informação.

(138) Um dia verei minha mãe se casar também. (http://www.fotolog.com.br/betterthandroug/41522210)

A negação do predicado matriz também bloqueia a leitura evidencial de uma construção, mesmo que ela esteja em primeira pessoa:

(139) Estava em casa e vi este avião voando baixo, mas não vi ele cair. (http://www.espumoso.net/folha/historia/salto2005-2.html)

Em construções com verbo de percepção negado, como acontece em (139), o que se tem é exatamente o contrário do que uma construção evidencial deve expressar, ou seja, em (139), nega-se que o falante tenha tido algum tipo de percepção do evento descrito na oração

\footnotetext{
${ }^{51}$ Nas ocorrências retiradas da Internet, para garantir uma melhor legibilidade, foram corrigidos problemas de ortografia, uma vez que tal correção não interferiria na descrição do fenômeno em estudo.
} 
complemento. De fato, em muitas línguas, a evidencialidade não ocorre sob o escopo da negação.

\section{PROCEDIMENTOS DE BUSCA DOS DADOS}

Esta pesquisa, como demonstrado no Capítulo III, tem como base teórica a GDF. Como em qualquer pesquisa funcionalista, subjacente à análise aqui proposta está o princípio de que a função primordial da língua é a comunicação ou, nas palavras de Dik (1997a, p.3), a

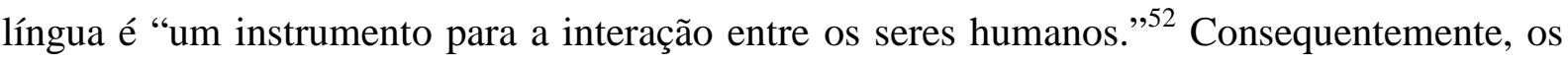
dados aqui considerados correspondem a produções linguísticas autênticas.

Uma vez que o objetivo principal deste trabalho é o de descrever os usos evidenciais dos verbos ver, ouvir e sentir em língua portuguesa ${ }^{53}$ e não o de descrever o comportamento desses verbos em determinado tipo de texto, o corpus desta pesquisa não foi determinado previamente ao início da busca dos dados. Com a intenção de ampliar de modo considerável o universo de textos de onde os dados pudessem ser extraídos, eles foram buscados na Internet.

Conforme demonstrado na seção anterior, com base na literatura sobre evidencialidade, foram levantadas hipóteses sobre a configuração de estruturas com os verbos ver, ouvir e sentir que pudessem permitir uma leitura evidencial. Considerando tais hipóteses, foram buscados, na Internet, usos desses verbos em primeira pessoa do singular, no presente e no passado e em contextos afirmativos com o auxílio da ferramenta de busca Google. Utilizando o mecanismo de pesquisa avançada oferecido pela ferramenta, tais usos dos verbos de percepção foram buscados somente em páginas escritas em português e no Brasil.

Após um primeiro levantamento dos dados, observou-se que a grande maioria das ocorrências encontradas eram provenientes de blogs e fóruns de discussão. A fim de saber se

\footnotetext{
${ }^{52}[\ldots]$ an instrument for social interaction among human beings (DIK, 1997a, p.3).

53 Apesar de o material de análise conter apenas dados do português brasileiro, acredita-se que a descrição aqui empreendida também se aplique a dados de outras variedades do português.
} 
haveria uma motivação para a maioria dos dados ter sido encontrada nesses dois tipos de texto ou se isso aconteceu simplesmente porque eles são tipos de textos bastante frequentes na Internet, buscou-se entender as características de cada um.

De acordo com Komesu (2004, p.111), o termo blog vem de weblog, expressão que pode ser traduzida como "arquivo na rede". Os blogs surgiram em agosto de 1999 com a utilização do software Blogger, produzido pela empresa do norte-americano Evan Willians para ser uma alternativa popular para publicação de textos on-line. Apesar de o software não ter sido concebido para a criação de blogs ou "diários digitais", o Blogger se tornou amplamente conhecido por ser utilizado para esse fim. Komesu (2004, p.112) observa que os blogs, por projetarem uma imagem estereotipada das pessoas que escrevem sobre si, narrando acontecimentos íntimos muitas vezes, inserem-se na prática diarista. No entanto, apresentam algumas características que os distanciam dos diários tradicionalmente escritos, como, por exemplo, a inserção de imagens e de sons para compor os textos, a rápida atualização e manutenção dos escritos na rede, além da interatividade com os leitores das páginas pessoais.

O fórum de discussão é uma ferramenta para páginas da Internet que tem como objetivo promover o debate sobre assuntos diversos por meio de mensagens publicadas pelos usuários da rede. A interatividade nos fóruns é mais explícita e sistemática do que nos blogs. Os textos dos blogs podem suscitar uma reação do leitor, que ocorre, publicamente, na forma de comentários publicados no mesmo blog, se o autor permitir, ou por meio de publicações em outros blogs, com a utilização de links apontando para o primeiro blog. Tal interação pode também ocorrer de maneira mais reservada, na forma de e-mails enviados ao autor do blog. Nos fóruns, a interação é característica fundamental, pois quem inicia um debate espera necessariamente reações dos leitores. Tais reações sempre aparecem na mesma página em que é publicado o texto que inicia o debate. 
De fato existem algumas relações que podem ser estabelecidas entre a evidencialidade expressa pelos verbos de percepção e os dois tipos de texto em que a maioria desses verbos foi encontrada na Internet. Tendo em vista que os verbos de percepção envolvem necessariamente uma exteriorização de algum tipo de apreensão pelos sentidos por parte do falante, nos blogs eles são usados em narrativas para especificar os mais diversos tipos de percepção, em comentários para expressar pontos de vista, em exposição de fatos, para fundamentá-los etc.; nos fóruns eles normalmente especificam a percepção de alguém sobre algum fato ou produto sobre o qual se pede uma opinião, apresenta-se uma reclamação, faz-se um elogio etc.

Durante uma análise preliminar dos dados encontrados na Internet, levantou-se a hipótese de que o contexto de interação face a face, em que há o compartilhamento do mesmo espaço físico entre os interlocutores, pudesse propiciar usos evidenciais dos verbos de percepção diferentes daqueles encontrados no material escrito. Decidiu-se, assim, estender a busca de dados também para textos de língua falada. O banco de dados Iboruna foi escolhido pela variedade de tipos de textos que apresenta. Esse banco de dados é composto por dois tipos de amostras: amostra censo, que reúne 152 entrevistas orais controladas sociolinguisticamente, e amostra de interação dialógica, que comporta 11 gravações coletadas secretamente em situações livres de interação social. Cada uma das 152 amostras que compõem a amostra censo contém cinco tipos de textos: i) narrativa de experiência (NE), em que o informante conta algo que aconteceu em sua vida, ii) narrativa recontada (NR), em que o informante fala sobre algo que lhe foi contado por outra pessoa, iii) descrição de local (DE), em que o informante descreve determinado lugar, iv) relato de procedimento (RP), em que o informante explica como fazer algo, e v) relato de opinião (RO), em que o informante apresenta uma opinião pessoal sobre algum fato ou sobre alguém. Das amostras de interação dialógica participam de dois a cinco informantes, além do documentador, que, em alguns casos, também participa da interação. 
É importante ressaltar que não se pretende, com a busca de dados em textos escritos e orais, caracterizar os tipos de evidencialidade codificados pelos verbos de percepção em termos da dicotomia fala $\mathrm{x}$ escrita. Com o levantamento de dados nesses diferentes tipos de textos, que se realizam em situações de interação distintas, busca-se, simplesmente, diversificar os tipos de contextos em que os verbos de percepção em seus usos evidenciais podem ocorrer. Da mesma forma, não se pretende caracterizar os usos evidenciais no português falado no interior paulista. Uma vez que a evidencialidade, a partir do ponto de vista aqui adotado, não constitui um fenômeno variável, acredita-se que os tipos evidenciais expressos pelos verbos de percepção estão mais relacionados com o tipo de interação e o contexto linguístico e situacional envolvidos do que com a região dos falantes, seu sexo, idade, nível de escolaridade ou profissão.

Levando em conta o que foi exposto, depreende-se que a metodologia empregada nesta pesquisa condiz com a que Tognini-Bonelli (2001, p.65) denominou "baseada em corpus" (corpus-based). Segundo a autora, essa metodologia se utiliza "do corpus principalmente para esclarecer, testar ou exemplificar teorias e descrições" ${ }^{, 54}$ (TOGNINIBONELLI, 2001, p.65). Assim, neste trabalho, a partir do ponto de vista teórico da GDF, busca-se caracterizar a evidencialidade expressa por meio dos verbos ver, ouvir e sentir, tomando como base um material de análise de língua real.

O termo "material de análise" é preferível neste estudo porque a noção de corpus, como uma coleção de textos "selecionados e organizados de acordo com um critério linguístico explícito para ser usado como uma amostra da língua"55 (EAGLES, 1994 apud TOGNINI-BONELLI, 2001, p.53), aplica-se apenas parcialmente ao universo de textos analisados neste trabalho. Como explicado anteriormente, parte dos dados desta pesquisa foi

\footnotetext{
${ }^{54}[\ldots]$ of the corpus mainly to expound, test or exemplify theories and descriptions (TOGNINI-BONELLI, 2001, p.65).

${ }_{55}[\ldots .$.$] selected and ordered according to explicit linguistic criteria in order to be used as a sample of the$ language (EAGLES, 1994 apud TOGNINI-BONELLI, 2001, p.53).
} 
buscada em um banco de dados de língua oral, que configura um corpus, mas a outra parte foi buscada na Internet. Do levantamento de dados da Internet resultou um conjunto de trechos de textos ou textos completos que necessariamente apresentam pelo menos uma ocorrência de um dos três verbos de percepção (ver, ouvir e sentir) usado em um contexto que pode propiciar a leitura evidencial. Essa coleção de trechos e textos, presume-se, não pode ser chamada de corpus, no sentido acima citado.

É importante ressaltar ainda que a análise aqui empreendida não se assenta em parâmetros quantitativos, mas nos traços formais e funcionais que caracterizam os valores evidenciais dos verbos de percepção aqui analisados.

\section{CRITÉRIOS DE ANÁLISE DOS DADOS}

Após o levantamento de ocorrências em que os verbos ver, ouvir e sentir permitem leitura evidencial, foi empreendida a análise dessas ocorrências de acordo com o modelo da GDF, de modo a caracterizar os diferentes tipos de contextos sintático-semânticos em que os verbos assumem valor evidencial. Para fazer tal análise, foram considerados os seguintes critérios:

a) Acepções dos verbos "ver", "ouvir" e "sentir"

Os verbos de percepção são, conforme discutido no Capítulo II, altamente polissêmicos. Dentre os vários significados dos três verbos considerados neste estudo, os que se relacionam com a evidencialidade ${ }^{56}$ são:

\footnotetext{
${ }^{56}$ Os significados atribuídos aos verbos de percepção ver, ouvir e sentir estão de acordo com o Dicionário gramatical de verbos do Português Contemporâneo (BORBA, 1990) e o Dicionário Houaiss da Língua Portuguesa (HOUAISS, VILLAR, 2001). Os exemplos dos diferentes significados são do corpus sob análise.
} 
i) ver com significado concreto de perceber pela visão:

(140) Vi eles correndo e comecei a ouvir o carro da polícia chegando também. (http://diariodochile.blogspot.com/2008/06/carta-um-irmao-distante-o-pas-dos.html)

ii) ver com significado concreto de perceber pela audição:

(141) Linda, eu estou falando pelo que eu vejo. Quando o Mark terrível falava mal do Max, você não via, aí hoje vejo ele falando besteira, vejo uma meia dúzia de pessoas dando parabéns pelas besteiras dele. (http://todeolhobbbs.blogspot.com/2009/11/respeito-e-o-quefalta.html)

iii) ver com significado abstrato de se dar conta de algo:

(142) "EU VÔ(u) PO AUSTA... eu vim dirigin(d)o eu vô(u) dirigin(d)o daqui lá" - aí levô(u) eu po Austa (inint.) aí fomo(s) pro Austa... eu vi que a viatura num ligava a sire::ne... tava devagar - "moço cê tá indo por onde?" - - "eu tô indo pela Murchid" eu falei - "LIGA ESSA SIRENE QUE EU VÔ MORRÊ(r) MOÇO (AC-027, L.32-36)

iv) ver com significado abstrato de chegar à conclusão de algo:

(143) cê pode tê(r) certeza que cê num encontra um marido bom"- e eu num queria nem sabê(r) respondia pra ela... foi o sofrimento pra ela que eu vejo que eu passei pra ela... aí depois que eu fiquei mais mocinha... fui pon(d)o na cabeça eu falei (AC-062, L.32-35)

v) ouvir com significado concreto de perceber pela audição de som não-articulado:

(144) Já no centro, perto do trabalho, ouço passarinhos cantando. (http://fabriani.com/?m=200801)

vi) ouvir com significado abstrato de perceber pela audição de som articulado:

(145) Estou reproduzindo, não sei se é verdade, mas ouço que as escolas portuguesas acham que o português do Brasil é uma língua menor... Para criança portuguesa não é recomendável ouvir o português do Brasil.

(http://www.gafieiras.com.br/Display.php?Area=Entrevistas\&SubArea=EntrevistasPartes\&ID=31\&ID Artista $=30 \& \operatorname{css}=1 \&$ ParteNo $=26$ )

vii) sentir com significado concreto de experimentar sensação tátil:

(146) Quanto às tremidinhas também já senti várias vezes. Mas, gente, fiquei tão feliz agora. SENTI ELA MEXER DE VERDADE! Agorinha mesmo. Nada brusco... uma cosquinha... mas que deu para ter certeza que é ela.

(http://www.e-familynet.com/phpbb/vcs-ja-sentem-o-bebe-mexer--vt95644.html) 
viii) sentir com significado concreto de experimentar sensação olfativa:

(147) Ao entrar na casa, senti o cheiro de sangue impregnar minhas narinas. Sangue quase seco. O desespero tomou conta de mim. Acendi a luz e vi as empregadas mortas, com expressões misturadas entre surpresa e dor. (http://www.fanfiction.net/s/4139087/1/Palavras)

ix) sentir com significado concreto de experimentar o gosto de algo:

(148) - Sasuke... - ouvi meu nome, de novo - Este é o sabor do sangue Uchiha. Me falou, rapidamente eu senti sua mão viscosa e escorregadia, em meu pescoço. Com plena certeza de que me mataria, fechei os olhos. Um beijo voraz e cruel foi o que me deu. Senti o gosto de sangue misturar-se com minha saliva e descendo como ácido por minha garganta. As lágrimas caíram de novo, enquanto ficava sem ar.

- Sentiu o gosto Sasuke? Este é o gosto do seu sangue. Sangue que você não merece. (http://www.fanfiction.net///4139087/1/Palavras)

$\mathrm{x})$ sentir com significado abstrato de chegar à conclusão de algo:

(149) O mundo do futebol requer equilíbrio. Um dia estamos no topo, no outro estamos em baixa. Sinto que fiz a escolha certa em voltar para o Brasil e também em vir para o Botafogo. (http://esportes.terra.com.br/futebol/estaduais/2010/noticias/0,,OI4249379-EI14479,00Senti+que+o+Botafogo+poderia+ser+minha+nova+casa+diz+Caio.html)

b) Natureza semântica da informação

Uma das propriedades definidoras da evidencialidade, como foi visto na seção 2 do Capítulo II, é a necessidade de haver, em enunciados que apresentam valor evidencial, duas proposições, uma que introduz a informação que o falante deseja veicular e a outra que apresenta a fonte da informação veiculada. Nos casos em que os verbos de percepção assumem valor evidencial, eles também informam o modo como a informação foi adquirida, se foi por meio da percepção física a partir de algum sentido ou por meio de uma inferência, baseada em algum tipo de evidência, experiência, fatos.

Devido à polissemia dos verbos de percepção, a identificação do tipo de evidencialidade, em muitos casos, depende também do conteúdo referencial da informação veiculada, que pode fazer referência a um conteúdo verbal perceptível por meio da visão ou 
da audição (150), a um conteúdo não-verbal perceptível por meio de qualquer um dos cinco sentidos (151), ou a um resultado de um cálculo mental do falante (152):

(150) Em conversas com alguns atletas, como Fernando Scherer, ouvi que as instalações do Maria Lenk são as melhores do mundo.

(http://www.papodebola.com.br/24horas/20070802.htm)

(151) ai ele trouxe o prato, e eu comecei a comer, mas quando engoli, senti minha boca pegando fogo e meu esôfago, também, era um pimenta da brava, e sai com a boca pegando fogo, e tive que tomar muita água pra passar o ardor da pimenta, eu não sabia que prato quente lá era apimentado.

(http://br.answers.yahoo.com/question/index?qid=20090123163621AA8B7qy)

(152) gente quando está... de bem com Deus eu acho que/

bem com a vida... bem com a família bem com tudo... eu acho que a gente tem essa/direito a essa proteção... e nesse meio de tempo o motorista que ocasionô(u)... o acidente que::... em parte digamos né? que... não teria tido tanta culpa apesar da sua falta de atenção... mas analisan(d)o a situação eu vi que ele... num teve como evitá(r) o acidente... e... eu como vít/ vítima né? tive que acon/ consolá(r) porque ele tava desesperado... desesperado pelo que fez né? pela situação das pessoa... (AC-103, L.92-98)

c) Referências a evidências no contexto

Tendo em vista a polissemia dos verbos de percepção, em muitos casos, especialmente em se tratando de ocorrências em que esses verbos expressam uma percepção mental, indicações de evidências no contexto mais amplo dos enunciados são importantes para identificar se a inferência está baseada em informação visual lida (153) ou sonora (154), por exemplo. Em casos de evidencialidade reportativa, pode-se explicitar, no contexto, a fonte da informação veiculada (155):

(153) Eu li inteiro e pelo que eu vi você está tentando se afastar dele. Ele está sendo educado e respeitando seu espaço eu acho que ele deve gostar muito de você para fazer isso, pois ele não está te ignorando e sim te dando espaço. (http://br.answers.yahoo.com/question/index?qid=20100307110552AAKziug)

(154) Senti que a briga no carro estava mais violenta, pois a garota começou a gritar e o rapaz a bronquear com ela. (http://bardoescritor.net/maobranca/contos/tatuagem.htm)

(155) Eu ouvi da polícia que havia briga lá e a polícia foi chamada e depois você estava discutindo com uma mulher no clube e foi ai que você foi preso.

(http://www.backstreet.hpg.ig.com.br/mnicktrl2.html) 
d) Tipos de evidencialidade dentro da GDF

Conforme foi exposto no Capítulo III, de acordo com a GDF, existem três tipos de evidencialidade: reportativa, inferida e percepção de evento (este último tipo chamado, nesta pesquisa, de evidencialidade direta). Na expressão de evidencialidade reportativa, os verbos de percepção se relacionam com uma unidade do Nível Interpessoal, o Conteúdo Comunicado (156); na expressão de evidencialidade inferida, os verbos se relacionam com uma unidade do Nível Representacional, o Conteúdo Proposicional (157); e, na expressão de evidencialidade direta, os verbos se relacionam com outra unidade do Nível Representacional, o Estado-deCoisas (158).

(156) Ouvi, no jornal da manhã da Jovem Pan hoje cedo, que o Serra vai ser o candidato e deve fazer o anúncio $h(o) j(e)$ à noite.

(http://forum.cifraclub.com.br/forum/11/127625/)

(157) eu vejo... que os jovens se deba::tem um po(u)co aliás se debatiam até mais... mas hoje em dia... eu sinto... uma... uma:.... como se isso tivesse voltado a sê(r) uma tendência... (AC-150, L. 406-408)

(158) ... meu filho estudava em escola longe e eu todo dia ia buscá(r) ele né?... no mesmo horário... e eu c'a cha::ve c'a bolsi::nha... de guardá(r) moeda eu tô subin(d)o:.... sossegada sem olhá(r) pa trás... de repente... eu vi uma a/ sabe? senti uma MÃO... puxan(d)o com TU-DO... minha mão/ eu assusTEI quase caí até no chão só num caí porque eu:: encostei na parede assim na hora que ele puxô(u)... e ele correu... (AC-062, L.90-94)

e) Tipo de contexto sintático

Os verbos ver, ouvir e sentir, quando assumem valor evidencial, podem ocorrer em diferentes contextos sintáticos, como orações simples (159) e orações complexas completivas (160) e adverbiais conformativas (161):

(159) Inf.2: é você vai tê(r) que recorrê(r) M. a única forma aí... e óh... se você recorrê(r) e não for lá... nem que cê num fizé(r) mas pelo menos vai lá fora no dia... eles nem lêem...não lêem... eu vi ontem lá óh... chega lá ((imita som de uma pessoa lendo rápido e baixo))... é mais é muito mais fácil pra eles M. mantê(r) sentença... -“ah 
mantém a sentença... por unanimidade é isso"- ontem eu desanimei viu?... esse sistema de recurso de escrevê(r) aquela/... um MONte de babose(i)ra... óh... pode pará(r)... até foi bom eu í(r) pra vê(r)... ontem (AI-010, L. 109-115)

(160) Ganhei um ovo serenata na páscoa, quando comi senti que o sabor não era o mesmo dos outros serenata a qual havia comido antes.

(http://www.reclameaqui.com.br/284758/chocolates-garoto/chocolate-com-sabor-horrivel/)

(161) Mah tente não ser tão grossa.

Eu li inteiro e pelo que eu vi você está tentando se afastar dele.

Ele está sendo educado e respeitando seu espaço eu acho que ele deve gostar muito de você para fazer isso, pois ele não está te ignorando e sim te dando espaço.

(http://br.answers.yahoo.com/question/index?qid=20100307110552AAKziug)

\section{f) Formato da oração completiva}

Os verbos ver, ouvir e sentir usados como predicado matriz em orações complexas completivas podem ter diferentes tipos de complementos: complemento não-finito reduzido de infinitivo (162), complemento não-finito reduzido de gerúndio (163) e complemento finito (164):

(162) — A gente se vê amanhã — Ele disse segurando minhas mãos. Eu só assenti com a cabeça e ele me beijou. Um beijo rápido, afinal todos estavam olhando, mais o suficiente para eu me arrepiar. Entrei no carro e fechei a porta. E aquela sensação estranha, de estar sendo observada voltou e eu senti o cheiro entrar pelas janelas abertas. (http://ashleygreece-livro.blogspot.com/2009/06/8-capitulo.html)

(163) eu ouvi o Diu dizendo que o serviço vai ser feito lá pelo pessoal do Rio e o coronel Ferreira falou que o repórter da globo era viado e burro que tinha deixado de comer um milhão para não berrar e agora ia morrer no assalto pra fazer denuncia no inferno. (http://www.observatoriodaimprensa.com.br/artigos/asp170720026.htm)

(164) Aí o dono do bar me deu um tapa na cara que caí. Perdi a noção do que estava acontecendo. O mundo deu uma girada, mas não chorei nada. Vi tudo escuro. Fiquei ali parada. Senti que alguma pessoa puxou meu cabelo. Deveria ser o dono do bar. Mas ele me pagou! Me pagou! Miserável!

(http://edbenicio.blogspot.com/2007/11/amarelos.html) 
g) Simultaneidade entre os Estados-de-Coisas da oração principal e da oração complemento

Nos casos de orações complexas, os Estados-de-Coisas das orações principais e de seus complementos podem ser simultâneos (165) ou não (166):

(165) passeando com meu marido e vi... um:: um carro batê(r) (AC-128, L.17)

(166) Sinto que voltei a perder peso. (http://anamylife.zip.net/)

Levando-se em conta todos esses critérios, foi feita a descrição da evidencialidade expressa pelos verbos ver, ouvir e sentir. Os resultados dessa descrição são apresentados no próximo Capítulo. 


\section{CAPÍtULO V}

\section{OS VERBOS VER, OUVIR E SENTIR E A EXPRESSÃO DA EVIDENCIALIDADE NA GDF}

\section{INTRODUÇÃO}

Os verbos de percepção, em muitas línguas, dão origem a marcadores evidenciais gramaticais. No atual estágio da língua portuguesa, não há indícios de desenvolvimento de evidenciais gramaticais a partir de verbos de percepção. No entanto, assume-se que os verbos ver, ouvir e sentir, em alguns contextos específicos, podem expressar valores evidenciais em língua portuguesa. Isso posto, utilizando o modelo de descrição linguística proposto pela GDF, busca-se, neste Capítulo, identificar quais são os tipos de evidencialidade codificados por cada um desses verbos e descrever os aspectos sintáticos, semânticos e pragmáticos das estruturas em que eles são usados com sentido evidencial.

Antes, porém, faz-se necessária uma observação em relação ao conjunto de dados aqui analisados. Conforme exposto no Capítulo IV, uma expectativa deste trabalho era a de encontrar usos evidenciais diferentes a depender do tipo de material de análise, escrito ou oral, uma vez que se supunha que o compartilhamento do mesmo ambiente físico, no caso da interação face a face, ou o distanciamento entre os interlocutores, no caso da interação mediada pela escrita, pudesse influenciar de alguma forma a percepção. Durante a análise dos dados, no entanto, não foram observadas diferenças significativas entre os usos evidenciais dos verbos de percepção em um e outro material. Dessa forma, a análise apresentada neste Capítulo considera as ocorrências indistintamente, como um conjunto unificado de dados. 
Na seção 1, os usos evidenciais dos verbos ver, ouvir e sentir são descritos no Nível Interpessoal; na seção 2, esses usos são descritos no Nível Representacional. Por fim, a seção 3 traz a descrição da evidencialidade no Nível Morfossintático.

\section{A DESCRIÇÃO DA EVIDENCIALIDADE NO NÍVEL INTERPESSOAL}

De acordo com os pressupostos da GDF expostos no Capítulo III, no Nível Interpessoal, as intenções comunicativas desenvolvidas no Componente Conceitual são traduzidas em representações pragmáticas. Nesse Nível da gramática, a expressão linguística é analisada em termos de sua função comunicativa. Nos casos de evidencialidade expressos por verbos de percepção, independentemente do tipo de evidencialidade e da semântica do verbo, a intenção do Falante é a mesma: a de comunicar ao Ouvinte o Conteúdo Proposicional evocado pelo Conteúdo Comunicado, por isso a representação subjacente interpessoal de ocorrências dos três tipos de evidencialidade é igual, como se pode observar nos casos apresentados a seguir de evidencialidade reportativa (167), inferida (168) e direta (169): ${ }^{57}$

(167) Eu ouvi que você estava trabalhando em um projeto solo.

(http://www.goethe-verlag.com/book2/PTHE/PTHE094.HTM)

$\left(\mathrm{M}_{\mathrm{I}}:\left(\mathrm{A}_{\mathrm{I}}:\left[\left(\mathbf{F}_{\mathrm{I}}: \operatorname{DECL}\left(\mathbf{F}_{\mathrm{I}}\right)\right)\left(\mathrm{P}_{\mathrm{I}}\right)_{\mathrm{S}}\left(\mathrm{P}_{\mathrm{J}}\right)_{\mathrm{A}}\left(\mathrm{C}_{\mathrm{I}}:\left[\left(\mathrm{T}_{\mathrm{I}}\right)\left(+\mathbf{i d} \mathbf{R}_{\mathrm{I}}:[+\mathrm{S},-\mathbf{A}]\left(\mathbf{R}_{\mathrm{I}}\right)\right)\left(\mathrm{T}_{\mathrm{J}}\right)\left(\mathrm{R}_{\mathrm{J}}\right)\left(\mathrm{R}_{\mathrm{K}}\right)\right]\right.\right.\right.\right.$ $\left.\left.\left.\left.\left(\mathrm{C}_{\mathrm{I}}\right)\right)\right]\left(\mathrm{A}_{\mathrm{I}}\right)\right)\left(\mathrm{M}_{\mathrm{I}}\right)\right)$

(168) Senti que a briga estava mais violenta, pois a garota começou a gritar e o rapaz a bronquear com ela. O carro estava balançando.

(http://bardoescritor.net/maobranca/contos/tatuagem.htm)

$\left(\mathrm{M}_{\mathrm{I}}:\left(\mathrm{A}_{\mathrm{I}}:\left[\left(\mathbf{F}_{\mathrm{I}}: \mathbf{D E C L}\left(\mathbf{F}_{\mathrm{I}}\right)\right)\left(\mathrm{P}_{\mathrm{I}}\right)_{\mathrm{S}}\left(\mathrm{P}_{\mathrm{J}}\right)_{\mathrm{A}}\left(\mathrm{C}_{\mathrm{I}}:\left[\left(\mathrm{T}_{\mathrm{I}}\right)\left(+\mathbf{i d} \mathbf{R}_{\mathrm{I}}:[+\mathbf{S},-\mathbf{A}]\left(\mathbf{R}_{\mathrm{I}}\right)\right)\left(\mathrm{T}_{\mathrm{J}}\right)\left(\mathrm{R}_{\mathrm{J}}\right)\right]\right.\right.\right.\right.$ $\left.\left.\left.\left.\left(\mathrm{C}_{\mathrm{I}}\right)\right)\right]\left(\mathrm{A}_{\mathrm{I}}\right)\right)\left(\mathrm{M}_{\mathrm{I}}\right)\right)$

(169) uma vez teve um:: eu pa/ a:: passeando com meu marido e vi... um:: um carro batê(r) e o cara... levantô(u) saiu do carro tacô(u) a mão assim toda aí ele passô(u) a mão na:: na testa... ele viu o sangue aí ele foi desmontan(d)o (AC-128, L. 17-19)

$\left(\mathrm{M}_{\mathrm{I}}:\left(\mathrm{A}_{\mathrm{I}}:\left[\left(\mathrm{F}_{\mathrm{I}}: \operatorname{DECL}\left(\mathrm{F}_{\mathrm{I}}\right)\right)\left(\mathrm{P}_{\mathrm{I}}\right)_{\mathrm{S}}\left(\mathrm{P}_{\mathrm{J}}\right)_{\mathrm{A}}\left(\mathrm{C}_{\mathrm{I}}:\left[\left(\mathrm{T}_{\mathrm{I}}\right)\left(+\mathbf{i d} \mathbf{R}_{\mathrm{I}}:[+\mathrm{S},-\mathbf{A}]\left(\mathbf{R}_{\mathrm{I}}\right)\right)\left(\mathrm{T}_{\mathrm{J}}\right)\left(\mathrm{R}_{\mathrm{J}}\right)\right]\right.\right.\right.\right.$ $\left.\left.\left.\left.\left(\mathrm{C}_{\mathrm{I}}\right)\right)\right]\left(\mathrm{A}_{\mathrm{I}}\right)\right)\left(\mathrm{M}_{\mathrm{I}}\right)\right)$

\footnotetext{
${ }^{57}$ Nas estruturas subjacentes só são representados os trechos em destaque das ocorrências analisadas.
} 
Como pode ser observado nas estruturas hierárquicas de (167) a (169), nos três casos de evidencialidade, há um Movimento $\left(\mathrm{M}_{\mathrm{I}}\right)$ constituído de um único Ato Discursivo $\left(\mathrm{A}_{\mathrm{I}}\right)$, que é proferido pelo Falante $\left(\left(\mathrm{P}_{\mathrm{I}}\right)_{\mathrm{S}}\right)$ e endereçado ao Ouvinte $\left(\left(\mathrm{P}_{\mathrm{J}}\right)_{\mathrm{A}}\right)$, com Força Ilocucionária Declarativa (DECL). O Ato Discursivo contém um Conteúdo Comunicado $\left(\mathrm{C}_{\mathrm{I}}\right)$, que é composto por dois Subatos Atributivos $\left(\left(\mathrm{T}_{\mathrm{I}}\right)\right.$ e $\left.\left(\mathrm{T}_{\mathrm{J}}\right)\right)$ e variado número de Subatos Referenciais. Dentre esses Subatos Referencias, o primeiro, nos três casos, corresponde ao Falante (+id $\left.\mathrm{R}_{\mathrm{I}}:[+\mathrm{S},-\mathrm{A}]\left(\mathrm{R}_{\mathrm{I}}\right)\right)$.

Como discutido na seção 2 do Capítulo II, os verbos de percepção são considerados evidenciais em usos declarativos afirmativos que têm o Falante como centro dêitico. Assim, pode-se dizer que, na representação da estrutura hierárquica interpessoal de ocorrências de evidencialidade com verbos de percepção, a Ilocução será necessariamente Declarativa e o primeiro Subato Referencial do Conteúdo Comunicado fará referência ao Falante.

$\mathrm{Na}$ estrutura hierárquica interpessoal, como apresentado de (167) a (169), cada elemento descreve uma ação do Falante. Esses elementos são dispostos, na hierarquia, em conformidade com a sequência temporal das ações que representam. Assim, a disposição das ações linguísticas reflete a ordem da organização estratégica dessas ações por parte do Falante. Em se tratando da evidencialidade expressa por verbos de percepção, o Falante pode, ainda, organizar estrategicamente seu discurso de uma forma diferente da apresentada nas três ocorrências acima, o que pode ser observado na seguinte ocorrência:

(170) A casa do Benfica em Moura também foi vandalizada esta madrugada. Ouvi isso na TV. (http://www.serbenfiquista.com/forum/index.php?topic=39648.900) $\left(\mathrm{M}_{\mathrm{I}}:\left[\left(\mathrm{A}_{\mathrm{I}}:\left[\left(\mathrm{F}_{\mathrm{I}}: \operatorname{DECL}\left(\mathrm{F}_{\mathrm{I}}\right)\right)\left(\mathrm{P}_{\mathrm{I}}\right)_{\mathrm{S}}\left(\mathrm{P}_{\mathrm{J}}\right)_{\mathrm{A}}\left(\mathrm{C}_{\mathrm{I}}:\left[\left(\mathrm{T}_{\mathrm{I}}\right)\left(\mathrm{R}_{\mathrm{I}}\right)\left(\mathrm{R}_{\mathrm{J}}\right)\left(\mathrm{R}_{\mathrm{K}}\right)\right]\left(\mathrm{C}_{\mathrm{I}}\right)\right)\right]\left(\mathrm{A}_{\mathrm{I}}\right)\right)\left(\mathrm{A}_{\mathrm{J}}:\left[\left(\mathrm{F}_{\mathrm{J}}\right.\right.\right.\right.\right.$ : $\left.\left.\left.\left.\operatorname{DECL}\left(\mathbf{F}_{\mathrm{J}}\right)\right)\left(\mathrm{P}_{\mathrm{I}}\right)_{\mathrm{S}}\left(\mathrm{P}_{\mathrm{J}}\right)_{\mathrm{A}}\left(\mathrm{C}_{\mathrm{J}}:\left[\left(\mathrm{T}_{\mathrm{I}}\right)\left(+\mathrm{id} \mathbf{R}_{\mathrm{L}}:[+\mathrm{S},-\mathbf{A}]\left(\mathbf{R}_{\mathrm{L}}\right)\right)\left(\mathrm{R}_{\mathrm{M}}\right)\left(\mathrm{R}_{\mathrm{N}}\right)\right]\left(\mathrm{C}_{\mathrm{J}}\right)\right)\right]\left(\mathrm{A}_{\mathrm{J}}\right)\right)\left(\mathrm{M}_{\mathrm{I}}\right)\right)$

Em (170), há um Movimento $\left(\mathrm{M}_{\mathrm{I}}\right)$ com dois Atos que têm a função de comunicar algo ao Ouvinte. Tendo em vista que o Falante dá estatuto comunicativo igual para os dois Atos, a relação que se estabelece entre $\left(\mathrm{A}_{\mathrm{I}}\right)$ e $\left(\mathrm{A}_{\mathrm{J}}\right)$ é a de equipolência. Há diferença, no entanto, entre 
o que é Comunicado em $\left(\mathrm{C}_{\mathrm{I}}\right)$ e em $\left(\mathrm{C}_{\mathrm{J}}\right)$. O Conteúdo Comunicado $\left(\mathrm{C}_{\mathrm{I}}\right)$ evoca o Conteúdo Proposicional que contém a informação que o Falante deseja comunicar a seu Ouvinte (a casa do Benfica em Moura também foi vandalizada esta madrugada). O Conteúdo Comunicado $\left(\mathrm{C}_{\mathrm{J}}\right)$, do segundo Ato, evoca o Conteúdo Proposicional que contém o modo como o Falante obteve a informação contida no Conteúdo Proposicional de $\left(\mathrm{C}_{\mathrm{I}}\right)$. Percebe-se, assim, que a intenção comunicativa dos Movimentos apresentados de (167) a (169), por um lado, e a do Movimento apresentado em (170), por outro, é a mesma, a de informar o Ouvinte, mas a organização das ações linguísticas é diferente. Observando o contexto de ocorrência de (167), repetida abaixo, nota-se que o entrevistador preocupa-se em destacar que ele não é a fonte da informação que ele apresenta. Por essa razão, ele introduz primeiro o modo de obtenção da informação, que é apresentada em seguida:

(167) S.: Você sabe, eu ouvi dizer e eu quero esclarecer isso. Eu ouvi que você estava trabalhando em um projeto solo. Eu ouvi que você estava indo ao estúdio sozinho. Eu não sei, eu estou apenas tentando esclarecer tudo de uma vez, você sabe.

N.: Sim, sim... Eu acho que todos nós já falamos, sabe, de talvez fazer coisas individuais, mas eu acho que a concentração principal agora é no grupo. (http://www.goethe-verlag.com/book2/PTHE/PTHE094.HTM)

Já em (170), acima, observa-se que o Falante dá destaque à informação, que é apresentada no primeiro Ato, e somente depois, no segundo Ato, qualifica essa informação como reportada.

Tendo em vista os usos evidenciais dos verbos ver, ouvir e sentir encontrados no levantamento dos dados aqui empreendido, existem, de um modo geral, duas possibilidades de organização das ações linguísticas no Nível Interpessoal para representar os diferentes tipos de evidencialidade, conforme mostra o Quadro a seguir: 


\begin{tabular}{|ll|}
\hline \multicolumn{2}{|c|}{ A EVIDENCIALIDADE NO NÍVEL INTERPESSOAL } \\
\hline$(171)$ & $\left(\mathrm{M}_{1}:\left(\mathrm{A}_{1}:\left[\left(\mathbf{F}_{1}: \operatorname{DECL}\left(\mathrm{F}_{1}\right)\right)\left(\mathrm{P}_{1}\right)_{\mathrm{S}}\left(\mathrm{P}_{2}\right)_{\mathrm{A}}\left(\mathrm{C}_{1}:\left[\left(\mathrm{T}_{1}\right)\left(+\mathbf{i d} \mathbf{R}_{\mathbf{1}}:[+\mathbf{S},-\mathbf{A}]\left(\mathrm{R}_{1}\right)\right) \ldots\left(\mathrm{T}_{2+\mathrm{N}}\right)\right.\right.\right.\right.\right.$ \\
& $\left.\left.\left.\left.\left.\ldots\left(\mathrm{R}_{2+\mathrm{N}}\right)\right]\left(\mathrm{C}_{1}\right)\right)\right]\left(\mathrm{A}_{1}\right)\right)\left(\mathrm{M}_{1}\right)\right)$ \\
\hline$(172)$ & $\left(\mathrm{M}_{1}:\left[\left(\mathrm{A}_{1}:\left[\left(\mathrm{F}_{1}\right)\left(\mathrm{P}_{1}\right)_{\mathrm{S}}\left(\mathrm{P}_{2}\right)_{\mathrm{A}}\left(\mathrm{C}_{1}:\left[\left(\mathrm{T}_{1+\mathrm{N}}\right) \ldots\left(\mathrm{R}_{1+\mathrm{N}}\right)\right]\left(\mathrm{C}_{1}\right)\right)\right]\left(\mathrm{A}_{1}\right)\right)\left(\mathrm{A}_{2}:\left[\left(\mathbf{F}_{2}: \mathbf{D E C L}\left(\mathbf{F}_{2}\right)\right)\right.\right.\right.\right.$ \\
& $\left.\left.\left.\left(\mathrm{P}_{1}\right)_{\mathrm{S}}\left(\mathrm{P}_{2}\right)_{\mathrm{A}}\left(\mathrm{C}_{2}:\left[\left(\mathrm{T}_{\mathrm{N}}\right)\left(+\mathbf{i d} \mathbf{R}_{\mathbf{1}}:[+\mathrm{S},-\mathbf{A}]\left(\mathrm{R}_{\mathrm{N}}\right)\right) \ldots\left(\mathrm{T}_{\mathrm{N}}\right) \ldots\left(\mathrm{R}_{\mathrm{N}}\right)\right]\left(\mathrm{C}_{2}\right)\right)\right]\left(\mathrm{A}_{2}\right)\right)\left(\mathrm{M}_{1}\right)\right)$ \\
\hline
\end{tabular}

Quadro 7. Estruturas subjacentes interpessoais da evidencialidade

Em (171), um único Ato, com Força Ilocucionária Declarativa, contém um Conteúdo Comunicado, que pode conter vários Subatos Atributivos e Referenciais, mas o primeiro Subato Referencial deve, necessariamente, corresponder ao Participante $\left(\mathrm{P}_{1}\right)$. Em (172), há dois Atos Discursivos. O primeiro contém um Conteúdo Comunicado cuja Força Ilocucionária pode variar, apesar de a Declarativa ser a mais comum nesses casos. Tal Conteúdo Comunicado pode conter vários Subatos Atributivos e Referenciais, dependendo do que o Falante deseja comunicar. O segundo Ato, com Força Ilocucionária necessariamente Declarativa, contém um Conteúdo Comunicado composto de diferentes Subatos Atributivos e Referenciais, dentre os quais, como acontece em (171), o primeiro Subato Referencial corresponde ao Participante $\left(\mathrm{P}_{1}\right)$. Quando se tratar de dois Atos, aquele que traz o modo de obtenção da informação pode ainda ocorrer depois do Ato cujo Conteúdo Comunicado contém a informação veiculada, antes desse Ato ou intercalando-o.

\section{A DESCRIÇÃO DA EVIDENCIALIDADE NO NÍVEL REPRESENTACIONAL}

No Nível Representacional, como exposto no Capítulo III, são considerados os aspectos semânticos das expressões linguísticas. As unidades de análise desse nível são determinadas pelo que elas designam no mundo extralinguístico. Assim, expressões linguísticas usadas para designar realidades diferentes no mundo extralinguístico são representadas por categorias semânticas distintas dentro da gramática. Tendo em vista que 
neste estudo são analisados três verbos com significados diferentes e que cada um pode exprimir vários tipos de percepção, a descrição da evidencialidade no Nível Representacional diferencia-se pela semântica do verbo e pela categoria semântica com a qual ele se relaciona.

De acordo com o modelo da GDF, a expressão da evidencialidade envolve as unidades mais altas do Nível Representacional, Estado-de-Coisas e Conteúdo Proposicional, e uma unidade do Nível Interpessoal, a do Conteúdo Comunicado. O Quadro a seguir mostra com quais unidades cada verbo de percepção considerado neste estudo interage e o tipo de evidencialidade resultante dessa interação:

\begin{tabular}{|l|c|c|c|}
\hline \multirow{2}{*}{$\begin{array}{c}\text { Verbo de } \\
\text { percepção }\end{array}$} & $\begin{array}{c}\text { Evidencialidade } \\
\text { reportativa }\end{array}$ & $\begin{array}{c}\text { Evidencialidade } \\
\text { inferida }\end{array}$ & $\begin{array}{c}\text { Evidencialidade } \\
\text { direta }\end{array}$ \\
\cline { 2 - 4 } & $\begin{array}{c}\text { Conteúdo } \\
\text { comunicado }\end{array}$ & $\begin{array}{c}\text { Conteúdo } \\
\text { Proposicional }\end{array}$ & Estado-de-Coisas \\
\hline Ver & + & + & + \\
\hline Ouvir & + & + & + \\
\hline Sentir & - & + & + \\
\hline
\end{tabular}

Quadro 8. Verbos de percepção por tipo de evidencialidade, camada e nível da GDF

Como se pode observar, na expressão de evidencialidade reportativa, podem ser usados apenas os verbos ver e ouvir; ao passo que, na expressão de evidencialidade inferida e direta, os três verbos podem ser usados. A seguir, cada tipo de evidencialidade é analisado a partir do ponto de vista semântico e são exemplificadas e discutidas todas as correlações possíveis apresentadas no Quadro 8.

\subsection{A evidencialidade reportativa}

A evidencialidade reportativa, conforme discutido no Capítulo III, diz respeito à retransmissão, por parte do Falante, de um Conteúdo Comunicado produzido em outra ocasião por um outro Falante. Dos três verbos considerados neste estudo, apenas ver e ouvir codificam esse tipo de evidencialidade, como se pode observar no Quadro 8. O verbo sentir não é usado 
na expressão de evidencialidade reportativa porque, dentre os sentidos relacionados a esse verbo, não está a retransmissão de informação de natureza linguística.

A seguir, são apresentadas duas ocorrências de evidencialidade reportativa, a primeira com o verbo ver (173) e a segunda com o verbo ouvir (174):

(173) agora depois disso essa programação do Gugu::... do Faustão:: (e coisas) nós num eles eh:: assim é muito sensacionalismo né? que nem o Faustão LEva... vamo(s) supor algum ator pra se mostrá(r) a vida então pare::ce:: as pessoas falan(d)o que aquela pessoa é o supra-sumo... tá certo... né?... SÃO todo mundo tem seus pontos negativos seus pontos positivos mais assim... é mui::to:: né? todo mundo ficá(r) choran(d)o que nem esses dias eu vi na Folha de São Paulo que o::... Marcos Paulo foi lá e num chorô(u) nenhum momento então [Doc.: ((risos))]... acharam que ele:: assim é muito durão eu/ eu/ eu num vi eu só só li na Folha de São Paulo criticando o Marcos Paulo porque ele num tinha chorado... uai a pessoa vai lá e é obrigado [a chorá(r)] (AC-118, L.548-557)

(174) Em conversas com alguns atletas, como Fernando Scherer, ouvi que as instalações do Maria Lenk são as melhores do mundo. O mesmo elogio ouvi do pessoal da patinação de velocidade e de atletas de outras modalidades. A abertura teve nível olímpico e as provas trouxeram para o papo de botequim desde o corte do Ricardinho, do vôlei, até a batida na bola do Hugo Hoyama, do tênis de mesa, popularizando um pouco mais esportes quase desconhecidos. Falhas é claro que existiram, mas o principal legado, além das instalações, é a moral alta por saber que somos capazes de fazer o melhor. (http://www.papodebola.com.br/24horas/20070802.htm)

A diferença entre a evidencialidade reportativa codificada por um e outro verbo está no modo como a informação retransmitida foi obtida pelo Falante. Em (173), o verbo ver indica que a informação sobre o fato de Marcos Paulo não ter chorado foi lida no jornal Folha de São Paulo. Esse sentido do verbo ver é confirmado no contexto posterior à ocorrência da estrutura evidencial em que o Falante diz que não viu o Marcos Paulo chorar, mas simplesmente leu a informação no jornal. Em (174), o uso do verbo ouvir indica que a informação que o Falante retransmite sobre as instalações do Maria Lenk foi ouvida por ele quando conversava com alguns atletas.

Essa diferença entre uma e outra leitura reportativa, gerada pelo significado de cada verbo (ver indica percepção visual de conteúdo linguístico em (173) e ouvir exprime 
percepção auditiva de conteúdo linguístico em (174)), não resulta em representações semânticas diferentes, ou seja, a informação que o Falante retransmite é, em ambos os casos, do tipo Conteúdo Comunicado, como se pode observar nas estruturas subjacentes dos trechos em destaque em (173) e (174), apresentadas respectivamente em (175) e (176):

(175) $\quad\left(\mathrm{p}_{\mathrm{i}}:\left(\right.\right.$ past ep $\mathrm{p}_{\mathrm{i}}:\left(\mathrm{e}_{\mathrm{i}}:\left[\left(\mathrm{f}_{\mathrm{i}}:\left[\left(\mathrm{f}_{\mathrm{j}}: \operatorname{ver}\left(\mathrm{f}_{\mathrm{j}}\right)\right)\left(\mathrm{x}_{\mathrm{i}}\right)_{\mathrm{A}}\left(\mathbf{C}_{\mathrm{I}}:\left(\mathrm{p}_{\mathrm{j}}(\right.\right.\right.\right.\right.\right.$ past ep $\mathrm{j}$ : $-\mathrm{o}$ Marcos Paulo foi lá e num chorou nenhum momento- $\left.\left.\left.\left.\left.\left.\left.\left.\left(\mathrm{ep}_{\mathrm{j}}\right)\right)\left(\mathrm{p}_{\mathrm{j}}\right)\right)\left(\mathrm{C}_{\mathrm{I}}\right)\right)_{\mathrm{U}} \mathrm{J}\left(\mathrm{f}_{\mathrm{i}}\right)\right)\left(\mathrm{e}_{\mathrm{i}}\right)_{\phi}\right]\right)\left(\mathrm{ep}_{\mathrm{i}}\right)\right)\left(\mathrm{p}_{\mathrm{i}}\right)\right)$

(176) $\quad\left(\mathrm{p}_{\mathrm{i}}:\right.$ (past ep $\mathrm{p}_{\mathrm{i}}:\left(\mathrm{e}_{\mathrm{i}}:\left[\left(\mathrm{f}_{\mathrm{i}}:\left[\left(\mathrm{f}_{\mathrm{j}}:\right.\right.\right.\right.\right.$ ouvir $\left.\left(\mathrm{f}_{\mathrm{j}}\right)\right)\left(\mathrm{x}_{\mathrm{i}}\right)_{\mathrm{A}}\left(\mathbf{C}_{\mathrm{I}}:\left(\mathrm{p}_{\mathrm{j}}:\left(\right.\right.\right.$ pres ep $\mathrm{p}_{\mathrm{j}}$ : -as instalações do Maria Lenk são as melhores do mundo- $\left.\left.\left.\left.\left.\left.\left.\left.\left.\left(\mathrm{ep}_{\mathrm{j}}\right)\right)\left(\mathrm{p}_{\mathrm{j}}\right)\right)\left(\mathrm{C}_{\mathrm{I}}\right)\right)_{\mathrm{U}}\right]\left(\mathrm{f}_{\mathrm{i}}\right)\right)\left(\mathrm{e}_{\mathrm{i}}\right)_{\phi}\right]\right)\left(\mathrm{ep}_{\mathrm{i}}\right)\right)\left(\mathrm{p}_{\mathrm{i}}\right)\right)$

Como se pode observar, os dois trechos são descritos por uma mesma estrutura constituída por uma Proposição $\left(\mathrm{p}_{\mathrm{i}}\right)$, que contém um Episódio $\left(\mathrm{ep}_{\mathrm{i}}\right)$, que, por sua vez, contém um Estado-deCoisas $\left(\mathrm{e}_{\mathrm{i}}\right)$. O Estado-de-Coisas $\left(\mathrm{e}_{\mathrm{i}}\right)$ é caracterizado pela Propriedade Configuracional $\left(\mathrm{f}_{\mathrm{i}}\right)$, composta por outra Propriedade $\left(\mathrm{f}_{\mathrm{j}}\right)$, que especifica a relação entre os outros dois constituintes: o Indivíduo $\left(\mathrm{x}_{\mathrm{i}}\right)$ e o Conteúdo Comunicado $\left(\mathrm{C}_{\mathrm{I}}\right)$. A unidade do Nível Interpessoal Conteúdo Comunicado entra na representação semântica para designar um conteúdo linguístico com o qual se relaciona a unidade semântica Indivíduo. Isso é possível na arquitetura da GDF porque, como os quatro níveis de organização da Gramática alimentam o Componente Contextual, qualquer unidade nele armazenada pode ser acessada pela Formulação e reutilizada em mensagens posteriores. Assim, nos casos de evidencialidade reportativa, o Falante retransmite um Conteúdo Comunicado produzido anteriormente por um outro Falante que estava armazenado no Componente Contextual.

A evidencialidade reportativa também pode ser expressa por um outro tipo de estrutura, representado pela ocorrência a seguir:

(177) A luz acabou umas 22:13, pelo que eu ouvi no jornal. (http://blog-lica-lilly.blogspot.com/2009/11/apagao-geral.html) $\left(\mathrm{p}_{\mathrm{i}}\right.$ : (pres ep $\mathrm{p}_{\mathrm{i}}:\left(\mathrm{e}_{\mathrm{i}}:\left[\left(\mathrm{f}_{\mathrm{i}}:[-\mathrm{a}\right.\right.\right.$ luz acabou umas $\left.\left.\left.22: 13-]\left(\mathrm{f}_{\mathrm{i}}\right)\left(\mathrm{e}_{\mathrm{i}}\right)\right]\right)\left(\mathrm{ep}_{\mathrm{i}}\right)\left(\mathrm{p}_{\mathrm{i}}\right)\right):\left(\mathrm{p}_{\mathrm{j}}:\left(\right.\right.$ past $_{\mathrm{j}} \mathrm{ep}_{\mathrm{j}}$ : $\left(\mathrm{e}_{\mathrm{j}}:\left[\left(\mathrm{f}_{\mathrm{j}}:\left[\left(\mathrm{f}_{\mathrm{k}}\right.\right.\right.\right.\right.$ : ouvir $\left.\left.\left.\left.\left.\left.\left(\mathrm{f}_{\mathrm{k}}\right)\right)\left(\mathrm{x}_{\mathrm{i}}\right)_{\mathrm{A}}\left(\mathrm{C}_{\mathrm{I}}:\left(\mathrm{p}_{\mathrm{i}}\right)\right)\left(\mathrm{l}_{\mathrm{i}}\right)\right]\left(\mathrm{f}_{\mathrm{j}}\right)\right)\left(\mathrm{e}_{\mathrm{j}}\right)\right]\right)\left(\mathrm{ep}_{\mathrm{j}}\right)\left(\mathrm{p}_{\mathrm{j}}\right)\right)$ 
Nesse caso, a informação sobre o horário em que a luz acabou é originária de um outro Falante, e não do Falante atual, que informa ter ouvido tal informação no jornal. Como pode ser observado na representação semântica, em primeiro lugar é representada a Proposição $\left(\mathrm{p}_{\mathrm{i}}\right)$, que contém a informação linguística que o Falante retransmite. A segunda Proposição, $\left(\mathrm{p}_{\mathrm{j}}\right)$, que contém o verbo ouvir, atua como modificador do Conteúdo Comunicado retransmitido, especificando a maneira como o Falante, representado por $\left(\mathrm{x}_{\mathrm{i}}\right)$, chegou ao conhecimento que retransmite, contido em $\left(\mathrm{p}_{\mathrm{i}}\right)$.

Um último tipo de organização semântica de evidencialidade reportativa é observado na ocorrência reapresentada a seguir:

(170) A casa do Benfica em Moura também foi vandalizada esta madrugada. Ouvi isso na TV. (http://www.serbenfiquista.com/forum/index.php?topic=39648.900)

$\left(\mathrm{p}_{\mathrm{i}}\right.$ : (past ep $\mathrm{p}_{\mathrm{i}}:\left(\mathrm{e}_{\mathrm{i}}:\left[\left(\mathrm{f}_{\mathrm{i}}:-\mathrm{a}\right.\right.\right.$ casa do Benfica em Moura também foi vandalizada esta madrugada- $\left.\left.\left.\left.\left.\left(\mathrm{f}_{\mathrm{i}}\right)\right)\left(\mathrm{e}_{\mathrm{i}}\right)\right]\right)\left(\mathrm{ep}_{\mathrm{i}}\right)\right)\left(\mathrm{p}_{\mathrm{i}}\right)\right)\left(\mathrm{p}_{\mathrm{j}}\right.$ : (past ep $\mathrm{p}_{\mathrm{j}}:\left(\mathrm{e}_{\mathrm{j}}:\left[\left(\mathrm{f}_{\mathrm{j}}:\left[\left(\mathrm{f}_{\mathrm{k}}\right.\right.\right.\right.\right.$ : ouvir $\left.\left(\mathrm{f}_{\mathrm{k}}\right)\right)\left(\mathrm{x}_{\mathrm{i}}\right)_{\mathrm{A}}\left(\mathrm{C}_{\mathrm{I}}:\left(\mathrm{p}_{\mathrm{i}}\right)\right.$ $\left.\left.\left.\left.\left.\left.\left.\left(\mathrm{C}_{\mathrm{I}}\right)\right)\left(\mathrm{l}_{\mathrm{i}}\right)\right]\left(\mathrm{f}_{\mathrm{j}}\right)\right)\left(\mathrm{e}_{\mathrm{j}}\right)_{\phi}\right]\right)\left(\mathrm{ep}_{\mathrm{j}}\right)\right)\left(\mathrm{p}_{\mathrm{j}}\right)\right)$

Diferentemente de (173) a (177), a ocorrência (170) é representada, no Nível Representacional, como duas Proposições independentes. A primeira proposição $\left(\mathrm{p}_{\mathrm{i}}\right)$ contém o conteúdo linguístico que o Falante retransmite, enquanto a segunda $\left(\mathrm{p}_{\mathrm{j}}\right)$ contém a descrição do modo como o Falante apreendeu tal conteúdo linguístico. Assim, a segunda proposição contém o Estado-de-Coisas $\left(\mathrm{e}_{\mathrm{j}}\right)$ em que o verbo ouvir, usado nesse caso para descrever a recepção auditiva do conteúdo linguístico por parte do Indivíduo $\left(\mathrm{x}_{\mathrm{i}}\right)$, toma como segundo argumento um Conteúdo Comunicado $\left(\mathrm{C}_{\mathrm{I}}\right)$, preenchido pelo pronome anafórico isso. Tal anáfora é representada por meio de repetição do mesmo índice $\left(\mathrm{p}_{\mathrm{i}}\right)$ no interior da unidade $\left(\mathrm{C}_{\mathrm{I}}\right)$, uma vez que o pronome isso se refere à proposição $\left(\mathrm{p}_{\mathrm{i}}\right)$.

Tendo em vista os usos reportativos dos verbos ver e ouvir analisados, três estruturas representacionais subjacentes são possíveis para representar a evidencialidade reportativa, conforme mostra o Quadro a seguir: 


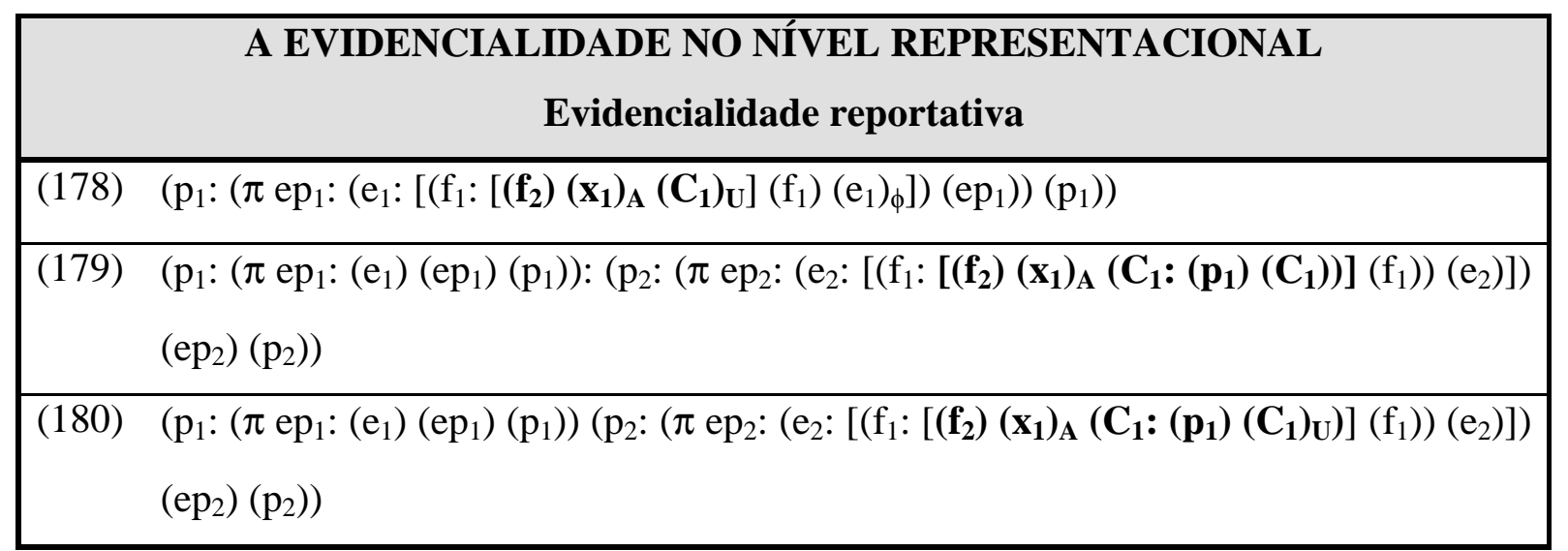

Quadro 9. Estruturas subjacentes representacionais da evidencialidade reportativa

Em (178), a única Proposição $\left(\mathrm{p}_{1}\right)$ contém um Estado-de-Coisas ( $\mathrm{e}_{1}$ ) caracterizado pela Propriedade Configuracional $\left(\mathrm{f}_{1}\right)$, que, por sua vez, contém a Propriedade $\left(\mathrm{f}_{2}\right)$, que especifica o tipo de relação entre $\left(\mathrm{x}_{1}\right)$ e $\left(\mathrm{C}_{1}\right)$; nesse caso, a Propriedade $\left(\mathrm{f}_{1}\right)$ indica como o Indivíduo $\left(\mathrm{x}_{1}\right)$, ou seja, o Falante, apreendeu o Conteúdo $\left(\mathrm{C}_{1}\right)$, se por meio da leitura ou da audição. Em (179), a Proposição $\left(\mathrm{p}_{2}\right)$, que atua como modificador do Conteúdo Comunicado que o Falante retransmite, contém um Estado-de-Coisas $\left(\mathrm{e}_{2}\right)$, caracterizado pela Propriedade Configuracional $\left(\mathrm{f}_{1}\right)$, que contém a Propriedade $\left(\mathrm{f}_{2}\right)$, que representa o verbo ver, o Indivíduo $\left(\mathrm{x}_{1}\right)$ e o argumento $\left(\mathrm{C}_{1}\right)$. Esse Estado-de-Coisas $\left(\mathrm{e}_{2}\right)$, portanto, descreve como o Falante, representado pelo Indivíduo $\left(\mathrm{x}_{1}\right)$, adquiriu a informação retransmitida contida em $\left(\mathrm{C}_{1}\right)$. Em (180), a Proposição $\left(\mathrm{p}_{1}\right)$ é retomada na segunda Proposição $\left(\mathrm{p}_{2}\right)$. O Estado-de-Coisas $\left(\mathrm{e}_{2}\right)$, de $\left(\mathrm{p}_{2}\right)$, apresenta uma Propriedade Configuracional que necessariamente contém uma Propriedade que especifica o tipo de contato sensorial que o Indivíduo $\left(\mathrm{x}_{1}\right)$, correspondente ao Falante, teve com o Conteúdo Comunicado $\left(\mathrm{C}_{1}\right)$, que necessariamente contém um pronome anafórico que retoma $\left(\mathrm{p}_{1}\right)$.

Com relação às funções semânticas, como se pode observar nas diferentes representações apresentadas anteriormente, ao Indivíduo $\left(\mathrm{x}_{1}\right)_{\mathrm{A}}$ é atribuída a função semântica de Ator. Apesar de $\left(\mathrm{x}_{1}\right)$, no caso o próprio Falante, não estar intencionalmente envolvido na 
percepção, ${ }^{58}$ a ele pode ser atribuída essa função porque, no português, não há distinção gramatical entre Atores volicionais e não-volicionais. A função semântica do argumento com o qual o Indivíduo se relaciona, o $\left(\mathrm{C}_{1}\right)_{\mathrm{U}}$, é a de Undergoer. ${ }^{59}$

Os aspectos relacionados à localização temporal dos Episódios e Estado-de-Coisas envolvidos na expressão da evidencialidade reportativa e dos outros tipos de evidencialidade são tratados na seção 2.5.2, especialmente dedicada a eles.

\subsection{A evidencialidade inferida}

A evidencialidade inferida é utilizada quando o Falante deseja expressar um Conteúdo Proposicional que é resultado de uma conjectura baseada em evidências internas ao falante. Em outras palavras, com base em seu conhecimento de mundo acumulado ou com base em experiências prévias de situações similares o Falante chega à conclusão apresentada no Conteúdo Proposicional. Como se observa no Quadro 8, os três verbos analisados neste estudo se prestam à expressão desse tipo de evidencialidade.

Nas ocorrências a seguir são apresentados casos de evidencialidade inferida codificados pelos verbos ver, sentir e ouvir:

(181) Mah, tente não ser tão grossa. Eu li [o texto] inteiro e pelo que eu vi você está tentando se afastar dele. Ele está sendo educado e respeitando seu espaço eu acho que ele deve gostar muito de você para fazer isso, pois ele não está te ignorando e sim te dando espaço.

(http://br.answers.yahoo.com/question/index?qid=20100307110552AAKziug)

(182) Elas são bem tratadas elas se vestem muito bem... elas até comem bem... né?... se CALçam bem... né? tão na moda vão e saem mas tem problemas psicológicos porque HÁ a falta desse pai e dessa mãe... que é uma necessidade que a criANça tem... éh:.... dela de tê(r) a figura do homem e da mulher pra educá(r) junto...

\footnotetext{
${ }^{58}$ Conforme discutido anteriormente, em diferentes Capítulos, apenas verbos que exprimem percepção passiva, ou seja, percepção não-intencional, podem ser usados em contextos evidenciais.

${ }^{59}$ O papel semântico de Undergoer, na GDF, é entendido, nos moldes de Foley e Van Valin (1984), como um macro-papel que identifica um participante mais passivo que o Ator, podendo se referir tanto ao objeto direto de um verbo transitivo na voz ativa quanto ao sujeito de um verbo na voz passiva.
} 
junto educá(r) a criança... éh aí a gente vê né? filho... a aí começa mexê(r) com dro::ga... éh o problema do alcoolis::mo... né?... a gente vê a FEBEM tão lotada de adolesCENtes... que há e a gente ahm:: eu sinto... que é essa falta da família... essa falta do SEio familiar dessa conviVÊN::cia com o pai e com a mãe... ou até mesmo dois irmãos... porque muitas vezes na separação... os filhos se dividem... éh:.... (AC102, L. 370-378)

(183) Eu fiz essa mesa para vocês. Você pode comer a vontade. Pelo barulho que ouvi, esse reencontro de vocês foi ótimo. Então vocês têm que repor as energias. (http://macaesther-portugues.mforos.com/1726172/8776460-encontrei-meu-amor-naadolescencia/?pag=13)

O trecho apresentado em (181) é uma das respostas dadas a uma pessoa que faz um relato sobre o seu relacionamento conturbado com um rapaz e pede a opinião de outras pessoas sobre a situação relatada. A estrutura evidencial pelo que eu vi indica, nesse caso, que a informação você está tentando se afastar dele é uma conclusão a que o Falante chegou após ler todo o texto sobre o relacionamento complicado. Em (182), o verbo sentir introduz uma inferência do Falante sobre uma possível causa para os problemas psicológicos de muitos adolescentes e para o envolvimento deles com drogas. Segundo o Falante, esses problemas devem-se à falta da família. Em (183), o Falante, comparando o que ouviu com situações semelhantes disponíveis no seu conhecimento de mundo, infere a informação esse reencontro de vocês foi ótimo, contida no Conteúdo Proposicional.

A diferença entre o uso do verbo ver e do verbo sentir parece estar relacionada com o grau de subjetividade, que é maior quando o verbo sentir é usado para exprimir a inferência. Uma explicação para tal diferença pode estar relacionada ao fato de que, como foi visto no Capítulo II, os usos metafóricos de verbos de percepção visual se relacionam com o domínio intelectual e objetivo, ao passo que os verbos de percepção gustativa e tátil se relacionam com a subjetividade, a intimidade e a emoção.

No conjunto de ocorrências levantadas neste estudo, há apenas dois casos em que o verbo ouvir é usado na expressão de evidencialidade inferida (um deles apresentado em (183)). Esse baixo número de ocorrências e a análise de (183) demonstram que o verbo ouvir 
está mais fortemente relacionado com a percepção física auditiva e, consequentemente, seu uso é muito mais característico de casos de evidencialidade reportativa e de evidencialidade direta, que envolvem mais diretamente a percepção auditiva.

Com relação à representação semântica dos casos de evidencialidade inferida expressos por verbos de percepção, de um modo geral, existem três formas de organização possíveis. Cada uma dessas formas é apresentada a seguir.

Em (184), apresenta-se um caso de evidencialidade inferida em que a Proposição que contém a inferência ocorre encaixada no verbo de percepção:

(184) Olá pessoal, na opinião de vocês, as oficinas eletrônicas (conserto de TV, DVD, som) ainda têm uma vida longa? É que tenho uma oficina e vejo que está cada vez mais difícil competir com o valor baixo dos aparelhos novos e para se conseguir peças está cada vez mais difícil... Que produtos e serviços posso agregar em minha oficina? (http://www2.eletronica.org/recently_modified?b_start:int=8919\&-C=) $\left(\mathrm{p}_{\mathrm{i}}:\left(\right.\right.$ pres ep $_{\mathrm{i}}:\left(\mathrm{e}_{\mathrm{i}}:\left[\left(\mathbf{f}_{\mathrm{i}}:\left[\left(\mathbf{f}_{\mathbf{j}}: \operatorname{ver}\left(\mathbf{f}_{\mathbf{j}}\right)\right)\left(\mathbf{x}_{\mathbf{i}}\right)_{\mathbf{A}}\left(\mathbf{p}_{\mathbf{j}}:\left(\right.\right.\right.\right.\right.\right.$ pres $_{\mathbf{j}} \mathbf{p}_{\mathbf{j}}:$ [-está cada vez mais difícil competir com o valor baixo dos aparelhos novos -$\left.\left.\left.\left.\left.\left.\left.]\left(\mathbf{e p}_{\mathbf{j}}\right)\right)\left(\mathbf{p}_{\mathbf{j}}\right)\right)\right]\left(\mathbf{f}_{\mathbf{i}}\right)\left(\mathrm{e}_{\mathbf{i}}\right)_{\phi}\right]\right)\left(e \mathrm{p}_{\mathrm{i}}\right)\right)\left(\mathrm{p}_{\mathrm{i}}\right)\right)$

A ocorrência (184) é representada, no Nível Representacional, como uma Proposição ( $\mathrm{p}_{\mathrm{i}}$ ), que contém um Episódio $\left(\mathrm{ep}_{\mathrm{i}}\right)$, que, por sua vez, contém um Estado-de-Coisas $\left(\mathrm{e}_{\mathrm{i}}\right)$. Esse Estadode-Coisas se caracteriza por uma Propriedade Configuracional ( $\left.\mathrm{f}_{\mathrm{i}}\right)$, que contém a Propriedade $\left(\mathrm{f}_{\mathrm{j}}\right)$, que especifica o tipo de relação que se estabelece entre o Indivíduo $\left(\mathrm{x}_{\mathrm{i}}\right)$, que designa o Falante, e $\left(\mathrm{p}_{\mathrm{j}}\right)$. Tendo em vista que, nesse caso, $\left(\mathrm{x}_{\mathrm{i}}\right)$ se relaciona com um construto mental, uma unidade do tipo (p), o verbo ver especifica uma operação mental, e não uma percepção física. Essa mesma representação semântica se aplica para o caso de inferência apresentado em (182).

A ocorrência (181) é reapresentada para ilustrar um caso em que o verbo ver ocorre como núcleo do modificador da Proposição que contém a informação inferida: 
(181) Mah, tente não ser tão grossa.

Eu li inteiro e pelo que eu vi você está tentando se afastar dele.

Ele está sendo educado e respeitando seu espaço eu acho que ele deve gostar muito de você para fazer isso, pois ele não está te ignorando e sim te dando espaço.

(http://br.answers.yahoo.com/question/index?qid=20100307110552AAKziug)

$\left(\mathrm{p}_{\mathrm{i}}\right.$ : (pres ep $\mathrm{p}_{\mathrm{i}}:\left(\mathrm{e}_{\mathrm{i}}\right.$ : [-você está tentando se afastar dele-] $\left.\left.\left.\left(\mathrm{e}_{\mathrm{i}}\right)_{\phi}\right]\right)\left(\mathrm{ep}_{\mathrm{i}}\right)\left(\mathrm{p}_{\mathrm{i}}\right)\right):\left(\mathrm{p}_{\mathrm{j}}\right.$ : (past ep $\mathrm{p}_{\mathrm{j}}$ :

$\left.\left(e_{j}:\left[\left(\mathbf{f}_{\mathbf{i}}:\left[\left(\mathbf{f}_{\mathbf{j}}: \operatorname{ver}\left(\mathbf{f}_{\mathbf{j}}\right)\right)\left(\mathbf{x}_{\mathbf{i}}\right)_{\mathbf{A}}\left(\mathbf{p}_{\mathbf{i}}\right)\right]\left(f_{\mathrm{i}}\right)\right)\left(\mathrm{e}_{\mathrm{j}}\right)\right]\right)\left(e \mathrm{p}_{\mathrm{j}}\right)\left(\mathrm{p}_{\mathrm{j}}\right)\right)$

Como pode ser observado em (181), em primeiro lugar é representado o Conteúdo Proposicional $\left(\mathrm{p}_{\mathrm{i}}\right)$, que contém a inferência do Falante. O verbo ver, que descreve percepção mental nesse caso, juntamente com o Indivíduo $\left(\mathrm{x}_{\mathrm{i}}\right)$, que corresponde ao Falante, e o argumento $\left(\mathrm{p}_{\mathrm{i}}\right)$ constituem a Propriedade Configuracional $\left(\mathrm{f}_{\mathrm{i}}\right)$, que caracteriza o Estado-deCoisas $\left(\mathrm{e}_{\mathrm{j}}\right)$, que, por sua vez, atua como um modificador do Conteúdo Proposicional $\left(\mathrm{p}_{\mathrm{i}}\right)$, especificando a maneira como o Falante chegou ao conhecimento presente nesse Conteúdo Proposicional. A representação semântica de (181) também se aplica a (183), em que o verbo ouvir ocorre como núcleo do modificador de Proposição.

Na ocorrência a seguir, a informação inferida e o verbo de percepção ocorrem em duas Proposições diferentes e independentes:

(185) — Bels? - Minha mãe chamou.

— Estou aqui no banheiro - Falei entre uma ânsia e outra.

Ouvi que minha mãe puxou a cadeira do meu computador e se sentou, ela esperou eu voltar do banheiro e me deu um remédio para ânsia e ficou ali abraçada comigo.

- Filha, posso te fazer uma pergunta? - Minha mãe perguntou.

- Pode, claro - Respondi sem imaginar qual seria a pergunta.

- Você já menstruou depois daquela noite com o Edward? - Ela perguntou com medo da resposta. Eu senti isso na voz dela.

- Não, mãe - Respondi.

(http://webcache.googleusercontent.com/search?q=cache:dUEynGDQ88EJ:fanfiction.nyah.com.br/histo ria/70890/Revivendo_Um_Sonho)

$\left(\mathrm{p}_{\mathrm{i}}\right.$ : (past ep $\mathrm{p}_{\mathrm{i}}$ : [-Ela perguntou com medo da resposta-] $\left.\left(e \mathrm{p}_{\mathrm{i}}\right)\left(\mathrm{p}_{\mathrm{i}}\right)\right)\left(\mathrm{p}_{\mathrm{j}}:\left(\right.\right.$ past $\mathrm{ep}_{\mathrm{j}}:\left(\mathrm{e}_{\mathrm{j}}:\left[\left(\mathrm{f}_{\mathrm{j}}\right.\right.\right.$ : $\left[\left(f_{\mathrm{k}}\right.\right.$ : sentir $\left.\left.\left.\left.\left.\left(\mathrm{f}_{\mathrm{k}}\right)\right)\left(\mathrm{x}_{\mathrm{i}}\right)_{\mathrm{A}}\left(\mathrm{p}_{\mathrm{i}}\right)\left(\mathrm{l}_{\mathrm{i}}:\left[\left(\mathrm{f}_{\mathrm{l}}:\left[\left(\mathrm{f}_{\mathrm{m}}: \operatorname{voz}_{\mathrm{N}}\left(\mathrm{f}_{\mathrm{m}}\right)\right)\left(\mathrm{x}_{\mathrm{j}}\right)_{\text {Ref }}\right]\left(\mathrm{f}_{\mathrm{l}}\right)\right)\left(\mathrm{l}_{\mathrm{i}}\right)\right]\right)\right]\left(\mathrm{f}_{\mathrm{j}}\right)\left(\mathrm{e}_{\mathrm{j}}\right)\right]\right)\left(\mathrm{ep}_{\mathrm{j}}\right)\left(\mathrm{p}_{\mathrm{j}}\right)\right)$

No trecho em destaque, há dois Conteúdos Proposicionais, $\left(\mathrm{p}_{\mathrm{i}}\right)$ e $\left(\mathrm{p}_{\mathrm{j}}\right)$. O primeiro contém uma inferência do Falante e o segundo contém a explicitação, por parte do Falante, de que tal inferência foi feita com base na percepção do tipo de voz usado por quem fez a pergunta. Em 
$\left(\mathrm{p}_{\mathrm{j}}\right)$, a Propriedade $\left(\mathrm{f}_{\mathrm{k}}\right)$ explicita que o Indivíduo $\left(\mathrm{x}_{\mathrm{i}}\right)$, o Falante, inferiu o Conteúdo Proposicional $\left(\mathrm{p}_{\mathrm{i}}\right)$, que é uma referência anafórica ao Conteúdo Proposicional anterior, por isso recebe o mesmo índice. O que o Falante tomou como base para fazer sua inferência está, nesse caso, explicitado pela categoria semântica lugar $\left(\mathrm{l}_{\mathrm{i}}\right)$, usada em sentido abstrato. Tal categoria é caracterizada por uma Propriedade Configuracional ( $\left.\mathrm{f}_{1}\right)$, que contém a Propriedade Lexical $\left(\mathrm{f}_{\mathrm{m}}\right)$, a voz, e o Indivíduo $\left(\mathrm{x}_{\mathrm{j}}\right)$ como seu argumento. A função semântica Referência (Ref) indica posse inalienável entre a "voz" e "ela".

O Quadro a seguir reúne os três tipos de estruturas semânticas subjacentes para representar os casos de evidencialidade inferida codificados pelos verbos ver, ouvir e sentir:

\begin{tabular}{|c|}
\hline $\begin{array}{l}\text { A EVIDENCIALIDADE NO NÍVEL REPRESENTACIONAL } \\
\text { Evidencialidade inferida }\end{array}$ \\
\hline$(186) \quad\left(\mathrm{p}_{1}:\left(\pi \mathrm{ep}_{1}:\left(\mathrm{e}_{1}:\left[\left(\mathrm{f}_{1}:\left[\left(\mathbf{f}_{2}\right)\left(\mathbf{x}_{1}\right)_{\mathrm{A}}\left(\mathbf{p}_{2}\right)_{\phi}\right]\left(\mathrm{f}_{1}\right)\right)\left(\mathrm{e}_{1}\right)_{\phi}\right]\right)\left(\mathrm{ep}_{1}\right)\right)\left(\mathrm{p}_{1}\right)\right)$ \\
\hline$(187) \quad\left(\mathrm{p}_{1}:\left(\pi \mathrm{ep}_{1}:\left(\mathrm{e}_{1}\right)\left(\mathrm{ep}_{1}\right)\left(\mathrm{p}_{1}\right)\right):\left(\mathrm{p}_{2}:\left(\pi \mathrm{ep}_{2}:\left(\mathrm{e}_{2}:\left[\left(\mathrm{f}_{1}:\left[\left(\mathbf{f}_{2}\right)\left(\mathbf{x}_{1}\right)_{\mathrm{A}}\left(\mathrm{p}_{1}\right)\right]\left(\mathrm{f}_{1}\right)\right)\left(\mathrm{e}_{2}\right)\right]\right)\left(\mathrm{ep}_{2}\right)\left(\mathrm{p}_{2}\right)\right)\right.\right.$ \\
\hline $\begin{array}{l}(188) \quad\left(\mathrm{p}_{1}:\left(\pi \mathrm{ep} \mathrm{p}_{1}:\left(\mathrm{e}_{1}\right)\left(\mathrm{ep}_{1}\right)\right)\left(\mathrm{p}_{1}\right)\right)\left(\mathrm{p}_{2}:\left(\pi \mathrm{ep}_{2}:\left(\mathrm{e}_{2}:\left[\left(\mathrm{f}_{1}:\left[\left(\mathbf{f}_{\mathbf{2}}\right)\left(\mathbf{x}_{1}\right)_{\mathbf{A}}\left(\mathrm{p}_{1}\right)\right]\left(\mathrm{f}_{1}\right)\right)\left(\mathrm{e}_{2}\right)\right]\right)\left(e \mathrm{p}_{2}\right)\right)\right. \\
\left.\left(\mathrm{p}_{2}\right)\right)\end{array}$ \\
\hline
\end{tabular}

Quadro 10. Estruturas subjacentes representacionais da evidencialidade inferida

A estrutura subjacente (186) representa os casos em que o Conteúdo Proposicional que contém a inferência do Falante ocorre como segundo argumento dentro do Conteúdo Proposicional que contém o verbo de percepção, que explicita a inferência do Falante. A estrutura apresentada em (187) representa os casos em que o verbo de percepção ocorre dentro de um Conteúdo Proposicional que funciona como modificador do Conteúdo Proposicional que contém a inferência do Falante. A estrutura apresentada em (188) representa os casos em que há dois Conteúdos Proposicionais independentes. Um deles apresenta a inferência do Falante e o outro, que contém o verbo de percepção, explicita o cálculo mental. 


\subsection{A evidencialidade deduzida}

Conforme exposto no Capítulo III, segundo Hengeveld e Mackenzie (2008), o Conteúdo Proposicional pode conter uma informação que foi obtida por meio de inferência com base em evidência sensorial, com base em inferência derivada de conhecimento existente e com base em conhecimento geral acumulado na comunidade. Na presente pesquisa, os casos em que a informação é obtida por meio de um cálculo mental com base em evidência sensorial é analisada, conforme Dall'Aglio-Hattnher e Hengeveld (em preparação), como casos de evidencialidade deduzida. Esse tipo de evidencialidade, segundo esses autores "opera na camada do Episódio e indica que a ocorrência de um Episódio é deduzida pelo Falante com base em alguma evidência disponível." Em outras palavras, o Falante, baseado em indícios ou resultados observáveis, é capaz de deduzir um Episódio, mesmo não tendo experienciado a sua ocorrência.

Os três verbos, ver, ouvir e sentir, também podem ser usados na expressão de evidencialidade deduzida, como se pode observar nas seguintes ocorrências:

(189) Inf.1.: ah depois que abriu essa igreja aí (inint) ((arrastou uma cadeira)) eu também fui lá olhá(r) mas eu desliguei eu já esqueci o arro::z

Inf.2: não (isso aí) eu vi que cê desligôo(u)

Inf.1: é né? eu/ mas eu fui lá olha de novo (AI-002, L. 2-6)

(190) E aí me acertaram bem. Senti vários golpes no corpo e na cabeça, como um choque elétrico. Depois vi uma luz intensa e perdi os sentidos. Ao despertar, estava de bruços, perdendo muito sangue pela cabeça. Meu pensamento estava claro. O corpo do russo estava sobre o meu, pingava sangue quente. Fechei os olhos, e fiz o possível para respirar sem ruído, embora me saísse sangue pelo nariz. Ouvi que o caminhão esquentava o motor, mas o pior veio quando ouvi o capitão Alvarenga dizer que dessem o tiro de graça em qualquer corpo que mostrasse sinal de vida.

(http://contra-dem.blogspot.com/search/label/hist\%C3\%B3rias\%20das\%20revolu\%C3\%A7\%C3\%B5e)

(191) Aí o dono do bar me deu um tapa na cara que caí. Perdi a noção do que estava acontecendo. O mundo deu uma girada, mas não chorei nada. Vi tudo escuro. Fiquei ali parada. Senti que alguma pessoa puxou meu cabelo. Deveria ser o dono do bar. (http://edbenicio.blogspot.com/2007/11/amarelos.html) 
Em (189), o informante 2, ao observar o fogo apagado, deduz que a informante 1 o tenha desligado e explicita o sentido envolvido na observação da evidência visual que tomou como base para sua dedução. Em (190), o Falante, com base em ruídos que ele ouve, deduz que o caminhão esquentava o motor. Em (191), com base em sensação tátil de dor no couro cabeludo, o Falante deduz que alguém puxou seu cabelo.

A diferença entre a evidencialidade inferida e a evidencialidade deduzida expressas por meio de verbos de percepção pode ser explicada levando-se em conta dois aspectos: a base para a inferência ou dedução e a natureza da informação apresentada como resultado de inferência ou dedução. Nos casos de evidencialidade inferida, conforme exemplificado de (181) a (185), o Falante baseia-se em evidências internas, como conhecimento de mundo e experiências de vida, e a informação que apresenta como resultado de sua inferência é sempre um construto mental, uma conclusão ou avaliação pessoal sobre algo. Essa informação, como visto na seção 2.2 deste Capítulo, é representada na GDF como um Conteúdo Proposicional. Nos casos de evidencialidade deduzida, conforme exemplificado de (189) a (191), o que o Falante toma como base para a sua dedução é sempre uma evidência apreendida por meio de um dos sentidos e a informação apresentada como resultado da dedução é mais concreta do que a resultante de uma inferência, sendo representada, na GDF, como um Episódio.

Essa diferença entre os usos inferenciais e dedutivos dos verbos de percepção corresponde aos dois tipos de percepção mental observados por Dik e Hengeveld (1991) e discutidos na seção 2 do Capítulo II. A evidencialidade dedutiva diz respeito à percepção mental primária e a evidencialidade inferida, à percepção mental secundária. Apesar de os autores terem observado essa diferença semântica, os complementos dos verbos de percepção, tanto na percepção mental primária quanto na percepção mental secundária, foram representados como Conteúdos Proposicionais, uma vez que, com as unidades de análise da GF, não era possível representar, na estrutura subjacente, tal diferença de sentido. 
No aparato teórico da GDF, por outro lado, é possível diferenciar as duas leituras em termos da unidade que o verbo de percepção toma como complemento em cada caso. Como dito anteriormente, na evidencialidade inferida, o verbo de percepção se relaciona com um Conteúdo Proposicional e, na evidencialidade deduzida, o verbo se relaciona com um Episódio. A comparação entre as representações de (184) e (190), aqui repetidas, demonstra essa diferença:

(184) vejo que está cada vez mais difícil competir com o valor baixo dos aparelhos novos $\left(\mathrm{p}_{\mathrm{i}}\right.$ : (pres ep $\mathrm{p}_{\mathrm{i}}:\left(\mathrm{e}_{\mathrm{i}}:\left[\left(\mathrm{f}_{\mathrm{i}}:\left[\left(\mathrm{f}_{\mathrm{j}}\right.\right.\right.\right.\right.$ : ver $\left.\left(\mathrm{f}_{\mathrm{j}}\right)\right)\left(\mathrm{x}_{\mathrm{i}}\right)_{\mathrm{A}}\left(\mathbf{p}_{\mathrm{j}}:\left(\right.\right.$ pres ep $\mathrm{p}_{\mathrm{j}}$ : [-está cada vez mais difícil competir com o valor baixo dos aparelhos novos -] $\left.\left.\left.\left.\left.\left.\left.\left.\left(e \mathrm{p}_{\mathrm{j}}\right)\right)\left(\mathbf{p}_{\mathrm{j}}\right)\right)\right]\left(\mathrm{f}_{\mathrm{i}}\right)\right)\left(\mathrm{e}_{\mathrm{i}}\right)_{\phi}\right]\right)\left(\mathrm{ep}_{\mathrm{i}}\right)\right)\left(\mathrm{p}_{\mathrm{i}}\right)\right)$

(190) Ouvi que o caminhão esquentava o motor.

$\left(\mathrm{p}_{\mathrm{i}}\right.$ : (past e $\mathrm{p}_{\mathrm{i}}:\left(\mathrm{e}_{\mathrm{i}}:\left[\left(\mathrm{f}_{\mathrm{i}}:\left[\left(\mathrm{f}_{\mathrm{j}}\right.\right.\right.\right.\right.$ : ouvir $\left.\left(\mathrm{f}_{\mathrm{j}}\right)\right)\left(\mathrm{x}_{\mathrm{i}}\right)_{\mathrm{A}}$ (past $\mathbf{e p}_{\mathrm{j}}$ : [-o caminhão esquentava o motor $\left.\left.\left.\left.\left.\left.\left.-]\left(\mathbf{e p}_{\mathrm{j}}\right)\right)\right]\left(\mathrm{f}_{\mathrm{i}}\right)\right)\left(\mathrm{e}_{\mathrm{i}}\right)_{\phi}\right]\right)\left(\mathrm{ep}_{\mathrm{i}}\right)\right)\left(\mathrm{p}_{\mathrm{i}}\right)\right)$

Em (184), o verbo toma como complemento um Conteúdo Proposicional, $\left(\mathrm{p}_{\mathrm{j}}\right.$ ), ao passo que em (190) o complemento é do tipo Episódio, $\left(\mathrm{ep}_{\mathrm{j}}\right)$. Assim, em (190) a Proposição ( $\left.\mathrm{p}_{\mathrm{i}}\right)$ contém um Episódio $\left(\mathrm{ep}_{\mathrm{i}}\right)$, que contém um Estado-de-Coisas $\left(\mathrm{e}_{\mathrm{i}}\right)$, que se caracteriza por uma Propriedade Configuracional $\left(\mathrm{f}_{\mathrm{i}}\right)$. Essa Propriedade $\left(\mathrm{f}_{\mathrm{i}}\right)$ contém a Propriedade $\left(\mathrm{f}_{\mathrm{j}}\right)$, que especifica o tipo de relação que se estabelece entre o Indivíduo $\left(\mathrm{x}_{\mathrm{i}}\right)$, que designa o Falante, e o Episódio $\left(\mathrm{ep}_{\mathrm{j}}\right)$. Em outras palavras, o verbo ouvir $\left(\mathrm{f}_{\mathrm{j}}\right)$, nesse caso, exprime que a dedução do Falante $\left(\mathrm{x}_{\mathrm{i}}\right)$, contida no Episódio $\left(\mathrm{ep}_{\mathrm{j}}\right)$, teve como base evidências apreendidas por meio do sentido da audição.

Além da organização semântica apresentada em (190), a evidencialidade deduzida pode ser representada de duas outras maneiras. Como se observa em (192) e (193):

(192) bom aí... descemo(s) do carro eu num sabia onde eu tava eu tava numa calçada subi uma esCAda... d'uma casa aí a hora que eu vi:: eu já tava num/ assim pelo que eu vi assim a casa já tava toda... tudo... bagunçada começaram a abrí(r) gaVEta jane/ éh:: porta de guarda-ro(u)pa tava tudo caído no chão... aí me jogaram num quarto... escuro lá... sempre [com] (AC-077, L. 44-49)

$\left(\mathrm{p}_{\mathrm{i}}\right.$ : (past e $\mathrm{p}_{\mathrm{i}}$ : $\left(\mathrm{e}_{\mathrm{i}}:\right.$ [-a casa já tava toda bagunçada-] $\left.\left.\left.\left(\mathrm{e}_{\mathrm{i}}\right)_{\phi}\right]\right)\left(\mathrm{ep}_{\mathrm{i}}\right)\left(\mathrm{p}_{\mathrm{i}}\right)\right):\left(\mathrm{p}_{\mathrm{j}}:\left(\right.\right.$ past ep $\mathrm{p}_{\mathrm{j}}:\left(\mathrm{e}_{\mathrm{j}}\right.$ : $\left.\left.\left[\left(\mathbf{f}_{\mathbf{i}}:\left[\left(\mathbf{f}_{\mathbf{j}}: \operatorname{ver}\left(\mathbf{f}_{\mathbf{j}}\right)\right)\left(\mathbf{x}_{\mathbf{i}}\right)_{\mathbf{A}}\left(\mathbf{e p}_{\mathbf{i}}\right)\right]\left(\mathrm{f}_{\mathrm{i}}\right)\right)\left(\mathrm{e}_{\mathrm{j}}\right)\right]\right)\left(\mathrm{ep} \mathrm{p}_{\mathrm{j}}\right)\left(\mathrm{p}_{\mathrm{j}}\right)\right)$ 
(193) Inf.2: é você vai tê(r) que recorrê(r) M. a única forma aí... e óh... se você recorrê(r) e não for lá... nem que cê num fizé(r) mas pelo menos vai lá fora no dia... eles nem lêem... eu vi ontem lá óh... chega lá ((imita som de uma pessoa lendo rápido e baixo))... é mais é muito mais fácil pra eles M. mantê(r) sentença... - “ah mantém a sentença... por unanimidade é isso"- ontem eu desanimei viu?... esse sistema de recurso de escrevê(r) aquela/... um MONte de babose(i)ra... óh... pode pará(r)... até foi bom eu í(r) pra vê(r)... ontem (AI-010, L. 109-115)

$\left(\mathrm{p}_{\mathrm{i}}:\left(\right.\right.$ past ep $\mathrm{i}$ : [-eles nem lêem-] $\left.\left(\mathrm{ep}_{\mathrm{i}}\right)\left(\mathrm{p}_{\mathrm{i}}\right)\right)\left(\mathrm{p}_{\mathrm{j}}:\left(\right.\right.$ past ep $\mathrm{j}:\left(\mathrm{e}_{\mathrm{j}}:\left[\left(\mathbf{f}_{\mathrm{j}}:\left[\left(\mathbf{f}_{\mathbf{k}}: \operatorname{ver}\left(\mathbf{f}_{\mathrm{k}}\right)\right)\left(\mathbf{x}_{\mathrm{i}}\right)_{\mathbf{A}}\left(\mathrm{t}_{\mathrm{i}}\right)\right.\right.\right.\right.$ $\left.\left.\left.\left.\left(l_{i}\right)\right]\left(f_{j}\right)\left(e_{j}\right)\right]\right)\left(e p_{j}\right)\left(p_{j}\right)\right)$

Em (192), o verbo ver ocorre na Proposição $\left(\mathrm{p}_{\mathrm{j}}\right)$, que atua como modificador do Episódio $\left(e \mathrm{p}_{\mathrm{i}}\right)$, contido dentro do Conteúdo Proposicional $\left(\mathrm{p}_{\mathrm{i}}\right)$. O escopo do modificador $\left(\mathrm{p}_{\mathrm{j}}\right)$ sobre $\left(e \mathrm{p}_{\mathrm{i}}\right)$, e não sobre $\left(\mathrm{p}_{\mathrm{i}}\right)$, deve-se ao tipo de relação que se estabelece entre o verbo ver e o que é percebido. Nesse caso, o verbo ver exprime uma dedução feita a partir de evidências visuais. A mesma análise é válida para (193): a Proposição $\left(\mathrm{p}_{\mathrm{j}}\right)$, que contém o verbo de percepção, exprime o tipo de percepção envolvido na dedução do Episódio $\left(\mathrm{ep}_{\mathrm{i}}\right)$. A diferença entre (192) e (193), que pode ser visualizada nas estruturas subjacentes de ambos os casos, é que, no segundo caso, a Proposição $\left(\mathrm{p}_{\mathrm{j}}\right)$ não atua como modificador; ela é uma Proposição independente daquela que contém o Episódio $\left(\mathrm{ep}_{\mathrm{i}}\right)$, que apresenta a dedução. Observa-se ainda que, em (193), o Falante não explicita verbalmente a referência anafórica, mas está claro pelo contexto que o que ele vê, nesse caso, é o Episódio apresentado antes. Como, na estrutura subjacente só são representadas as unidades linguísticas de fato realizadas, a referência anafórica implícita não está presente na estrutura subjacente de (193).

O Quadro 11, a seguir, resume as três estruturas subjacentes possíveis para os casos de evidencialidade deduzida: 


\begin{tabular}{|c|}
\hline $\begin{array}{l}\text { A EVIDENCIALIDADE NO NÍVEL REPRESENTACIONAL } \\
\text { Evidencialidade deduzida }\end{array}$ \\
\hline (194) $\quad\left(\mathrm{p}_{1}:\left(\pi \mathrm{ep}_{1}:\left(\mathrm{e}_{1}:\left[\left(\mathrm{f}_{1}:\left[\left(\mathbf{f}_{2}\right)\left(\mathbf{x}_{1}\right)_{\mathbf{A}}\left(\mathbf{e p}_{2}\right)_{\phi}\right]\left(\mathrm{f}_{1}\right)\right)\left(\mathrm{e}_{1}\right)_{\phi}\right]\right)\left(\mathrm{ep}_{1}\right)\right)\left(\mathrm{p}_{1}\right)\right)$ \\
\hline $\begin{array}{l}(195) \quad\left(\mathrm{p}_{1}:\left(\pi \text { ep }{ }_{1}:\left(\mathrm{e}_{1}\right)\left(\mathrm{ep}_{1}\right)\left(\mathrm{p}_{1}\right)\right):\left(\mathrm{p}_{2}:\left(\pi \mathrm{ep}_{2}:\left(\mathrm{e}_{2}:\left[\left(\mathbf{f}_{\mathbf{1}}:\left[\left(\mathbf{f}_{2}\right)\left(\mathbf{x}_{\mathbf{n}}\right)_{\mathbf{A}}\left(\mathbf{e p}_{1}\right)\right]\left(\mathrm{f}_{1}\right)\right)\left(\mathrm{e}_{2}\right)\right]\right)\left(\mathrm{ep}_{2}\right)\right.\right.\right. \\
\left.\left(\mathrm{p}_{2}\right)\right)\end{array}$ \\
\hline $\begin{array}{l}(196) \quad\left(\mathrm{p}_{1}:\left(\pi \text { ep } \mathrm{p}_{1}:\left(\mathrm{e}_{1}\right)\left(\mathrm{ep}_{1}\right)\right)\left(\mathrm{p}_{1}\right)\right)\left(\mathrm{p}_{2}:\left(\pi \mathrm{ep}_{2}:\left(\mathrm{e}_{2}:\left[\left(\mathrm{f}_{1}:\left[\left(\mathbf{f}_{2}\right)\left(\mathbf{x}_{1}\right)_{\mathbf{A}}\left(\mathbf{e p}_{1}\right)\right]\left(\mathrm{f}_{1}\right)\right)\left(\mathrm{e}_{2}\right)\right]\right)\left(e \mathrm{p}_{2}\right)\right)\right. \\
\left.\left(\mathrm{p}_{2}\right)\right)\end{array}$ \\
\hline
\end{tabular}

Quadro 11. Estruturas subjacentes representacionais da evidencialidade deduzida

A estrutura subjacente (194) representa os casos em que o Episódio que contém a informação deduzida pelo Falante ocorre como segundo argumento dentro do Conteúdo Proposicional que contém o verbo de percepção, que explicita a partir de que sentido foi obtida a evidência para se fazer a dedução. A estrutura apresentada em (195) representa os casos em que o verbo de percepção ocorre dentro de um Conteúdo Proposicional que funciona como modificador do Episódio que contém a informação deduzida pelo Falante. A estrutura apresentada em (196) representa os casos em que há dois Conteúdos Proposicionais independentes. Um deles apresenta a informação deduzida pelo Falante e o outro, que contém o verbo de percepção, explicita o sentido envolvido na dedução. Como visto na ocorrência apresentada em (193), o Episódio $\left(\mathrm{ep}_{\mathrm{i}}\right)$ pode não ser retomado explicitamente a partir de referência anafórica dentro do Conteúdo Proposicional que contém o verbo de percepção.

Os resultados apresentados nesta seção mostram que a evidencialidade deduzida também é um tipo evidencial relevante em língua portuguesa, pelo menos no que se refere à evidencialidade expressa por meio de verbos de percepção. Assim, esses verbos podem se relacionar com três camadas do Nível Representacional, e não duas como está previsto em Hengeveld e Mackenzie (2008). Além da evidencialidade inferida, que atua na camada do Conteúdo Proposicional, e da direta, que atua na camada do Estado-de-Coisas, deve ser considerada também a evidencialidade que atua na camada do Episódio, a dedutiva. 
Tendo em vista esse quarto tipo de evidencialidade identificado na análise das ocorrências de verbos de percepção, o Quadro 8, apresentado anteriormente, precisa ser revisto de modo que a dedução seja introduzida como um tipo diferente de evidencialidade. $\mathrm{O}$ Quadro reformulado é apresentado a seguir:

\begin{tabular}{|l|c|c|c|c|}
\hline \multirow{2}{*}{$\begin{array}{c}\text { Verbo de } \\
\text { percepção }\end{array}$} & $\begin{array}{c}\text { Evidencialidade } \\
\text { reportativa }\end{array}$ & $\begin{array}{c}\text { Evidencialidade } \\
\text { inferida }\end{array}$ & $\begin{array}{c}\text { Evidencialidade } \\
\text { deduzida }\end{array}$ & $\begin{array}{c}\text { Evidencialidade } \\
\text { direta }\end{array}$ \\
\cline { 2 - 5 } & $\begin{array}{c}\text { Conteúdo } \\
\text { Comunicado }\end{array}$ & $\begin{array}{c}\text { Conteúdo } \\
\text { Proposicional }\end{array}$ & Episódio & Estado-de-Coisas \\
\hline Ver & + & + & + & + \\
\hline Ouvir & + & + & + & + \\
\hline Sentir & - & + & + & + \\
\hline
\end{tabular}

Quadro 12. Verbos de percepção por tipo de evidencialidade, camada e nível da GDF II

\subsection{A evidencialidade direta}

A evidencialidade direta é utilizada pelo Falante quando ele deseja informar ao Ouvinte que testemunhou um Estado-de-Coisas acontecer. Como mostram os Quadros 8 e 12, esse tipo de evidencialidade pode ser codificado pelos três verbos analisados neste estudo. O uso desses verbos na expressão de evidencialidade direta depende da maneira como o Estadode-Coisas foi percebido pelo Falante, como pode ser observado a seguir.

O verbo ver indica que o Estado-de-Coisas foi percebido pelo Falante por meio da visão (197) ou da audição (198), o verbo ouvir introduz um Estado-de-Coisas percebido pela audição (199) e o verbo sentir apresenta Estados-de-Coisas percebidos pelo tato (200), olfato (201) e paladar (202):

(197) Depois de pegar minha medalha e meu lanche, fui para a linha de chegada esperar os vencedores da maratona. Deu tempo certinho. Vi a chegada da Marizete Resende (2h42m46s) e depois do estreante na Maratona do Rio, o Marco Antonio Pereira ( $2 \mathrm{~h} 17 \mathrm{~m} 10 \mathrm{~s})$, fechando a dobradinha brasileira, derrotando os quenianos.

(http://www.podcorrer.com/2009/06/29/meia-maratona-do-rio-resultado/) 
(198) Recentemente eu adquiri um casal de platis e coloquei no meu aquário. Acho que já tem entre 2 a 3 semanas. Até hoje nada. Não vejo sinais de "cruzamento". Só vejo o macho correndo atrás da fêmea e nada. Aí eu fiquei na dúvida. Existe cio para fêmeas de platis? Se existir, quanto é esse tempo? Outra coisa. Qual o motivo para eles ainda não terem acasalados? Tem que bater os "gênios" dos peixinhos? Brincadeiras à parte, eu sempre vejo o pessoal falando que o tempo é em torno de 2 a 3 semanas para ela ter os alevinos. Também vejo falar que os casais de bandeiras formam por afinidade. Será que é assim também com os platis?

(http://www.aquaonline.com.br/forum/viewtopic.php?f=7\&t=16014)

(199) Sete e meia da manhã. Cruzo a cidade adormecida e escura. Já no centro, perto do trabalho, ouço passarinhos cantando. Passarinhos cantando. Em pleno janeiro. (http://fabriani.com/?m=200801)

(200) Quanto as tremidinhas também já senti várias vezes. Mas, gente, fiquei tão feliz agora. Senti ela mexer de verdade! Agorinha mesmo. Nada brusco, uma cosquinha, mas que deu para ter certeza que é ela. (http://www.e-familynet.com/phpbb/vcs-ja-sentem-o-bebe-mexer-vt95644.html)

(201) — A gente se vê amanhã — Ele disse segurando minhas mãos. Eu só assenti com a cabeça e ele me beijou. Um beijo rápido, afinal todos estavam olhando, mais o suficiente para eu me arrepiar.

Entrei no carro e fechei a porta. E aquela sensação estranha, de estar sendo observada voltou e eu senti o cheiro entrar pelas janelas abertas.

Quando meu pai parou o carro na frente do meu prédio o cheiro ainda estava lá, como se o cara estivesse nos seguido. (http://ashleygreece-livro.blogspot.com/2009/06/8-capitulo.html)

(202) - Sasuke... - ouvi meu nome, de novo — Este é o sabor do sangue Uchiha.

Me falou, rapidamente eu senti sua mão viscosa e escorregadia, em meu pescoço. Com plena certeza de que me mataria, fechei os olhos. Um beijo voraz e cruel foi o que me deu. Senti o gosto de sangue misturar-se com minha saliva e descendo como ácido por minha garganta. As lágrimas caíram de novo, enquanto ficava sem ar.

- Sentiu o gosto Sasuke? Este é o gosto do seu sangue. Sangue que você não merece. (http://www.fanfiction.net/s/4139087/1/Palavras)

Todas essas ocorrências de evidencialidade direta têm em comum o fato de os verbos de percepção expressarem que o Falante testemunhou, de maneira direta por meio de algum sentido, um Estados-de-Coisas acontecer. Em (197), o verbo ver indica que o Estado-deCoisas da chegada da Marizete Resende foi percebido pelo falante por meio da visão. Em (198), há dois casos em que esse mesmo verbo se relaciona com Estados-de-Coisas perceptíveis por meio da audição: em ambos os casos, trata-se do Estado-de-Coisas de alguém falar algo. Em (199), o verbo ouvir também introduz um Estado-de-Coisas perceptível por meio da audição. A diferença entre (198) e (199) está na natureza da informação sonora 
percebida: no primeiro caso, a informação é verbal e, no segundo caso, ela é não-verbal. Em (200), o verbo sentir introduz um Estado-de-Coisas percebido por meio do tato. Em (201), esse verbo indica que o Falante percebeu, por meio do olfato, o cheiro entrar pelas janelas; e, em (202), o verbo sentir é usado para indicar uma informação que foi apreendida pelo Falante por meio do seu paladar. Nos dois últimos casos, há a especificação do tipo de sentido envolvido pela introdução de um nome ("cheiro" em (201) e "gosto" em (202)) que complementa o verbo sentir. Como foi visto no Capítulo II, esse verbo, em muitas línguas, e também parece ser o caso em português, precisa ser especificado por um nome ao se referir a percepções olfativas e gustativas.

A análise das ocorrências de evidencialidade direta apresentadas de (197) a (202) mostra que existem mecanismos linguísticos disponíveis aos Falantes do português para que eles possam expressar as diferentes formas de obtenção de informações via percepção direta por meio de algum sentido. Tais resultados estão em desacordo com o que afirma Dall'AglioHattnher (2001). Segundo a autora, "na língua portuguesa a expressão de um conhecimento originado na experiência do próprio falante parece dispensar a marca evidencial" (DALL'AGLIO-HATTNHER, 2001, p.33). Tal afirmação poderia dar a entender que em língua portuguesa não há expressão de evidencialidade direta, o que não é verdade. $\mathrm{Na}$ ocorrência a seguir, o contraste entre a apresentação da mesma informação sem e com a marcação evidencial demonstra a produtividade da evidencialidade direta em língua portuguesa:

(203) Inf.: ah e aí:: eu fui no Pales::tra... encontrei e::la... a gente [conversô.:(u)] Doc.: [o(u)tro dia] cê foi no Palestra? Inf.: é... no dia do desfile... ela desfilô::(u) vi ela desfilá::(r)... tava lin::da... aí depois do desfile a gente conversô(u)... aí eu dei um/ umas indiretas nela... NÃO indireta foi... BEM direta... porque senão num ia conseguí(r) falá(r) (AC-021, L.62-66) 
Em (203), a informação "ela desfilou" é apresentada, num primeiro momento, sem a especificação evidencial, não deixando clara a maneira como o Falante adquiriu tal informação. Sem a qualificação evidencial, não é possível dizer se o falante presenciou o Estado-de-Coisas de alguém desfilar ou se tal informação chegou ao seu conhecimento por meio de um relato de uma terceira pessoa. Ao reintroduzir a mesma informação como complemento do verbo ver, na construção "vi ela desfilar", o Falante especifica que presenciou o desfile, indicando a maneira como a informação apresentada foi obtida por ele: de maneira direta a partir de uma percepção visual.

Em todos os casos de evidencialidade direta apresentados acima, a mesma representação semântica se aplica. A última ocorrência, (203), é tomada como modelo para ilustrar a estrutura subjacente que também se aplica aos demais casos, apresentados de (197) a (202):

(204) ( $\mathrm{p}_{\mathrm{i}}:\left(\right.$ past ep $\mathrm{p}_{\mathrm{i}}:\left(\mathrm{e}_{\mathrm{i}}:\left[\left(\mathrm{f}_{\mathrm{i}}:\left[\left(\mathrm{f}_{\mathrm{j}}: \operatorname{ver}\left(\mathrm{f}_{\mathrm{j}}\right)\right)\left(\mathrm{x}_{\mathrm{i}}\right)_{\mathrm{A}}\left(\operatorname{sim} \mathrm{e}_{\mathrm{j}}:\left(\mathrm{f}_{\mathrm{k}}:[\right.\right.\right.\right.\right.\right.$-ela desfilar- $\left.\left.\left.\left.\left.\left.]\left(\mathrm{f}_{\mathrm{k}}\right)\right)\left(\mathrm{e}_{\mathrm{j}}\right)\right)\right]\left(\mathrm{f}_{\mathrm{i}}\right)\right)\left(\mathrm{e}_{\mathrm{i}}\right)\right]\right)$ $\left.\left.\left(\mathrm{ep}_{\mathrm{i}}\right)\right)\left(\mathrm{p}_{\mathrm{i}}\right)\right)$

Conforme se pode observar na representação semântica, o Estado-de-Coisas $\left(\mathrm{e}_{\mathrm{i}}\right)$ é caracterizado pela Propriedade Configuracional $\left(\mathrm{f}_{\mathrm{i}}\right)$, que contém a Propriedade $\left(\mathrm{f}_{\mathrm{j}}\right)$ que especifica a relação, ou seja, a percepção direta, entre o Indivíduo $\left(\mathrm{x}_{\mathrm{i}}\right)$, o Falante, e o Estadode-Coisas $\left(\mathrm{e}_{\mathrm{j}}\right)$.

A estrutura hierárquica representacional que se aplica aos casos de evidencialidade direta é a seguinte:

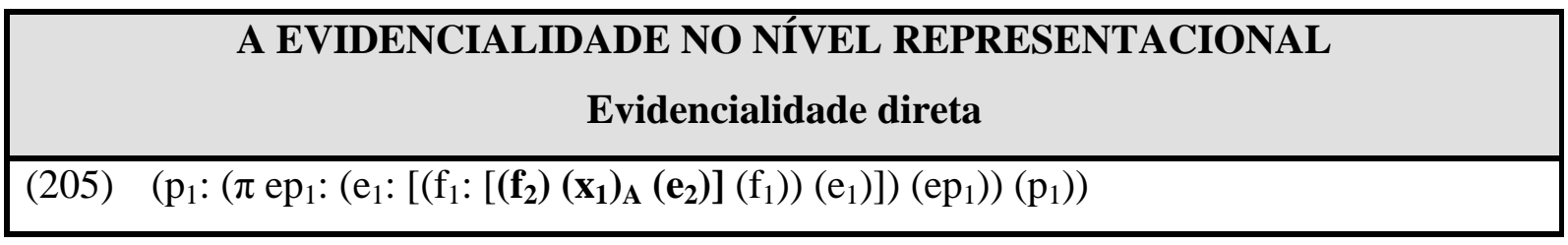

Quadro 13. Estrutura subjacente representacional da evidencialidade direta 
Em tal estrutura, o Estado-de-Coisas $\left(\mathrm{e}_{1}\right)$ representa a estrutura evidencial como um todo. Ele é caracterizado pela Propriedade Configuracional $\left(\mathrm{f}_{1}\right)$, em que a Propriedade $\left(\mathrm{f}_{2}\right)$ corresponde ao verbo percepção, o Indivíduo $\left(\mathrm{x}_{1}\right)$ corresponde ao Falante e o Estado-de-Coisas $\left(\mathrm{e}_{2}\right)$ corresponde ao que foi percebido pelo Falante.

Tendo em vista que, na expressão da evidencialidade direta, o Falante afirma ter observado um Estado-de-Coisas acontecer, a simultaneidade entre o Estado-de-Coisas da percepção e o Estado-de-Coisas percebido é uma característica fundamental nesse tipo de evidencialidade. Assim, considerando a estrutura subjacente (205), $\left(\mathrm{e}_{2}\right)$ deve necessariamente ser simultâneo a $\left(\mathrm{e}_{1}\right)$. Esse ponto será retomado de uma forma mais detalhada em 2.5.2.

Em resumo, o Quadro a seguir reúne todos os tipos de estruturas subjacentes representacionais que descrevem a evidencialidade expressa pelos verbos ver, ouvir e sentir: 


\begin{tabular}{|c|c|}
\hline & A EVIDENCIALIDADE NO NÍVEL REPRESENTACIONAL \\
\hline \multirow{3}{*}{ 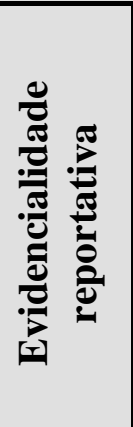 } & $\left(\mathrm{p}_{1}:\left(\pi \mathrm{ep}_{1}:\left(\mathrm{e}_{1}:\left[\left(\mathrm{f}_{1}:\left[\left(\mathbf{f}_{2}\right)\left(\mathbf{x}_{\mathbf{1}}\right)_{\mathbf{A}}\left(\mathbf{C}_{\mathbf{1}}\right)_{\mathbf{U}}\right]\left(\mathrm{f}_{1}\right)\right)\left(\mathrm{e}_{1}\right)_{\phi}\right]\right)\left(\mathrm{ep}_{1}\right)\right)\left(\mathrm{p}_{1}\right)\right)$ \\
\hline & $\begin{array}{l}\left(\mathrm{p}_{1}:\left(\pi \mathrm{ep}_{1}:\left(\mathrm{e}_{1}\right)\left(\mathrm{ep}_{1}\right)\right)\left(\mathrm{p}_{1}\right)\right):\left(\mathrm{p}_{2}:\left(\pi \mathrm{ep}_{2}:\left(\mathrm{e}_{2}:\left[\left(\mathrm{f}_{1}:\left[\left(\mathbf{f}_{2}\right)\left(\mathbf{x}_{1}\right)_{\mathrm{A}}\left(\mathbf{C}_{\mathbf{1}}:\left(\mathbf{p}_{1}\right)\right)\right]\left(\mathrm{f}_{1}\right)\right)\left(\mathrm{e}_{2}\right)\right]\right)\right.\right. \\
\left.\left.\left(\mathrm{ep}_{2}\right)\right)\left(\mathrm{p}_{2}\right)\right)\end{array}$ \\
\hline & $\begin{array}{l}\left(\mathrm{p}_{1}:\left(\pi \mathrm{ep}_{1}:\left(\mathrm{e}_{1}\right)\left(e \mathrm{p}_{1}\right)\left(\mathrm{p}_{1}\right)\right)\left(\mathrm{p}_{2}:\left(\pi \mathrm{ep}_{2}:\left(\mathrm{e}_{2}:\left[\left(\mathrm{f}_{1}:\left[\left(\mathbf{f}_{2}\right)\left(\mathbf{x}_{1}\right)_{\mathbf{A}}\left(\mathbf{C}_{\mathbf{1}}:\left(\mathrm{p}_{1}\right)\left(\mathbf{C}_{1}\right)_{\mathrm{U}}\right)\right]\left(\mathrm{f}_{1}\right)\right.\right.\right.\right.\right.\right. \\
\left.\left.\left.\left(\mathrm{e}_{2}\right)\right]\right)\left(\mathrm{ep}_{2}\right)\left(\mathrm{p}_{2}\right)\right)\end{array}$ \\
\hline \multirow{3}{*}{ 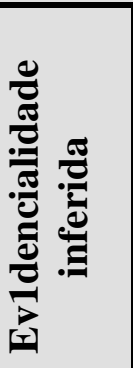 } & $\left(\mathrm{p}_{1}:\left(\pi \mathrm{ep}_{1}:\left(\mathrm{e}_{1}:\left[\left(\mathrm{f}_{1}:\left[\left(\mathbf{f}_{2}\right)\left(\mathbf{x}_{1}\right)_{\mathrm{A}}\left(\mathbf{p}_{2}\right)_{\mathrm{U}}\right]\left(\mathrm{f}_{1}\right)\left(\mathrm{e}_{1}\right)_{\phi}\right]\right)\left(\mathrm{ep}_{1}\right)\left(\mathrm{p}_{1}\right)\right)\right.\right.$ \\
\hline & $\left(\mathrm{p}_{1}:\left(\pi \mathrm{ep}_{1}:\left(\mathrm{e}_{1}\right)\left(\mathrm{ep}_{1}\right)\left(\mathrm{p}_{1}\right)\right):\left(\mathrm{p}_{2}:\left(\pi \mathrm{ep}_{2}:\left(\mathrm{e}_{2}:\left[\left(\mathbf{f}_{\mathbf{1}}:\left(\left(\mathbf{f}_{\mathbf{2}}\right)\left(\mathbf{x}_{\mathbf{1}}\right)_{\mathrm{A}}\right]\left(\mathrm{f}_{1}\right)\right)\left(\mathrm{e}_{2}\right)\right]\right)\left(\mathrm{ep}_{2}\right)\right)\left(\mathrm{p}_{2}\right)\right)\right.$ \\
\hline & $\left(\mathrm{p}_{1}:\left(\pi \mathrm{ep}_{1}:\left(\mathrm{e}_{1}\right)\left(\mathrm{ep}_{1}\right)\left(\mathrm{p}_{1}\right)\right)\left(\mathrm{p}_{2}:\left(\pi \mathrm{ep}_{2}:\left(\mathrm{e}_{2}:\left[\left(\mathbf{f}_{\mathbf{1}}:\left[\left(\mathbf{f}_{2}\right)\right)\left(\mathbf{x}_{\mathbf{1}}\right)_{\mathbf{A}}\left(\mathbf{p}_{1}\right)\right]\left(\mathrm{f}_{1}\right)\left(\mathrm{e}_{2}\right)\right]\right)\left(\mathrm{ep}_{2}\right)\left(\mathrm{p}_{2}\right)\right)\right.\right.$ \\
\hline \multirow{3}{*}{ 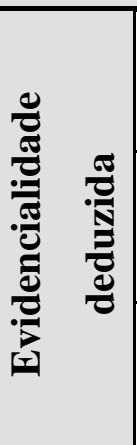 } & $\left(\mathrm{p}_{1}:\left(\pi \mathrm{ep}_{1}:\left(\mathrm{e}_{1}:\left[\left(\mathrm{f}_{1}:\left[\left(\mathbf{f}_{\mathbf{2}}\right)\left(\mathbf{x}_{\mathbf{1}}\right)_{\mathbf{A}}\left(\mathbf{e p}_{2}\right)_{\mathrm{U}}\right]\left(\mathrm{f}_{1}\right)\left(\mathrm{e}_{1}\right)_{\phi}\right]\right)\left(\mathrm{ep}_{1}\right)\left(\mathrm{p}_{1}\right)\right)\right.\right.$ \\
\hline & $\left(\mathrm{p}_{1}:\left(\pi \mathrm{ep}_{1}:\left(\mathrm{e}_{1}\right)\left(\mathrm{ep}_{1}\right)\left(\mathrm{p}_{1}\right)\right):\left(\mathrm{p}_{2}:\left(\pi \mathrm{ep}_{2}:\left(\mathrm{e}_{2}:\left[\left(\mathbf{f}_{\mathbf{1}}:\left(\left(\mathbf{f}_{2}\right)\left(\mathbf{x}_{1}\right)_{\mathrm{A}}\right]\left(\mathrm{f}_{1}\right)\right)\left(\mathrm{e}_{2}\right)\right]\right)\left(\mathrm{ep}_{2}\right)\right)\left(\mathrm{p}_{2}\right)\right)\right.$ \\
\hline & $\begin{array}{l}\left(\mathrm{p}_{1}:\left(\pi \mathrm{ep}_{1}:\left(\mathrm{e}_{1}\right)\left(\mathrm{ep}_{1}\right)\left(\mathrm{p}_{1}\right)\right)\left(\mathrm{p}_{2}:\left(\pi \mathrm{ep}_{2}:\left(\mathrm{e}_{2}:\left[\left(\mathbf{f}_{\mathbf{1}}:\left[\left(\mathbf{f}_{2}\right)\right)\left(\mathbf{x}_{\mathbf{1}}\right)_{\mathbf{A}}\left(\mathbf{e p}_{\mathbf{1}}\right)\right]\left(\mathrm{f}_{1}\right)\right)\left(\mathrm{e}_{2}\right)\right]\right)\left(\mathrm{ep}_{2}\right)\right)\right. \\
\left.\left(\mathrm{p}_{2}\right)\right)\end{array}$ \\
\hline تِ & $\left(\mathrm{p}_{1}:\left(\pi \mathrm{ep}_{1}:\left(\mathrm{e}_{1}:\left[\left(\mathrm{f}_{1}:\left[\left(\mathbf{f}_{2}\right)\left(\mathbf{x}_{1}\right)_{\mathbf{A}}\left(\mathbf{e}_{2}\right)_{\mathbf{U}}\left(\mathrm{f}_{1}\right)\right]\left(\mathrm{e}_{1}\right)\right)\left(\mathrm{ep}_{1}\right)\left(\mathrm{p}_{1}\right)\right)\right.\right.\right.$ \\
\hline
\end{tabular}

Quadro 14. Estruturas subjacentes representacionais da evidencialidade

\subsection{Outras características dos subtipos evidenciais codificados por ver, ouvir e sentir}

Ainda com relação à semântica dos tipos evidenciais, dois outros aspectos são importantes no tratamento da evidencialidade: a indicação da fonte da informação e o tempo verbal. Como discutido no Capítulo III, os verbos de percepção evidenciais, devido à sua 
natureza semântica, caracterizam-se por focalizar o modo de obtenção da informação e não a fonte da informação. No entanto, as possibilidades de identificação da fonte da informação assumem características específicas em cada subtipo evidencial, como será visto na seção 2.5.1. Como visto no Capítulo II, nos casos de evidencialidade expressos por meio de verbos de percepção, a localização temporal do verbo de percepção, somada a outros fatores, determina a natureza evidencial do verbo. Na seção 2.5.2, serão tratadas as distinções temporais não só do verbo de percepção, mas também dos outros verbos que interagem com ele nas estruturas evidenciais.

\subsubsection{Modo de obtenção da informação e fonte da informação}

Nos casos de evidencialidade reportativa, além de retransmitir informações de terceiros, o Falante necessariamente informa que obteve essas informações utilizando algum sentido: o visual, quando usa o verbo ver no sentido de ler, e o auditivo, quando usa o verbo ouvir. Nesses casos, quando se deseja explicitar a fonte escrita ou o falante original da informação, referências a eles devem ser feitas no contexto por meio da introdução de itens lexicais, como acontece em (173), em que é fornecida a fonte escrita em que constava a informação retransmitida (a Folha de São Paulo), e em (174), em que se indicam os responsáveis por produzir a mensagem que o falante retransmite (alguns atletas).

(173) agora depois disso essa programação

do Gugu::... do Faustão:: (e coisas) nós num eles eh:: assim é muito sensacionalismo né? que nem o Faustão LEva... vamo(s) supor algum ator pra se mostrá(r) a vida então pare::ce:: as pessoas falan(d)o que aquela pessoa é o supra-sumo... tá certo... né?... SÃO todo mundo tem seus pontos negativos seus pontos positivos mais assim... é mui::to:: né? todo mundo ficá(r) choran(d)o que nem esses dias eu vi na Folha de São Paulo que o::... Marcos Paulo foi lá e num chorô(u) nenhum momento então [Doc.: ((risos))]... acharam que ele:: assim é muito durão eu/ eu/ eu num vi eu só só li na Folha de São Paulo criticando o Marcos Paulo porque ele num tinha chorado... uai a pessoa vai lá e é obrigado [a chorá(r)] (AC-118, L.548-557) 
(174) Em conversas com alguns atletas, como Fernando Scherer, ouvi que as instalações do Maria Lenk são as melhores do mundo. O mesmo elogio ouvi do pessoal da patinação de velocidade e de atletas de outras modalidades. A abertura teve nível olímpico e as provas trouxeram para o papo de botequim desde o corte do Ricardinho, do vôlei, até a batida na bola do Hugo Hoyama, do tênis de mesa, popularizando um pouco mais esportes quase desconhecidos. Falhas é claro que existiram, mas o principal legado, além das instalações, é a moral alta por saber que somos capazes de fazer o melhor. (http://www.papodebola.com.br/24horas/20070802.htm)

É interessante comparar esse uso dos verbos ver e ouvir com o uso dos verbos de dizer para exprimir evidencialidade reportativa. Nos casos de evidencialidade reportativa com fonte definida expressos por verbos de dizer, o que se focaliza é exatamente a fonte da informação, e não o modo como o Falante a obteve, como exemplificado em (206):

(206) Em entrevista ao SBT nesta sexta-feira, o deputado federal Ciro Gomes (PSB-CE) disse que o presidente Luiz Inácio Lula da Silva está "perdendo a humildade." (http://jovempan.uol.com.br/noticias/em-entrevista-ciro-ataca-lula-e-dilma-rousseff-196730,,0)

A informação de que o presidente Lula está perdendo a humildade é atribuída, em (206), ao deputado federal Ciro Gomes. Embora seja possível supor, a partir de dados apresentados no contexto anterior à construção evidencial, que o falante obteve tal informação ao ouvir a entrevista que o deputado deu ao SBT, essa indicação do modo de obtenção da informação não é fornecida pelo verbo dizer, como acontece com os verbos ver e ouvir.

Os dados de evidencialidade reportativa codificados por verbos de percepção e de dizer mostram que, na expressão desse tipo de evidencialidade, a fonte da informação é sempre diferente do Falante, podendo ou não estar explicitada no contexto. Nos casos de evidencialidade inferida, deduzida e direta, por outro lado, o Falante é sempre a fonte da informação veiculada, uma vez ele é o responsável pelo cálculo mental, no caso de evidencialidade inferida, pela dedução, no caso de evidencialidade deduzida, e pela percepção sensorial, no caso de evidencialidade direta. Assim, na estrutura subjacente dos casos de 
evidencialidade inferida, deduzida e direta, a fonte da informação está sempre representada como o Indivíduo $\left(\mathrm{x}_{\mathrm{i}}\right)$, que designa o Falante.

Nos casos de evidencialidade inferida, o Falante pode inserir, no contexto, o tipo de evidência que tomou como base para fazer a sua inferência, como acontece nas duas ocorrências repetidas a seguir:

(181) Mah tente não ser tão grossa.

Eu li inteiro e pelo que eu vi você está tentando se afastar dele.

Ele está sendo educado e respeitando seu espaço eu acho que ele deve gostar muito de você para fazer isso, pois ele não está te ignorando e sim te dando espaço.

(http://br.answers.yahoo.com/question/index?qid=20100307110552AAKziug)

(185) — Bels? - Minha mãe chamou.

— Estou aqui no banheiro - Falei entre uma ânsia e outra.

Ouvi que minha mãe puxou a cadeira do meu computador e se sentou, ela esperou eu voltar do banheiro e me deu um remédio para ânsia e ficou ali abraçada comigo.

- Filha, posso te fazer uma pergunta? - Minha mãe perguntou.

- Pode, claro - Respondi sem imaginar qual seria a pergunta.

- Você já menstruou depois daquela noite com o Edward? - Ela perguntou com medo da resposta. Eu senti isso na voz dela.

— Não, mãe - Respondi.

(http://webcache.googleusercontent.com/search?q=cache:dUEynGDQ88EJ:fanfiction.nyah.com.br/histo ria/70890/Revivendo_Um_Sonho/capitulo/5+\%22senti+isso\%22\&cd=41\&hl=BR\&ct=clnk\&gl=br\&lr=1 ang)

Como discutido anteriormente, em (181), o Falante apresenta uma inferência feita a partir da leitura de um texto e, em (185), a inferência do Falante é decorrente de evidência percebida por meio da audição.

\subsubsection{Tempo e aspecto na expressão da evidencialidade}

Como discutido no Capítulo II, os verbos de percepção podem propiciar leitura evidencial apenas quando estão nos tempos presente e passado do modo indicativo. As distinções de tempo, no modelo da GDF, são feitas por meio de operadores e modificadores que atuam nas camadas do Episódio e do Estado-de-Coisas. Os Episódios são caracterizados 
pela localização em tempo absoluto, ao passo que os Estados-de-Coisas são caracterizados pela localização em tempo relativo.

Nos casos de evidencialidade reportativa, nos Episódios que contêm os verbos de percepção, ocorrem operadores de tempo passado e presente e, nos Episódios que ocorrem no interior do Conteúdo Comunicado retransmitido, a localização temporal é variada, podendo inclusive haver referências ao tempo futuro. As ocorrências a seguir ilustram a marcação temporal em casos de evidencialidade reportativa:

(207) Desde o início do ano passado, eu ouço que os preços dos LCDs vão cair, que os CRT vão dar lugar a eles. Mas a realidade hoje é que o preço de um bom monitor LCD (que desbanque um CRT) está lá nas alturas.

(http://www.adrenaline.com.br/forum/monitores/64577-comprei-19-lg-t910b-recomendado.html)

$\left(\mathrm{p}_{\mathrm{i}}:\right.$ (pres ep $\mathrm{p}_{\mathrm{i}}:\left(\mathrm{e}_{\mathrm{i}}:\left[\left(\mathrm{f}_{\mathrm{i}}:\left[\left(\mathrm{f}_{\mathrm{j}}:\right.\right.\right.\right.\right.$ ouvir $\left.\left(\mathrm{f}_{\mathrm{j}}\right)\right)\left(\mathrm{x}_{\mathrm{i}}\right)_{\mathrm{A}}\left(\mathrm{C}_{\mathrm{I}}:\left(\mathrm{p}_{\mathrm{j}}:\left(\right.\right.\right.$ fut ep $\mathrm{p}_{\mathrm{j}}:(-$ os preços dos LCDs vão cair- $\left.\left.\left.\left.\left.\left.\left.\left.\left.\left(\mathrm{ep}_{\mathrm{j}}\right)\right)\left(\mathrm{p}_{\mathrm{j}}\right)\right)\left(\mathrm{C}_{\mathrm{I}}\right)\right)_{\mathrm{U}}\right]\right)\left(\mathrm{f}_{\mathrm{i}}\right)\right)\left(\mathrm{e}_{\mathrm{i}}\right)_{\phi}\right]\right)\left(\mathrm{ep}_{\mathrm{i}}\right)\right):\left[\left(\mathrm{t}_{\mathrm{i}}:\right.\right.$ [-desde o início do ano passado-] $\left(\mathrm{t}_{\mathrm{i}}\right)_{\mathrm{L}}$ $\left.\left.\left.\left(\mathrm{ep}_{\mathrm{i}}\right)_{\phi}\right]\right)\left(\mathrm{p}_{\mathrm{i}}\right)\right)$

(170) A casa do Benfica em Moura também foi vandalizada esta madrugada. Ouvi isso na TV. (http://www.serbenfiquista.com/forum/index.php?topic=39648.900)

$\left(\mathrm{p}_{\mathrm{i}}\right.$ : (past $\mathrm{ep}_{\mathrm{i}}$ : $\left(\mathrm{e}_{\mathrm{i}}:\left[\left(\mathrm{f}_{\mathrm{i}}:-\mathrm{A}\right.\right.\right.$ casa do Benfica em Moura também foi vandalizada esta madrugada- $\left.\left.\left.\left.\left.\left(\mathrm{f}_{\mathrm{i}}\right)\right)\left(\mathrm{e}_{\mathrm{i}}\right)\right]\right)\left(\mathrm{ep}_{\mathrm{i}}\right)\right)\left(\mathrm{p}_{\mathrm{i}}\right)\right)\left(\mathrm{p}_{\mathrm{j}}:\left(\right.\right.$ past ep $\mathrm{j}:\left(\mathrm{e}_{\mathrm{j}}:\left[\left(\mathrm{f}_{\mathrm{j}}:\left[\left(\mathrm{f}_{\mathrm{k}}:\right.\right.\right.\right.\right.$ ouvir $\left.\left(\mathrm{f}_{\mathrm{k}}\right)\right)\left(\mathrm{x}_{\mathrm{i}}\right)_{\mathrm{A}}\left(\mathrm{C}_{\mathrm{I}}:\left(\mathrm{p}_{\mathrm{i}}\right)\right.$ $\left.\left.\left.\left.\left.\left.\left.\left.\left(\mathrm{C}_{\mathrm{I}}\right)\right)\left(\mathrm{l}_{\mathrm{i}}\right)\right)\right]\left(\mathrm{f}_{\mathrm{j}}\right)\right)\left(\mathrm{e}_{\mathrm{j}}\right)_{\phi}\right]\right)\left(\mathrm{ep}_{\mathrm{j}}\right)\right)\left(\mathrm{p}_{\mathrm{j}}\right)\right)$

Nas representações apresentadas acima é possível observar a atuação dos operadores de tempo absoluto nos Episódios. Em (207), a localização do Episódio (ep $\mathrm{p}_{\mathrm{i}}$, que contém o verbo de percepção, em tempo presente não significa que a percepção auditiva tenha acontecido no momento do Ato de Fala. Nos casos de evidencialidade reportativa de um modo geral, tal marcação temporal indica que o Falante vem tendo acesso à mesma informação linguística (nesse caso, os preços dos LCDs vão cair) há algum tempo, como fica claro também pela presença do modificador temporal desde o início do ano passado. Em (170), a localização temporal de $\left(e p_{j}\right)$, que contém o verbo de percepção, indica quando o Falante obteve a informação: no passado. A localização temporal dos Episódios que contêm a informação que o Falante retransmite varia de acordo com a marcação temporal que tal informação tinha 
quando foi produzida por seu Falante original. Assim, em (207), os episódios (ep $\mathrm{j}_{\mathrm{j}}$ e e (ep $\mathrm{k}$, que fazem parte do Conteúdo Comunicado $\left(\mathrm{C}_{\mathrm{I}}\right)$, são localizados no futuro porque, quando o Falante apreendeu as informações contidas neles, elas provavelmente estavam localizadas em tal tempo. Em (170), a informação contida em $\left(\mathrm{ep}_{\mathrm{i}}\right)$ que o Falante retransmite está localizada no passado porque ela informa sobre um fato que chegou ao conhecimento do Falante depois de ter acontecido.

Há ainda casos de evidencialidade reportativa em que o Episódio que contém a informação retransmitida não está localizado temporalmente, como ilustrado a seguir:

(208) Vi estar aberta a inscrição do concurso do IBGE em www.ibge.mylink.com.br. (http://br.answers.yahoo.com/question/index?qid=20061101060325AAunrGM) $\left(\mathrm{p}_{\mathrm{i}}:\left(\right.\right.$ past $\mathrm{ep}_{\mathrm{i}}:\left(\mathrm{e}_{\mathrm{i}}:\left[\left(\mathrm{f}_{\mathrm{i}}:\left[\left(\mathrm{f}_{\mathrm{j}}: \operatorname{ver}\left(\mathrm{f}_{\mathrm{j}}\right)\right)\left(\mathrm{x}_{\mathrm{i}}\right)_{\mathrm{A}}\left(\mathrm{C}_{\mathrm{I}}:\left(\mathrm{p}_{\mathrm{j}}:\left(\mathrm{ep}_{\mathrm{j}}:\left(\operatorname{sim} \mathrm{e}_{\mathrm{j}}:\right.\right.\right.\right.\right.\right.\right.\right.$-estar aberta a inscrição do concurso do IBGE- $\left.\left.\left.\left.\left.\left.\left.\left.\left.\left(\mathrm{e}_{\mathrm{j}}\right)\left(\mathrm{ep}_{\mathrm{j}}\right)\right)\left(\mathrm{p}_{\mathrm{j}}\right)\right)\left(\mathrm{C}_{\mathrm{I}}\right)\right)_{\mathrm{U}}\left(\mathrm{l}_{\mathrm{i}}\right)\right]\left(\mathrm{f}_{\mathrm{i}}\right)\right)\left(\mathrm{e}_{\mathrm{i}}\right)_{\phi}\right]\right)\left(\mathrm{ep}_{\mathrm{i}}\right)\right)\left(\mathrm{p}_{\mathrm{i}}\right)\right)$

(209) Desde criança ouço ser erradíssimo homem sentir atração por homens. (http://arnaldoporto1989.blogspot.com/2010/06/sou-gaysou-homossexual-e-gosto-de-minha.html) $\left(\mathrm{p}_{\mathrm{i}}:\left(\right.\right.$ pres e $\mathrm{p}_{\mathrm{i}}:\left(\mathrm{e}_{\mathrm{i}}:\left[\left(\mathrm{f}_{\mathrm{i}}:\left[\left(\mathrm{f}_{\mathrm{j}}:\right.\right.\right.\right.\right.$ ouvir $\left.\left(\mathrm{f}_{\mathrm{j}}\right)\right)\left(\mathrm{x}_{\mathrm{i}}\right)_{\mathrm{A}}\left(\mathrm{C}_{\mathrm{I}}:\left(\mathrm{p}_{\mathrm{j}}:\left(\mathrm{ep}_{\mathrm{j}}:\left(\operatorname{sim} \mathrm{e}_{\mathrm{j}}:-\right.\right.\right.\right.$ ser erradíssimo homem sentir atração por homens- $\left.\left.\left.\left.\left.\left.\left.\left.\left.\left.\left(\mathrm{e}_{\mathrm{j}}\right)\right)\left(\mathrm{ep}_{\mathrm{j}}\right)\right)\left(\mathrm{p}_{\mathrm{j}}\right)\right)\left(\mathrm{C}_{\mathrm{I}}\right)\right)_{\mathrm{U}}\left(\mathrm{l}_{\mathrm{i}}\right)\right]\left(\mathrm{f}_{\mathrm{i}}\right)\right)\left(\mathrm{e}_{\mathrm{i}}\right)_{\phi}\right]\right)\left(\mathrm{ep}_{\mathrm{i}}\right)\right)\left(\mathrm{p}_{\mathrm{i}}\right)\right)$

Tanto em (208) quanto em (209), o operador de simultaneidade não marca o Estado-de-Coisas que contém a informação retransmitida como sendo simultâneo à sua percepção por parte do Falante. Independentemente da localização temporal dos Episódios (ep $\left.\mathrm{p}_{\mathrm{i}}\right)$, que exprimem a percepção, a referência temporal dos Episódios $\left(\mathrm{ep}_{\mathrm{j}}\right)$ de (208) e (209) deve ser interpretada como presente.

Nos casos de evidencialidade inferida, assim como acontece com os casos de evidencialidade reportativa, os Episódios que contêm os verbos de percepção são localizados em tempo presente e passado e os Episódios que ocorrem no interior do Conteúdo Proposicional que contém o cálculo mental do Falante possuem localização temporal variada. Nas ocorrências apresentadas a seguir, observa-se a localização temporal independente entre os Episódios nos casos de evidencialidade inferida: 
(210) Saiu o novo Trailer de Percy Jackson e os Olimpianos: O Ladrão de Raios (nossa, que nome grande). E pelo que eu vi o filme não compartilha muitas semelhanças com o livro que o inspira. (http://www.yespop.com.br/2009/11/percy-jackson-e-adaptacao-infiel.html) $\left(\mathrm{p}_{\mathrm{i}}\right.$ : (pres e $\mathrm{p}_{\mathrm{i}}$ : [ $-\mathrm{o}$ filme não compartilha muitas semelhanças com o livro que o inspira $\left.\left.-]\left(\mathrm{ep}_{\mathrm{i}}\right)\right)\left(\mathrm{p}_{\mathrm{i}}\right)\right):\left(\mathrm{p}_{\mathrm{j}}:\left(\mathbf{p a s t} \mathrm{ep}_{\mathrm{j}}:\left(\mathrm{e}_{\mathrm{j}}:\left[\left(\mathbf{f}_{\mathbf{i}}:\left(\mathbf{f}_{\mathbf{j}}: \operatorname{ver}\left(\mathbf{f}_{\mathbf{j}}\right)\left(\mathbf{x}_{\mathbf{i}}\right)_{\mathbf{A}}\left(\mathbf{p}_{\mathbf{i}}\right)\right]\left(\mathrm{f}_{\mathrm{i}}\right)\right)\left(\mathrm{e}_{\mathrm{j}}\right)\right)\left(\mathrm{ep}_{\mathrm{j}}\right)\right)\left(\mathrm{p}_{\mathrm{j}}\right)\right)\right.$

(211) O mundo do futebol requer equilíbrio. Um dia estamos no topo, no outro estamos em baixa. Sinto que fiz a escolha certa em voltar para o Brasil e também em vir para o Botafogo. Gostava de viver lá, tive outras propostas até mesmo no Brasil, mas senti que aqui poderia ser minha nova casa.

(http://esportes.terra.com.br/futebol/estaduais/2010/noticias/0,,OI4249379-EI14479,00-

Senti+que+o+Botafogo+poderia+ser+minha+nova+casa+diz+Caio.html)

$\left(\mathrm{p}_{\mathrm{i}}:\left(\right.\right.$ pres ep $\mathrm{p}_{\mathrm{i}}:\left(\mathrm{e}_{\mathrm{i}}:\left[\left(\mathrm{f}_{\mathrm{i}}:\left[\left(\mathrm{f}_{\mathrm{j}}: \operatorname{sentir}\left(\mathrm{f}_{\mathrm{j}}\right)\right)\left(\mathrm{x}_{\mathrm{i}}\right)_{\mathrm{A}}\left(\mathrm{p}_{\mathrm{j}}:\left(\right.\right.\right.\right.\right.\right.$ past $\mathrm{ep}_{\mathrm{j}}:[-\mathrm{fiz}$ a escolha certa em voltar para o Brasil e também em vir para o Botafogo-] $\left.\left.\left.\left.\left.\left.\left.\left.\left(e \mathrm{p}_{\mathrm{j}}\right)\right)\left(\mathrm{p}_{\mathrm{j}}\right)\right)\right]\left(\mathrm{f}_{\mathrm{i}}\right)\right)\left(\mathrm{e}_{\mathrm{i}}\right)_{\phi}\right]\right)\left(\mathrm{ep}_{\mathrm{i}}\right)\right)\left(\mathrm{p}_{\mathrm{i}}\right)\right)$

Em (210), o Episódio que contém o verbo de percepção está localizado no passado, o que indica que o ato de inferir aconteceu no passado. Em outras palavras, nesse caso, o Falante inferiu algo sobre o filme "Percy Jackson e os Olimpianos: O Ladrão de Raios" quando assistiu ao seu trailer. O Episódio que contém a inferência propriamente dita está localizado no presente, o que indica que a avaliação do Falante ainda é válida no momento em que o Falante a comunica ao Ouvinte. Em (211), acontece o contrário, o Episódio que contém o verbo de percepção está localizado no presente e o Episódio que contém a inferência está localizado no passado. Essa combinação temporal indica que o Falante infere, no presente, um Conteúdo Proposicional que contém a descrição de uma situação que já aconteceu.

Em (212), o Episódio que contém a inferência do Falante não é localizado temporalmente:

(212) Ouvi a entrevista na íntegra e senti ser Dilma uma pessoa muito arrogante. (http://veja.abril.com.br/blog/augusto-nunes/sanatorio-geral/nenhum-neuronio/) $\left(\mathrm{p}_{\mathrm{i}}\right.$ : (past ep $\mathrm{p}_{\mathrm{i}}:\left(\mathrm{e}_{\mathrm{i}}:\left[\left(\mathrm{f}_{\mathrm{i}}:\left[\left(\mathrm{f}_{\mathrm{j}}: \operatorname{sentir}\left(\mathrm{f}_{\mathrm{j}}\right)\right)\left(\mathrm{x}_{\mathrm{i}}\right)_{\mathrm{A}}\left(\mathrm{p}_{\mathrm{j}}:\left(\mathrm{ep}_{\mathrm{j}}:\left(\right.\right.\right.\right.\right.\right.\right.$ sim $\mathrm{e}_{\mathrm{j}}:[-$ ser Dilma uma pessoa muito arrogante- $\left.\left.\left.\left.\left.\left.\left.\left.\left.]\left(\mathrm{e}_{\mathrm{j}}\right)\right)\left(\mathrm{ep}_{\mathrm{j}}\right)\right)\left(\mathrm{p}_{\mathrm{j}}\right)\right)_{\mathrm{U}}\right]\left(\mathrm{f}_{\mathrm{i}}\right)\right)\left(\mathrm{e}_{\mathrm{i}}\right)_{\phi}\right]\right)\left(\mathrm{ep}_{\mathrm{i}}\right)\right)\left(\mathrm{p}_{\mathrm{i}}\right)\right)$

Assim como acontece com os casos de evidencialidade reportativa apresentados em (208) e (209), a simultaneidade marcada no Estado-de-Coisas ( $\mathrm{e}_{\mathrm{j}}$ ), em (212), não indica que ele seja simultâneo ao Estado-de-Coisas $\left(\mathrm{e}_{\mathrm{i}}\right)$, em que ocorre o verbo de percepção. Como o Episódio 
(ep $\mathrm{p}_{\mathrm{i}}$, de (212), está localizado no passado, deve-se interpretar que o Falante descreve uma inferência que foi feita por ele no passado, ou seja, no momento em que ele ouviu a entrevista que serviu como base para sua inferência. O Episódio que contém a inferência em si, apesar de não estar localizado temporalmente, indica que a inferência ainda é válida, pelo menos para o Falante, no momento em que ele a comunica.

Nos casos de evidencialidade deduzida, as combinações possíveis de localização temporal dos Episódios são mais restritas do que nos casos de evidencialidade reportativa e inferida, variando entre os tempos presente e passado, como pode ser observado nas ocorrências apresentadas a seguir:

(213) Antes do Vectra eu tinha uma Twister que tirei zero. Tinha um cuidado do caramba com a moto, até que num belo dia eu chego na garagem (moro num condomínio!) e vou passar o cordão do chaveiro no retrovisor e vejo que ele estava solto. Pensei: tentaram roubar meu retrovisor!

(http://www.vectraclube.com.br/forum/viewtopic.php?f=3\&t=25098\&start=15)

$\left(\mathrm{p}_{\mathrm{i}}:\left(\right.\right.$ pres ep $\mathrm{e}:\left(\mathrm{e}_{\mathrm{i}}:\left[\left(\mathrm{f}_{\mathrm{i}}:\left[\left(\mathrm{f}_{\mathrm{j}}: \operatorname{ver}\left(\mathrm{f}_{\mathrm{j}}\right)\right)\left(\mathrm{x}_{\mathrm{i}}\right)_{\mathrm{A}}\left(\text { past } \mathrm{ep}_{\mathrm{j}}:\left(\mathrm{e}_{\mathrm{j}}: \text { [-ele estava solto-] }\left(\mathrm{e}_{\mathrm{j}}\right)\right)\left(\mathrm{ep}_{\mathrm{j}}\right)\right)_{\mathrm{U}}\right]\right.\right.\right.$ $\left.\left.\left.\left.\left.\left(\mathrm{f}_{\mathrm{i}}\right)\right)\left(\mathrm{e}_{\mathrm{i}}\right)\right]\right)\left(\mathrm{ep}_{\mathrm{i}}\right)\right)\left(\mathrm{p}_{\mathrm{i}}\right)\right)$

(214) aí você desconversa porque num é o momento de entrá(r) naquele assunto... entendeu? aí eu acabei desconversan(d)o e de(i)xei... ele... por que é o PRIme(i)ro dia dele comigo... enTÃO SE EU maltratasse ele ou se EU... éh:: éh:: não entendesse o que:.... porque aquilo pra mim era tipo/ ele tava com uma RAIva de mim e pô ele tava na segunda série tinha voltado pra prime(i)ra... ele tinha motivo... né?... do jeito do pensamento dele mas ele tinha... voltô(u)/ aí depois passô(u) um tempo eu vi que ele tava levando o material numa bolsinha de... de supermercado... e num tinha/ os lápis dele ficava tudo solto dentro da sacolinha... eu:: peguei tinha uma bolsa aí que... todo ano o Chamequinho manda pra gente uma pasta... do professor... e eu tinha uma já dos anos anteriores né?... eu falei vô(u) dá(r) essa pasta pro M.... aí eu dei...dei a pasta pro M.... (AC-086, L.938-948)

$\left(\mathrm{p}_{\mathrm{i}}:\left(\right.\right.$ past $\mathrm{ep}_{\mathrm{i}}:\left(\mathrm{e}_{\mathrm{i}}:\left[\left(\mathrm{f}_{\mathrm{i}}:\left[\left(\mathrm{f}_{\mathrm{j}}: \operatorname{ver}\left(\mathrm{f}_{\mathrm{j}}\right)\right)\left(\mathrm{x}_{\mathrm{i}}\right)_{\mathrm{A}}\left(\right.\right.\right.\right.\right.$ past $\mathrm{ep}_{\mathrm{j}}:\left(\mathrm{e}_{\mathrm{j}}:\left[\left(\operatorname{prog} \mathrm{f}_{\mathrm{k}}:\left[\left(\mathrm{f}_{\mathrm{l}}: \operatorname{levar}\left(\mathrm{f}_{\mathrm{l}}\right)\right)\left(\mathrm{x}_{\mathrm{j}}\right)\left(\mathrm{x}_{\mathrm{k}}\right.\right.\right.\right.\right.$ : [-o material-] $\left.\left(\mathrm{x}_{\mathrm{k}}\right)\right)\left(\mathrm{l}_{\mathrm{i}}:\right.$ [-numa bolsinha de supermercado- $\left.\left.\left.\left.\left.\left.\left.]\left(\mathrm{l}_{\mathrm{i}}\right)\right)\right]\left(\mathrm{f}_{\mathrm{k}}\right)\right)\right]\left(\mathrm{e}_{\mathrm{j}}\right)\right)\left(\mathrm{ep}_{\mathrm{j}}\right)\right)_{\mathrm{U}}\right]$ $\left.\left.\left.\left.\left.\left(\mathrm{f}_{\mathrm{i}}\right)\right)\left(\mathrm{e}_{\mathrm{i}}\right)\right]\right)\left(\mathrm{ep}_{\mathrm{i}}\right)\right)\left(\mathrm{p}_{\mathrm{i}}\right)\right)$

Em (213), a localização do Episódio ( $\mathrm{ep}_{\mathrm{i}}$ ) no presente indica que a percepção de evidências visuais pelo Falante acontece depois do Episódio $\left(\mathrm{ep}_{\mathrm{j}}\right)$, que contém a dedução propriamente dita, localizado temporalmente no passado. Em outras palavras, em (213), o Falante tem contato com as evidências no presente e deduz o que aconteceu. Em (214), ambos os 
Episódios, o que contém o verbo de percepção $\left(e p_{i}\right)$ e o que contém a dedução $\left(e p_{j}\right)$, são localizados no passado. A marcação temporal de $\left(e \mathrm{p}_{\mathrm{i}}\right)$ no passado indica que o Falante teve contato com as evidências que fundamentaram sua dedução em um momento anterior ao do Ato de Fala. O operador de Aspecto Progressivo que atua na Propriedade Configuracional $\left(\mathrm{f}_{\mathrm{k}}\right)$ indica que o Estado-de-Coisas $\left(\mathrm{e}_{\mathrm{j}}\right)$ estava em desenvolvimento no passado.

Diferentemente dos casos de evidencialidade reportativa e inferida ilustrados em (208), (209) e (212), não foram identificados casos de evidencialidade deduzida em que o Episódio que contém a dedução não é localizado temporalmente. Tendo em vista a natureza semântica mais concreta dos Episódios que contêm a dedução, a simultaneidade proporcionada pela falta de localização temporal acarreta a leitura das estruturas como casos de evidencialidade direta, conforme se discute a seguir.

Nos casos de evidencialidade direta, o verbo de percepção se relaciona com a categoria semântica Estado-de-Coisas, explicitando o sentido a partir do qual o Falante testemunhou tal Estado-de-Coisas acontecer. Da mesma forma como acontece com os outros tipos de evidencialidade, o Episódio que contém o verbo de percepção só pode ser localizado temporalmente no presente ou no passado, como pode ser observado nas ocorrências a seguir:

(215) Então senti uma pontada de pavor. Tinha me esquecido de contar. Comecei a gaguejar: Um mil... Senti um puxão nos ombros e meu corpo esticou-se. (http://www.osmedievais.kit.net/historia_poesia/historiamedieval1.html) $\left(\mathrm{p}_{\mathrm{i}}:\left(\right.\right.$ past ep $\mathrm{p}_{\mathrm{i}}:\left(\mathrm{e}_{\mathrm{i}}:\left[\left(\mathrm{f}_{\mathrm{i}}:\left[\left(\mathrm{f}_{\mathrm{j}}: \operatorname{sentir}\left(\mathrm{f}_{\mathrm{j}}\right)\right)\left(\mathrm{x}_{\mathrm{i}}\right)_{\mathrm{A}}\left(\operatorname{sim} \mathrm{e}_{\mathrm{j}}:\left(\mathrm{f}_{\mathrm{k}}:[-\mathrm{um}\right.\right.\right.\right.\right.\right.$ puxão-$\left.\left.]\left(\mathrm{f}_{\mathrm{k}}\right)\right)\left(\mathrm{e}_{\mathrm{j}}\right)\right)\left(\mathrm{l}_{\mathrm{i}}:\left[\left(\mathrm{f}_{\mathrm{l}}\right.\right.\right.$ : $[-\operatorname{nos}$ ombros- -$\left.\left.\left.\left.\left.\left.\left.\left.\left.]\left(\mathrm{f}_{\mathrm{l}}\right)\right)\right]\left(\mathrm{l}_{\mathrm{i}}\right)\right)\left(\mathrm{f}_{\mathrm{i}}\right)\right)\right]\left(\mathrm{e}_{\mathrm{i}}\right)\right]\right)\left(\mathrm{ep}_{\mathrm{i}}\right)\right)\left(\mathrm{p}_{\mathrm{i}}\right)\right)$

(216) e ele gastava o dinhe(i)ro tudo... em bebi::da... chegava batia na minha mãe quantas e quantas vezes eu vi minha mãe... sangra::n(d)o... e eu/ e choran(d)o e choran(d)o... e a gente sem podê(r) ajudá(r) ela... (AC-062, L.12-13)

$\left(\mathrm{p}_{\mathrm{i}}:\right.$ (past $\mathrm{ep}_{\mathrm{i}}:\left(\mathrm{e}_{\mathrm{i}}:\left[\left(\mathrm{f}_{\mathrm{i}}:\left[\left(\mathrm{f}_{\mathrm{j}}: \operatorname{ver}\left(\mathrm{f}_{\mathrm{j}}\right)\right)\left(\mathrm{x}_{\mathrm{i}}\right)_{\mathrm{A}}\left(\operatorname{sim} \mathrm{e}_{\mathrm{j}}:\left[\left(\operatorname{prog} \mathrm{f}_{\mathrm{k}}:\left[\left(\mathrm{f}_{\mathrm{l}}: \operatorname{sangrar}\left(\mathrm{f}_{\mathrm{l}}\right)\right)\left(\mathrm{x}_{\mathrm{j}}:\left[\left(\mathrm{f}_{\mathrm{m}}\right.\right.\right.\right.\right.\right.\right.\right.\right.\right.\right.$ : $\left[\left(\mathrm{f}_{\mathrm{n}}\right.\right.$ : mãe $\left.\left.\left.\left.\left.\left.\left.\left.\left.\left.\left.\left.\left.\left(\mathrm{f}_{\mathrm{n}}\right)\right)\left(\mathrm{x}_{\mathrm{i}}\right)_{\operatorname{Ref}}\right]\left(\mathrm{f}_{\mathrm{m}}\right)\right)\left(\mathrm{x}_{\mathrm{j}}\right)\right]\right)\left(\mathrm{f}_{\mathrm{k}}\right)\right)\right]\left(\mathrm{e}_{\mathrm{j}}\right)\right)\left(\mathrm{f}_{\mathrm{i}}\right)\right)\right]\left(\mathrm{e}_{\mathrm{i}}\right)\right)\left(\mathrm{ep}_{\mathrm{i}}\right)\right)\left(\mathrm{p}_{\mathrm{i}}\right)\right)$

(217) Ei! Espera aí... estou ouvindo alguém gritar o meu nome.

(http://felipetomasi.blogspot.com/2010/05/comidinhas-para-depois.html)

$\left(\mathrm{p}_{\mathrm{i}}:\left(\right.\right.$ pres ep $\mathrm{p}_{\mathrm{i}}:\left(\mathrm{e}_{\mathrm{i}}:\left[\left(\boldsymbol{p r o g} \mathrm{f}_{\mathrm{i}}:\left[\left(\mathrm{f}_{\mathrm{j}}: \operatorname{ouvir}\left(\mathrm{f}_{\mathrm{j}}\right)\right)\left(\mathrm{x}_{\mathrm{i}}\right)_{\mathrm{A}}\left(\right.\right.\right.\right.\right.$ sim $_{\mathrm{j}}:\left(\mathrm{f}_{\mathrm{k}}:[-\right.$ alguém gritar o meu nome-] $\left.\left.\left.\left.\left.\left.\left.\left(\mathrm{f}_{\mathrm{k}}\right)\right)\left(\mathrm{e}_{\mathrm{j}}\right)\right)\left(\mathrm{f}_{\mathrm{i}}\right)\right)\right]\left(\mathrm{e}_{\mathrm{i}}\right)\right)\left(\mathrm{ep}_{\mathrm{i}}\right)\right)\left(\mathrm{p}_{\mathrm{i}}\right)\right)$ 
Nos três casos, a localização temporal do Episódio que contém o verbo de percepção indica de fato o momento em que o Falante percebeu o Estado-de-Coisas que o verbo toma como complemento. Em (215) e (216), a localização temporal de $\left(e_{\mathrm{i}}\right)$ no passado mostra que a percepção aconteceu antes do momento da fala, ao passo que, em (217), o operador de tempo presente que atua no $\left(\mathrm{ep}_{\mathrm{i}}\right)$ e o operador de Aspecto Progressivo que atua em $\left(\mathrm{f}_{\mathrm{i}}\right)$ indicam que a percepção estava acontecendo no momento da fala.

Com relação aos Estados-de-Coisas que, nos três casos, funcionam como complemento do verbo de percepção, observa-se que nenhum deles é localizado em tempo presente, passado ou futuro. O fato de eles não serem localizados em tempo absoluto está de acordo com o princípio da GDF segundo o qual uma camada só aceita operadores e modificadores que atuem nessa camada ou em camadas inferiores, mas nunca operadores e modificadores de camadas mais altas. Na camada do Estado-de-Coisas, portanto, operadores temporais da camada do Episódio são bloqueados. Nos três casos apresentados acima, o operador de simultaneidade mostra que os Estado-de-Coisas encaixados nos verbos de percepção aconteceram no mesmo momento em que foram percebidos. Em (216), o Estadode-Coisas $\left(\mathrm{e}_{\mathrm{j}}\right)$ é também caracterizado como estando em desenvolvimento no passado devido à atuação do operador de Aspecto Progressivo na Propriedade Configuracional $\left(\mathrm{f}_{\mathrm{k}}\right)$.

\section{A DESCRIÇÃO DA EVIDENCIALIDADE NO NÍVEL MORFOSSINTÁTICO}

O Nível Morfossintático, como visto no Capítulo III, é o responsável por receber as informações semânticas e pragmáticas e transformá-las em uma única representação estrutural. Nos casos de evidencialidade codificados pelos verbos ver, ouvir e sentir analisados neste estudo, observou-se a ocorrência de quatro contextos sintáticos diferentes: 
i) duas Expressões Linguísticas, cada uma composta por uma Oração;

ii) uma Expressão Linguística composta por Oração principal e Oração subordinada adverbial conformativa;

iii) uma Expressão Linguística composta por Oração principal e Oração subordinada completiva; e

iv) uma Expressão Linguística composta por uma Oração simples.

No Quadro a seguir, esses quatro contextos sintáticos estão relacionados com os quatro tipos de evidencialidade:

\begin{tabular}{|c|c|c|c|c|}
\cline { 2 - 5 } \multicolumn{1}{c|}{} & $\begin{array}{c}\text { Evidencialidade } \\
\text { reportativa }\end{array}$ & $\begin{array}{c}\text { Evidencialidade } \\
\text { inferida }\end{array}$ & $\begin{array}{c}\text { Evidencialidade } \\
\text { deduzida }\end{array}$ & $\begin{array}{c}\text { Evidencialidade } \\
\text { direta }\end{array}$ \\
\hline $\begin{array}{c}\text { Duas Expressões } \\
\text { Lingüísticas }\end{array}$ & + & + & + & - \\
\hline $\begin{array}{c}\text { Uma Expressão } \\
\text { Linguística } \\
\text { (Oração principal + } \\
\text { Oração subordinada } \\
\text { adverbial) }\end{array}$ & + & + & + & - \\
\hline $\begin{array}{c}\text { Uma Expressão } \\
\text { Linguística } \\
\text { (Oração principal }+ \\
\text { Oração subordinada } \\
\text { completiva) }\end{array}$ & + & + & + & + \\
\hline $\begin{array}{c}\text { Uma Expressão } \\
\text { Linguística } \\
\text { (Oração simples) }\end{array}$ & - & - & - & + \\
\hline
\end{tabular}

Quadro 15. Estruturas sintáticas e tipos de evidencialidade

A seguir, cada uma dessas estruturas é considerada.

\subsection{Duas Expressões Linguísticas}

Os casos de evidencialidade reportativa, inferida e deduzida representados, no Nível Interpessoal, como dois Atos Discursivos e, no Nível Representacional, como duas 
Proposições independentes, são representados, no Nível Morfossintático, como duas

Expressões Linguísticas, como se observa nas ocorrências repetidas a seguir:

(170) A casa do Benfica em Moura também foi vandalizada esta madrugada. Ouvi isso

na TV. (http://www.serbenfiquista.com/forum/index.php?topic=39648.900)

$\left(\mathrm{Le}_{\mathrm{i}}:\left(\mathrm{Cl}_{\mathrm{i}}\right)\left(\mathrm{Le}_{\mathrm{i}}\right)\right)\left(\mathrm{Le}_{\mathrm{j}}:\left(\mathrm{Cl}_{\mathrm{j}}:\left[\left(\mathrm{Nw}_{\mathrm{i}}\right)_{\mathrm{Sbj}}\left(\mathrm{Vp}_{\mathrm{i}}\right)\left(\mathrm{Nw}_{\mathrm{j}}\right)_{\mathrm{Obj}}\left(\mathrm{Advp}_{\mathrm{i}}\right)\right]\left(\mathrm{Cl}_{\mathrm{j}}\right)\right)\left(\mathrm{Le}_{\mathrm{j}}\right)\right)^{60}$

(185) — Bels? - Minha mãe chamou.

- Estou aqui no banheiro - Falei entre uma ânsia e outra.

Ouvi que minha mãe puxou a cadeira do meu computador e se sentou, ela esperou eu voltar do banheiro e me deu um remédio para ânsia e ficou ali abraçada comigo.

— Filha, posso te fazer uma pergunta? - Minha mãe perguntou.

- Pode, claro - Respondi sem imaginar qual seria a pergunta.

— Você já menstruou depois daquela noite com o Edward? - Ela perguntou com medo da resposta. Eu senti isso na voz dela.

— Não, mãe - Respondi.

(http://webcache.googleusercontent.com/search?q=cache:dUEynGDQ88EJ:fanfiction.nyah.com.br/histo ria/70890/Revivendo_Um_Sonho/capitulo/5+\%22senti+isso\%22\&cd=41\&hl=BR\&ct=clnk\&gl=br\&lr=1 ang)

$\left(\mathrm{Le}_{\mathrm{i}}:\left(\mathrm{Cl}_{\mathrm{i}}\right)\left(\mathrm{Le}_{\mathrm{i}}\right)\right)\left(\mathrm{Le}_{\mathrm{j}}:\left(\mathrm{Cl}_{\mathrm{j}}:\left[\left(\mathrm{Nw}_{\mathrm{i}}\right)_{\mathrm{Sbj}}\left(\mathrm{Vp}_{\mathrm{i}}\right)\left(\mathrm{Nw}_{\mathrm{j}}\right)_{\mathrm{Obj}}\left(\mathrm{Advp}_{\mathrm{i}}\right)\right]\left(\mathrm{Cl}_{\mathrm{j}}\right)\right)\left(\mathrm{Le}_{\mathrm{j}}\right)\right)$

(193) Inf.2: é você vai tê(r) que recorrê(r) M. a única forma aí... e óh... se você recorrê(r) e não for lá... nem que cê num fizé(r) mas pelo menos vai lá fora no dia... eles nem lêem... não lêem... eu vi ontem lá óh... chega lá ((imita som de uma pessoa lendo rápido e baixo))... é mais é muito mais fácil pra eles M. mantê(r) sentença... - "ah mantém a sentença... por unanimidade é isso"- ontem eu desanimei viu?... esse sistema de recurso de escrevê(r) aquela/... um MONte de babose(i)ra... óh... pode pará(r)... até foi bom eu í(r) pra vê(r)... ontem (AI-010, L. 109-115)

$\left(\mathrm{Le}_{\mathrm{i}}:\left(\mathrm{Cl}_{\mathrm{i}}\right)\left(\mathrm{Le}_{\mathrm{i}}\right)\right)\left(\mathrm{Le}_{\mathrm{j}}:\left(\mathrm{Cl}_{\mathrm{j}}:\left[\left(\mathrm{Nw}_{\mathrm{i}}\right)_{\mathrm{Sbj}}\left(\mathrm{Vp}_{\mathrm{i}}\right)\left(\mathrm{Advp}_{\mathrm{i}}\right)\left(\mathrm{Advp}_{\mathrm{j}}\right)\right]\left(\mathrm{Cl}_{\mathrm{j}}\right)\right)\left(\mathrm{Le}_{\mathrm{j}}\right)\right)$

Como visto no Capítulo III, a Expressão Linguística diz respeito a qualquer grupo de pelo menos uma unidade (Oração ou Sintagma) que pode ser usada independentemente. Isso é o que acontece nos três casos apresentados acima. O trecho em destaque, em cada caso, contém duas Expressões Linguísticas diferentes, uma vez que não há dependência sintática entre as Orações que compõem as Expressões Linguísticas. A Oração $\left(\mathrm{Cl}_{\mathrm{j}}\right)$, que ocorre dentro da Expressão Linguística $\left(\mathrm{Le}_{\mathrm{j}}\right)$, em todos os casos, contém a Palavra Nominal $\left(\mathrm{Nw}_{\mathrm{i}}\right)$, que representa, no Nível Morfossintático, o pronome sujeito "eu", que se refere ao Falante. O

\footnotetext{
${ }^{60}$ Somente a Oração $\left(\mathrm{Cl}_{\mathrm{j}}\right)$, contida na segunda Expressão Linguística, é representada em detalhes porque é ela que contém o verbo de percepção.
} 
Sintagma Verbal $\left(\mathrm{Vp}_{\mathrm{i}}\right)$ representa o verbo de percepção. Depreende-se, assim, a partir das representações dos três casos, (170), (185) e (193), que não há diferença morfossintática entre os três tipos de evidencialidade. Quando o Falante opta por expressar a sua informação e o modo como a obteve em dois Atos Discursivos independentes, a mesma estrutura subjacente se aplica no Nível Morfossintático, como mostra o Quadro a seguir:

\begin{tabular}{|c|c|}
\hline \multicolumn{2}{|c|}{ A EVIDENCIALIDADE NO NÍVEL MORFOSSINTÁTICO } \\
Duas Expressões Linguísticas \\
\hline$(218) \quad\left(\mathrm{Le}_{1}:\left(\mathrm{Cl}_{1}\right)\left(\mathrm{Le}_{1}\right)\right)\left(\mathrm{Le}_{2}:\left(\mathrm{Cl}_{2}:\left[\left(\mathrm{Nw}_{1}\right)_{\mathrm{Sbj}}\left(\mathrm{Vp}_{1}\right)\left(\mathrm{Advp}_{1}\right)\left(\mathrm{Advp}_{2}\right)\right]\left(\mathrm{Cl}_{2}\right)\right)\left(\mathrm{Le}_{2}\right)\right)$ \\
\hline
\end{tabular}

Quadro 16. Estrutura subjacente morfossintática da evidencialidade codificada por duas Expressões Linguísticas

\subsection{Uma Expressão Linguística}

Quando a evidencialidade é codificada em uma única Expressão Linguística, esta pode ser constituída por duas Orações, uma principal e outra subordinada, ou por uma única Oração simples. No primeiro caso, em que uma Oração ocorre como constituinte de outra, a Oração subordinada pode ser do tipo adverbial ou completiva, como visto no Quadro 15 , acima. ${ }^{61}$ Quando a Oração subordinada é adverbial, o verbo de percepção ocorre dentro da Oração Subordinada e a Oração principal contém a informação percebida pelo Falante. Quando a Oração subordinada é completiva, ao contrário, o verbo de percepção é o predicado da Oração matriz e a Oração complemento contém a informação percebida pelo Falante. Quando a Oração é simples, o predicado matriz é um verbo de percepção e o complemento é do tipo nominalizado.

\footnotetext{
${ }^{61}$ As construções complexas são o tipo de contexto sintático mais comum de expressão da evidencialidade em língua portuguesa, não só no que diz respeito aos verbos de percepção, mas também no que se refere a outras classes verbais, como os verbos de dizer, de atitude proposicional e de conhecimento (cf. DALL'AGLIOHATTNHER, 2001; GONÇALVES, 2003; VENDRAME, 2005).
} 
Como visto no Capítulo III, no Nível Morfossintático, as Orações subordinadas são descritas em termos da unidade representacional ou interpessoal que representam. Assim, as Orações subordinadas adverbiais que contêm verbos de percepção evidenciais são descritas como Conteúdos Proposicionais que atuam como modificadores de outros Conteúdos Proposicionais ou de Episódios, dependendo do tipo de evidencialidade que expressam.

No caso das Orações subordinadas completivas, a posição de segundo argumento dos verbos de percepção pode ser ocupada por três camadas do Nível Representacional (Conteúdo Proposicional, Episódio e Estado-de-Coisas) e uma camada do Nível Interpessoal (Conteúdo Comunicado), de acordo com o sentido evidencial em que o verbo é empregado.

No caso das Orações simples, os verbos de percepção tomam como complemento um Sintagma nominal que necessariamente corresponde à camada Estado-de-Coisas, do Nível Representacional.

Com relação ao aspecto formal das Orações subordinadas completivas, o grau de finitude do verbo que ocorre dentro da Oração complemento pode variar dependendo do tipo de unidade representacional ou interpessoal que ela representa. O Quadro 17, a seguir, apresenta o grau de finitude do complemento correlacionado com o tipo de evidencialidade e a camada do Nível Representacional ou Interpessoal a que corresponde:

\begin{tabular}{|c|c|c|c|c|c|}
\hline \multirow{2}{*}{$\begin{array}{c}\text { Forma } \\
\text { do } \\
\text { complemento }\end{array}$} & $\begin{array}{c}\text { Tidencialidade } \\
\text { reportativa (C) }\end{array}$ & $\begin{array}{c}\text { Evidencialidade } \\
\text { inferida (p) }\end{array}$ & $\begin{array}{c}\text { Evidencialidade } \\
\text { deduzida (ep) }\end{array}$ & $\begin{array}{c}\text { Evidencialidade } \\
\text { direta (e) }\end{array}$ \\
\cline { 2 - 6 } & + & + & + & - \\
\hline & finita & + & + & - & + \\
\hline
\end{tabular}

Quadro 17. Forma da Oração subordinada completiva por tipo de evidencialidade 
Como pode ser observado no Quadro acima, a evidencialidade reportativa e a evidencialidade inferida podem ser expressas em construções complexas que possuem como complemento orações finitas e não-finitas reduzidas de infinitivo.

Nos casos de evidencialidade deduzida, só são possíveis complementos finitos. O fato de não terem sido encontrados casos de dedução com complemento não-finito parece estar relacionado a dois fatores: i) a natureza semântica mais concreta dos Episódios que contêm a dedução (em comparação com os Conteúdos Proposicionais e Conteúdos Comunicados dos casos de evidencialidade inferida e reportativa) e ii) a falta de localização temporal nos casos de complementos não-finitos, que acarreta a simultaneidade entre o Estado-de-Coisas do complemento e o Estado-de-Coisas da Oração principal. Assim, se, por exemplo, se transforma o complemento finito de uma ocorrência de dedução em complemento não-finito, a nova estrutura passa a ser considerada um caso de evidencialidade direta, como se pode observar a seguir:

(189) Inf.1.: ah depois que abriu essa igreja aí (inint) ((arrastou uma cadeira)) eu também fui lá olhá(r) mas eu desliguei eu já esqueci o arro::z

Inf.2: não (isso aí) eu vi que cê desligôo(u)

Inf.1: é né? eu/ mas eu fui lá olha de novo (AI-002, L. 2-6)

(189)' Inf.2: não (isso aí) eu vi você desligar

Enquanto o complemento finito de (189) indica que o informante 2 focaliza o resultado do processo de o informante 1 desligar o fogo (ele provavelmente viu o fogo apagado e deduziu que o informante 1 apagou o fogo), o complemento não-finito de (189)' focaliza o processo de apagar o fogo. Nesse caso, não há dúvidas de que o informante 2 presenciou o Estado-deCoisas acontecer, não apenas o seu resultado.

Nos casos de evidencialidade direta, só ocorrem complementos na forma não-finita (de infinitivo e de gerúndio). Uma vez que, nesse tipo de evidencialidade, os verbos de percepção relacionam-se com a camada do Estado-de-Coisas, o fato de não ocorrerem complementos 
finitos está de acordo com o princípio da GDF segundo o qual é mais provável que uma Oração Subordinada seja do tipo reduzida quanto mais baixa for a camada em que está baseada.

Com relação às representações morfossintáticas da evidencialidade expressa pelos verbos ver, ouvir e sentir quando eles ocorrem em uma única Expressão Linguística, observase que, nos casos de Oração subordinada adverbial conformativa, independentemente do tipo de evidencialidade codificado pelos três verbos, a mesma estrutura subjacente se aplica. A ocorrência (177), repetida a seguir, é usada como modelo para a apresentação da representação morfossintática desse tipo de estrutura:

(177) A luz acabou umas 22:13, pelo que eu ouvi no jornal.

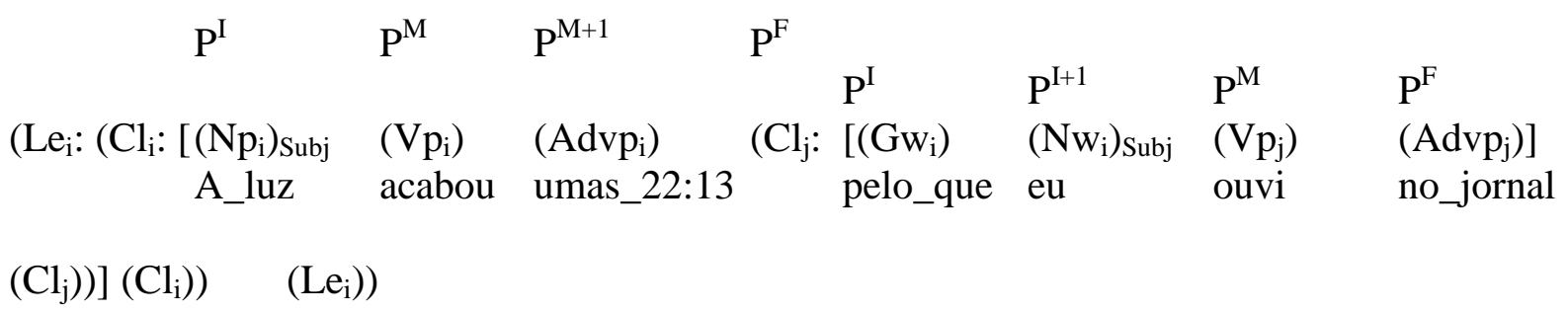

Em (177), a Oração subordinada adverbial ocupa a posição $\mathrm{P}^{\mathrm{F}}$ da Oração principal. Essa não é uma posição fixa para esse tipo de Oração. Em outros exemplos já discutidos neste Capítulo (cf. (181), (183) e (192)), uma Oração subordinada adverbial com a mesma função aparece ocupando a posição $\mathrm{P}^{\mathrm{I}}$, e é possível pensar ainda em outras posições possíveis para a Oração subordinada adverbial ocorrer no interior da Oração principal. No que se refere ao posicionamento dos constituintes dentro da Oração subordinada, observa-se que a Palavra gramatical $\left(\mathrm{Gw}_{\mathrm{i}}\right)$, pelo que, ocupa a posição $\mathrm{P}^{\mathrm{I}}$, o pronome de primeira pessoa eu $\left(\mathrm{Nw}_{\mathrm{i}}\right)$, que tem função de Sujeito, ocupa a posição à direita de $\mathrm{P}^{\mathrm{I}}$, o verbo de percepção ver $\left(\mathrm{Vp}_{\mathrm{j}}\right)$ ocupa a posição $\mathrm{P}^{\mathrm{M}}$ e, por fim, o sintagma adjetival no jornal $\left(\mathrm{Advp}_{\mathrm{j}}\right)$ ocupa a posição final $\left(\mathrm{P}^{\mathrm{F}}\right)$. A organização sintática da Oração subordinada adverbial é fixa, ou seja, as três primeiras 
posições devem ser ocupadas por constituintes desses tipos na expressão de evidencialidade reportativa, inferida e deduzida.

O Quadro a seguir mostra a estrutura subjacente morfossintática que se aplica aos casos de evidencialidade codificados por uma oração subordinada adverbial:

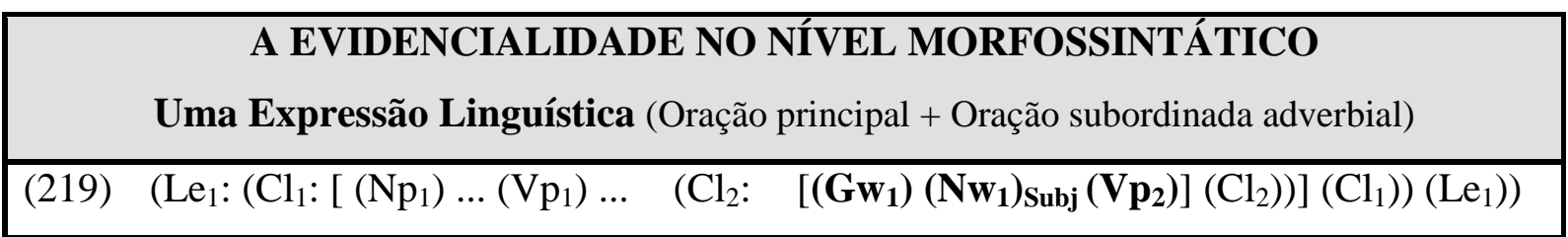

Quadro 18. Estrutura subjacente morfossintática da evidencialidade codificada por Oração adverbial

Nos casos em que uma Oração subordinada completiva finita é usada como complemento dos verbos de percepção, da mesma forma como acontece com as Orações subordinadas adverbiais, a mesma estrutura subjacente representa os casos de evidencialidade reportativa, inferida e deduzida. O trecho em destaque em (220) é usado como modelo para a exposição da representação morfossintática desse tipo de estrutura:

(220) Inf.: [nem:: conta] agora já minha o(u)tra irmã... fala tudo um dia... eu matei aula... foi que:: deu um (problema)... aí... chegô(u) lá... aí... eu fui na:: fe(i)ra da:: escola dela... aí eu vi ela de longe... aí eu vi que ela virô(u) a esquina assim... e saiu mostran(d)o a o/ nao(u)tra esquina que é aquela desce né (AC-017, L.110-113)

\begin{tabular}{|c|c|c|c|c|c|c|}
\hline $\mathrm{P}^{\mathrm{I}}$ & $\mathrm{P}^{\mathrm{M}}$ & $\mathrm{P}^{\mathrm{F}}$ & & & & \\
\hline $\begin{array}{c}\mathrm{Le}_{\mathrm{i}}:\left(\mathrm{Cl}_{\mathrm{i}}:\left[\left(\mathrm{Nw}_{\mathrm{i}}\right)_{\text {Subj }}\right.\right. \\
\mathrm{eu}\end{array}$ & $\begin{array}{l}\left(\mathrm{Vp}_{\mathrm{i}}\right) \\
\text { vi }\end{array}$ & $\begin{array}{c}\left(\mathrm{Cl}_{\mathrm{j}}:\left[\left(\mathrm{Gw}_{\mathrm{j}}\right)\right.\right. \\
\text { que }\end{array}$ & $\begin{array}{l}\left(\mathrm{Nw}_{\mathrm{j}}\right)_{\text {Subj }} \\
\text { ela }\end{array}$ & $\begin{array}{l}\left(\mathrm{Vp}_{\mathrm{j}}\right) \\
\text { virou }\end{array}$ & $\begin{array}{l}\left.\left(\mathrm{Np}_{\mathrm{i}}\right)\right] \\
\text { a_esquina }\end{array}$ & $\left.\left.\left(\mathrm{Cl}_{\mathrm{j}}\right)\right)_{\mathrm{Obj}}\right]$ \\
\hline
\end{tabular}

$\left.\left.\left(\mathrm{Cl}_{\mathrm{i}}\right)\right)\left(\mathrm{Le}_{\mathrm{i}}\right)\right)$

Conforme mostra a representação morfossintática de (220), na Oração principal $\left(\mathrm{Cl}_{\mathrm{i}}\right)$, a posição $\mathrm{P}^{\mathrm{I}}$ é ocupada pelo pronome $e u\left(\mathrm{Nw}_{\mathrm{i}}\right)$, que tem a função de Sujeito. A posição $\mathrm{P}^{\mathrm{M}}$ é ocupada pelo verbo de percepção ver $\left(\mathrm{Vp}_{\mathrm{i}}\right)$ e a posição $\mathrm{P}^{\mathrm{F}}$ é ocupada pela Oração subordinada $\left(\mathrm{Cl}_{\mathrm{j}}\right)$, que tem a função de Objeto. No interior da Oração subordinada, uma vez que ela é 
desenvolvida, o complementizador que ocupa a posição $\mathrm{P}^{\mathrm{I}}$, a posição à direita de $\mathrm{P}^{\mathrm{I}}$ é ocupada por um pronome que tem função de Sujeito dentro da Oração Subordinada, a posição $\mathrm{P}^{\mathrm{M}}$ é ocupada por um verbo e a posição $\mathrm{P}^{\mathrm{M}+1}$ pelo objeto desse verbo. Quando se usa esse tipo de configuração morfossintática na expressão da evidencialidade, a posição final da Oração Subordinada é fixa, devido à sua complexidade. No interior da Oração principal, a posição $\mathrm{P}^{\mathrm{I}}$ é reservada para o sujeito, que pode ser expresso ou não, mas sempre vai corresponder ao pronome de primeira pessoa do singular, e a posição $\mathrm{P}^{\mathrm{M}}$ necessariamente vai ser ocupada por um verbo de percepção, que toma como complemento a Oração $\left(\mathrm{Cl}_{\mathrm{j}}\right)$. Os constituintes dessa Oração podem variar, dependendo da informação que o Falante queira transmitir.

Como visto no Quadro 17, as Orações subordinadas completivas não-finitas reduzidas de infinitivo podem ser usadas na expressão de três tipos de evidencialidade: reportativa, inferida e direta. Há uma diferença, no entanto, na configuração morfossintática desse tipo de estrutura quando expressam evidencialidade reportativa e inferida, por um lado, e evidencialidade direta, por outro. Primeiramente, são apresentadas representações morfossintáticas para um caso de evidencialidade reportativa (221) e um caso de evidencialidade inferida (212):

(221) Viram que, após ser feita a entrada pro número de valores do vetor, dá erro de execução e o programa fecha? Gostaria de saber por quê. Imagino que tenha a ver com a minha declaração de variáveis fora do início da função, mas mesmo isso eu ouvi ser aceito nas versões mais novas da linguagem. (http://55chan.org/prog/7.html)

\begin{tabular}{|c|c|c|c|}
\hline $\mathrm{P}^{\mathrm{I}}$ & $\mathrm{P}^{\mathrm{I}+1}$ & $\mathrm{P}^{\mathrm{M}}$ & $\mathrm{P}^{\mathrm{F}}$ \\
\hline$\left(\mathrm{Le}_{\mathrm{i}}:\left(\mathrm{Cl}_{\mathrm{i}}:\left[\left(\mathrm{Nw}_{\mathrm{i}}\right)\right.\right.\right.$ & $\left(\mathrm{Nw}_{\mathrm{j}}\right)_{\mathrm{Sbj}}$ & $\left(\mathrm{Vp}_{\mathrm{i}}\right)$ & $\begin{array}{l}\mathrm{P}^{\mathrm{l}} \quad \mathrm{P}^{\mathrm{M}} \\
\left(\mathrm{Cl}_{\mathrm{j}}:\left[\left(\mathrm{Vp}_{\mathrm{j}}:\left[\left(\mathrm{Vw}_{\mathrm{i}}: \operatorname{ser}-\inf \left(\mathrm{Vw}_{\mathrm{i}}\right)\right)\right.\right.\right.\right.\end{array}$ \\
\hline isso & $\mathrm{eu}$ & ouvi & ser_aceito \\
\hline
\end{tabular}

Em (221), a Oração subordinada não-finita $\left(\mathrm{Cl}_{\mathrm{j}}\right)$ ocupa a posição $\mathrm{P}^{\mathrm{F}}$ da Oração principal $\left(\mathrm{Cl}_{\mathrm{i}}\right)$, mas o constituinte sujeito da Oração subordinada aparece no interior da Oração principal, na 
posição $\mathrm{P}^{\mathrm{I}}$. Como essa posição está ocupada, o sujeito do verbo ouvir vai para a posição $\mathrm{P}^{\mathrm{I}+1}$. No interior da Oração subordinada, a posição $\mathrm{P}^{\mathrm{M}}$ é ocupada pelo Sintagma verbal $\left(\mathrm{Vp}_{\mathrm{j}}\right)$, que contém a cópula e o predicado lexical como complemento. Esse tipo de Sintagma verbal é o que caracteriza os complementos reduzidos de infinitivo que codificam evidencialidade reportativa e inferida. Não foram encontrados casos desses dois tipos de evidencialidade com complementos reduzidos de infinitivo em que o Sintagma verbal do complemento contivesse um verbo lexical como núcleo. O mesmo acontece no caso de evidencialidade inferida representado a seguir:

(212) Ouvi a entrevista na íntegra e senti ser Dilma uma pessoa muito arrogante. (http://veja.abril.com.br/blog/augusto-nunes/sanatorio-geral/nenhum-neuronio/)

\begin{tabular}{|c|c|c|c|c|}
\hline $\mathrm{P}$ & $\mathrm{P}^{\mathrm{M}}$ & $\mathrm{P}^{\mathrm{F}}$ & & \\
\hline & & $\mathrm{P}^{\mathrm{I}} \quad \mathrm{P}^{\mathrm{M}}$ & $\mathrm{P}^{\mathrm{M}+1}$ & $\mathrm{P}^{\mathrm{M}+2}$ \\
\hline$\left(\mathrm{Le}_{\mathrm{i}}:\left(\mathrm{Cl}_{\mathrm{i}}:[\right.\right.$ & $\begin{array}{l}\left(\mathrm{Vp}_{\mathrm{i}}\right) \\
\text { senti }\end{array}$ & $\begin{array}{c}\left(\mathrm{Cl}_{\mathrm{j}}:\left[\left(\mathrm{Vp}_{\mathrm{j}}:\left[\left(\mathrm{Vw}_{\mathrm{i}}: \operatorname{ser}-\inf \left(\mathrm{Vw}_{\mathrm{i}}\right)\right)\right.\right.\right.\right. \\
\text { ser }\end{array}$ & $\begin{array}{l}\left(\mathrm{Nw}_{\mathrm{i}}\right) \\
\text { Dilma }\end{array}$ & $\begin{array}{l}\left(\mathrm{Np}_{\mathrm{i}}\right) \\
\text { uma_pessoa }\end{array}$ \\
\hline
\end{tabular}

$\mathrm{P}^{\mathrm{M}+3}$

$\left.\left.\left.\left.\left.\left.\left.\left(\operatorname{Adjp}_{\mathrm{i}}:\left(\operatorname{Advw}_{\mathrm{i}}\right)\left(\operatorname{Adjw}_{\mathrm{i}}\right)\left(\operatorname{Adjp}_{\mathrm{i}}\right)\right)\right] \quad\left(\mathrm{Vp}_{\mathrm{j}}\right)\right)\right] \quad\left(\mathrm{Cl}_{\mathrm{j}}\right)\right)_{\mathrm{Obj}}\right] \quad\left(\mathrm{Cl}_{\mathrm{i}}\right)\right)\left(\mathrm{Le}_{\mathrm{i}}\right)\right)$ muito_arrogante

A mesma configuração morfossintática de (221) acontece em (212). A diferença está no posicionamento do sujeito da Oração subordinada; enquanto em (221) ele ocupa a posição $\mathrm{P}^{\mathrm{I}}$ no interior da Oração principal, em (212), ele ocorre no interior da Oração subordinada, depois da cópula, na posição $\mathrm{P}^{\mathrm{M}+1}$.

Nas Orações subordinadas reduzidas de infinitivo que codificam evidencialidade direta, a seguinte representação morfossintática se aplica: 
(222) Inf.: ah eles num tão nem aí... ((risos)) [entendeu?] [Doc.: é verdade] eu tava lá na frente e vi a polícia passá(r) assim eles falaram -“a lá os homem... óh lá os homem"daí a pouco a polícia desce na rua de casa... [Doc.: nossa] só iss/ o que faltava tá atrás deles né? (AC-058, L.392-395)

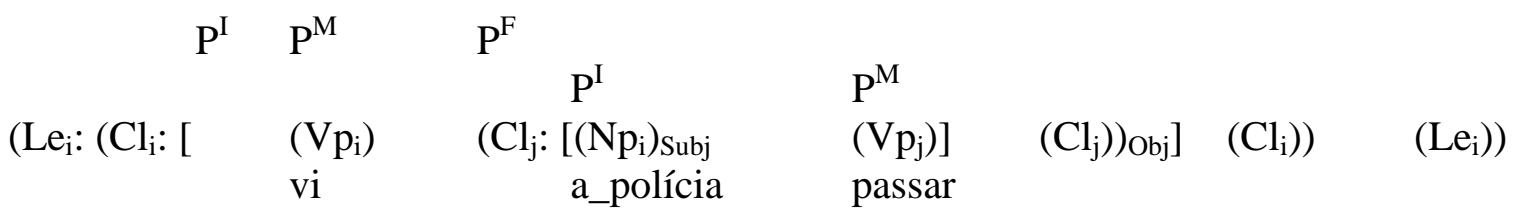

Em (222), a posição $\mathrm{P}^{\mathrm{I}}$ da Oração principal não é preenchida porque o Sujeito do verbo ver, que ocupa a posição $\mathrm{P}^{\mathrm{M}}$, não é realizado verbalmente. A posição $\mathrm{P}^{\mathrm{F}}$ é ocupada pela Oração não-finita. No interior da Oração complemento, a posição $\mathrm{P}^{\mathrm{I}}$ é ocupada pelo sujeito do verbo, que ocupa a posição $\mathrm{P}^{\mathrm{M}}$. Diferentemente dos casos de evidencialidade reportativa e inferida expressos por complementos reduzidos de infinitivo, nos casos de evidencialidade direta o Sintagma verbal da Oração subordinada pode ter como núcleo um verbo lexical. Na verdade, na grande maioria dos casos de evidencialidade direta, o núcleo do Sintagma verbal é de fato um verbo lexical.

Como visto no Quadro 17, Orações subordinadas na forma não-finita reduzida de gerúndio só são usadas na expressão da evidencialidade direta. Na representação morfossintática da ocorrência apresentada a seguir, observa-se que a mesma estrutura subjacente usada para representar a Oração subordinada reduzida de infinitivo é empregada. Como visto em 2.5.2, a distinção de Aspecto Progressivo, que diferencia a ocorrência (199) da ocorrência (222), é feita no Nível Representacional.

(199) Sete e meia da manhã. Cruzo a cidade adormecida e escura. Já no centro, perto do trabalho, ouço passarinhos cantando. Passarinhos cantando. Em pleno janeiro. (http://fabriani.com/?m=200801)

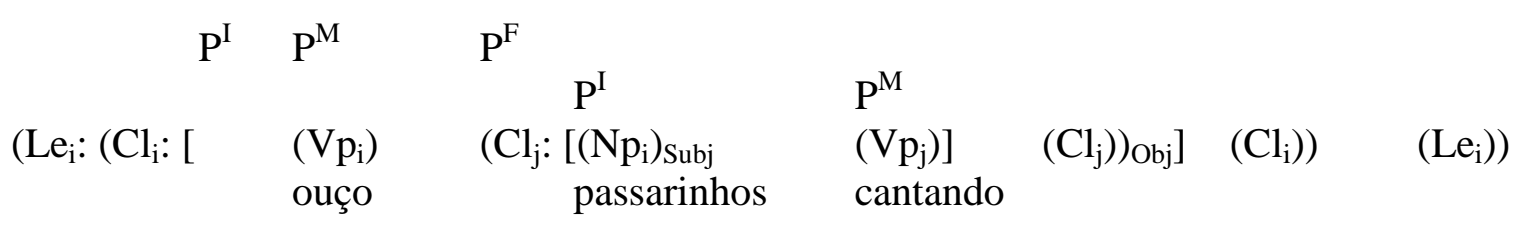


Em (199), o verbo de percepção ouvir atua como o predicado da Oração principal, ocupando a posição $\mathrm{P}^{\mathrm{M}}$. A posição $\mathrm{P}^{\mathrm{F}}$ é ocupada pela Oração subordinada reduzida de gerúndio. No interior da Oração subordinada, a posição $\mathrm{P}^{\mathrm{I}}$ é ocupada pelo sujeito do Sintagma verbal $\left(\mathrm{Vp}_{\mathrm{j}}\right)$, que ocupa a posição $\mathrm{P}^{\mathrm{M}}$. Como se pode observar, o núcleo do Sintagma verbal $\left(\mathrm{Vp}_{\mathrm{j}}\right)$ é um verbo lexical, o que caracteriza os casos de evidencialidade direta expressos por complementos reduzidos.

O Quadro a seguir mostra as estruturas subjacentes morfossintáticas que se aplicam aos casos de evidencialidade codificados por orações subordinadas completivas:

\begin{tabular}{|c|c|}
\hline & $\begin{array}{l}\text { A EVIDENCIALIDADE NO NÍVEL MORFOSSINTÁTICO } \\
\text { Uma Expressão Linguística (Oração principal + Oração subordinada completiva) }\end{array}$ \\
\hline$\stackrel{\square}{:}$ & $\begin{array}{l}\text { Evidencialidade reportativa, inferida e dedução } \\
\left(\mathrm{Le}_{1}:\left(\mathrm{Cl}_{1}:\left[\left(\mathbf{N w}_{\mathbf{1}}\right)_{\text {Subj }}\left(\mathbf{V p}_{\mathbf{1}}\right)\left(\mathbf{C l}_{\mathbf{2}}:\left[\left(\mathbf{N w}_{\mathbf{2}}\right)\left(\mathrm{Np}_{1}\right)_{\text {Subj }}\left(\mathrm{Vp}_{2}\right) \ldots\left(\mathrm{Np}_{2}\right) \ldots\right]\left(\mathrm{Cl}_{2}\right)\right)_{\mathrm{Obj}}\right]\left(\mathrm{Cl}_{1}\right)\right)\right. \\
\left.\left(\mathrm{Le}_{1}\right)\right)\end{array}$ \\
\hline : & 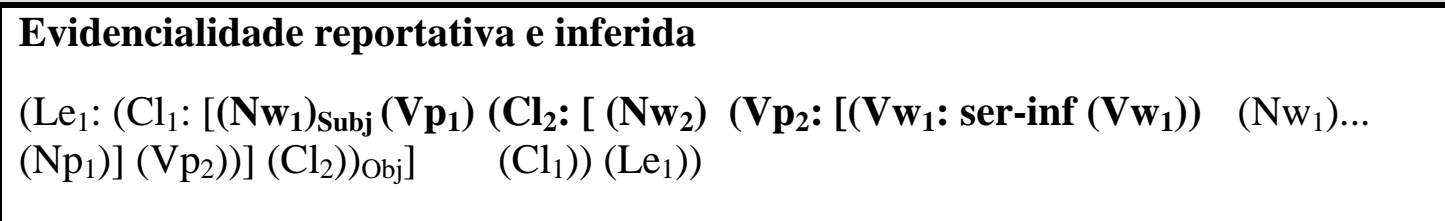 \\
\hline 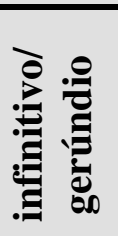 & $\begin{array}{l}\text { Evidencialidade direta } \\
\left(\mathrm{Le}_{1}:\left(\mathrm{Cl}_{1}:\left[(\mathbf{N w})_{\text {Subj }}\left(\mathbf{V} \mathbf{p}_{1}\right)\left(\mathbf{C l} \mathbf{l}_{2}:\left[\left(\mathbf{N p}_{\mathbf{1}}\right)_{\mathrm{Subj}}\left(\mathbf{V} \mathbf{p}_{2}\right) \ldots\right]\left(\mathrm{Cl}_{2}\right)\right)_{\mathrm{Obj}}\right]\right.\right.\end{array}$ \\
\hline
\end{tabular}

Quadro 19. Estruturas subjacentes morfossintáticas da evidencialidade codificada por Oração subordinada completiva

Por fim, como visto no Quadro 15, nos casos em que os verbos ver, ouvir e sentir ocorrem em Orações simples, apenas um tipo de evidencialidade pode ser expresso: a evidencialidade direta. A representação morfossintática da ocorrência apresentada a seguir mostra os constituintes envolvidos nesse tipo de estrutura: 
(223) Eu vi a impressão agora aqui. Ela imprime uma linha certo e a outra linha na metade. (http://www.guiadohardware.net/comunidade/funcional-multi/884784/)

$\begin{array}{cllll}\mathrm{P}^{\mathrm{I}} & \mathrm{P}^{\mathrm{M}} & \mathrm{P}^{\mathrm{M}+1} & \mathrm{P}^{\mathrm{F}} & \mathrm{P}^{\mathrm{F}+1} \\ \left(\mathrm{Le}_{\mathrm{i}}:\left(\mathrm{Cl}_{\mathrm{i}}:\left[\left(\mathrm{Nw}_{\mathrm{i}}\right)_{\mathrm{Subj}}\right.\right.\right. & \left(\mathrm{Vp} \mathrm{p}_{\mathrm{i}}\right) & \left(\mathrm{Np}_{\mathrm{i}}\right)_{\mathrm{Obj}} & \left(\operatorname{Advp} \mathrm{i}_{\mathrm{i}}\right) & \left.\left.\left.\left(\mathrm{Advp}_{\mathrm{j}}\right)\right]\left(\mathrm{Cl}_{\mathrm{i}}\right)\right)\left(\mathrm{Le}_{\mathrm{i}}\right)\right) \\ \text { eu } & \text { vi } & \text { a_impressão } & \text { agora } & \text { aqui }\end{array}$

Nesse caso, o pronome de primeira pessoa, quando expresso, ocupa a posição $\mathrm{P}^{\mathrm{I}}$, funcionando como sujeito do verbo de percepção, que ocupa a posição $\mathrm{P}^{\mathrm{M}}$. O complemento do verbo de percepção, que ocupa a posição $\mathrm{P}^{\mathrm{M}+1}$, é um Sintagma nominal que necessariamente corresponde a um Estado-de-Coisas no Nível Representacional. Se o Sintagma nominal que completa o verbo corresponder a categorias como Indivíduo ou Propriedade, a estrutura não é considerada evidencial, como discutido em Capítulos anteriores.

O Quadro a seguir mostra a estrutura subjacente morfossintática que se aplica aos casos de evidencialidade direta codificados por orações simples:

\begin{tabular}{|cc|}
\hline & A EVIDENCIALIDADE NO Ní VEL MORFOSSINTÁTICO \\
& Uma Expressão Linguística (Oração simples) \\
\hline$(224)$ & $\left(\mathrm{Le}_{1}:\left(\mathrm{Cl}_{1}:\left[\left(\mathbf{N w}_{\mathbf{1}}\right)_{\mathrm{Subj}}\left(\mathbf{V p}_{\mathbf{1}}\right)\left(\mathbf{N p}_{\mathbf{1}}\right)_{\mathrm{Obj}} \ldots\right]\left(\mathrm{Cl}_{1}\right)\right)\left(\mathrm{Le}_{1}\right)\right)$ \\
\hline
\end{tabular}

Quadro 20. Estrutura subjacente morfossintática da evidencialidade direta

\subsection{Outro tipo de estrutura evidencial}

Resta ainda um outro tipo de estrutura em que os verbos ver, ouvir e sentir são usados com sentido evidencial: os casos em que a Oração subordinada é introduzida por pronomes interrogativos. Tendo em vista as especificidades do comportamento de tais estruturas, uma análise aprofundada exigiria um estudo à parte, fugindo ao escopo da presente investigação. Uma análise preliminar mostra, no entanto, não haver dúvidas sobre o caráter evidencial de tais estruturas. Uma pequena amostra dos dados já levantados ilustra a estrutura em questão: 
(225) Minha expressão, que não deveria ser nada bela, se abrandou quando eu vi a minha roubadora de livros debruçar-se sobre mim, chorando e implorando. Agora eu desprezava a mim mesmo. Como pude pensar aquelas coisas horrorosas de Liesel? Ela sempre esteve ao meu lado, também. Ela se preocupava comigo. Senti quando tocou meu tórax. Senti a pele macia dela.

(http://fanfiction.nyah.com.br/viewstory.php?action=printable\&textsize $=0 \&$ sid=44248\&chapter=all)

(226) Era uma tarde de calor muito intenso e eu aguardava o encerramento de uma feira beneficente organizada por amigos que me hospedavam bondosa e gentilmente no aconchego de seu lar. No meio de tantas vozes pedindo por um desconto, ouvi quando alguém chamou pelo meu nome. (http://www.verdadebiblica.com.br/blog/?cat=21)

(227) Ainda o vejo, ainda me lembro dele caindo quando os americanos atiraram nele; vi como ele arranhava o chão, malogrado, antes de sua alma deixar seu corpo. Depois disso comecei a ajudar na fabricação das bombas caseiras".

(http://delas.ig.com.br/como+baida+queria+morrer+perfil+da+mulherbomba/n1237504927803.html)

(228) Trabalhei numa fábrica de placas de gesso em Itamonte-MG e vi quanto resíduo era desperdiçado. (http://www.araripina.com.br/sustentabilidade-e-prioridade-na-lafarge-revista-fator)

(229) Eu atuo ainda como diretor-presidente da Cooperativa de Crédito de Tambaú, que está ligada ao sistema bancário. Como empreendedor vi por que o sistema bancário é o top de linha em ganhos financeiros. A ferramenta principal deles é a instantaneidade dos resultados pela informática.

(http://www.empresario.com.br/memoria/entrevista.php3?pic_me=774)

A partir de um primeiro olhar lançado a esses dados, considera-se que as ocorrências apresentadas em (225), (226) e (227) possam ser casos de evidencialidade direta, uma vez que expressam Estados-de-Coisas com os quais o Falante teve contato direto a partir dos sentidos. A ocorrência apresentada em (228) pode ser considerada um caso de evidencialidade deduzida, uma vez que expressa uma informação deduzida pelo Falante a partir de evidências apreendidas por meio de um dos sentidos. E, por fim, considera-se que, em (229), há um caso de evidencialidade inferida, uma vez que o Falante expressa a conclusão a que chegou a partir de fatos.

Vários aspectos precisam ainda ser considerados no tratamento desse tipo de estrutura como casos de evidencialidade, tais como:

i) a natureza completiva da Oração subordinada (apesar de estruturalmente se parecerem com orações relativas, as Orações subordinadas funcionam como complemento do verbo de percepção e por isso devem ser consideradas completivas); 
ii) a natureza semântica da palavra que introduz a oração subordinada (que parece influenciar a determinação da natureza semântica da oração subordinada);

iii) a localização temporal (é preciso verificar se as relações entre tempo verbal e tipo de evidencialidade acontecem, nesse tipo de estrutura, da mesma forma como se verificou nos outros tipos de Orações subordinadas).

A consideração desses pontos deverá guiar, em investigação futura, os desdobramentos desta pesquisa. 


\section{CONCLUSÃO}

Partindo da hipótese de que os verbos de percepção podem ser considerados formas de expressão da evidencialidade em língua portuguesa, esta pesquisa buscou analisar quais tipos evidenciais são codificados pelos verbos ver, ouvir e sentir, identificando os contextos sintático-semânticos e pragmáticos que propiciam a leitura evidencial. Para atingir tal objetivo, seguiu-se a classificação dos evidenciais proposta pela GDF e levaram-se em conta os pressupostos teórico-metodológicos mais gerais desse modelo de descrição linguística, buscando-se também verificar sua adequação ao estudo do fenômeno da evidencialidade em língua portuguesa.

Com relação à metodologia adotada nesta pesquisa, os mapas semânticos mostraramse úteis para a seleção do objeto de estudo. A adoção de uma abordagem baseada em corpus (corpus-based, TOGNINI-BONELLI, 2001) permitiu que, a partir do conhecimento teórico sobre evidencialidade e sobre verbos de percepção, fossem levantadas hipóteses sobre as propriedades semânticas e sintáticas dos verbos ver, ouvir e sentir. Essas hipóteses resultaram em um conjunto de propriedades que reúne: Ilocução Declarativa, sujeito do verbo de percepção em primeira pessoa, verbo de percepção em tempo presente ou passado, verbo de percepção relacionado com as camadas mais altas do Nível Representacional e com uma camada do Nível Interpessoal. As análises dos dados de língua real levantados validaram as expectativas, comprovando que os verbos de percepção que exibem tais propriedades podem ser considerados evidenciais.

A análise dos dados seguindo o modelo de descrição proposto pela GDF mostrou que, no Nível Interpessoal, os diferentes tipos de evidencialidade podem ser representados por um 
ou dois Atos Discursivos, que se caracterizam pela mesma Força Ilocucionária (Declarativa) e pela presença de um Subato Referencial correspondente ao Falante. Além disso, tendo em vista que os elementos, nesse nível, são organizados de acordo com a sequência temporal das ações que representam, foi possível identificar dois modos de o Falante organizar o seu discurso quando usa verbos de percepção evidenciais: destacando a informação que veicula ou o modo como ela foi obtida.

Tendo em vista que o fenômeno aqui estudado está relacionado, em primeiro lugar, com os significados dos verbos, as diferenças entre os tipos evidenciais codificados pelos três verbos analisados puderam ser claramente observadas a partir da descrição dos dados no Nível Representacional. Nesse Nível, a identificação do tipo evidencial expresso por cada verbo foi feita levando-se em conta tanto a natureza semântica do verbo de percepção quanto a natureza semântica da oração que contém a informação que o Falante deseja veicular. Nesse processo de identificação dos tipos evidenciais codificados pelos três verbos, as camadas propostas pela GDF mostraram-se absolutamente relevantes, uma vez que elas permitiram caracterizar cada tipo evidencial.

Durante a análise dos dados, observou-se que alguns casos não se enquadravam em nenhum dos tipos evidenciais propostos por Hengeveld e Mackenzie (2008). A partir de uma análise mais aprofundada dessas ocorrências, constatou-se que elas poderiam ser classificadas como casos de evidencialidade deduzida, um tipo evidencial identificado em diferentes línguas por Dall'Aglio-Hattnher e Hengeveld (em preparação), mas ainda não descrito em língua portuguesa. Incluindo esse quarto tipo de evidencialidade na análise das ocorrências levantadas, a descrição semântica dos casos de evidencialidade expressos pelos verbos de percepção pode ser resumida da seguinte forma:

i) evidencialidade reportativa: codificada pelos verbos ver e ouvir quando eles apresentam uma informação linguística retransmitida pelo Falante. A informação que o 
Falante retransmite corresponde a um Conteúdo Comunicado, unidade do Nível Interpessoal;

ii) evidencialidade inferida: codificada pelos verbos ver, ouvir e sentir quando eles apresentam um cálculo mental do Falante. A informação inferida corresponde a um Conteúdo Proposicional, unidade do Nível Representacional;

iii) evidencialidade deduzida: codificada pelos verbos ver, ouvir e sentir quando eles apresentam uma dedução baseada em evidências sensoriais. A informação deduzida corresponde a um Episódio, unidade do Nível Representacional;

iv) evidencialidade direta: codificada pelos verbos ver, ouvir e sentir quando eles expressam que o Falante presenciou um Estado-de-Coisas acontecer. A unidade com a qual o verbo se relaciona, nesse caso, é o Estado-de-Coisas, do Nível Representacional.

Com relação ao tempo verbal, observou-se que as possibilidades de combinação entre o tempo verbal do verbo de percepção e o tempo verbal do verbo que ocorre no interior da oração que apresenta a informação percebida diminuem quanto mais baixa é a camada a que pertence essa oração. Assim, nos casos de evidencialidade reportativa, os tempos presente e passado dos verbos de percepção podem se combinar com tempos variados da oração com a qual se relacionam. O tempo verbal dessas orações condiz com o que foi usado no Conteúdo Comunicado do Falante original, por isso não depende do tempo verbal do verbo de percepção. Nos casos de evidencialidade inferida e deduzida, o cálculo mental ou a dedução introduzidos pelos verbos de percepção normalmente estão localizados em tempo presente ou passado, coincidindo ou não com o tempo verbal do próprio verbo de percepção. Nos casos de evidencialidade direta, o Estado-de-Coisas presenciado pelo Falante não é localizado temporalmente no presente, passado ou futuro porque ele é marcado como simultâneo em relação ao Estado-de-Coisas da percepção. 
Ainda com relação a aspectos semânticos das estruturas evidenciais com os verbos ver, ouvir e sentir, observou-se que uma característica desses verbos é o fato de que eles, por expressarem diversos tipos de percepções, indicam necessariamente o modo como o falante obteve a informação: por meio da leitura ou da escuta de um conteúdo linguístico, no caso da evidencialidade reportativa; por meio de um cálculo mental baseado em diferentes tipos de evidências, no caso da evidencialidade inferida; por meio de dedução a partir de evidências sensoriais, no caso da evidencialidade deduzida; ou por meio da percepção sensorial propriamente dita de um estado de coisas, no caso da evidencialidade direta.

No que se refere à fonte da informação, nos casos de evidencialidade reportativa, ela é sempre diferente do falante, podendo ou não ser explicitada no contexto. Nos outros três tipos de evidencialidade, por outro lado, a fonte da informação é o próprio falante, uma vez ele é o responsável pelo cálculo mental, no caso de evidencialidade inferida, pela dedução, no caso de evidencialidade deduzida, e pela percepção sensorial, no caso de evidencialidade direta. Nos casos de evidencialidade inferida, recursos linguísticos podem ser usados no contexto para explicitar o tipo de informação que o falante tomou como base para fazer a inferência. Nos casos de evidencialidade deduzida e direta, tais recursos linguísticos contextuais não são necessários porque, como os verbos de percepção são usados em seus sentidos mais concretos, o próprio significado do verbo já traz informações sobre o tipo de percepção envolvida.

Com relação aos aspectos sintáticos das estruturas em que os verbos ver, ouvir e sentir são usados com valor evidencial, quatro tipos de construções diferentes foram identificados e analisados: i) duas Expressões Linguísticas, cada uma composta por uma Oração; ii) uma Expressão Linguística composta por Oração principal e Oração subordinada adverbial conformativa; iii) uma Expressão Linguística composta por Oração principal e Oração subordinada completiva; e iv) uma Expressão Linguística composta por uma Oração simples. 
Nos casos de evidencialidade reportativa, inferida e deduzida em que ocorrem duas Expressões Linguísticas, uma expressa a informação que o falante deseja veicular e a outra transmite o modo como ele a obteve. Esses mesmos três tipos de evidencialidade também são codificados por construções que contêm uma Expressão Linguística composta por Oração principal e Oração subordinada adverbial conformativa. Nesses casos, a Oração subordinada expressa o modo de obtenção da informação apresentada na Oração principal.

Quando há uma Expressão Linguística composta por Oração principal e Oração subordinada completiva, a Oração encaixada contém a informação que o Falante deseja veicular e a Oração matriz expressa o modo como tal informação foi apreendida por ele. Nesse tipo de estrutura, o grau de finitude do verbo da Oração completiva correlacionado com a natureza semântica do complemento determina o tipo de evidencialidade. Assim, Orações complexas com complementos finitos codificam três tipos de evidencialidade: reportativa, inferida e deduzida. As Orações complexas completivas reduzidas de infinitivo expressam evidencialidade reportativa, inferida e direta. Existe, porém, uma particularidade nos complementos infinitivos que atuam na expressão de evidencialidade reportativa e inferida: eles necessariamente têm uma cópula como núcleo do Sintagma verbal, ao passo que os complementos infinitivos que expressam evidencialidade direta normalmente apresentam como núcleo do Sintagma verbal um verbo lexical. As Orações complexas com complementos reduzidos de gerúndio são usadas apenas na codificação de evidencialidade direta, assim como as Orações simples. Neste último caso, o verbo de percepção toma como complemento uma nominalização que necessariamente corresponde a um Estado-de-Coisas. Tendo em vista que, nos casos de evidencialidade direta, o verbo de percepção encaixa um complemento do tipo Estado-de-Coisas, o fato de esse tipo evidencial ocorrer apenas com complementos nãofinitos (infinitivos e gerundivos) está de acordo com o princípio da GDF segundo o qual a 
Oração subordinada tende a ser do tipo reduzida quanto mais baixa for a camada em que está baseada.

A análise em três níveis aqui empreendida, além de demonstrar a adequação do modelo teórico da GDF para a descrição do fenômeno aqui investigado, revela especificidades importantes para uma caracterização pormenorizada dos usos dos verbos de percepção em contextos evidenciais. A partir da compreensão dos aspectos sintático-semânticos e pragmáticos envolvidos no conjunto de dados analisados, conclui-se que os verbos ver, ouvir e sentir são formas de expressão da evidencialidade bastante produtivas em língua portuguesa. A diversidade de tipos evidenciais expressos por cada verbo e as diferentes estruturas sintáticas em que esses verbos podem ocorrer demonstram a variedade de recursos linguísticos de que os falantes do português dispõem quando decidem disponibilizar a seus ouvintes o modo como obtiveram as informações que transmitem. 


\section{REFERÊNCIAS BIBLIOGRÁFICAS}

AIKHENVALD, A. Y.; DIXON, R. M. W. (Ed.). Studies in evidentiality. Amsterdam: John Benjamins Publishing Company, 2003. (Typological studies in language 54).

AIKHENVALD, A. Y. Evidentiality. Oxford University Press, 2004.

ANDERSON, S. R.; KEENAN, E. L. Deixis. In: SHOPEN, T. (Ed.). Language typology and syntactic description Vol. III, Grammatical categories and the lexicon. Cambridge: Cambridge University Press, 1985. p.259-308.

ANDERSON, L. B. Evidentials, paths of change and mental maps: typologically regular asymmetries. In: CHAFE, W.; NICHOLS, J. (Ed.). Evidentiality: the linguistic coding of epistemology. Norwood, New Jersey: Ablex Publishing Corporation, 1986, p.188-202.

ANSTEY, M. Layers and operators revisited. Working Papers in Functional Grammar n.77, 2002.

BARRON, J. LFG and the history of raising verbs. In: BUTT, M.; KING, T. H. (Ed). Proceedings of the LFG97 Conference, Stanford: CSLI Publications, 1997. Disponível em: <http://csli-publications.stanford.edu/LFG/2/barron-lfg97.html>. Acesso em: 15 nov. 2009.

BARROS, A. R. M. P. Aspectos da complementação de uma classe de verbos de percepção. 1977. 129 f. Dissertação (Mestrado em Linguística) - Instituto de Estudos Linguísticos, Universidade Estadual de Campinas, Campinas, 1977.

BOLINGER, D. Concept and percept: Two infinitive constructions and their vicissitudes. In: World Papers in Phonetics: Festschrift for Dr. Onishi's Kiju. Tokyo: Phonetics Society of Japan, p.65-91, 1974.

BORBA, F. S. (Coord.) Dicionário gramatical de verbos do português contemporâneo. São Paulo: Editora Unesp, 1990.

BOTNE, R. Evidentiality and epistemic modality in Lega. Studies in Language, v.2., n.3, p.509-532, 1997.

BRAGA, M. L. et al. Perception verbs in Brazilian Portuguese: a functional approach (em preparação).

CAPLAN, D. A note on the abstract readings of verbs of perception. Cognition, v.2, n.3, p.269-77, 1973.

CARIOCA, C. R. A manifestação da evidencialidade nas dissertações acadêmicas do português brasileiro contemporâneo. 2005. 115f. Dissertação (Mestrado em Linguística) Universidade Federal do Ceará, Fortaleza.

CARVALHO, C. S. Cláusulas encaixadas em verbos causativos e perceptivos: uma análise funcionalista. 251f. 2004. Tese (Doutorado em Linguística) - Instituto de Estudos Linguísticos, Universidade Estadual de Campinas, Campinas, 2004. 
CASSEB-GALVÃO, V. C. O 'achar' no Português do Brasil: um caso de gramaticalização. 1999. 167f. Dissertação (Mestrado em Linguística) - Instituto de Estudos da Linguagem, Universidade Estadual de Campinas, Campinas, 1999.

Evidencialidade e gramaticalização no português do Brasil: os usos da expressão diz que. 2001. 231f. Tese (Doutorado em Linguística) - Faculdade de Ciências e Letras, Universidade Estadual Paulista, Araraquara, 2001.

CHAFE, W. Evidentiality in English conversation and academic writing. In: CHAFE, W.; NICHOLS, J. (Ed.). Evidentiality: The linguistic coding of epistemology. Norwood, New Jersey: Ablex Publishing Corporation, 1986, p.261-72.

CHAFE, W.; NICHOLS, J. (Ed.). Evidentiality: the linguistic coding of epistemology. Norwood, New Jersey: Ablex Publishing Corporation, 1986.

CONNOLLY, John H. The question of discourse representation in Functional Discourse Grammar. In: MACKENZIE, J. L.; GÓMEZ-GONZÁLEZ, M. Á. A new architecture for Functional Grammar. Berlin: Mouton de Gruyter, 2004, p.89-116.

Context in Functional Discourse Grammar. Alfa. São Paulo, v.51, n.2, p.11-33, 2007.

CROFT, W. Radical Construction Grammar. Syntactic theory in typological perspective. Oxford: Oxford University Press, 2001.

2003.

Typology and Universals, second edition. Cambridge: Cambridge University Press,

DALL'AGLIO-HATTNHER, M. M. Evidencialidade e modalidade: forma e função. (Relatório de pesquisa). São Paulo: FAPESP, 2001.

DALl'AGLIO-HATTNHER, M. M.; HENGEVELD, K. Four types of evidentiality (em preparação).

Pesquisas em sintaxe: a abordagem funcionalista da evidencialidade In: MASSINICAGLIARI, G. et. al. (Org.) Trilhas de Mattoso Câmara e outras trilhas: fonologia, morfologia, sintaxe. São Paulo: Cultura Acadêmica, 2007. p.103-145.

De HAAN, F. The interaction of modality and negation: a typological study. New York: Garland Press, 1997.

Evidentiality and epistemic modality: setting boundaries. Southwest Journal of Linguistics, v.18, p.83-101, 1999.

The relation between modality and evidentiality. Linguistische Berichte, Sonderheft 9, p.201-216, 2001.

Visual evidentiality and its origins. Diachronica. No prelo.

Encoding speaker perspective: evidentials. In: FRAJZYNGIER, Z.; HODGES, A.; ROOD, D. (Ed.). Linguistic diversity and language theories. Amsterdam: Benjamins, 2005. p.379-397. 
DECLERK, R. On the role of the progressive aspect in nonfinite perception verb complements. Glossa, v.15, n.1, p.83-114, 1981.

DENDALE, P.; TASMOWSKI, L. Introduction: evidentiality and related notions. Journal of Pragmatics, v.33, p.339-348, 2001.

DIK, S. The Theory of Functional Grammar. Part I: The structure of the clause. 2.ed. Dordrecht: Foris, 1997a.

The Theory of Functional Grammar. Part II: Complex and derived constructions. 2.ed. New York: Mouton de Gruyter, 1997b.

DIK, S.; HENGEVELD, K. The hierarquical structure of the clause and the typology of perception-verbs complements. Linguistics, v.29, p.231-259, 1991.

FLOYD, R. The structure of evidencial categories in wanka quechua. Dallas: Summer Institute of Linguistics, 1999.

FOLEY, W. A.; VAN VALIN, R. D. Functional syntax and universal grammar. Cambridge, England: Cambridge University Press, 1984.

GONÇALVES, S. C. L. G. Banco de dados Iboruna: amostras eletrônicas do português falado no interior paulista. Disponível em: http://www.alip.ibilce.unesp.br/iboruna.

Gramaticalização, modalidade epistêmica e evidencialidade: um estudo de caso no português do Brasil. 2003. 250 f. Tese (Doutorado em Linguística) - Instituto de Estudos Linguísticos, Universidade Estadual de Campinas, Campinas, 2003.

HASPELMATH, M. The Geometry of Grammatical Meaning: Semantic Maps and CrossLinguistic Comparison. In: Tomasello, M. (ed.) (2003) The new psychology of language, vol. 2. Mahwah. NJ: Erlbaum, 211-242.

HENGEVELD, K. Adverbial clauses in the languages of Europe. In: AWERA, J.; BAOILL, D. P. (Eds). Adverbial constructions in the languages of Europe. Berlin; New York: Mouton de Gruyter. 1998. p. 349-356.

HENGEVELD, K.; MACKENZIE, L. Functional Discourse Grammar. A typologically-based theory of language structure. Oxford: Oxford University Press, 2008.

Functional Discourse Grammar. In: HEINE, B.; NARROG, H. (Ed.). The Oxford handbook of linguistic analysis. Oxford: Oxford University Press, 2009, p.403-438.

HEINE, B.; CLAUDI, U.; HÜNNENMEYER, F. Grammaticalization. A conceptual Framwork. Chicago: Chicago University Press, 1991.

HORIE, K. A cross-linguistic study of perception and cognition verb complements: a cognitive perspective. 1993. PhD Dissertation. University of Southern California, 1993.

HOUAISS, A.; VILlAR, M. S. Dicionário Houaiss da Língua Portuguesa. v.1. Rio de Janeiro: Objetiva, 2001. 
IBARRETXE-ANTUÑANO, B. I. Polysemy and metaphor in perception verbs: a crosslinguistic study. 1999. 235f. PhD Thesis. University of Edinburgh 1999.

JAKOBSON, R. Shifters, verbal categories, and the Russian verb. Selected writings. The Hague: Mouton, 1957.

JOHANSON, L.; UTAS, B. (Ed.). Evidentials: Turkic, Iranian and neighbouring languages. Berlin: Mouton de Gruyter, 2000. (Empirical Approaches to Language Typology, 24).

JOSEPH, B. D. Evidentials: summation, questions and prospects. In: AIKHENVALD, A.; DIXON, R. M. W. (Ed.). Studies in evidentiality. Amsterdam: John Benjamins Publishing Company, 2003. p.307-327. (Typological studies in language, 54).

KIRSNER, R.; THOMPSON, S. The role of pragmatic inference in semantics: A study of sensory verb complements in English. Glossa. n.10, p.200-240, 1976.

KOMESU, F. Blogs e as práticas de escrita sobre si na internet. In: MARCUSCHI, L. A.; XAVIER, A. C. (Org.) Hipertexto e gêneros digitais: novas formas de construção do sentido. Rio de Janeiro: Lucerna, 2004. p.110-119.

KROON, C. Discourse markers, discourse structure and Functional Grammar. In: CONOLLY, H. J.; VISMANS, R. M.; BUTLER, C. S.; GATWARD, R. A (Ed.). Discourse and Pragmatics in Functional Grammar. Berlin/New York: Mouton de Gruyter, 1997.

LAKOFF, G.; JOHNSON, M. Metaphors We Live by. Chicago and London: Chicago University Press, 1980.

LEECH, G. Meaning and the English Verb. London: Longman, 1971.

LEVELT, W. J. M. Speaking. Cabridge: MIT Press, 1989.

LUCENA, I. L. A expressão da evidencialidade no discurso político: uma análise da oratória política da Assembléia do Ceará. 2008. 112f. Dissertação (Mestrado em Linguística) Universidade Federal do Ceará, Fortaleza, 2008.

LYONS, John. Semantics. Cambridge: Cambridge University Press, 1977.

MASLOVA, E. Evidentiality in Yukaghir. In: AIKHENVALD, A. Y.; DIXON, R. M. W. (Ed.). Studies in evidentiality. Amsterdam: John Benjamins Publishing Company, 2003. p.237-241. (Typological studies in language, 54).

NEVES, M. H. M. Gramática de usos do português. São Paulo: Editora UNESP, 2000.

NUYTS, J. Epistemic modal adverbs and adjectives and the layered representation of conceptual and linguistic structure. Linguistics, v.31, p.933-969, 1993.

Subjectivity as an evidential dimension in epistemic modal expressions. Journal of Pragmatics, v.33, p.383-400, 2001.

OLIVEIRA, M. R.; VOTRE, S. J. A trajetória das concepções de discurso e de gramática na perspectiva funcionalista. Matraga, v.16, n.24, jan./jun. 2009. 
RODRIGUES, P. A. A complementação e a interpretação dos verbos de percepção. In: NOS DOMÍNIOS DO VERBO. UFPR, Curitiba, 2007. Anais eletrônicos... Curitiba. Debates. Disponível em: <http://www.pgletras.ufpr.br/eventos/docs_eventos/Patricia_Rodrigues.pdf>. Acesso em: 24 fev. 2009.

SANTANA, L. Motivações funcionais da gradação entre construções encaixadas nominais e verbais. 2010. 264 f. Tese (Doutorado em Estudos Linguísticos). Universidade Estadual Paulista "Júlio de Mesquita Filho", 2010.

SANTOS, M. F. Modalidade epistêmica e evidencialidade: um exercício de análise funcionalista em textos acadêmicos e em entrevistas com pesquisadores. 2008. 92f. Dissertação (Mestrado em Letras) - Centro de Ciências Humanas, Letras e Artes, Universidade Estadual de Maringá, Maringá, 2008.

SWEETSER, E. From etymology to pragmatics: metaphorical and cultural aspects of semantic structure. Cambridge: Cambridge University Press, 1990.

TOGNINI-BONELLI, E. Corpus Linguistics at Work. (Studies in Corpus Linguistics 6). Amsterdam: Benjamins, 2001.

PALMER, F. R. A Linguistic Study of the English Verb. London: Longman, 1966.

POUTSMA, H. A Grammar of LateModern English. Part II: The Parts of Speech. Section II. Groningen: P. Nordhoff, 1926.

VENDRAME, V. A evidencialidade em construções complexas. 2005.114 f. Dissertação (Mestrado em Estudos Linguísticos). Universidade Estadual Paulista "Júlio de Mesquita Filho", 2005.

VIBERG, A. The verbs of perception: a typological study. In: BUTTERWORTH, B.; COMRIE, B.; DAHL, O. (Ed.). Explanations for Language Universals. Berlin: Mouton de Gruyter, p.123-162, 1984.

WILLET, T. A cross-linguistic survey of the grammaticalization of evidentiality. Studies in Language, v.12, 1, p.51-97, 1988.

WHITT, R. J. Auditory evidentiality in English and German: the case of perception verbs. Lingua, v.119, n.7, p.1083-1095, 2009.

WOODBURY, A. C. Interactions of tense and evidentiality: a study of Sherpa and English. In: CHAFE, W.; NICHOLS, J. (Ed.). Evidentiality: the linguistic coding of epistemology. Norwood, New Jersey: Ablex Publishing Corporation, 1986, p.188-202. 
Autorizo a reprodução xerográfica para fins de pesquisa

São José do Rio Preto, 13 de setembro de 2010

\section{VALÉRIA VENDRAME}

